\title{
You, me, and that god damn lighthouse over there 888
}

66 An explorative story between the tourist as performer and lighthouse as the stage 


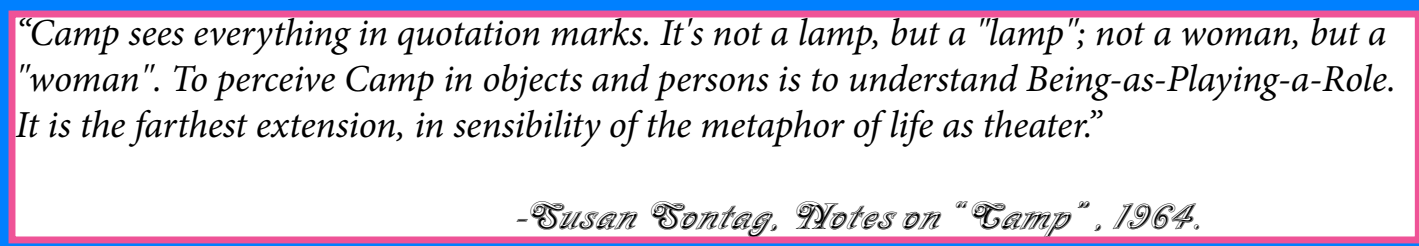


So... with that being said. Welcome to my

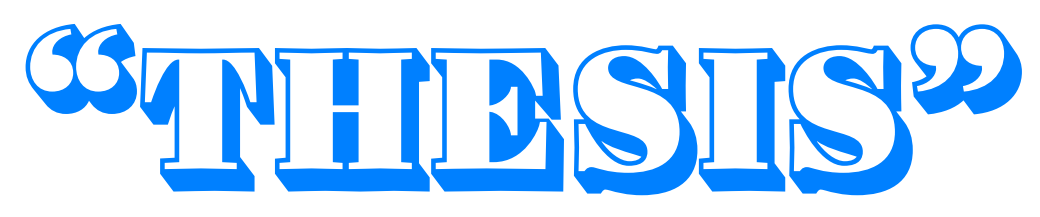

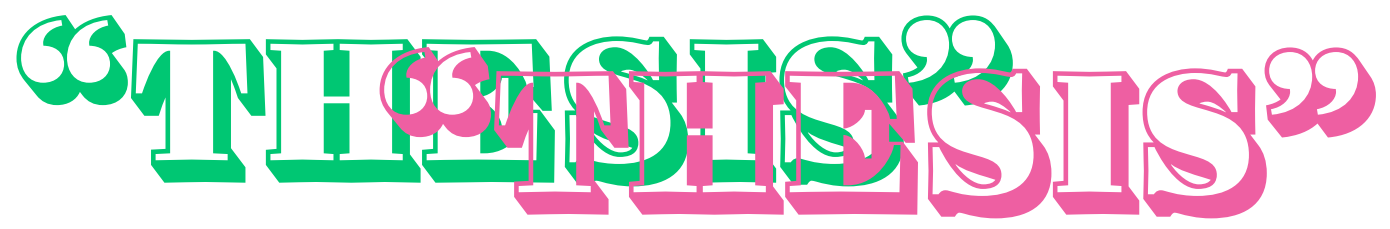

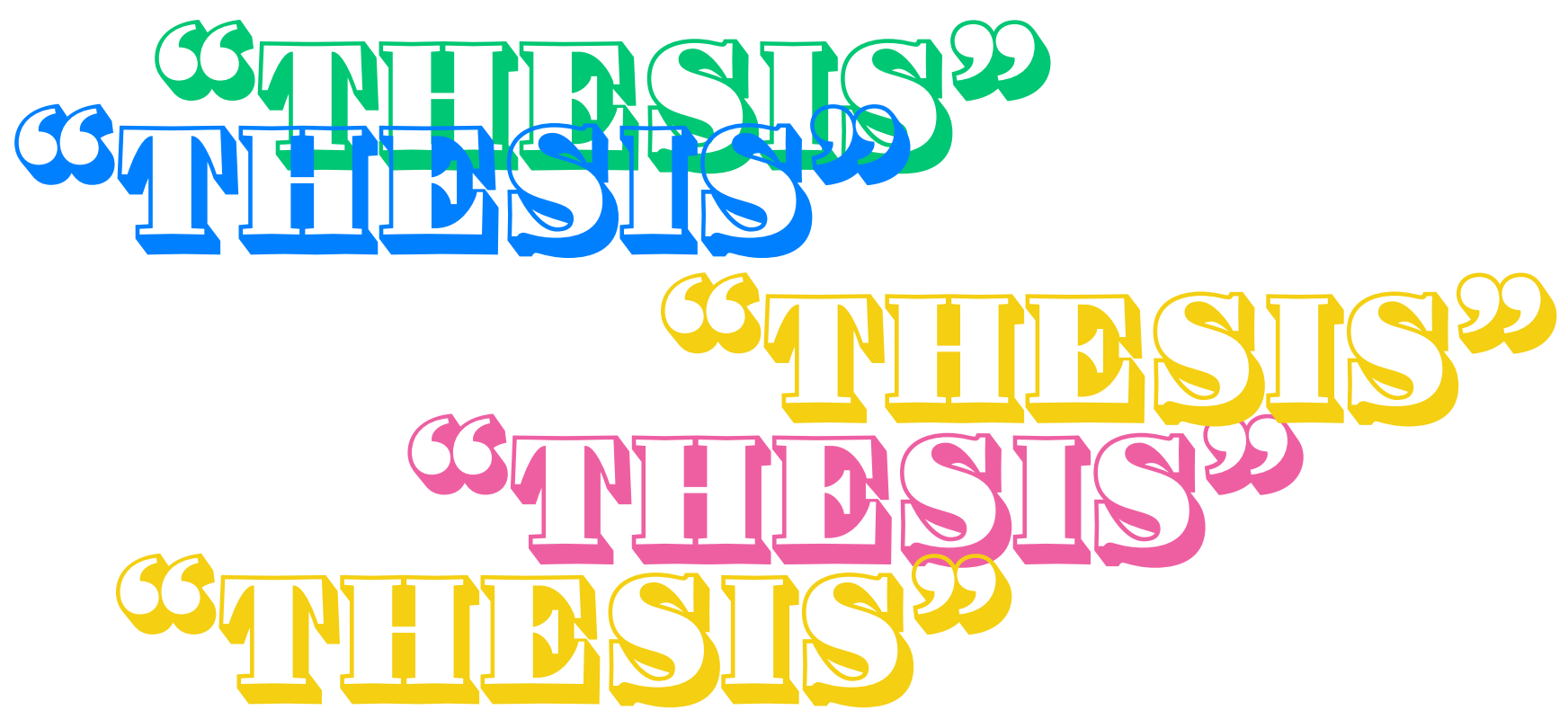



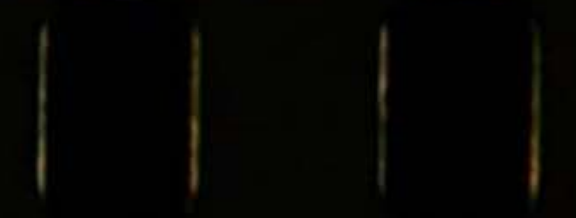

\section{1}

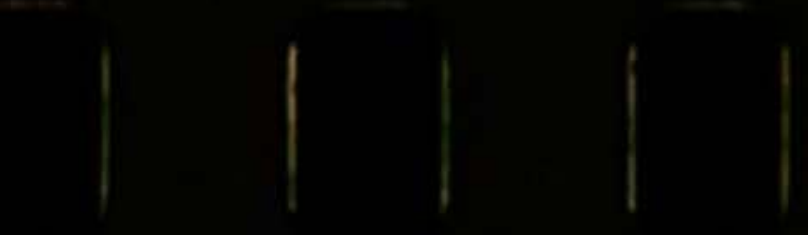

(2)

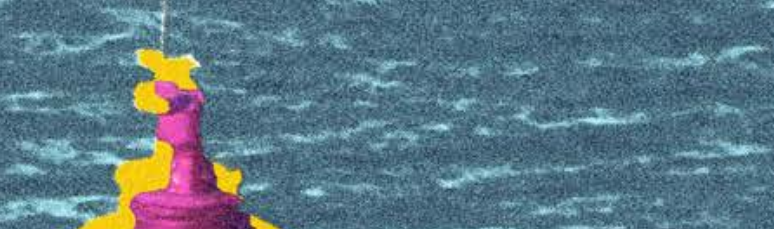

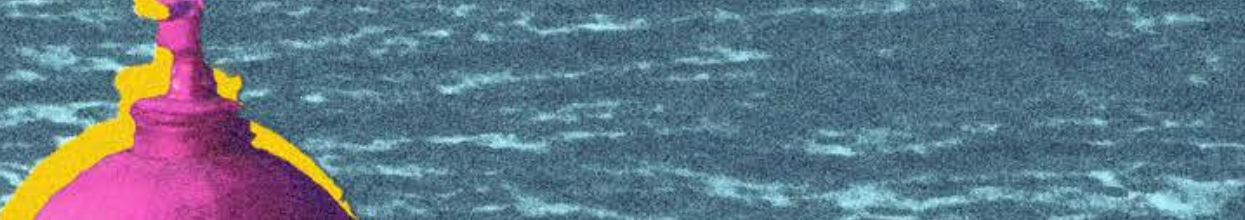

, त)

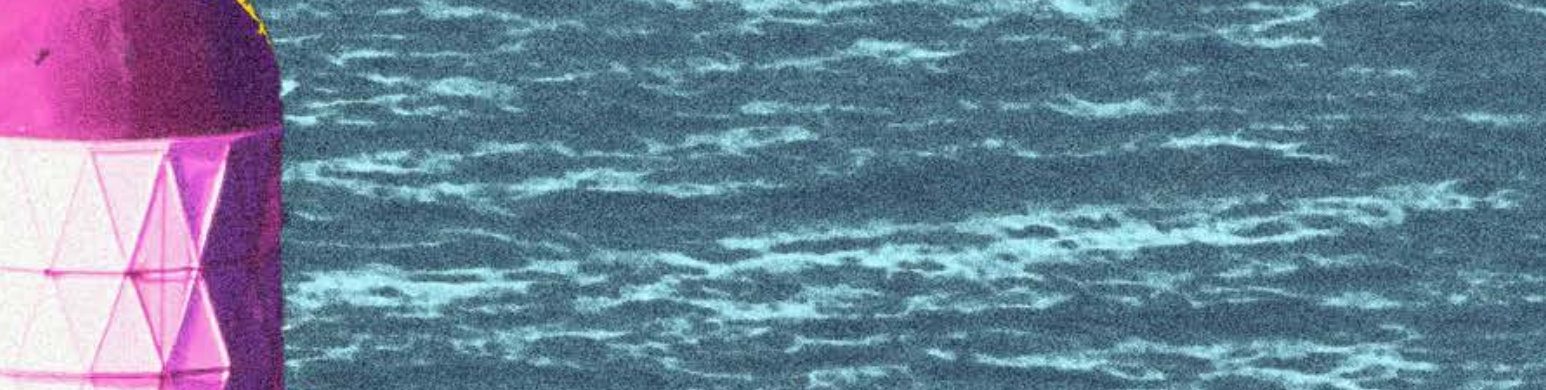

st

sing $x+2 x-2=0$ a x-core-

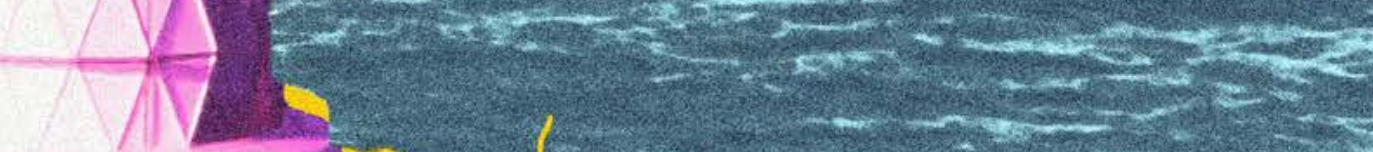
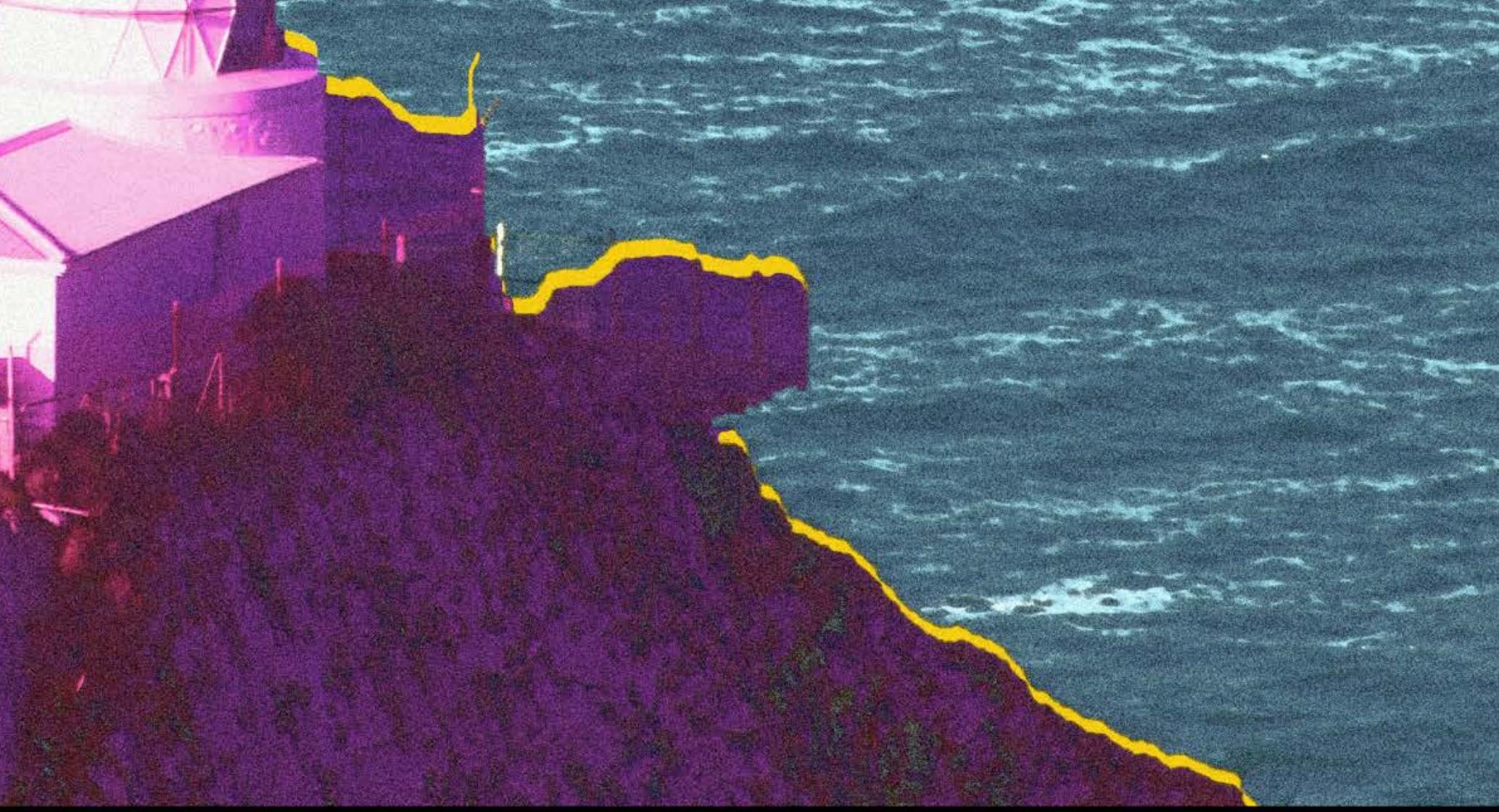

$\mid$ 


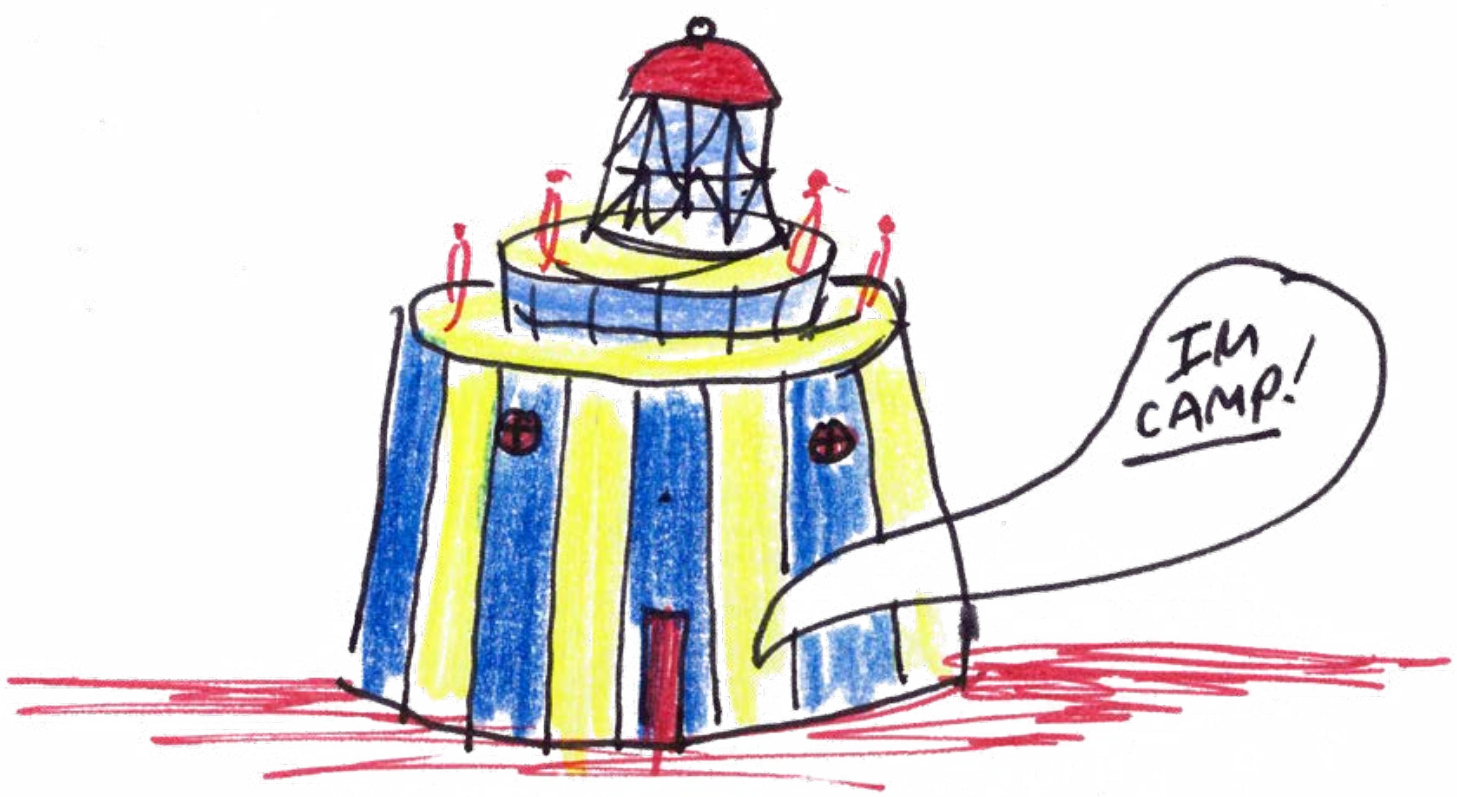

Figure 1 IM CAMP Sketch, an exploration in camp buildings. 


\section{ABSTRACT}

The 'gaze' has been traditionally established as the primary way tourists consume space. However, recent research proposes 'the performance' as an alternative mode of touring that doesn't centre around just the visual, and looks to design for tourists to 'perform; opposed to simply 'gaze?. This thesis examines the relationship between tourists and existing tourism objects, focussing on the lighthouses of New Zealand as an architecture that has the potential for repurposing or developing for consumption as tourism. A 'design through research' methodology has been employed using 'camp' as a lens of exploration. Iterative design experiments that involve, physical modelling, drawing, collage, photography and digital modelling explore different conceptual opportunities for the lighthouse and with ultimate goal of creating a stage for tourists to perform upon. Developed through three distinct design phases, the first, looks at the lighthouse and transforms it into a theme park, adopting humour and a satirical approach to comment on mass-tourism and kitsch consumption, treating the lighthouse as a collective of activities that makes a single experience. The second takes an intimate approach to what makes a lighthouse. Here the camp lens is removed and the light is analysed through photographic strategies and model making. This seeks to find a real 'authenticity' to contribute to the final design phase, exploring 'camp' by its absence. The final phase, is 'the stage complete', an architecture that encloses the lighthouse, re-adapting camp design methods to explain that story and attract tourists with its camp aesthetics. 


\section{ACKNOWLEDGMENTS \{PIANRPTOU\}\}}

First and foremost this thesis is dedicated to Mum and Dad. Thank you.

My Friends, I love you all. Thanks for making this the most Fantastic 5 years of my life to date! (Never to be repeated). The conversations, the coffee, the cries, and for 'taking the piss' with me!

Jacquie, Thanks for your words and guidance.

I am truly thankful. 


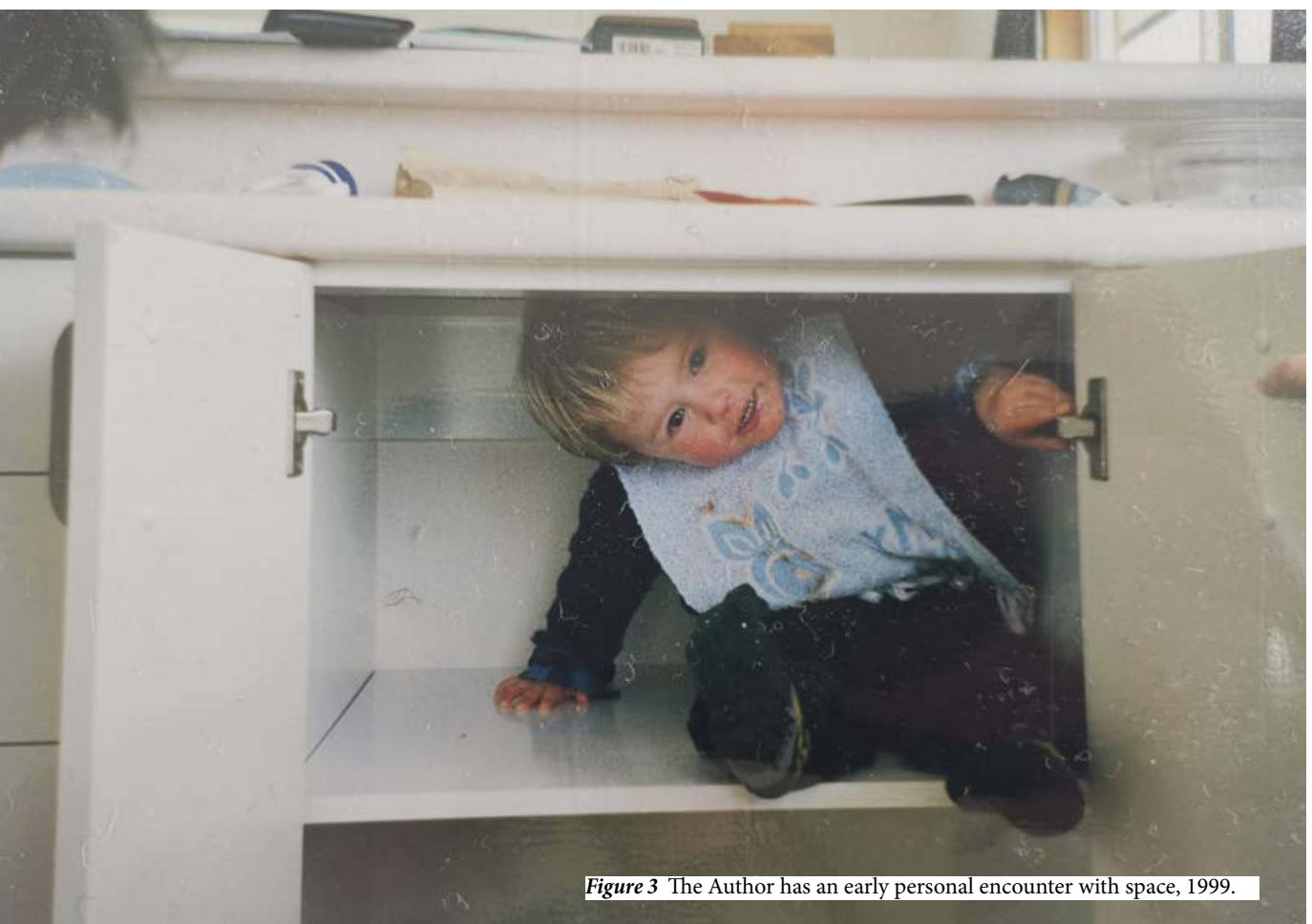


Growing up on a rural farm, my sense of space was different from many. Wide-open spaces, nature, nothing but rolling hills in sight, this was a huge privilege - I know this, now more than ever living in a city.

With this vast space also comes the experience of isolation, not in a terrifying way but in a slowed down, semi-disconnect from the world kind of way. From an early age, I understood the concepts of isolation or for a better word, wilderness. What it feels like to be stuck in torrential rain and having to walk kilometres home, or getting up to get the cows in at $4.30 \mathrm{am}$ in the middle of winter and not being able to feel my fingers (I am from a dairy farm).

These feelings of exposure to the elements, isolation, vulnerability, fear, and relief, running the risk of sounding moralistic make us feel most human, they are the extremes of the human experience. Ever since leaving my childhood home to start my adult life, these feelings have been something I did not want to lose, something I feared losing. It is my personal stance that exposing ourselves to these extremes is important for humans to re-evaluate and reconnect to what we are.

This body of work started with a fascination of the photograph/ and at playing the tourist, how an environment evokes something innate within oneself. Starting my thesis journey, I needed something to begin with that would explore these ideas, I lived 30 minutes from Nugget Point Lighthouse growing up, it was one of the first places and memories I can remember where these ideas I have previously mentioned, of isolation and exposure were elevated. I was curious about these structures, like a lot of people. The whimsical, camp nature of these stoic buildings, so out of place had always fascinated me. The way people interact with lighthouses, their history, their different facets of their purpose. In their present capacity, they very much are a tourist architecture. I want to explore lighthouses, not because I am obsessed with them - even though I am. I want to explore the tourist performance; how supplementary architecture could create a curated stage around these interesting architypes. 


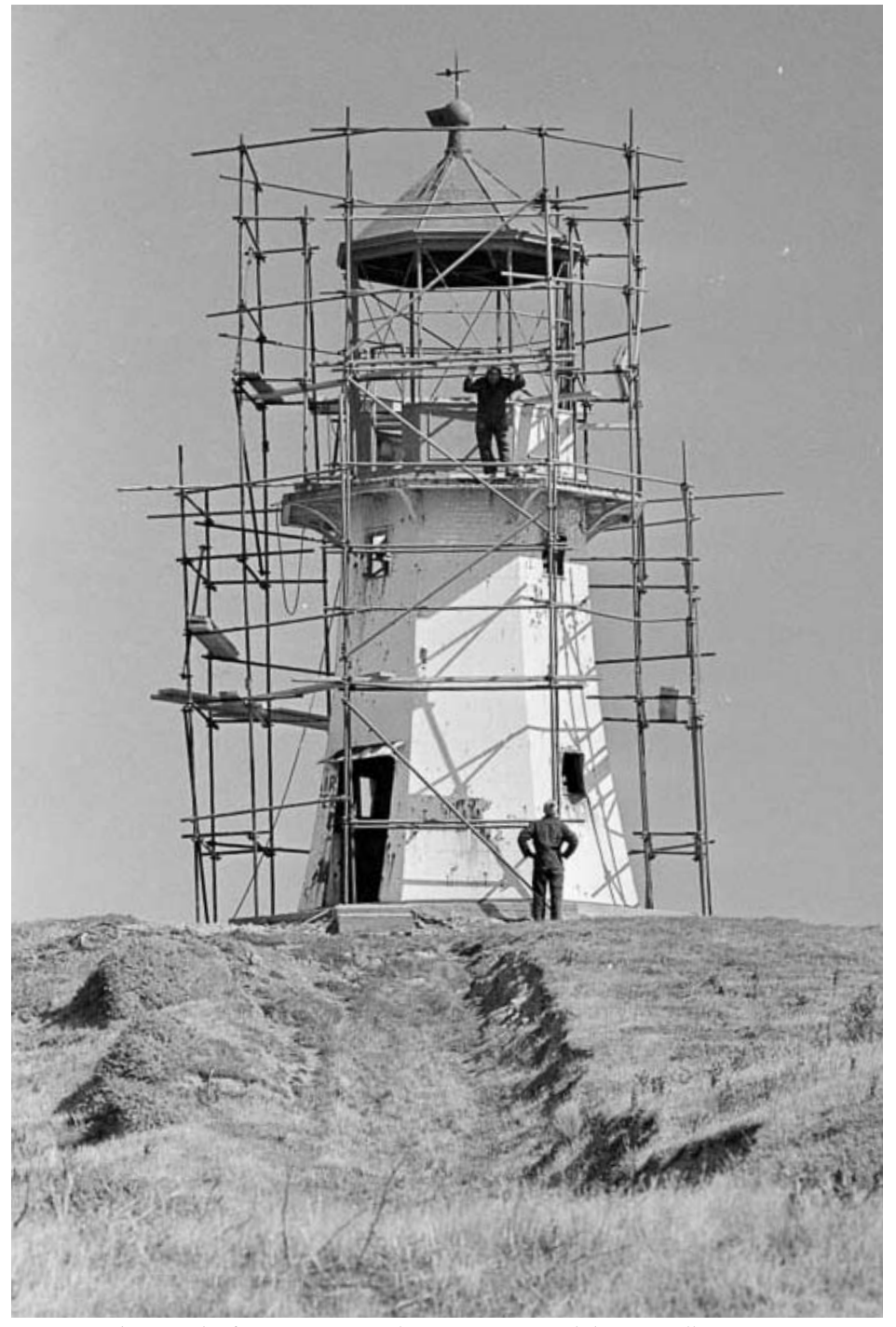

Figure 4 A photograph of maintenance work on Pencarrow Lighthouse, Wellington , 1980. 


\section{CONTENTS I

ब्रe

01. ABSTRACT

... II

02. ACKNOWLEDGMENTS

... IV

PREFACE

04. TABLE OF CONTENTS

... VI

... VIII

05. INTRODUCTION

... 2

06. TOURISM

... 10

07. THE CAMP SENSIBILITY

... 15

08. CAMP AS A DESIGN METHOD

... 23

09. KEY THINKERS

\section{ONE \\ I] COLD DAMN DISNEY LAND}

1.1 Introduction

... 44

Dog Island

... 50

The Consumer Palace

... 58

$\begin{array}{ll}1.3 & \text { Collage }\end{array}$

1.5 Cold Damn Disneyland

... 67

... 77

1.6 Model

... 97

1.7 Conclusion

\section{THO THE LIGHT DEVICE}

2.1 Introduction

Waipapa Point

... 122

Key Thinkers

... 131

Light Maquette's

... 140

Atmospheric studies

... 160

$\begin{array}{ll}2.6 & \text { Worshipping the light } \\ 2.7 & \text { Reflection }\end{array}$

... 169

\section{(3) ${ }^{\text {THREE }}$}

83 THE STAGE COMPLETE

3.1 Introduction

... 192

Design reasoning

... 196

3.3 Conceptualising the stage

... XI

The Stage Complete

... XIII

3.5 Model

... 1

3.6 Reflection

3.7 Conclusion 
Baily, daily, nightly brightly,

Danger reckons, beacon beckons,

Stranger warning, keep well clear,

Pass by safely in my care.

Lighthouse Keeper, all alone,

Shines his light to show his home;

Longs for friendship every day,

Greets his guests with 'stay away'.

Great tradition, generations,

Each new era, proud elations,

Sense of duty ever deeper:

Am I not my brother's keeper?

Now this noble role has ended.

Better off computer tended;

Rest are done, the Baily's last;

A great tradition now has passed.

Saving lives with techno power,

Same old light from same old tower.

Worried still how seamen fare;

Brave new world, computer care!

-Adrian Taheny, wrote this poem 'Baily' on the demanning of the Baily Lighthouse in Dublin,

Ireland. This applies equally to the demanning of Lighthouse's in New Zealand. The last Lighthouse to be demmaned in New Zealand was the

Brothers Light in 1990. 


\section{\{PBP8\}\}}

The lighthouse takes form in the psyche of humans as something whimsical within the landscape, something that sparks notions of nostalgia, of a by-gone era, of an adventure; a checkpoint on a journey, and at a time when they are playing the tourist. First and foremost, they are a colonial surveillance architecture (Sheehan \& Gibbons, 1991) often found on isolated peninsulas, spits, or rocky outcrops. Designed by engineers these structures fit under the category of pragmatism, utilitarianism, and steadfastness. They had one purpose, to keep watch.

They protect passing by ships in the night, from rough weather, hidden shallows, and reefs, indicating safe travel and always warning. Their message is always simple; STAY AWAY. This thesis proposes that New Zealand's Lighthouse's Context has shifted, that these important archetypes with one singular duty, now have found an additional purpose in the current day. It sees these structures largely as objects of tourism, an icon of fascination, things that contribute to the tourism industry and offer the possibility for a conceptual architectural approach to repurpose an architecture of a bygone era.

This thesis aims to contribute to the dialogue around our architectural building stock that centres their use around New Zealand's tourism industry. The research seeks to explore conceptual alternatives to already existing architectures and research through design alternative ways of viewing what tourism architecture may look like.
From studying Sontag's Notes on camp, this thesis aims to purposefully strive to achieve a certain level of flaw. A self-conscious parody, through its understanding of itself, becomes something highly serious and sentimental towards the people and subjects It speaks of. While additionally, considering the nature of the human mode of touring. This thesis is about taste, style, the subjectivity of it all (just as architecture is), and how as Humans we navigate the world. It looks at the lighthouse, not because of what it is in a context but what it is to humans as an object of fascination, as an architecture of fascination, it is not really about the lighthouse as a lighthouse but as a 'lighthouse' (Sontag, 1964). Camp theory within this thesis offers the method of viewing and designing but also a tonality in which I propose for the reader to view this project under.

The design research builds on the current state of the lighthouse as a stage, the tourist as a performer, and camp as a mode of viewing the world to develop three architectural logics that suggest a way in which we, as humans develop a greater experience and connection to that 'God Damn Lighthouse'. The three logics, structured as design phases are; 1- Cold Damn Disneyland, 2- The Light Device -and 3- The Stage Complete.

This thesis explores the lighthouse at its core, how we experience them, their purpose as an archetype - the absurdity of possibility, contradiction, and the role of architecture to initiate experience derived from theory.

\section{Proposition:}

\section{How can the architecture of a tourism object be relevant in a current world?}


This thesis aims to contribute to the dialogue around our architectural building stock that centres their use around New Zealand's tourism industry. The research explores conceptual alternatives to already existing architectures and researches through design alternative ways of viewing what tourism architecture might look like.

From studying Sontag's 'Notes on Camp', this thesis aims to purposefully strive to achieve a certain level of flaw, a selfconscious parody. Through its reflected understanding of itself, it becomes something highly serious and sentimental towards the people and subjects it speaks of. As well as considering the nature of the human mode of touring. This thesis indirectly addresses taste, style, and the subjectivity of it all (just as architecture is) and how as Humans we navigate the world. It looks at the lighthouse, not because of what it is in a context but what it is to humans as an object of enthrallment, as an architecture of fascination, it is not really about the lighthouse as a lighthouse but as a 'lighthouse.'

In ways this is a deeply personal thesis, not because of how it is the author's body of work, but because it is revealing the journey of the author and identifying how they see the world, through the lens of camp.

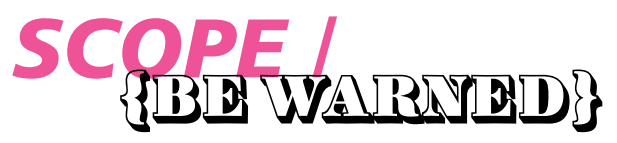

This thesis does not attempt to provide concrete architectural solutions to create a tourism experience. It explores architecture's capacity to facilitate experience within the context of tourism as a performance and inquires and tests how one can create a fantastical architecture to add to an existing architectural narrative. It uses the notions of 'camp' as a method and sensibility to achieve these things and produce design outcomes. 

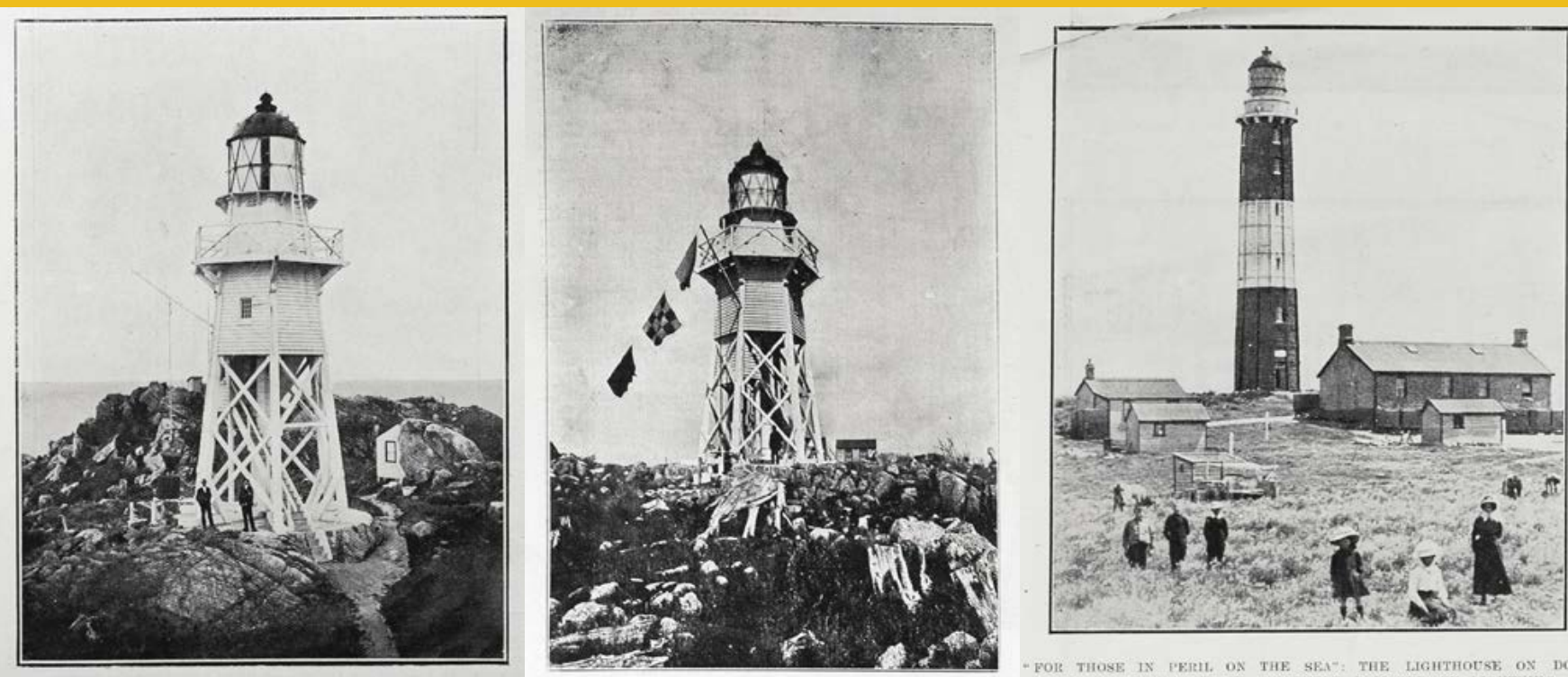

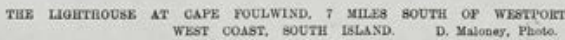

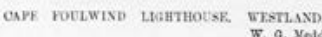

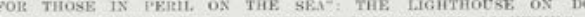

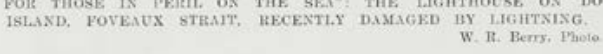

Figure 5 Historic images of lighthouse throughout New Zealand, far right is of Dog Island Lighthouse, site for design phase one. 



\section{May within this thesis you see the humour, the fun, the joy and the seriousness that I have left on these pages and in my work. Welcome to:}

$$
\text { ब(ख्वि }
$$

GYDT, IVIE, ANYD THEAT

ADD DAVNT WIGHTHOOSE (DVER THERES? 


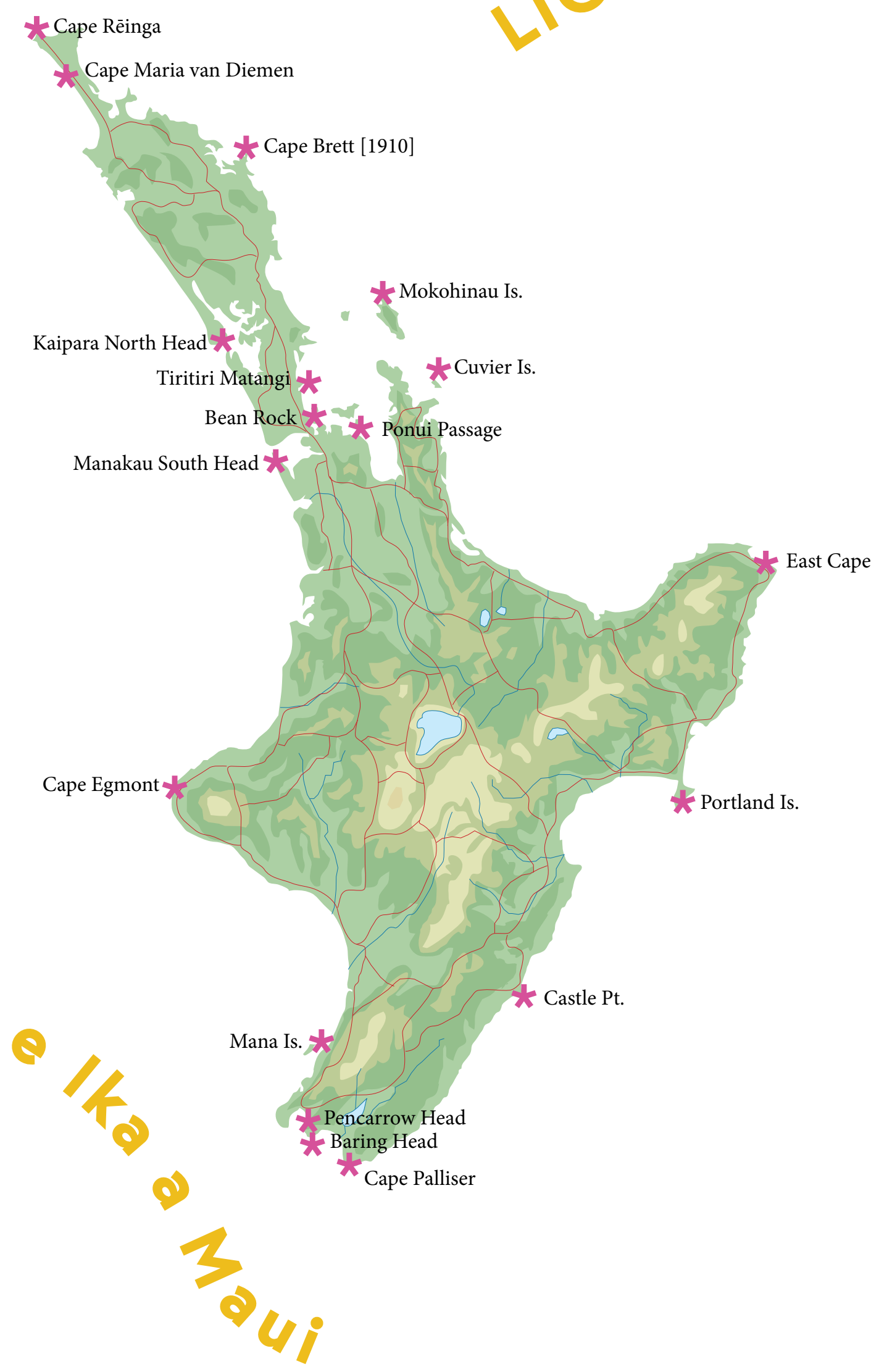



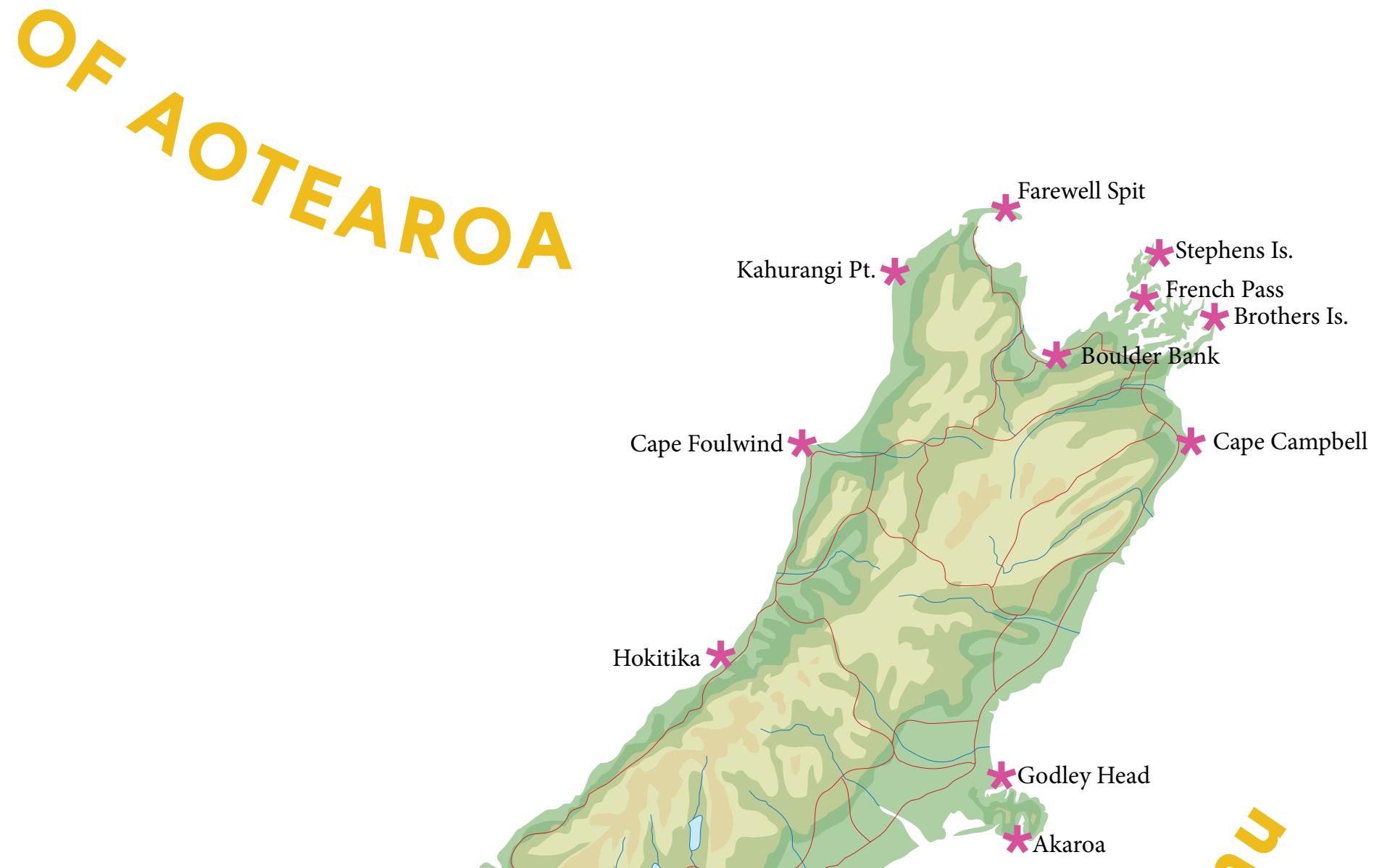

Puysegur Pt.

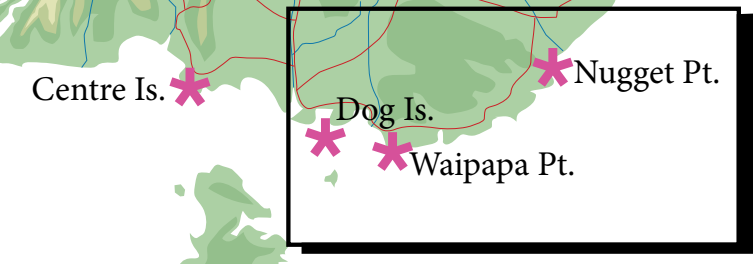

Selected Lighthouse Sites 
66

An explorative story between the tourist as performer and lighthouse as the stage<smiles>[C]1[C+]=C1</smiles> 
This thesis places itself in the academic field of tourism theory, championed by John Urry and reinforced by Tim Edensor, that Tourism is a performance or that the 'tourist' performs and that 'tourist ventures are carried out upon particular stages - on beaches and mountains, in cities, heritage sites, museums, and theme parks.' (Edensor, 2001, p. 63). John Urry's notion of the "tourist gaze" (Urry, 1990) has been extremely influential in portraying the tourist experience as a visual experience; "the tourist gaze" suggests that people travel to destinations that are to be consumed visually. Under this theory, tourist destinations and places market themselves in ways that are pleasing to the eye. In contrast "the performance turn" highlights how tourists experience places in more multisensuous ways that can involve more bodily sensations, from touching, smelling, and so on. The performance turn came about as a reaction to John Urry's articulation on the tourist gaze, as an argument explaining there are multiple ways one would tour something. While this research on the tourist gaze and performance has been integral in designing and understanding how one consumes architecture, throughout this thesis, the most important takeaway from this research has been understanding and creating using the metaphors of tourist as performer and architecture as the stage.

\section{THE GAZE}

The tourist gaze is a concept that brings out the fundamentally visual and image-saturated nature of tourism encounters. Reflecting modernity's hegemony of the visual and postmodernity's lust for the spectacle, it portrays tourism as 'ways of seeing' and exemplifies how many tourist buildings and objects are designed and framed to be viewed through a camera or the eye. (Larsen \& Urry, 2011) Gazing is not just the act of seeing, it involves physical movement through landscapes, cities, and sights, aesthetic sensibility, daydreaming and mind travelling, embodied practices capturing places and moving through them, led by the eye. Many tourist places are designed according to the logic of visualism, and the visual sense is normally the organising sense within tourist experiences, of course privileging the eye over all other senses can lead to a world where aestheticism is everything, of course, this is not the world we live in, people navigate in a variety of ways.

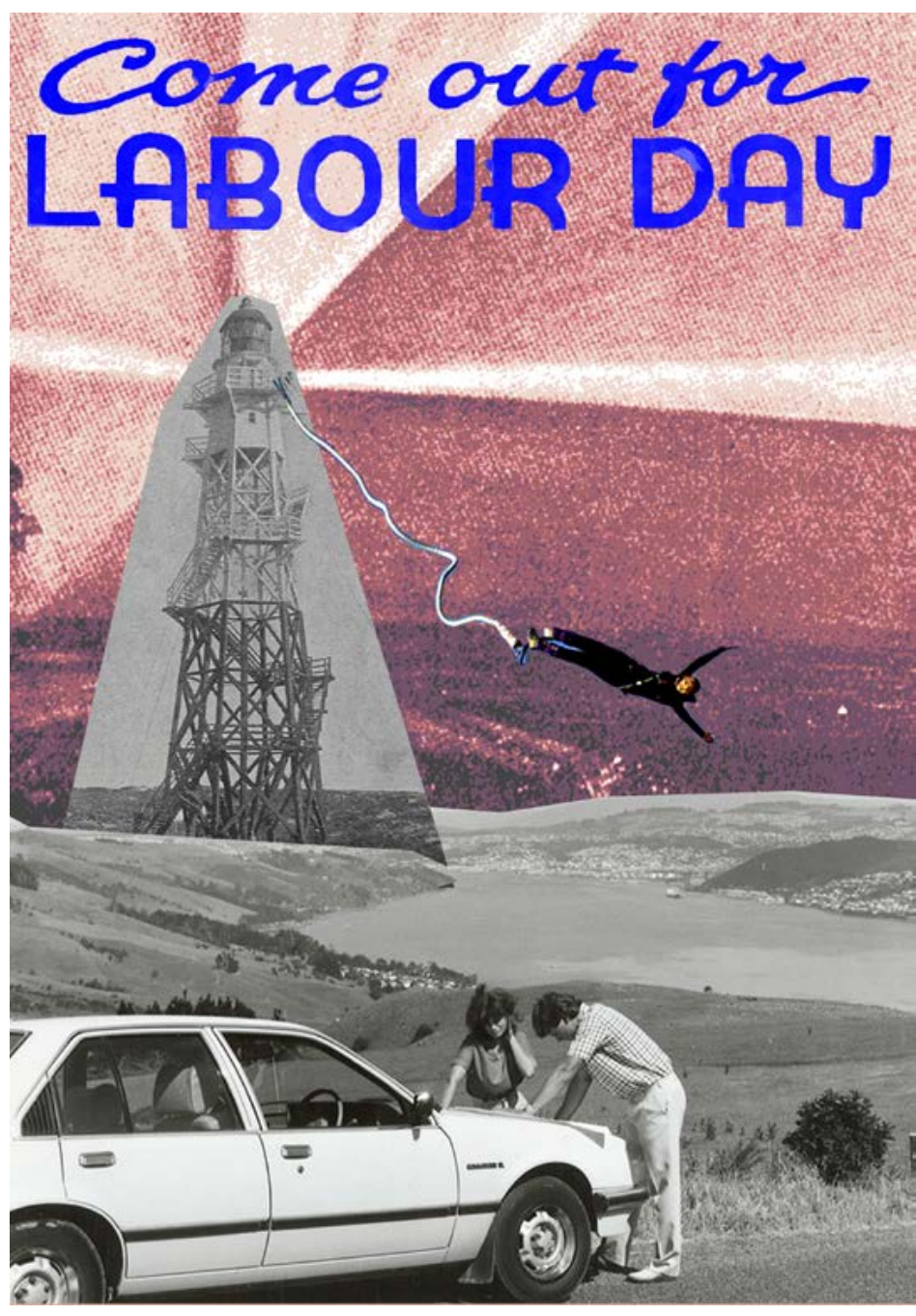

Figure 7 An early collage, completed over covid lockdown, looking at old NZ tourism posters and creating an experience around the lighthouse. 


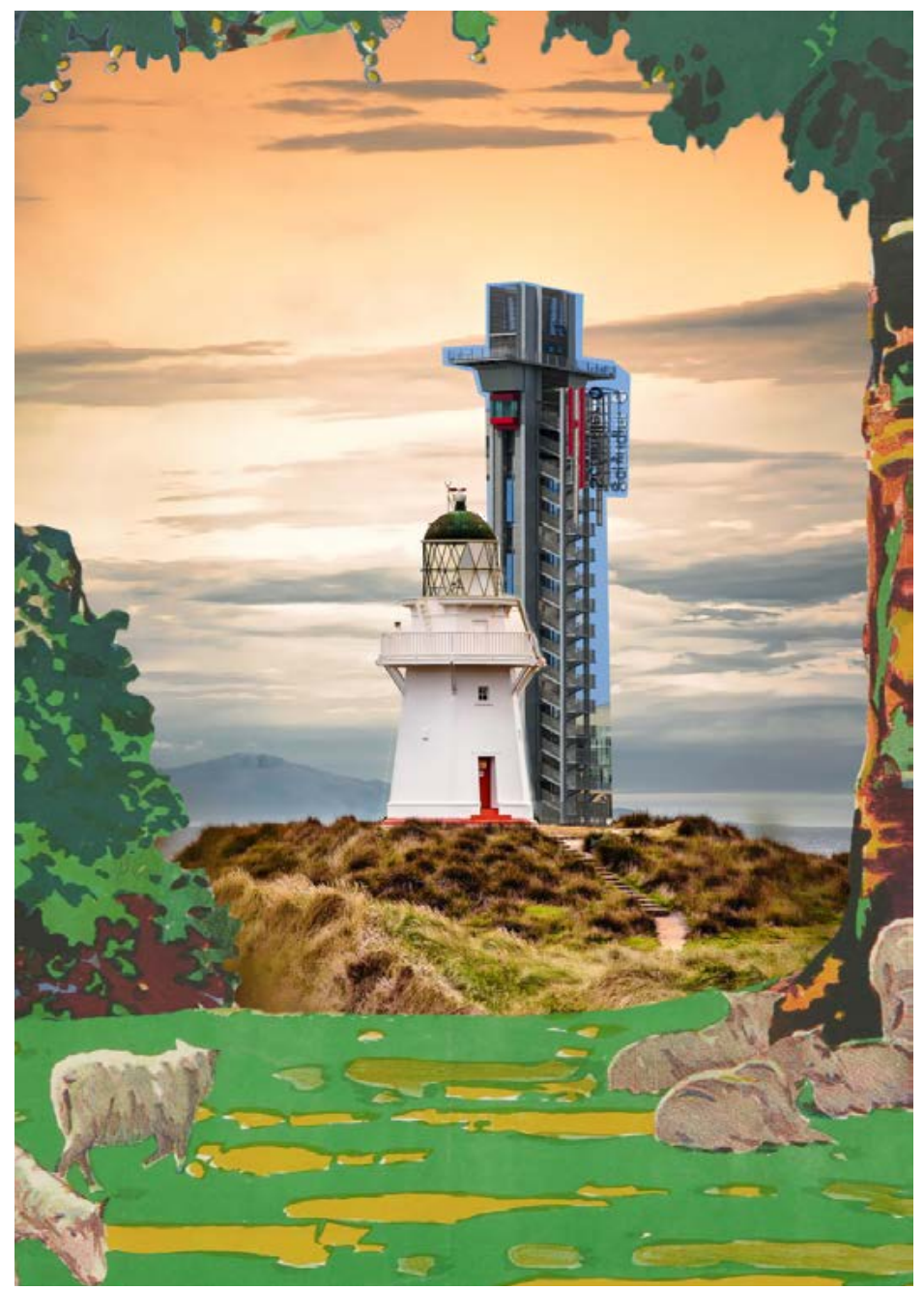

Figure 8 An early collage, completed over covid lockdown, looking at old NZ tourism posters and creating an experience around the lighthouse. 
The metaphor of "Performance Turn" in Tourism Studies can be traced from the late 1990s in tourism theory (Edensor, 2001) Much cultural tourism research has been concerned with how tourists are drawn to and experience - sense and represent - destinations, and the "performance turn" continues in that direction. The "performance turn" is formed in opposition to the "tourist gaze" and other representational approaches privileging the eye by arguing that "tourism demands new metaphors based more on being, doing, touching and seeing rather than just 'seeing"' (Perkin \& Thorns, 2001, p. 189). The performance turn allows a deeper understanding of the tourist experience that goes beyond the purely visual. The performances of tourists are in many ways staged and controlled within places, but equally, tourists produce place through their individual and collective performances, indicating that neither tourism nor place is merely products, but part of a process.

To understand this theory, it is important to grasp the idea that tourism is a performance. By using the metaphor of performance, we can explore why we carry out particular habits and practices and, consequently reproduce and challenge the social world. How putting a thoroughfare here, or a ramp around a lighthouse will change an experience and manipulate how a tourist will perform on that stage. This has implications on what one consumes and takes away from an experience.

\section{THE STAGE}

If tourism is a performance and tourists are performers then the context or architecture is the stage. Tourism takes place within meaningful spatial contexts - places and therefore stages. Different Tourism ventures are carried out upon particular stages, on beaches and mountains, cities, heritage sites, museums, and theme parks. These setting whether physical or symbolic are often organised or stage-managed to provide a common-sense about what activities should take place on said stage (Edensor,2001). By looking at the stages in which tourism is regulated, directed, and designed, I will consider how stages and performance are reproduced.

\section{CONCLUSION}

The implication of this knowledge in architectural design practice is that the built environments created in which performances are staged are critically important in helping convey ideas for tourists to consume. To create stages and tourists to perform the architectural environment must be purposeful and self-aware, does one want the performer to look towards the sea? Build a wall or an aperture. Through the metaphors of Performer and stage, architecture is designed that enables the tourist to interact in a back and forth nature with the lighthouse.

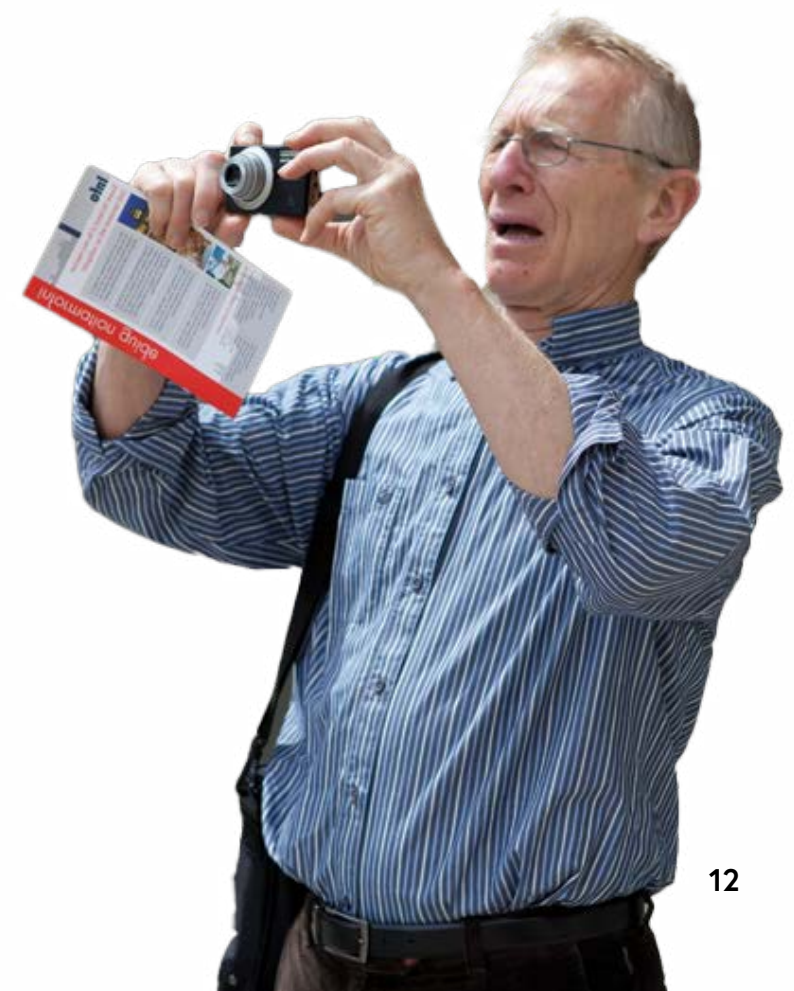


This content is unavailable.

Please consult the figure

list for further details.

Figure 9 Self potrait of Andy Warhol, 1986 
This content is unavailable.

Please consult the figure

list for further details. 


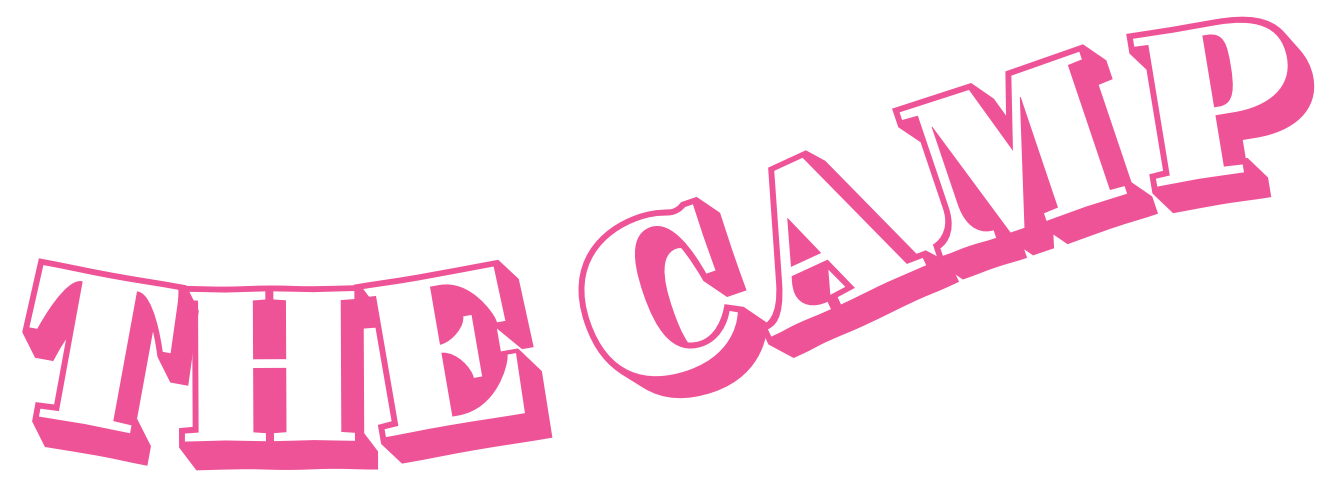

Mapplethorpe was a well known photographer emerging

from the New York art scene, his work is often described

as having a camp This content is unavailable.

sensibility, often Please consult the figure

photographing list for further details.

way he would

approach a nude.

Normally alluding

to other ideas in his

work.

Figure 11 Poppy, Robert Mapplethorpe, 1988. 


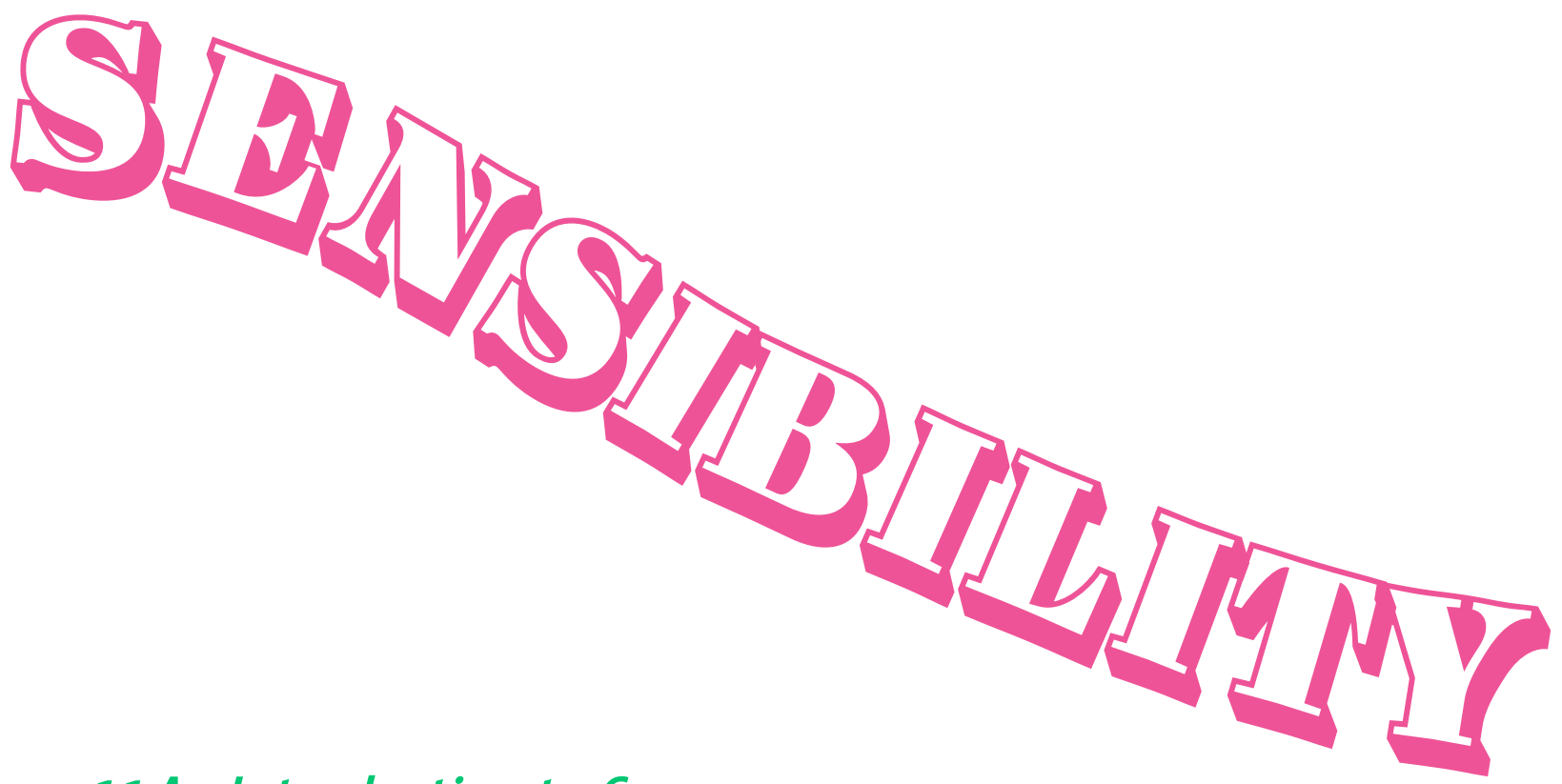

\subsection{An Introduction to Camp}

Camps historical origins are unknown, like a lot about 'Camp', a degree of ambiguity surrounds its birth, it was not until the 19 th to early 20th century that the term, 'Camp' began to emerge, as a reference to slang for the underworld, the fashion scenes and design worlds (Cleto,1999). It is posed that camp started around 1860 not breaking mainstream until about the 1960s with the help of course from Sontag and her 'Notes on Camp'. The Definition of camp to this day remains elusive, stated once by Margaret Gillespie that "camp is terribly hard to define but you'll find yourself wanting to use the word whenever you discuss aesthetics or philosophy or almost anything. I can never understand how critics managed to do without it" (Gillespie,2016). 'Camp' is the aesthetic taste which might prompt someone to exclaim, 'it's so dreadful! It's wonderful!' The juxtaposition of the two opposite sentiments in this statement should be noted carefully (Kates,1997). These contradictions enforce the notion that camp architecture, camp art, or any product of camp, contains within themselves important paradoxes, and inversions that help subvert conventional order and a mainstream way of consuming ideas. Or to be put simply, 'Camp' is an ironic sensibility, relating to a product, where the physical object itself conceals a deeper, hidden meaning beneath a façade of absurdity (Kleinberg,1992).

It's important to note that camp is not defined or limited by sexual orientation (Booth,1999), this is the most misunderstood notion towards camp, people tend to have. 'Camp' is a human sensibility, to define it in such binary terms would be reductive and exclusive. Anyone and anything can be camp, it is just the question of whether they are or not.

Susan Sontag's Seminal 'Notes on Camp' 1964, helps form a basis of the argument and mode of viewing for this thesis, design research, process, and outcome. It is her definition of Camp and other theorists supporting material in which I will be basing mine off.

Sontag set out in her notes to define a sensibility and way of looking at the world that was undeniably modern and is still being interpreted today (Rubin, 1974). To understand this body of work is to understand within our contexts and choices, that we are all playing a role, everything is playing a role. 
Sontag states camp as a way of seeing things as good because they are bad, 1) they are marginal; 2) they are artificial or exaggerated,3) they are demode, 4) they emphasis style at the expense of content. It is the embracing of flamboyance, the expressing what's serious to you in terms of fun and artifice and elegance of making fun out of what you take seriously as opposed to making fun of it. (Booth, 1999)

In, 'Camp: The lie that tells the truth' (Core, 1999), Philip Core- like Sontag, sets out to define a set of 'Camp Rules', examples include the following: "CAMP is, first of all, a second childhood, CAMP is character limited to context, CAMP is an embarrassment without cowardice and CAMP is a lie which tells the truth." The last two examples being close to fits that of Sontag's. To understand 'Camp' is therefore to understand how to design unwaveringly, to do silly things without the fear of failing. 'Camp' is silly, with the intention of it being so silly, or 'too much', so over the top that one might learn something. That behind the façade is something of substance and seriousness.

When understanding this in architectural condition one only needs to look at the likes of those of the Memphis style persuasion. The colour, the pattern all act as a surface to something deeper, a welldesigned couch perhaps or a lampshade. Sontag points out that camp emphasis is on the artifice, surfaces, and the appreciation of failed seriousness, of 'things-beingwhat-they-are-not,' and of middle-class kitsch (Sontag, 1964). Originally, I would have called it all fake, it is how Phase One is framed, but when understanding camp, it is understanding that the artifice is that because it is playing a role, that the mode of being is still completely authentic.
While 'Camp' may be a difficult sensation to define, the rules are also very simple, it is an ironic, modern way of viewing the world. It is full of contradictions and artifice, facades and flamboyance, but behind it all is an object, a thing, that is saying something serious.

Take a Lighthouse, for example, they look playful, whimsical, and very much are fantastical architectures. If an architect were to design them with the mainstream having no idea what they were in the first place, these odd structures, would very much be classed as 'other' as 'Camp' It's suggested that these archetypes are camp not because of some agenda, but because to see them as 'camp' is to see them as a failed seriousness. That while they have a particularly important and serious job of protecting ships, they provide nothing but delight and joy to the on-looker in daylight.

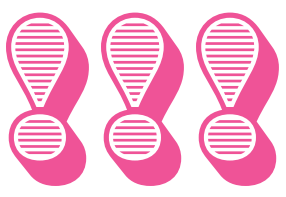



This content is unavailable.

Please consult the figure

list for further details.

Figure 14 Potrait of Susan Sontag photographed by Jill Krementz on November 18, 1974

This content is unavailable.

Please consult the figure

list for further details.

Figure 15 Anne and Charles Duncan Hall - Rice University designed by John Outram in 1996 


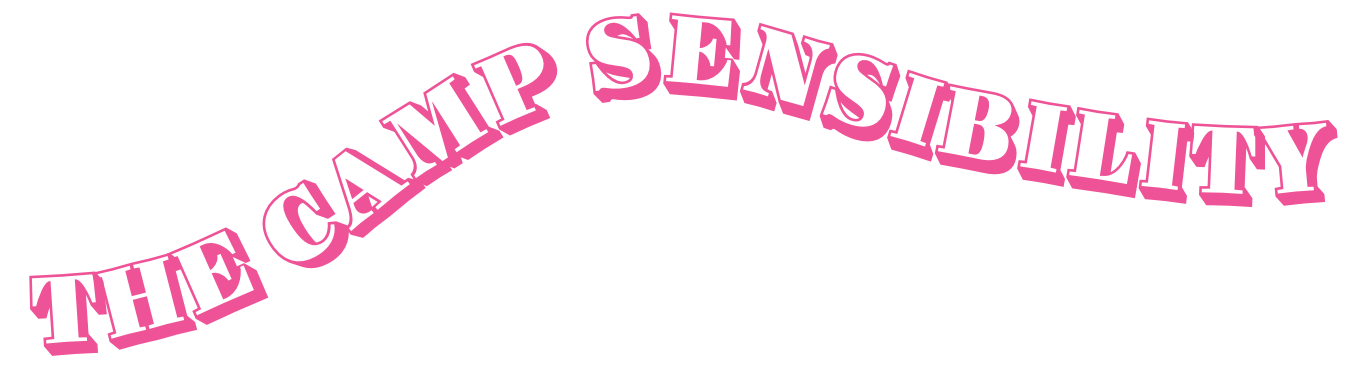

(U) While theory and the analysis of the sensibility of camp has been highly popularised ever since the release of Sontag's Notes on Camp, there is still a large gap in knowledge between bridging that sensibility into the discourse of Architecture.

One notable source who has written on it however is that of Charles Jencks, somewhat of a master on all things Modern and post-modern, Jencks starts the sixth chapter in his book Modern Movements in Architecture entitled " Recent American architecture: Camp - Non-Camp. " (Jencks,1973) In this section of the book, he shifts from describing past movements to define a more contemporary condition with what he calls 'camp' architecture.

He takes a step towards defining and creating a group instead of merely describing the sensibility. Jencks defines camp's attitude as "a mental set towards all sorts of objects which fail from a serious point of view. Instead of condemning these failures, it partially contemplates them and partially enjoys them." For Jencks, Camp is a way of accepting imitation and enjoying it by finding beauty in the "fantastic hidden in the banal."

As Susan Sontag states in her definitive text, camp is a way of 'seeing the world as an aesthetic phenomenon (Sontag,1964). As such, it tries to outflank all the other stereotyped views of failure and then asks what is left to enjoy, to salvage. It is realistic because it accepts monotony, cliché, and the habitual gestures of a massproduction society as the norm without trying to change them. What Jencks failed to predict- or perhaps completely predicts in this anthology of modern styles (including camp) as well as pop, the international style and formalism are that they all participate in birthing what now was known as the Post-Modern movement, something Jencks too later would go on to become a master in.

While It's not explicit that Pomo is ultimately a camp style of architecture, difficult to be definitive as camp is a sensibility, but the post-modern love of colour, facadism, artifice, and rejection of the normal lend itself to the camp sensibility.

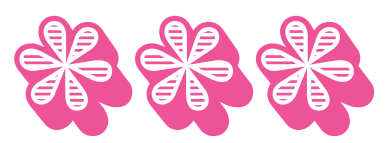


This content is unavailable.

Please consult the figure

list for further details.

Figure 16 The London Mastaba - a floating platform of wrapped oil barrels, moored on the Serpentine Lake, Hyde Park, 2016 by Christo 
In conclusion, Sontag's sensibilities on camp provide the reader a refreshing way of looking at the world, with utmost inhibited joy, to favor the flamboyant and 'over the top'. To look at things through camp humour means to understand that things are serious but don't treat them so. It's what I, the author am asking of the reader, to look past the whimsical, fun aestheticism of the work and look at a deeper discussion going on.

Camp begins a conversation that is critiquing or commenting on our current state of tourism, how we view things, how we as humans interact with focal objects and buildings in general. How we entertain ourselves and how we tour environments. Behind the silliness and the kitsch, the play and colour I attempt to add to a bigger discussion through architecture and the design process.

The goal of dethroning seriousness means approaching something with no preconception, or expectation of an outcome, to attempt the anthesis of seriousness and design with humour, and satirical methods. It is in this thesis that I attempt to not take my work seriously, even though there are serious intentions, that it's okay to perceive something as what they are not, and that life is a theatre. How fun it is to realise we are all performing.

"May within this thesis you see the humour, the fun, the joy, and the seriousness that I have left on these pages and in my work. Welcome to; 'You, me, and that god damn lighthouse over there!'” 


\section{Camp as a Design Method}

The key texts of Sontag's 'Notes on camp' along with supporting material create a tonal basis in which the author suggests how one should view this body of work. This method not only explains how one will structure and execute the design work, what the author is proposing is also how one should view it. To look at this project one must look at it through the camp lens.

Camp as a design method, states that camp is a way in which we as humans are either intrinsically are and/or purposefully act. In this, the author states that how they design is undoubted 'Camp' that, a striving for failed seriousness and performance is how they design.

This project starts in chapter one by using 'camp' to explore a historic structure, this is executed by re-designing the lighthouse and its environment through a camp lens. Chapter two then removes this lens and explores anti-camp, removing all artifice and thoughtfully exploring design without the façade. Finally, it restores the artifice but adds a level of complexity that permits deeper engagement with the lighthouse through architecture.

Specific literature is analysed at varying stages in the designing process to create assumptions, ideas and guide subsequent design. On-going development of ideas of design and theory work in a back-and-forth model that helps form a developed outcome (that being phase three or The Stage Complete). This thesis is undertaken as a project that sits within the field of 'Architecture' that allows the concepts of architecture to be explored and then critiqued and discussed. 


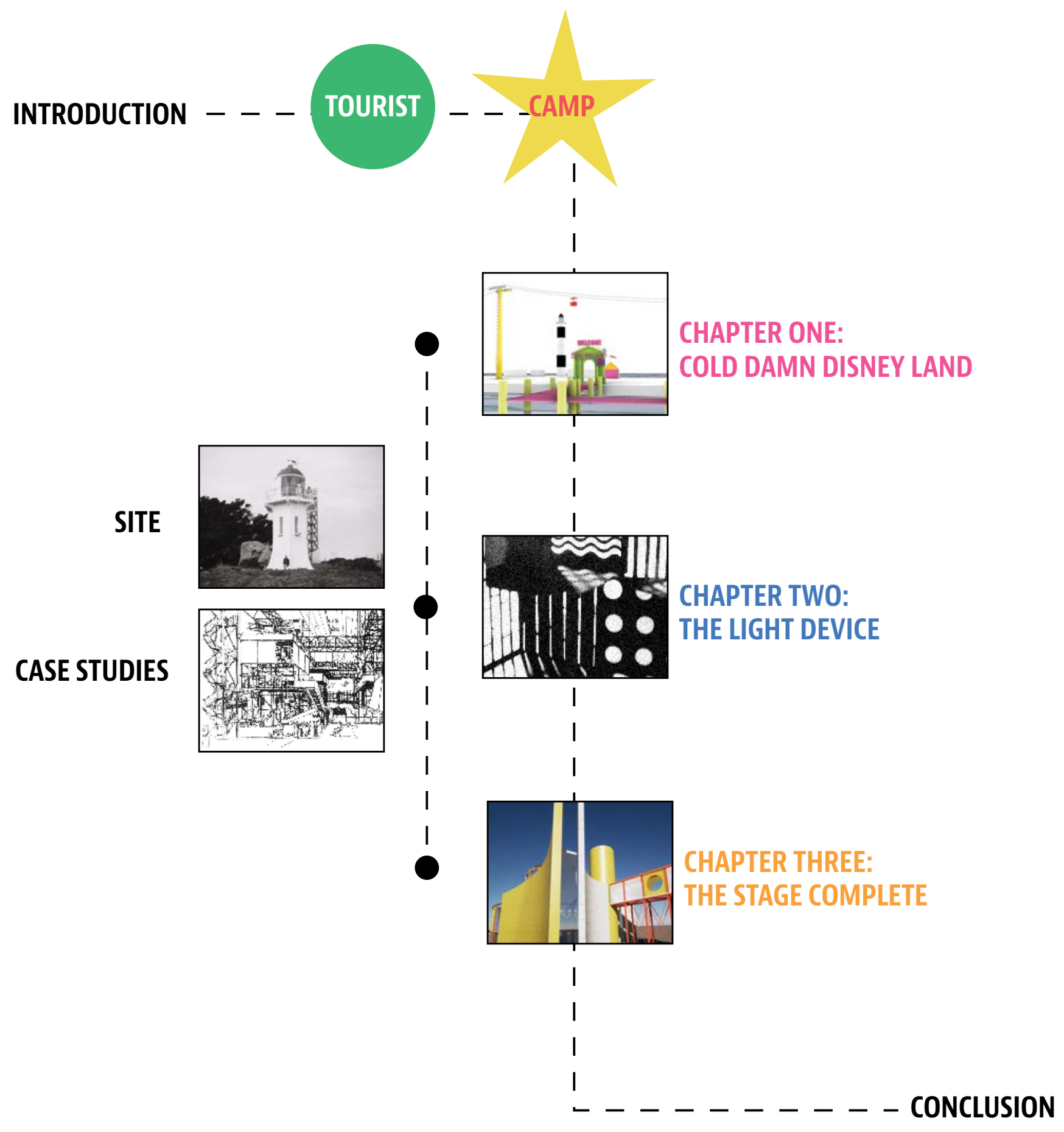

\section{Methodology Diagram}

'Research through design' methodology diagram, and overview of this thesis. Site and case studies support the research while the three chapters help inform each other in a back-and-forth conversation with each other, informing what chapter the research of this design portfolio fall into. 
If. 


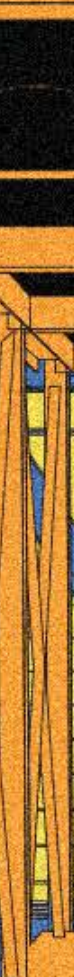




\section{Susan Sontag (1933 to 2004)}

Its here, I dedicate this space to Sontag, her writings have inspired my train of thought and way of thinking, far more than I could have ever realised when beginning this thesis journey. From her 'Notes on Camp' to here quips on photography and other essays. Each idea executed with grace, grit and from an inspiring point of view.

This thesis, if anything, is an exploration on how to build on the shoulders of giants. Translating an idea as undefinable as Camp would have seemed absolutely foolish if it wasn't for her. 
This content is unavailable.

Please consult the figure

list for further details.

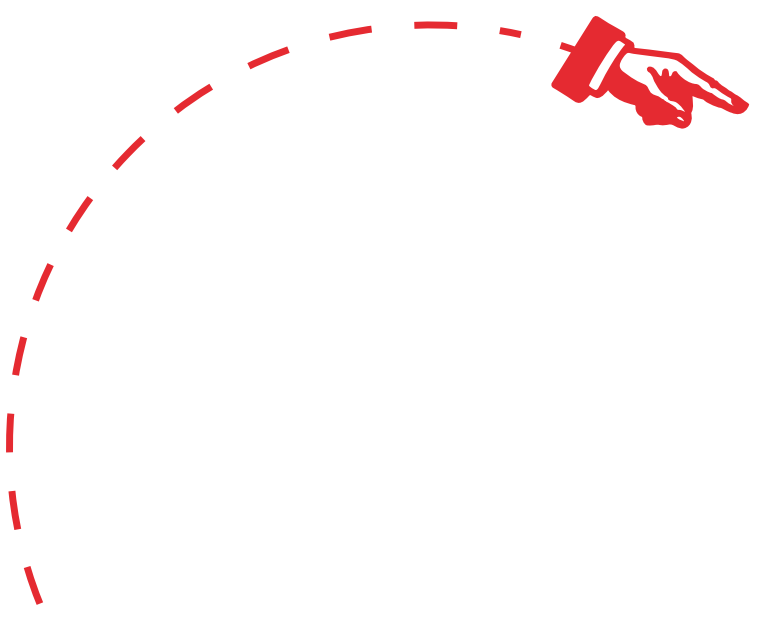

Figure 17 Potrait of Susan Sontag photographed by Jill Krementz on November 18, 1974 (Sourced from: https://lithub.com/rememberingsusan-sontags-final-days/)

This content is unavailable.

Please consult the figure

list for further details. 


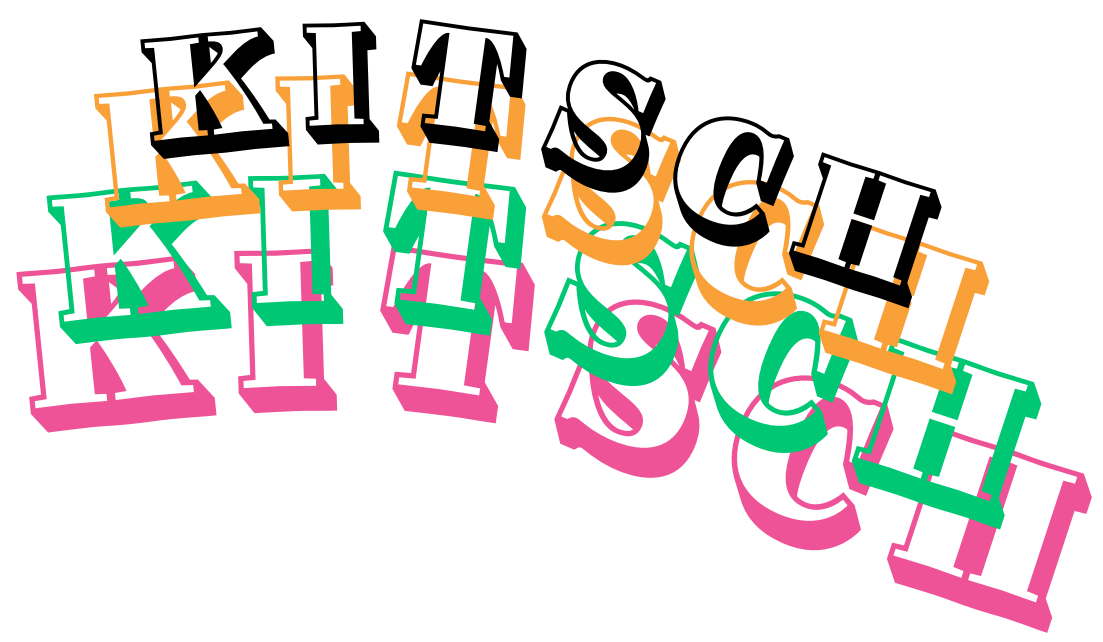

Kitsch theory is important to this research as it provides many a warning at what happens when mass tourism takes hold and nothing is done about it, when mass consumption and economics are given priority over what made that first tourist explore in the first place. In this thesis kitsch is applied to the over-commodification of experience. In which Architectures and place are places being experienced and created only in terms of stereotyped, contrived, superficial and of mass-value. An inauthentic attitude to place is essentially, no sense of place. (Farrelly, 2008) describes "Kitsch as not just bad taste. Bad taste, as has become adored by those in postmodern circles of thought. Kitsch, so to speak, is based on a deep deceit. It is, in a word, bullshit." Bullshit - not being a very academic word to say the least, is defined as not the same as lying, but it also isn't truthfulness, bullshit implies a complete disregard for the truth, a sort of truthfulness where a fantasy exists in place of the truth. The essence of Bullshit is not that it is false but that it is phony.

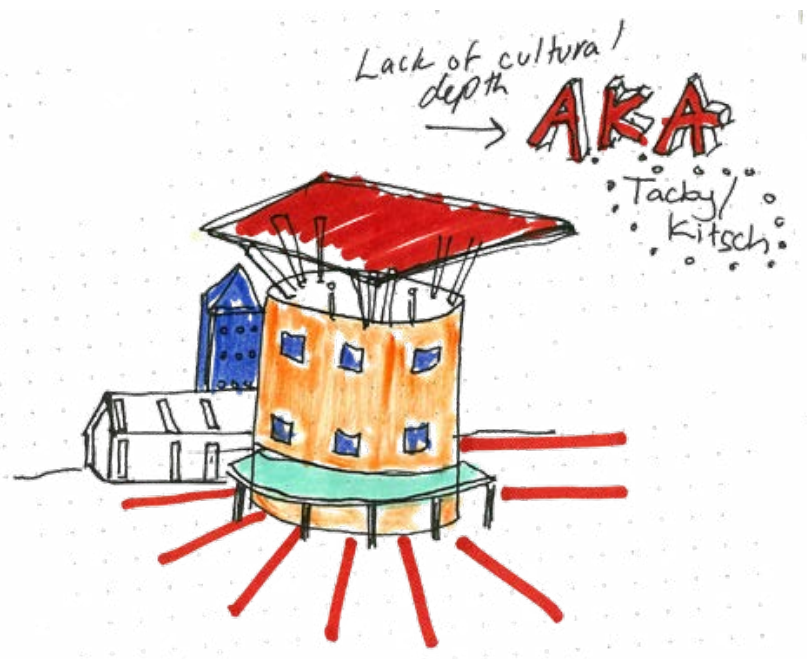

Figure 19 Sketch of a Kitsch building.
Where authentic is on one side, the inauthentic, the fake is on the other. In this thesis I have identified 'the fake' to be seen as kitsch, something that is observed as inauthentic but in some circles of taste, is very much the ironic opposite. Understanding Kitsch means ones understands the contradiction of what really is authentic anyway? Strictly the term 'Kitsch' refers to the mediocre, styles, sweetly sentimental objects that are sold as souvenirs and gifts and to their related forms in household goods, music, architecture and literature. Behind these attitudes, however, is a distinct kitsch style and kitsch attitude. The main features of this attitude identified by Abraham Moles (1971, p.7) is that it is a way of being, where many people can afford the trivial, and the showy. And occurs especially between the relationship of human and object, specifically for the purpose of mass-consumption. The fantastic is made real.

Another common confusion, is between Camp and Kitsch, which as Roland Barthes has written 'Implies a recognition of high aesthetic values' (Booth, 1999) it represents an unwitting failure on a massive scale. Key chains of landmark buildings are Kitsch, the American independence is kitsch. Providing the biggest key in this argument is Oscar Wilde's quotes (one of the most camp humans to exist) "The worst art is done with the best intentions" Unlike Kitsch, camp does not even have honourable intentions, though kitsch is never intrinsically camp, it has a certain eye rolling, gut wrenching quality that appeals to the camp sense of humour. Kitsch is one of Camp's favourite fads and fancies. (Booth, 1999) 


\section{It is, in a word, Bullshit. 99}

- Farrelly, E. M. (2008).

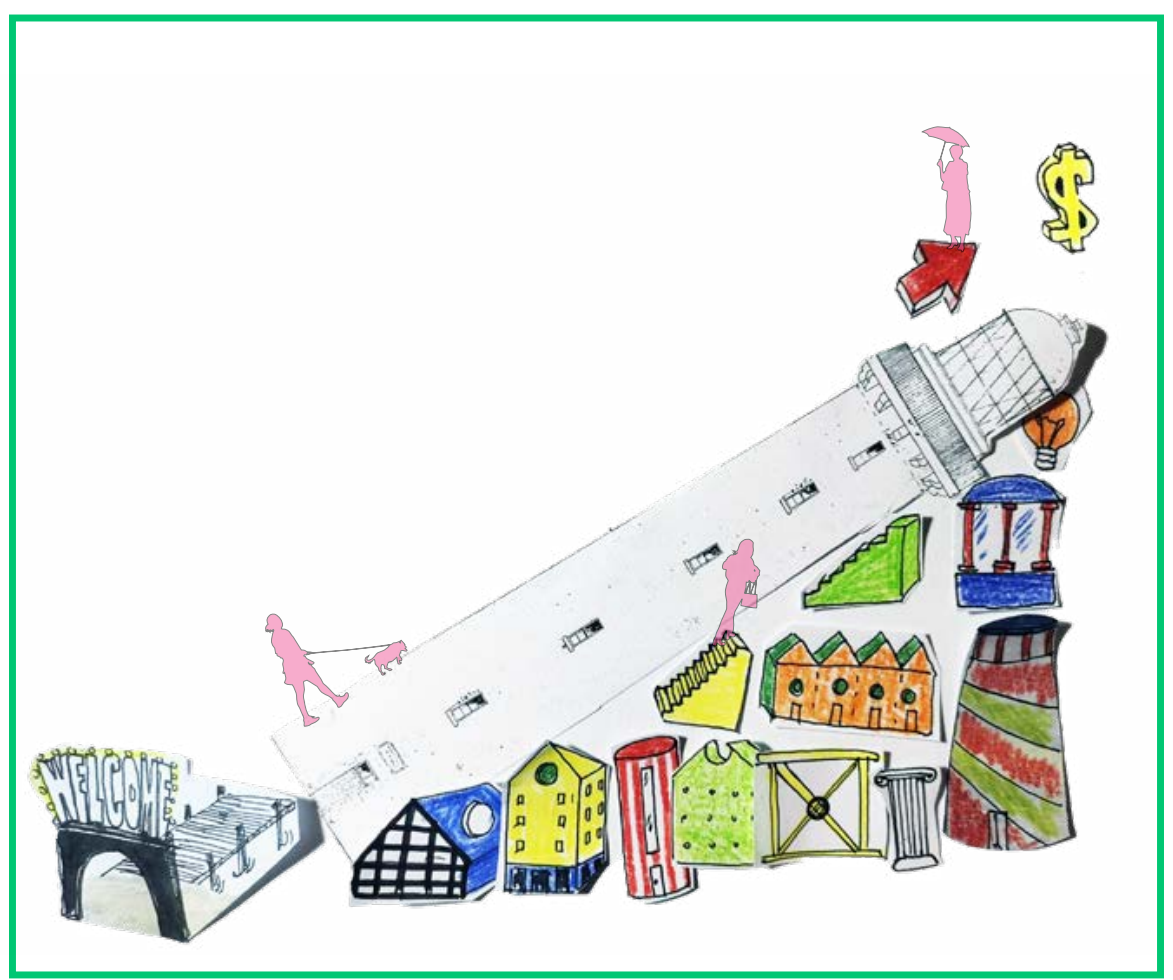

Figure 20 KITSCH collage of folly designs, each providing or facilitating a consumer stage for the tourist to perform. 
"A deep human need exists for associations with significant places. If we choose to ignore that need, and to allow the forces of placelessness to continue unchallenged, then the future can only hold an environment in which places simply do not matter... But one thing at least is clear -whether the world we live in has a placeless geography or a geography of significant places, the responsibility for it is ours alone."

-Relph, E. C. Place and Placelessness. 1976, p.147 


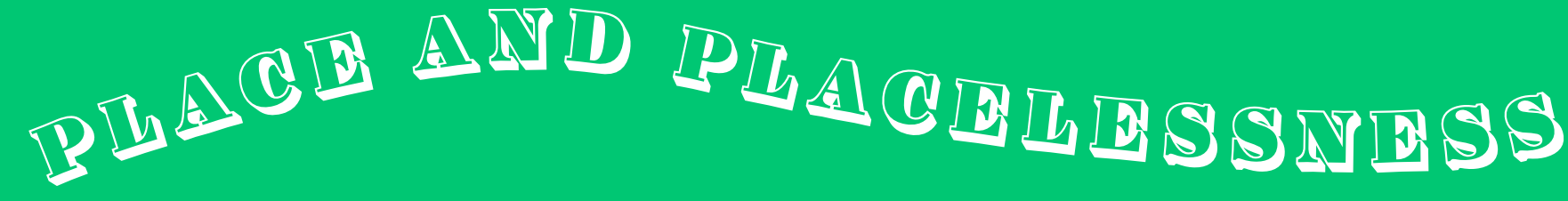

In 'Place and Placelessness' Relph attempts to shine light on what is a deeply theoretical issue of defining what is place and how to avoid placelessness. Of course, to understand what place is, one also should recognise what placelessness looks like, Placelessness or nonplace is culturally unidentifiable environments that a similar anywhere. And as Relph states is a result of modernity and globalisation. There are many a definition for the term place but generally place opposed to space is the strong bond between a human and a particular setting (Najafi and Shariff,2011). In other words what makes place different to space is the attributed human values and principles.

Manifestations of placelessness can take form in many ways, many are for/in reaction to tourism. These are entertainment districts, commercial strips in a city or more synthetic/pseudo-places such as Disneyified places/Theme parks, museum and futurist places. Placelessness also takes form, in uniformity and standardisation like the suburb or new development and international styles of architecture juxtaposed onto place. These characteristics identified are a simple classification and are by no means the all-inclusive manifestations of placelessness, it is also important to point out that these manifestations are the superficial expressions of deeper processes and attitudes within society that cause placelessness. 
Being-as-playing-a-role understands 'lighthouse' isn't just a building, In the daylight, the lighthouse is the joker, the exhibitionist, the whimsical folly that is admired to which people flock too. However, at night, it becomes a surveillance architecture, sentinel and protector. 


\subsection{SMOUT ALLEN AND THEIR 'UNIVERSAL TEA MACHINE'}

Smout Allen is a London based collaborative architectural practice. There work takes two routes: The first are Architectural competitions, where the rigor of the competition brief, site and program provide a basis for new investigations. The Second is formed by conceptual design projects which test out the agenda and methodology of the design research practice. They tend to focus on the dynamic relationship between the natural and the man made and how this can be revealed to enhance the experience of the architectural landscape. Smout Allen, consisting of Mark Smout and Laura Allen are both current Senior Lectures at the Bartlett School of Architecture, UCL. Their studio and teachings have often been compared to that of Peter Cook's Archigram and thought of continuing his line of research from his time at the Bartlett between 1990 and 2006.

Their work often lends itself by tackling serious issues through speculation in more Satirical, Playful and Subversive approaches. Smout Allen's practice lends itself to this thesis as an example of how one consumes architectural information and considerable research ideas in an easily digestible way.

The Universal Tea Machine is a built project that encompasses multiple objectives, one being a homage to the late Mathematician Alan Turing's 'universal Turing machine.' The pavilion was Built as part of London's 2012 Olympic celebrations, that was to celebrate the British appetite for trade, technological innovation, and tea. Visitors to the design operated the Universal Tea Machine to produce displays of calculation, as one of the fundamental logics of trading and computation. The project is a representation of a simple principle of computation, evoking the educational possibilities of play and public engagement.

This project while very much grounded in a normal brief, managed to create a design for public consumption that evoked the essence of Turing and the British tea industry through tools of play and doing so with humour.

\section{This content is unavailable. Please consult the figure list for further details.}


This content is unavailable.

Please consult the figure

list for further details.

Figure 23 The Universal Tea Machine Pavillion built (sourced from: http://www.smoutallen.com/universal-tea-machine) 
Adam Nathaniel Furman is a London based multi-disciplined artist and designer. Trained in Architecture and Fine Art, as well as working beyond his field in product design, interiors, and teaching. His work takes inspiration from a lifelong exploration of form, colour and ornament as a political-aesthetic. He describes his work as 'embodiments of the diasporic, fluid and roaming cultures that surrounded me as I grew up.' (Adam Nathaniel Furman, 2020)

Furman's Boudoir Babylon (in collaboration with Sibling Architecture) takes space in the NGV, National Gallery of Victoria, Melbourne as part of the 2020 Triennial. The design of the space pays homage to three distinct spatial typologies - boudoirs, salons, and clubs - which toe the line between public and private and have historically acted as safe spaces for marginalised groups in society. Self-described as a 'Super-Camp' space the use of "Queer-oglyphs" and a "genderf*ck" colour palette create a space that celebrates 'otherness' by using queer aesthetics to create spaces for gathering and socialising (Adam Nathaniel Furman and Sibling Architecture Design Boudoir Babylon, n.d.). The design incorporates stereotypically gendered colours such as baby blue and pink, these are recontextualised and subverted to challenge traditional notions of what is male or female. This is known in the LGBTQ+ community as a "genderf* ${ }^{*}$ ".

When talking about the typologies that inspired this design Furman states, "These are places where, from the 18th century onwards, women, queer people and people of different political or religious beliefs were able to meet and share their identity with others but also where they could express their identity through the design of a space".

\section{"I see colour as a political, social, active agent within architecture and design, rather than something that's superficial and to be disregarded"}

-Adam Nathaniel Furman, 2020

This content is unavailable.

Please consult the figure list for further details. 

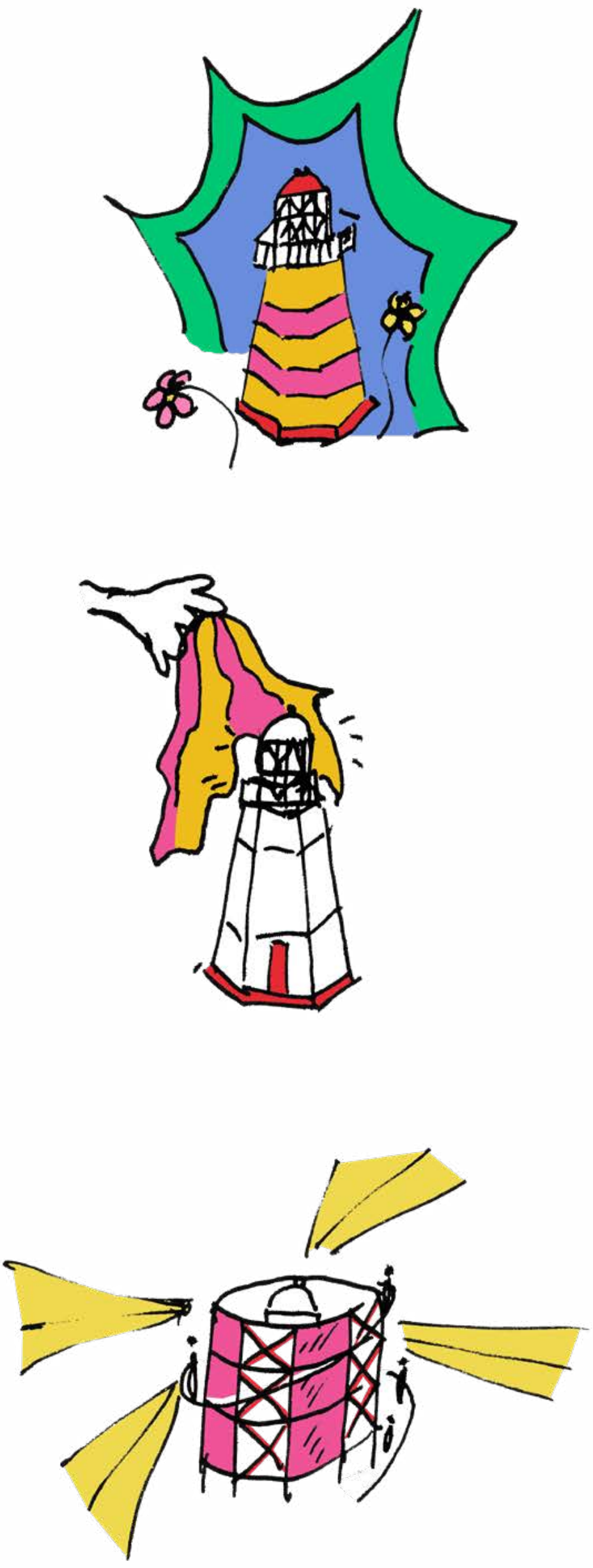


\section{IDATICS}

1. Camp lens is applied, concealing the intensity of the seriousness with artifice.

2. The Camp lens is removed, the lighthouse is revealed without artifice, a.k.a anti-camp.

3. The Camp lens is reinstated, but is refined, the design is a stage, showcasing the crux of the lighthouse. 


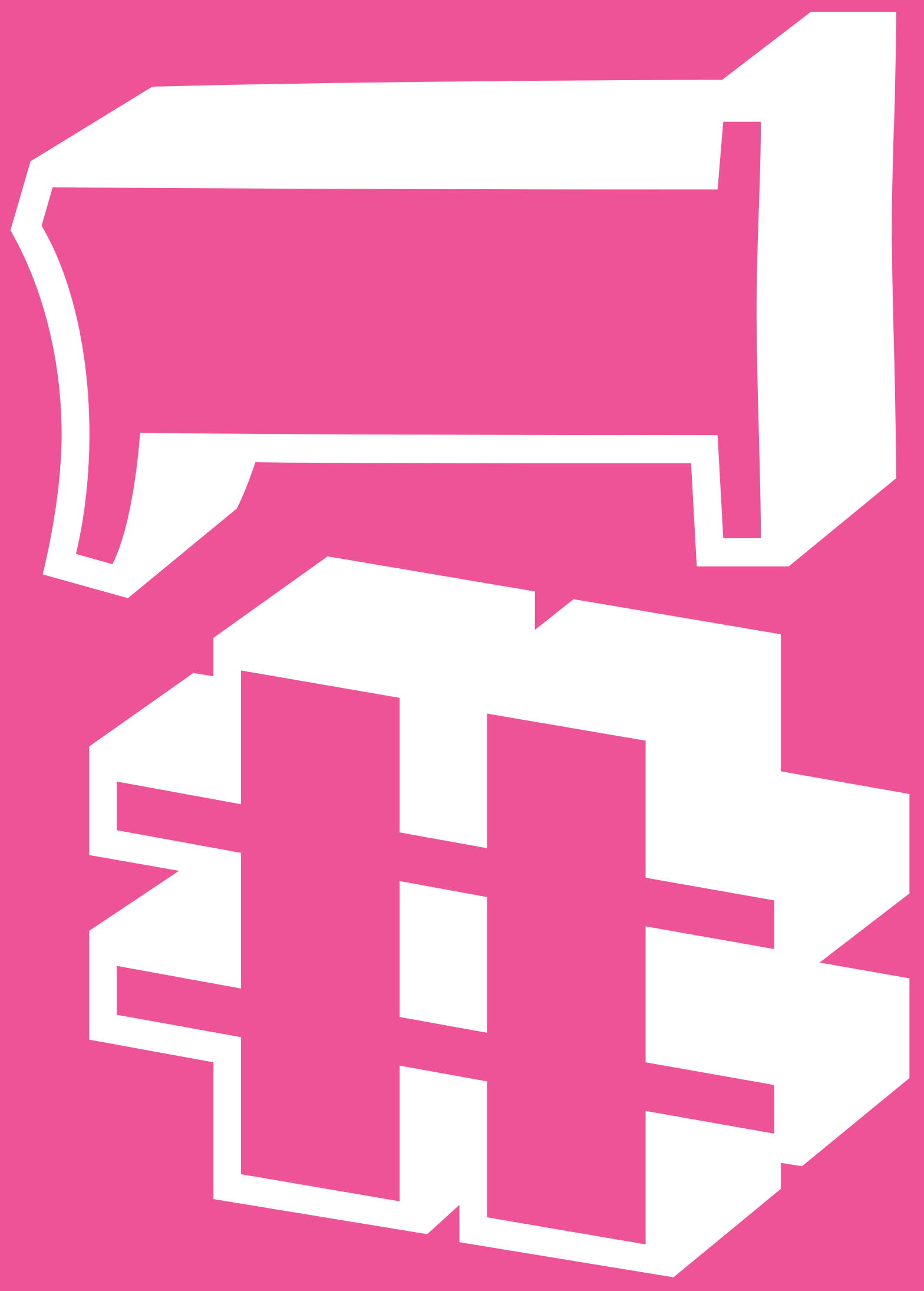




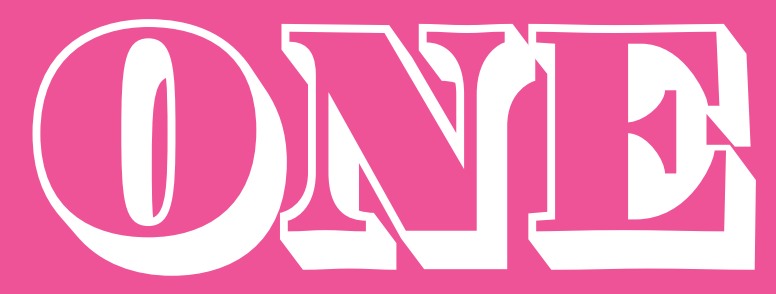

\section{"COLD DAMN DISNEYLAND"}

Camp lens is applied, concealing the intensity of the seriousness with artifice. 


\section{1 INRODUCTION}

This design phase uses a camp lens to explore and re-design the lighthouse and its environment, employing satire to observe and critique mass tourism and kitsch. The scheme produced is named: Cold Damn Disneyland. Disneyland is often seen as a utopia of sorts, an escaped world for tourists to play the child.

Under the satirical guise of 'Cold damn Disneyland', I conceptually transform Dog Island- an island $5 \mathrm{~km}$ off the shores of Bluff, the site of New Zealand's oldest lighthouses', a lighthouse that has protected ships from the treacherous conditions of the Foveaux strait since 1865, into a utopian Theme park, an attraction of things, placeless and superficial. The collection of work interrogates tourism-on-masse and seeks to use Edward Relph's place-lessness theory in a way to recognise what a theme park is. Its first logic to the series of three looks at the superficiality of it all, experiencing architectures from a purely visual aesthetic and style point of view and in a subversive way looking at how the tourist performs in space/ stage purely designed for mass- consumption. Space where the place is irrelevant and, in this case, - the place is one of the most exposed and coldest places in New Zealand, plays on the absurdity of it all.

'Cold Damn Disneyland' is a scheme that looks at the fantastical and whimsical aesthetics of both theme park and the ridiculousness of its proposed site., this body of work attempts to suggest that these stages are sophisticated in the way they promise escapism, without saying anything. That these places while full of stuff are empty and are playing a role. In this conceptual masterplan, the Lighthouse becomes null and void, it is part of the colourful, meaningless fabricated world that is 'Cold Damn Disneyland'.

Susan Sontag describes camp as something that 'Indefatigably patronized the past... Lighthouses and their whimsy selves are camp. they are meant to be designed as stoic utilitarian structures but these lighthouses are very much personable and colourful in nature. Lighthouse is an architecture that doesn't fit in, stands by itself, and has lasted a test of time, a barrage of elements and the ongoing curiosity of the tourist.

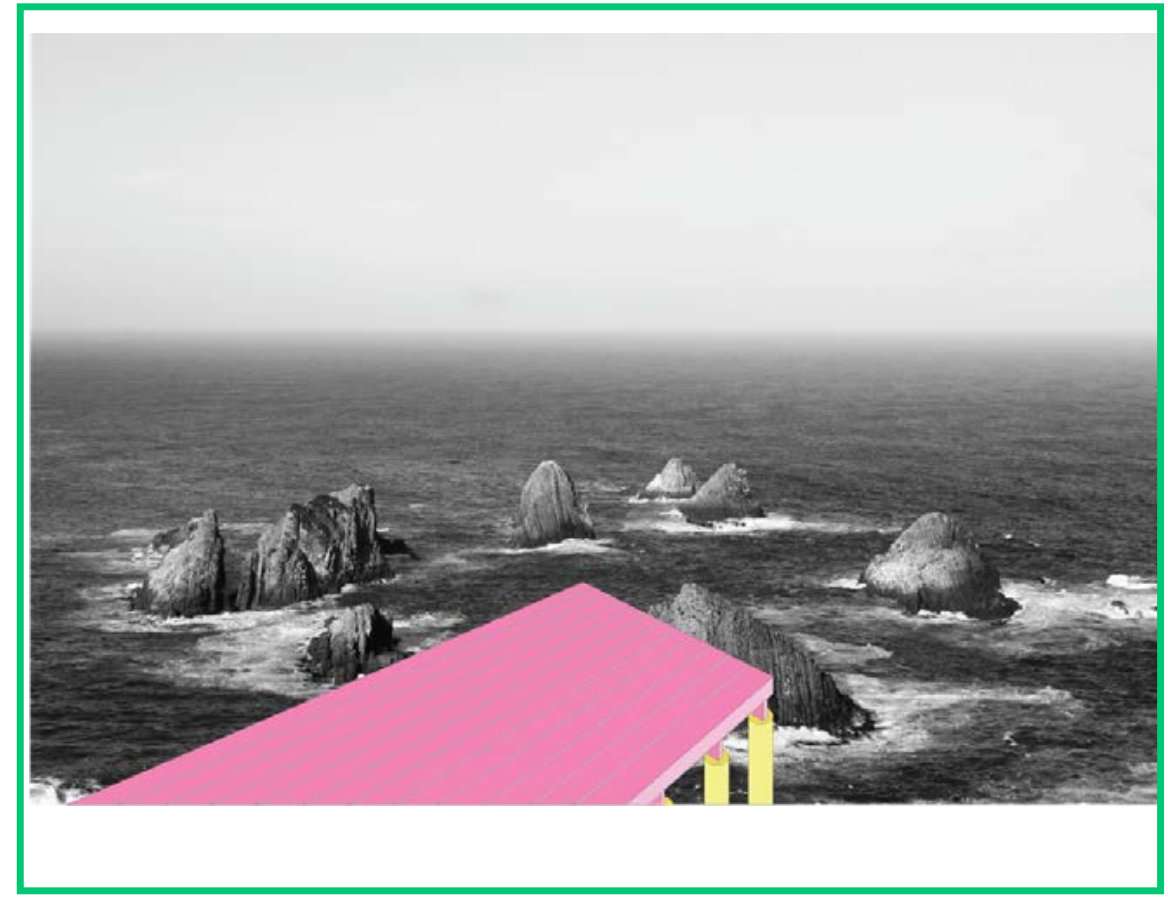

Figure 26 'Kitsch City Baby' an Architecture made from kitsch objects

This project starts in phase one by using 'camp' to explore a historic structure applying a new context onto in a hope in giving it a new fantastical life.

This is executed by re-designing the lighthouse and its environment through a camp lens. 


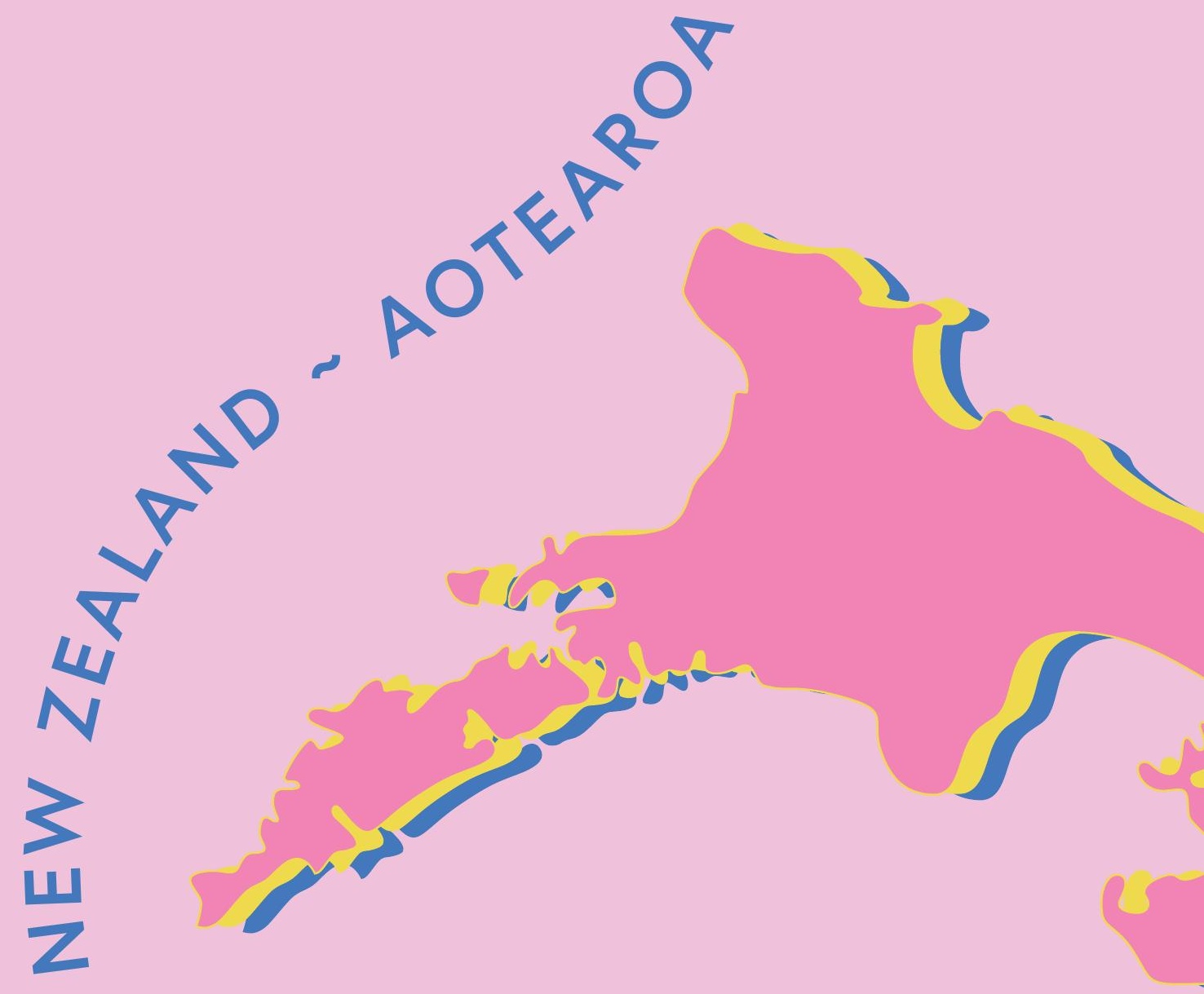






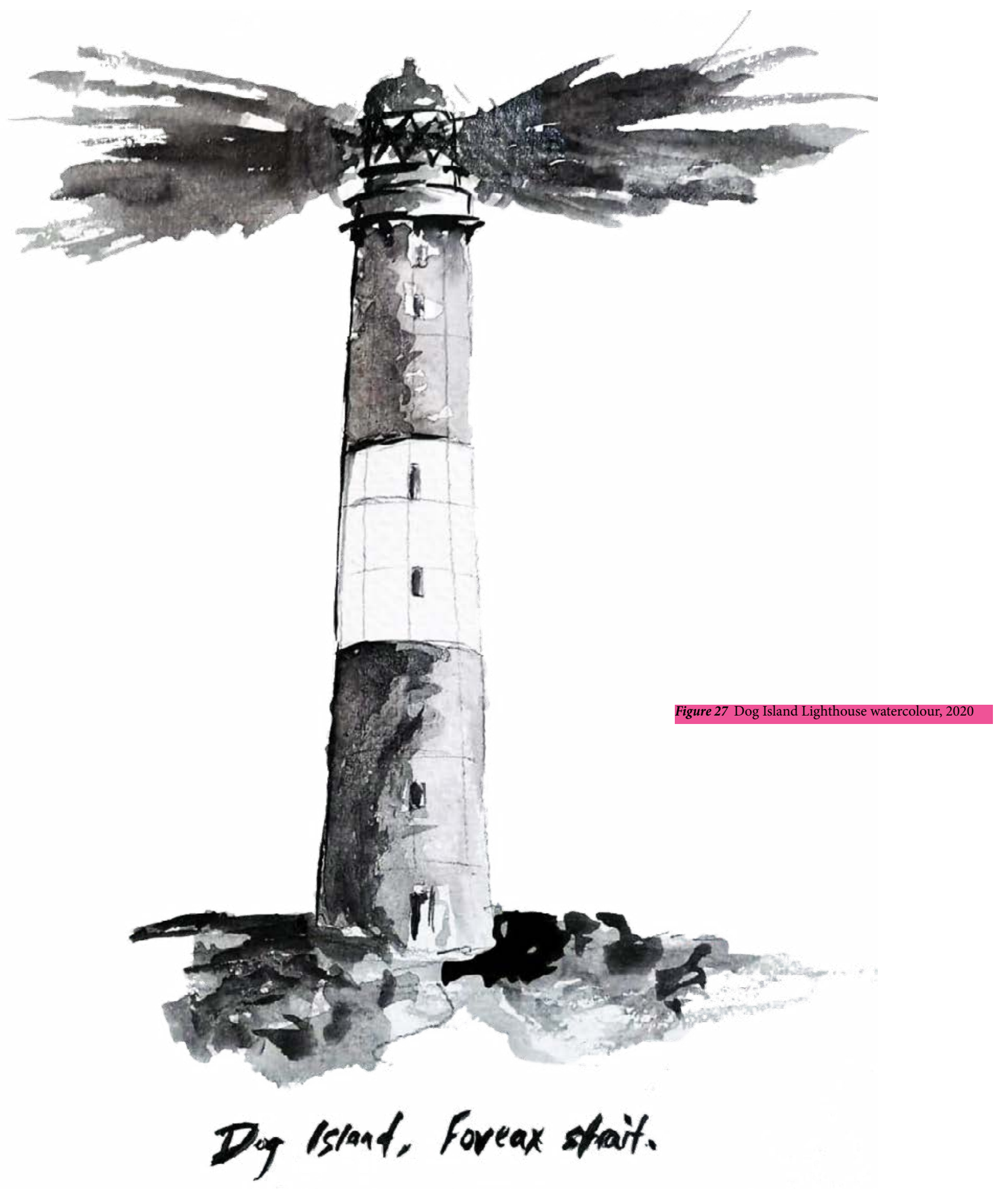




\section{2 DOG ISLAND}

For centuries Dog Island has been a vital component of survival in the Foveaux Strait. Maori previously occupied the island as a place of habitation, of kai Moana gathering and stone tool making. European history on the island is also significant with the establishment of the lighthouse 150 years ago which provided a pathway of safety for sea vessels entering the eastern side of the strait (Bain et al., 2010). Until 1989 the island was home to permanent lighthouse keepers, before automation. Today the island, located five kilometres south-east of Bluff, is on the verge of becoming one of Southlands, key tourist attractions. Also, the Island is uniquely predator-free which enables opportunities for trans relocation and breeding of unique and endangered native species to thrive.

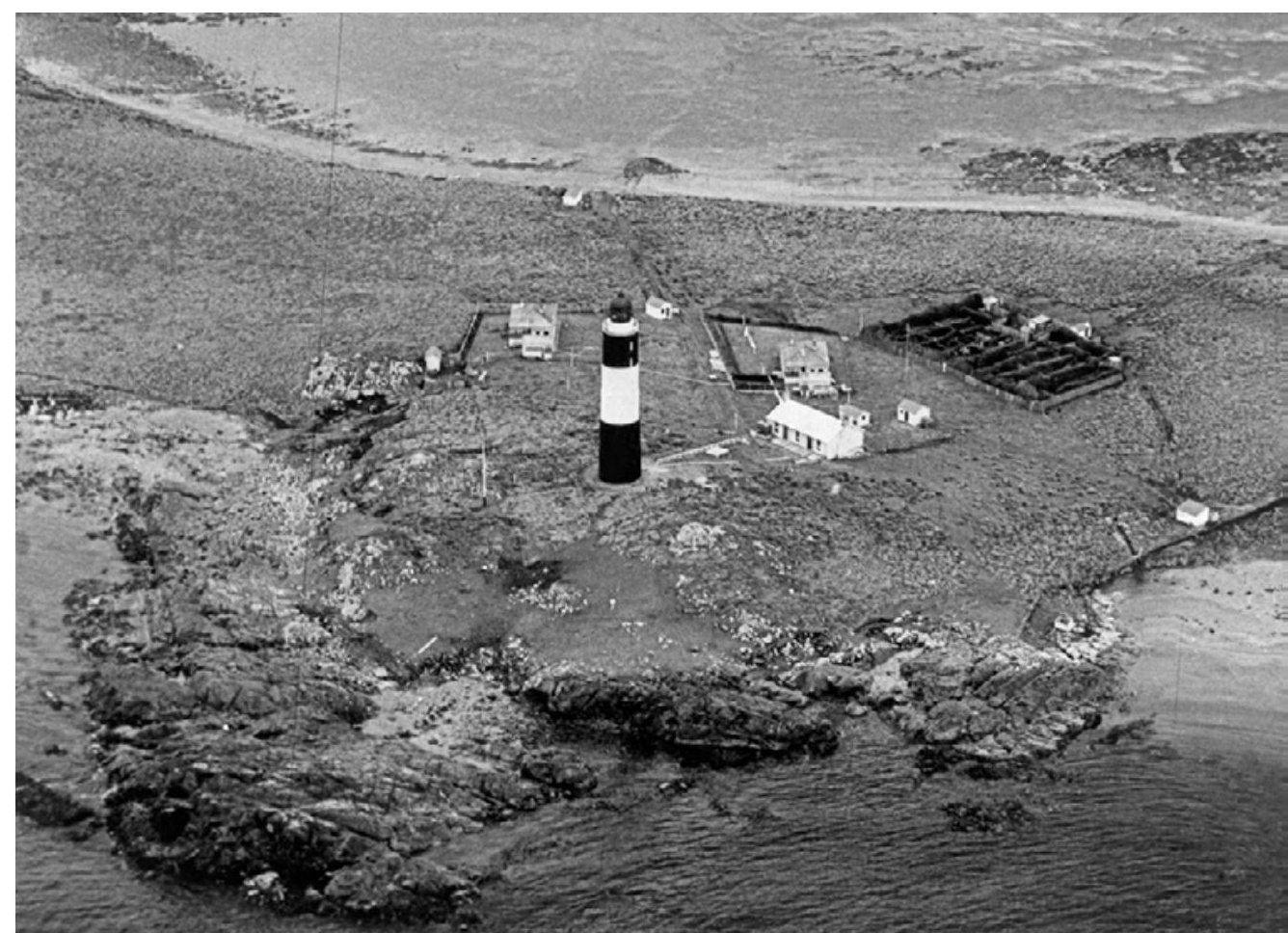

Figure 28 An aerial view of the Dog Island Lighthouse Settlement, while the island was still inhabitated 


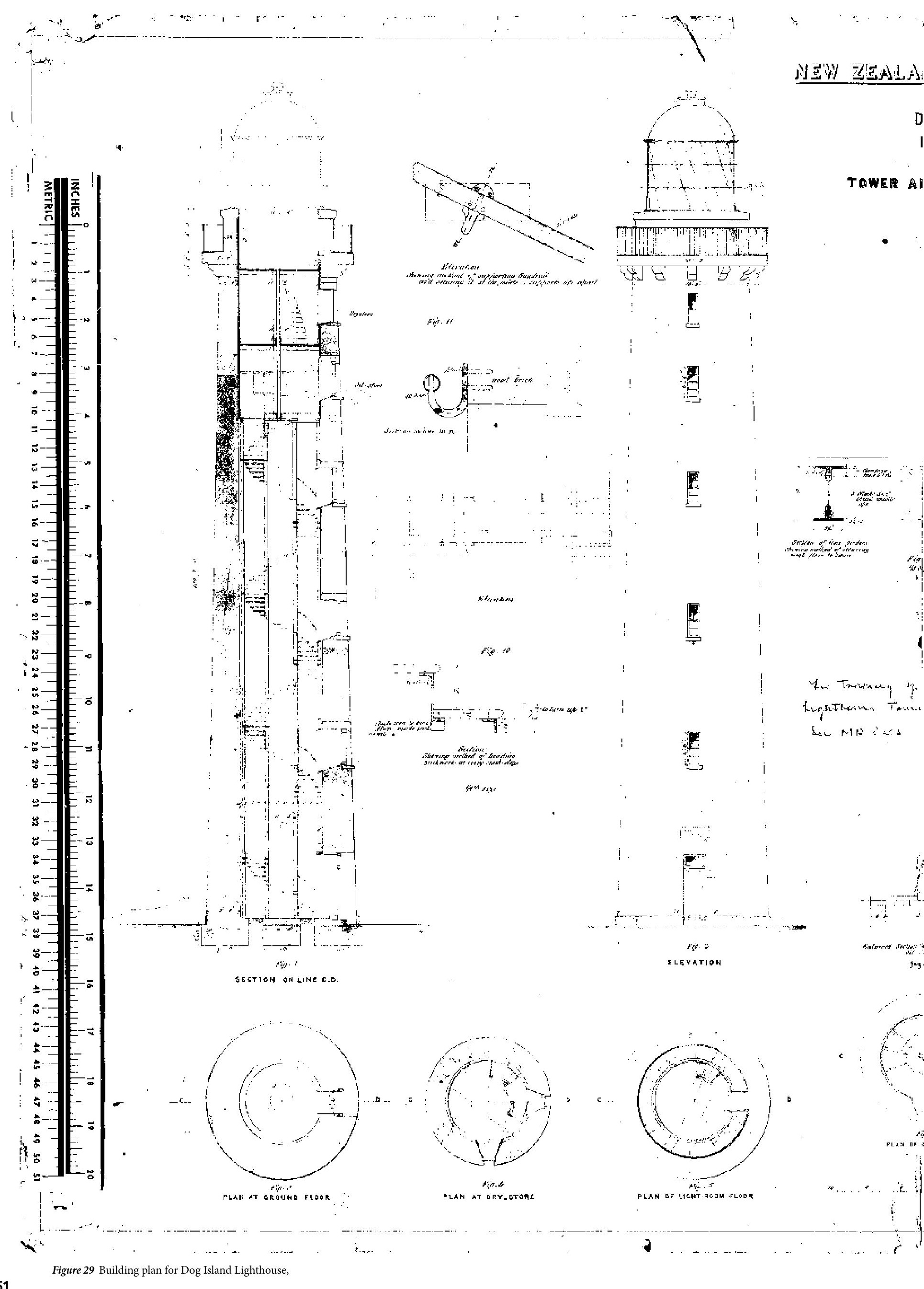


InMay2020, thesitewasvisited startingfromBluff,stoppingoffat Waipapa Point and then onto Nugget Point. Originally a more serious approach to the site was intended, however when realising how cold and isolated the lighthouse and Bluff was then a more satirical approach was decided.

The buildings of Bluff were also a major oddity, a large number, had been painted in bright colours and patterns, often contrasting each other.

Other take-away's from the trip being the isolated nature of all sites, typically placed precariously on an island, rock outcrop and spit. The wind was relentless and the weather almost always was overcast.

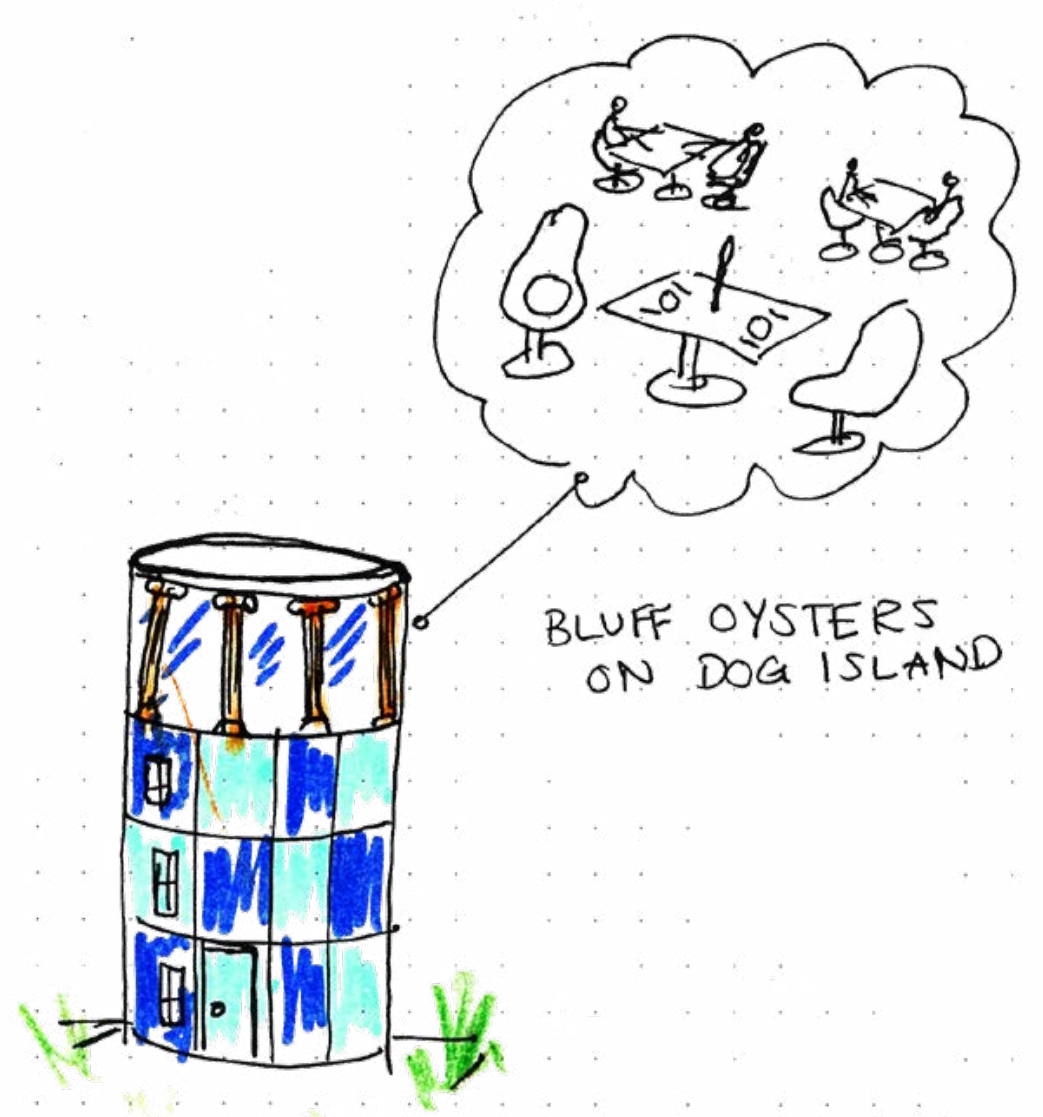

Figure 30 Bluff oysters on Dog Island, taking a popular concept and creating imagined architectures that would facilitate such an activity 


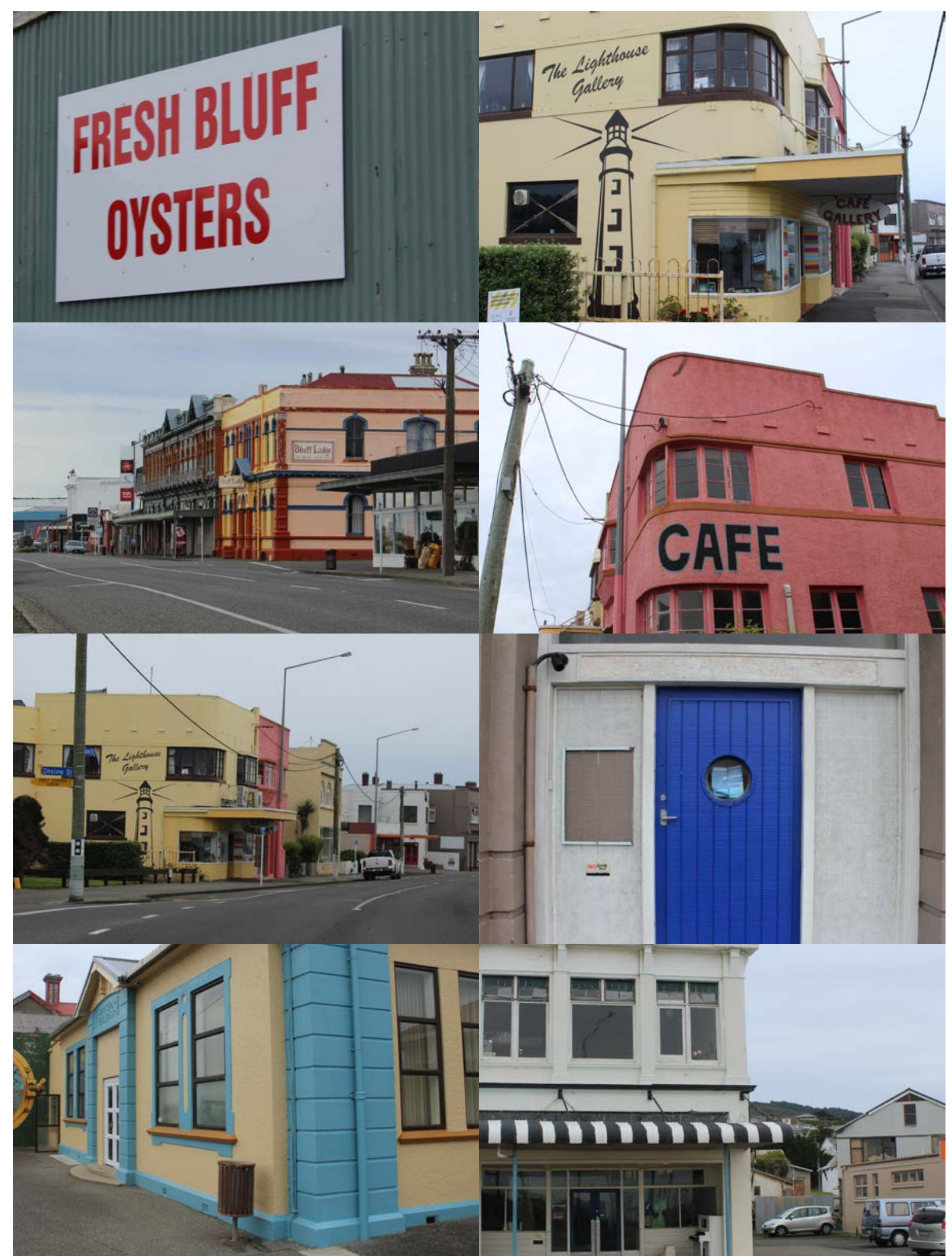

Figure 31 Authors visual observations throughout the town of Bluff, the building treatment was rather 'fantastic', either channeling the whimsy nature of the lighthouse and maritime culture or completly mimicking it. 

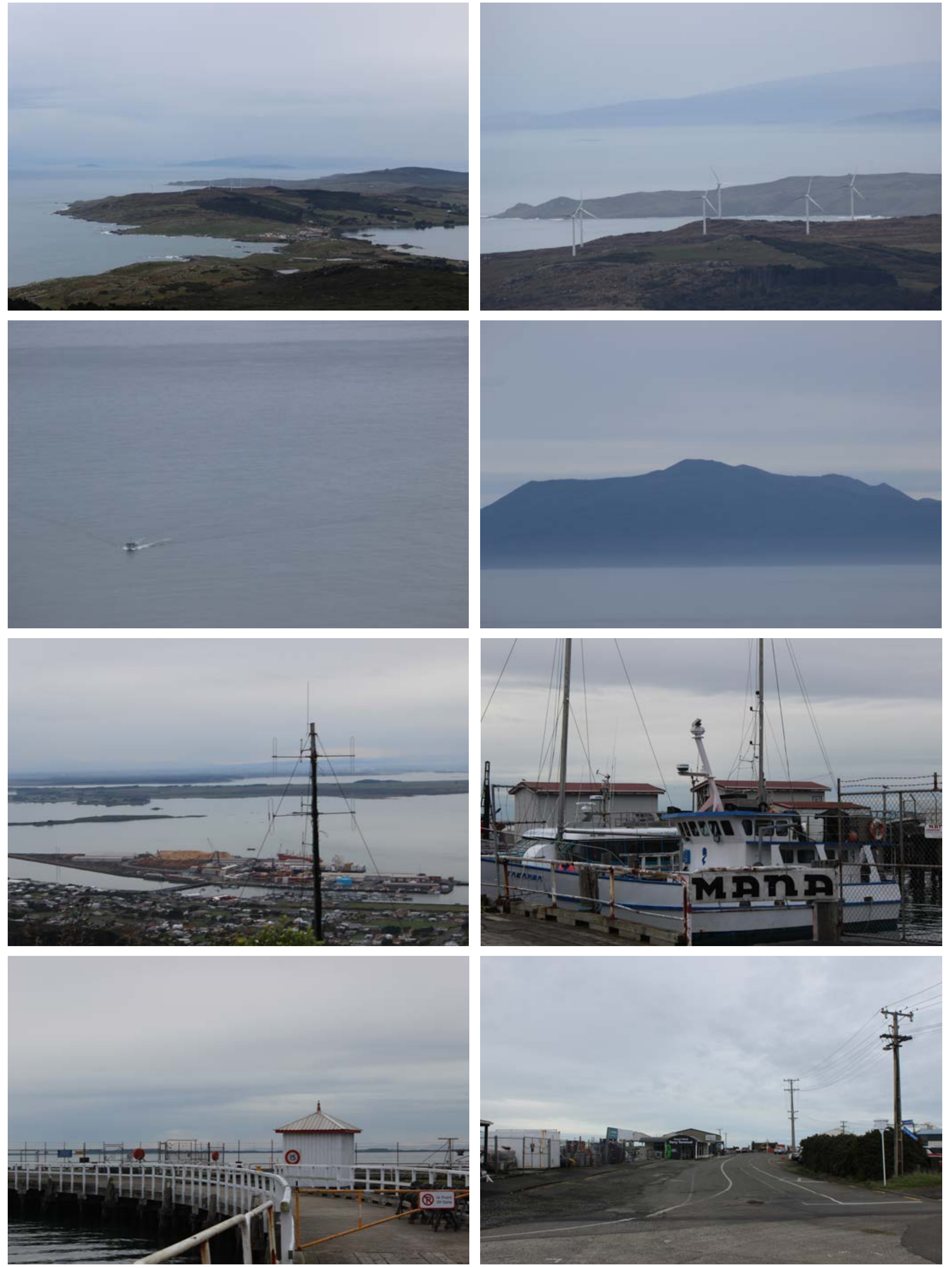

Figure 32 More site observations, of the condition of Bluff, Warfs, Stewart Island and Foveaux strait. 


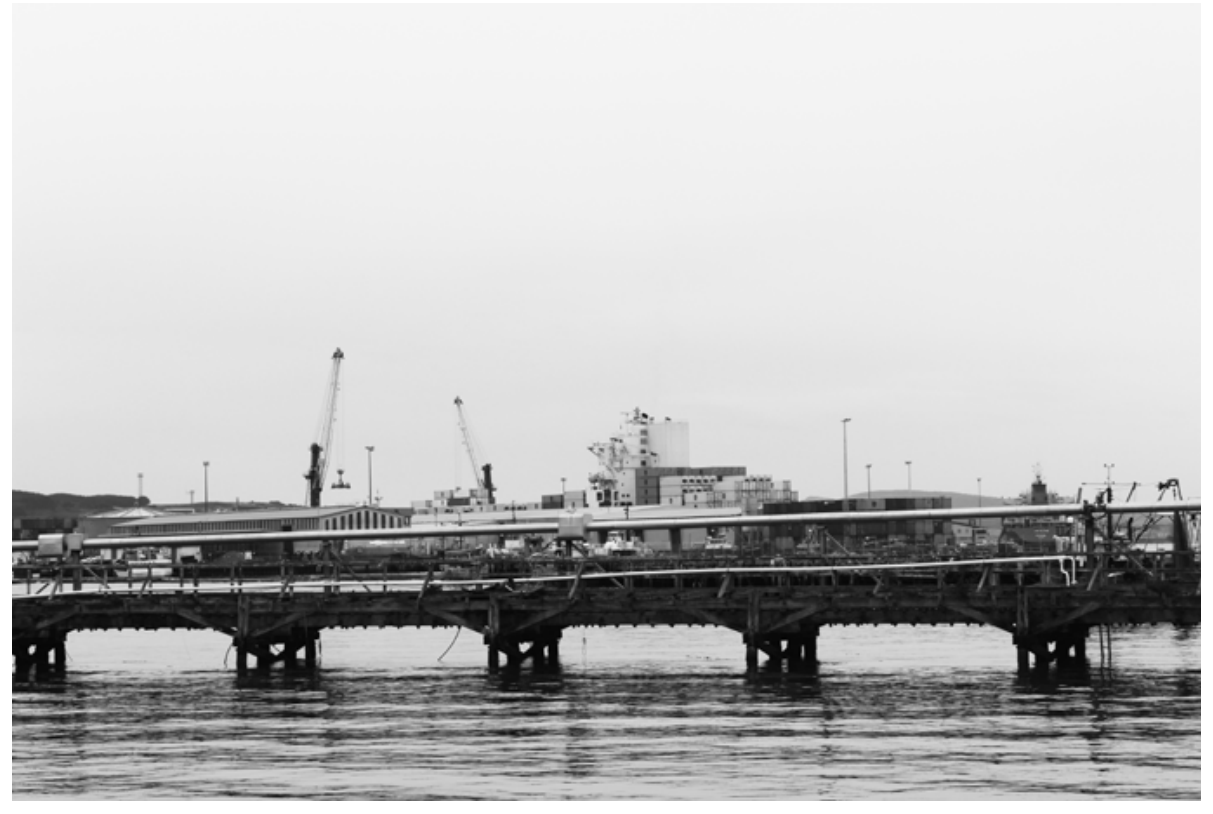

Figure 33 Bluff, New Zealand

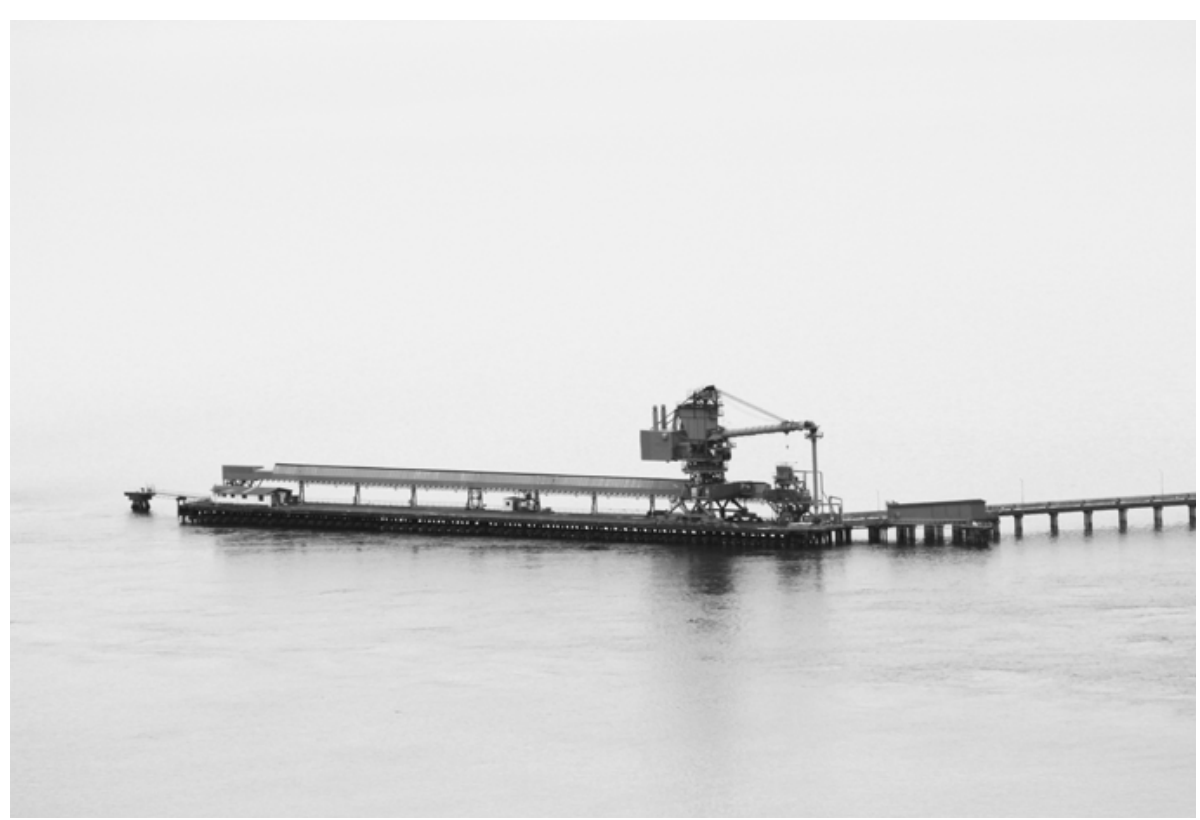

Figure 35 Tiwai Point Aluminium Smelter's own jetty

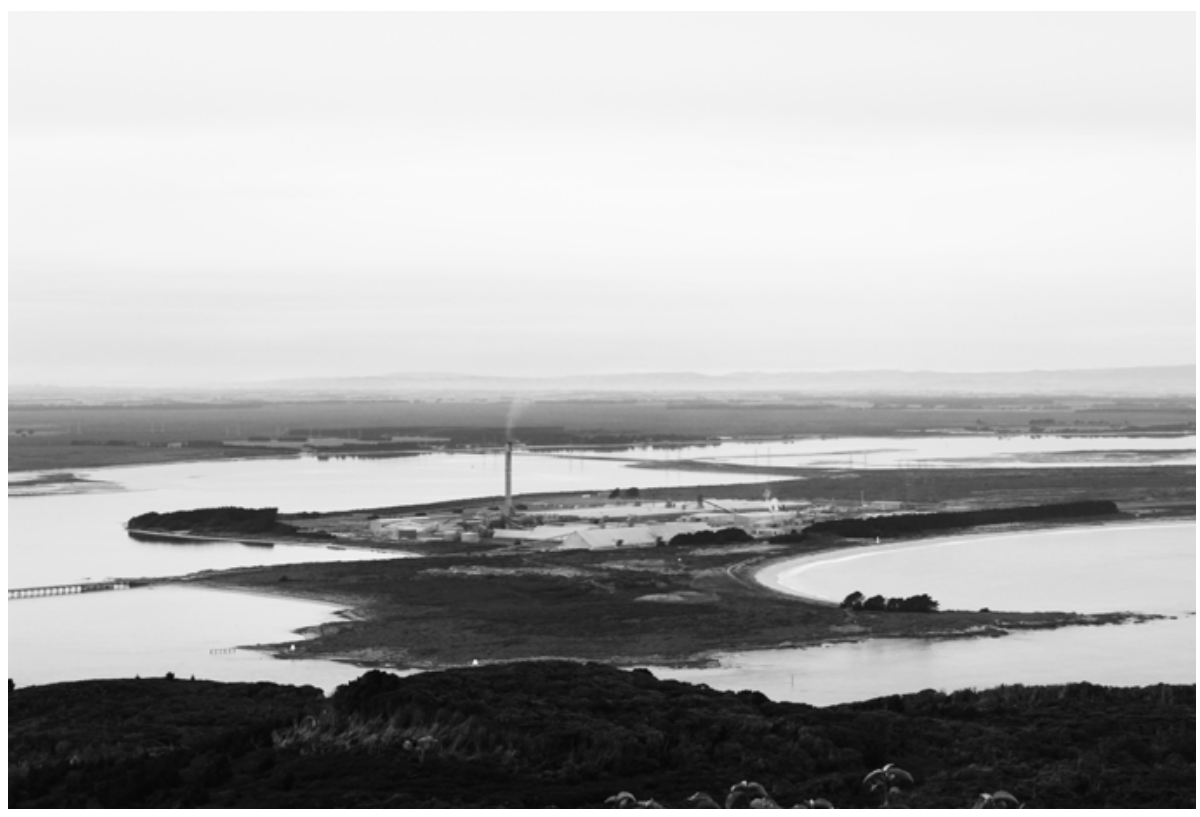


This content is unavailable.

Please consult the figure

list for further details.

Figure 36 Potrait of Cedric Price. (Sourced from: https://www. architectural-review.com/essays/reputations/cedric-price-1934-2003)

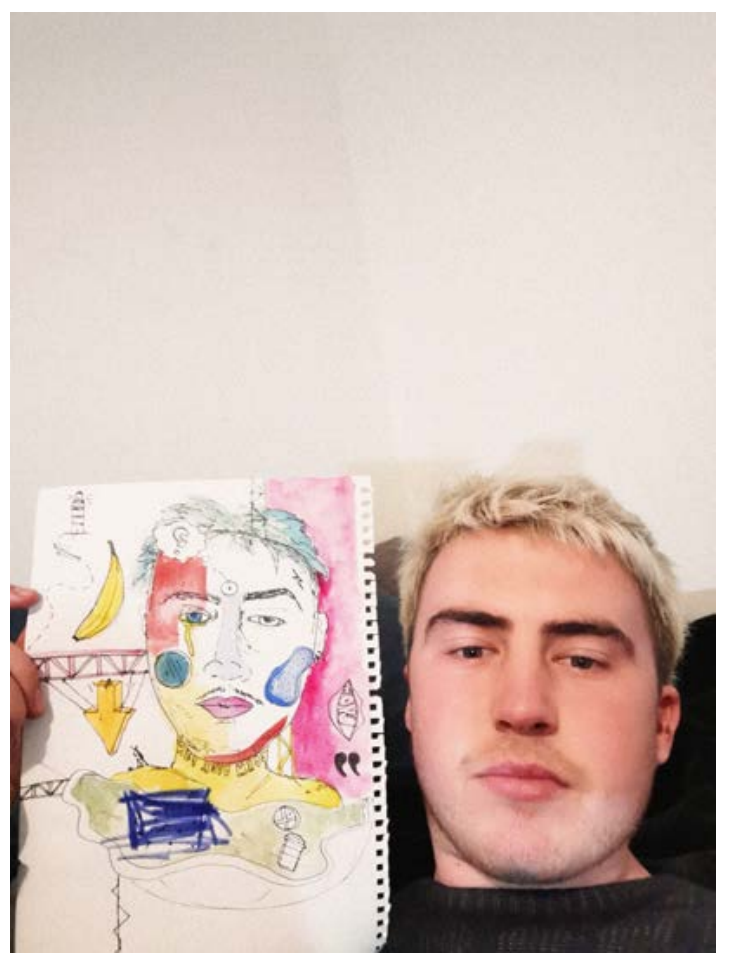

Figure 37 Self Potrait of Author during the covid pandemic, 2020, a homage to Cedric Price and Sontag's sensibilities on Camp.

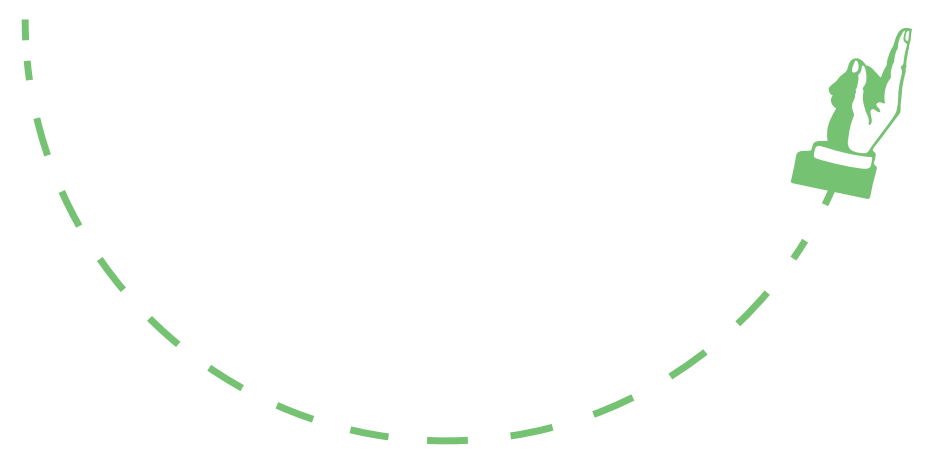




\section{CEDRIC PRICE AND HIS 'FUN PALACE'}

The late Cedric Price was a post-war situationist, the role Price played in architectural history is that of the Last Amateur. The iconoclast had a certain holistic expertise, a non-scientific scientism, trying to make new connections across an exploding terrain of information and knowledge.

Cedric Price's Fun Palace, 1964, builds on situationism to create spaces that encourage situations using a unique range of theatre and improvisational architecture (Mathews,2005). Mathews elaborates that his designs are a conceptual response to the post WWII landscape, post industrialism and the rise of consumerism. While the structure was never built, it served as an example of how architecture can transform the city scape and the way people interact with in it. They aimed to achieve this by creating an interactive, performing space which would provide a structure that allowed culture, education, leisure and creativity to be brought the masses and provide an escape from everyday life (Mathews 2005). Prices models are comprised of scaffolding in which structures are customisable with cranes, moveable panels, rotating staircases, pulleys and so on. As his designs are centred around people and actions.

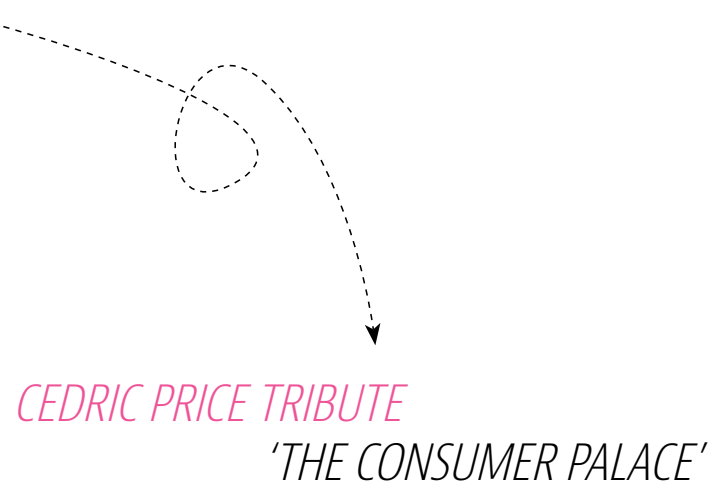

Designed as a direct translation from reading about Cedric Price and his unrealised 'Fun Palace. The Consumer Palace is a Box truss structure rising as five stories up Dog Point Lighthouse, intending to wrap the lighthouse by creating a frame around the building. The structure supports stairs that enable visitors to walk around the lighthouse, observing as well as reaching the top. The Structure supports motifs hanging on key chains. A comment on kitsch consumer culture that often surrounds places that experience tourism en masse. Attractions with high visitor numbers will have gift shops, typically one must pass through them to exit the attraction, causing the tourist to pick up a t-shirt, key chain, or bottle opener as they leave. This structure is a comment on Cedric Price's optimistic utopia, combining the author's opinion on high capitalism touring. Creating 'The Consumer Palace'.

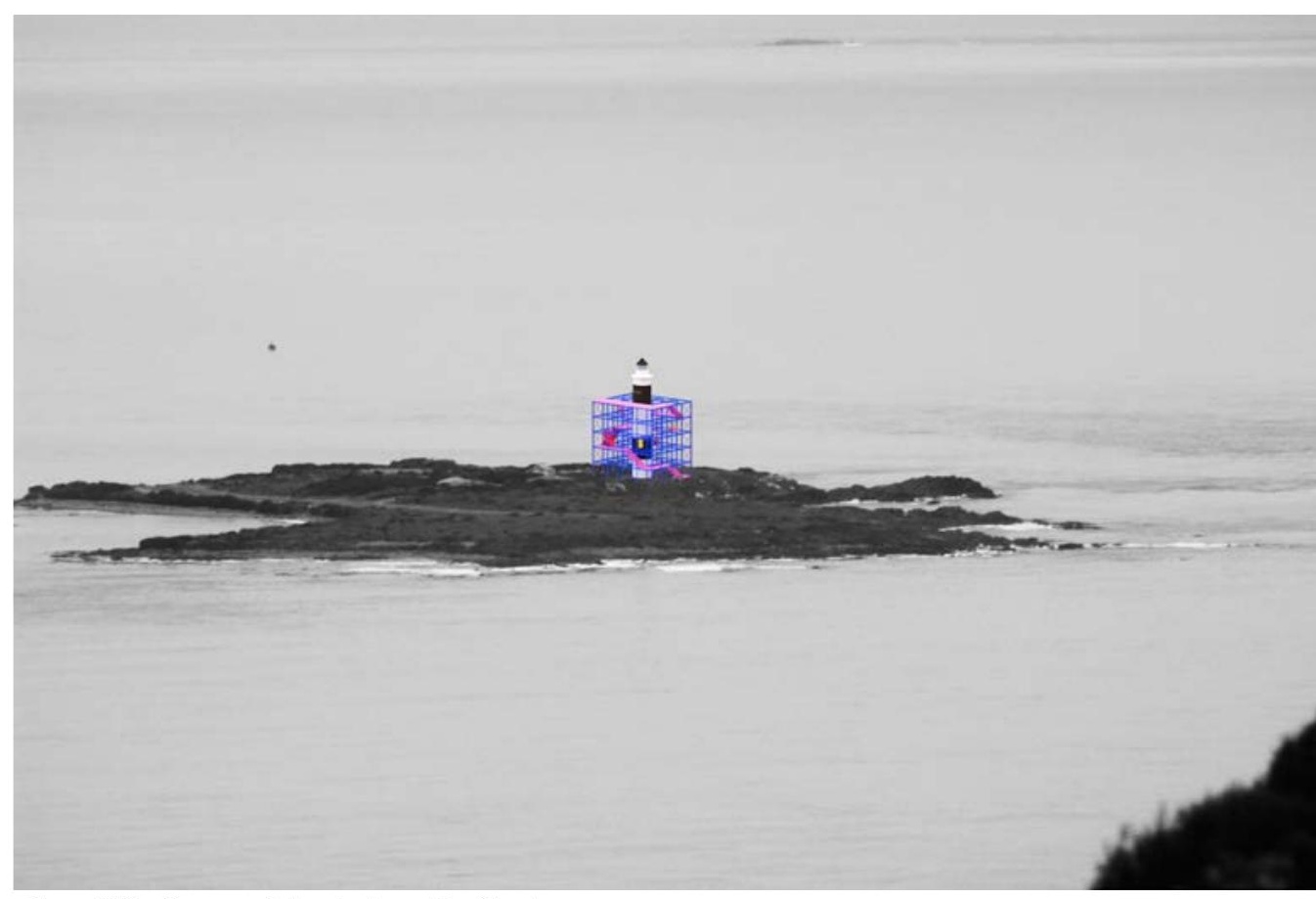

Figure 38 The Consumer Palace in-situ on Dog Island. 
This content is unavailable.

Please consult the figure

list for further details. 


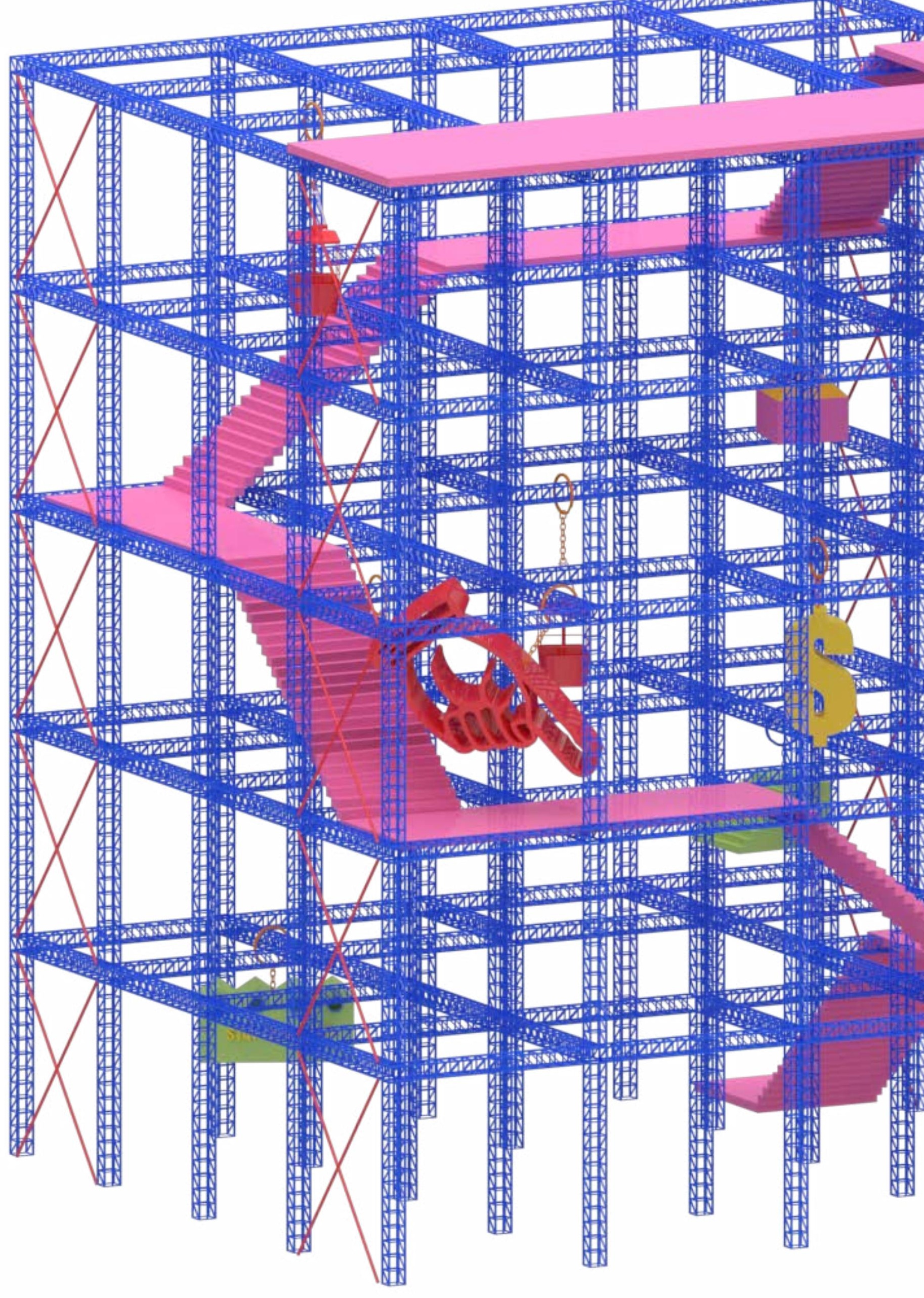



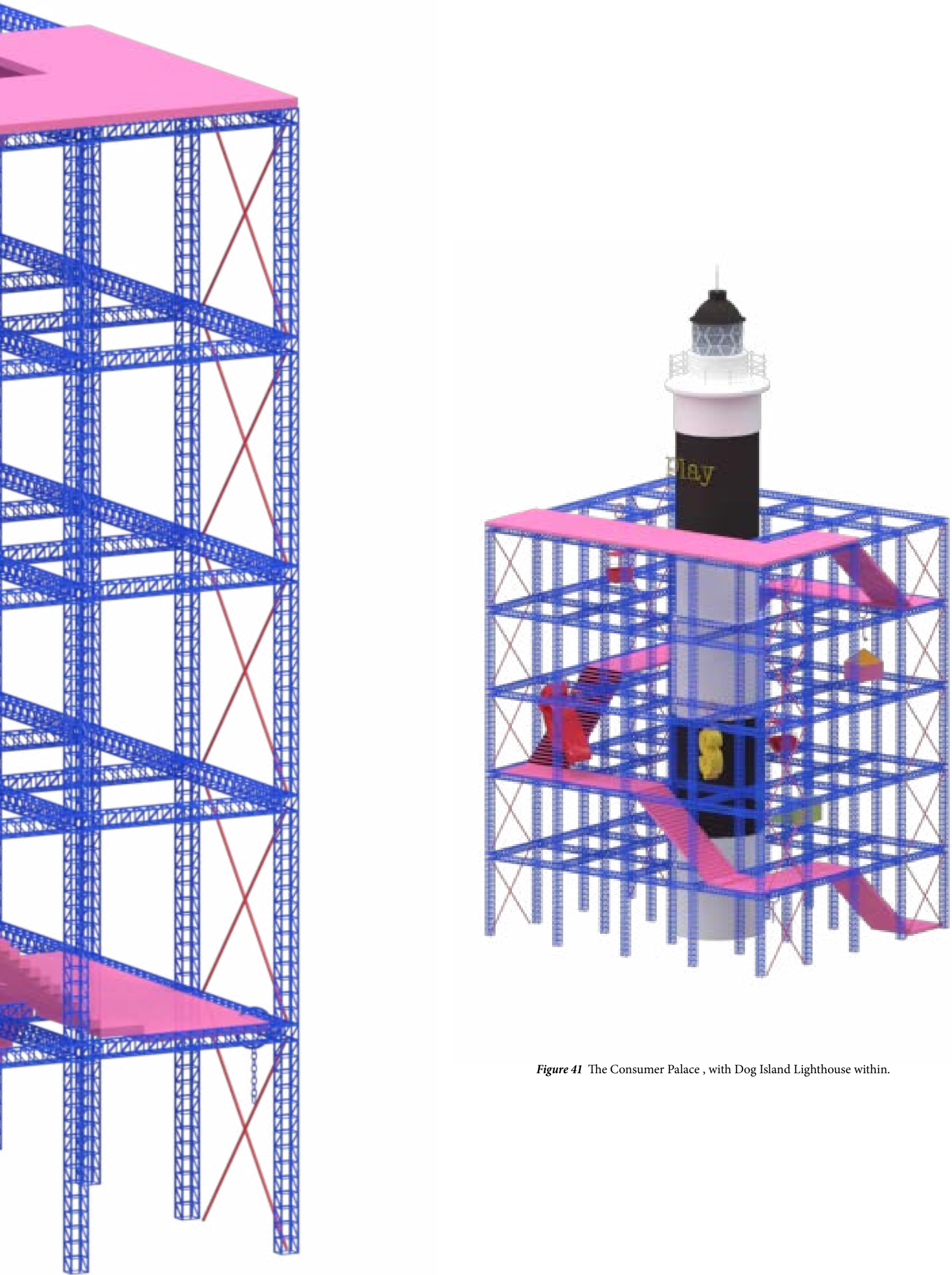

Figure 41 The Consumer Palace, with Dog Island Lighthouse within. 


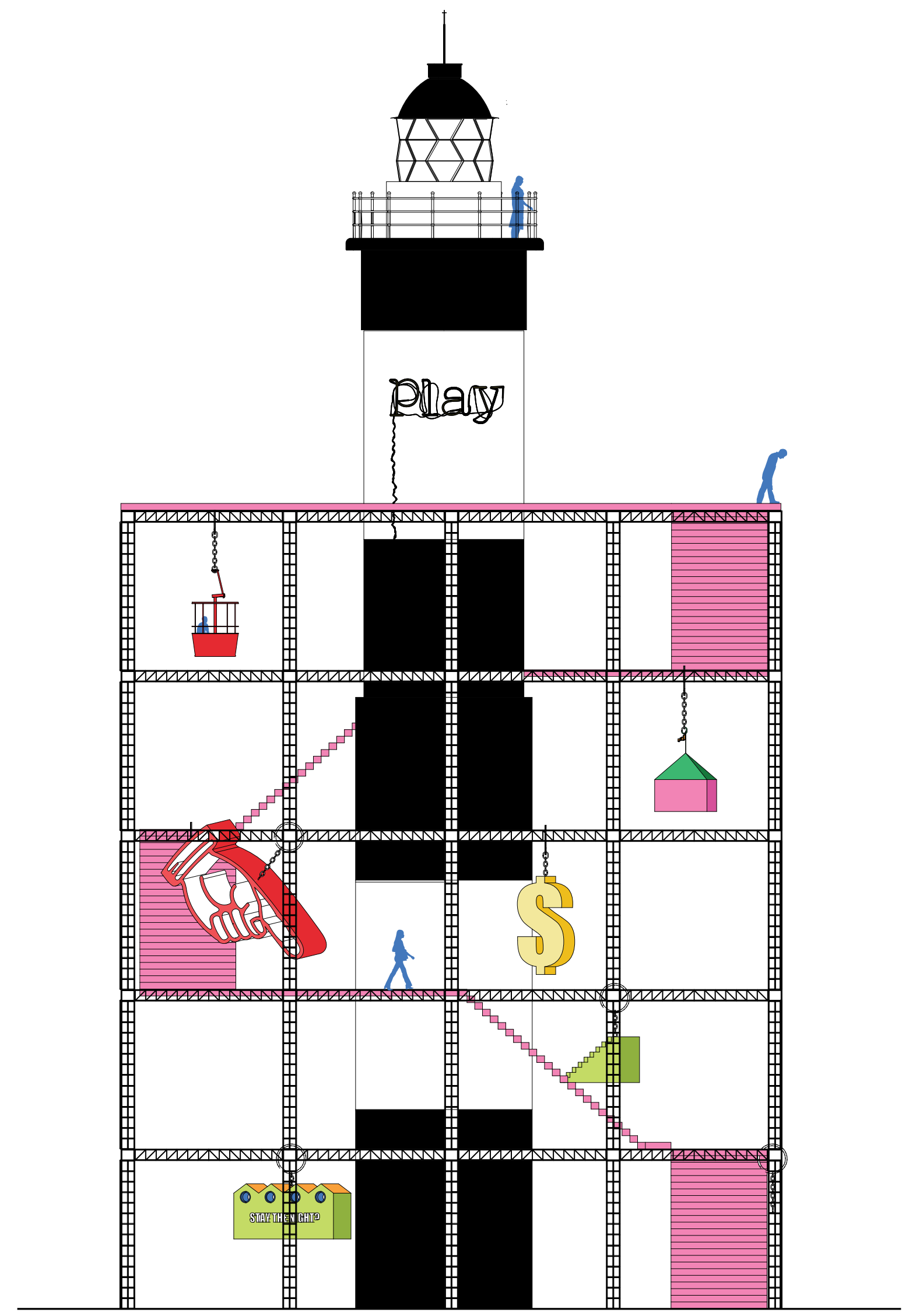

Figure 42 Dog Island Consumer Palace, Front Elevation 



\section{7

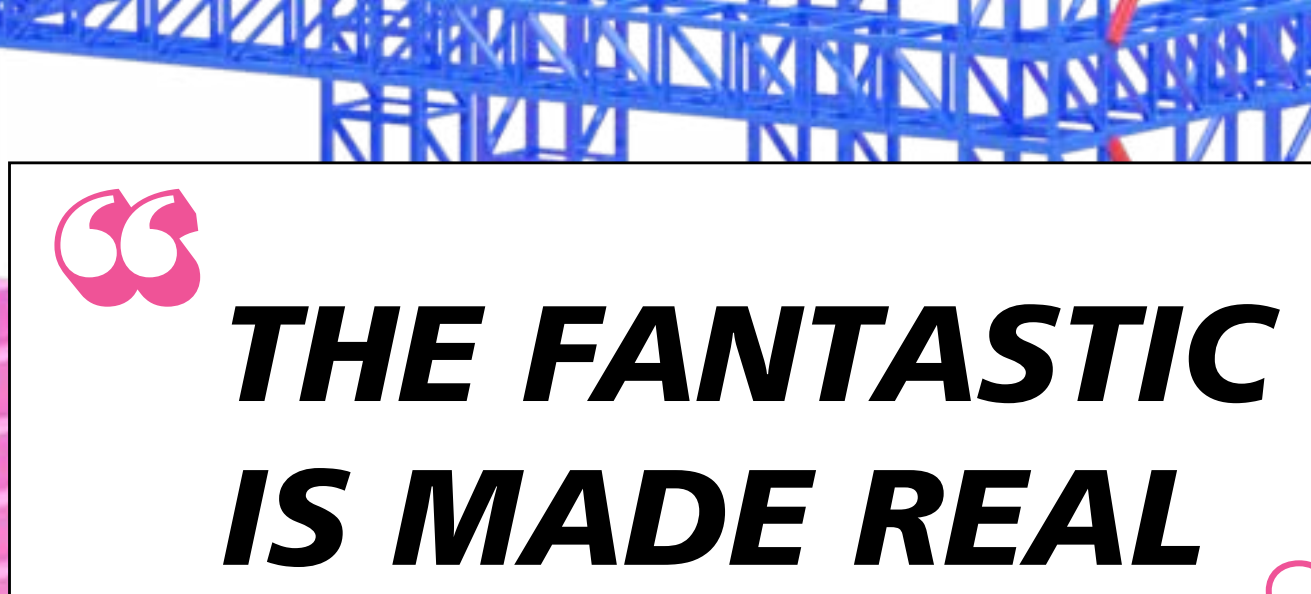

VI $\quad$ Net

-Author

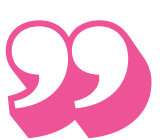

$\frac{1}{2}$

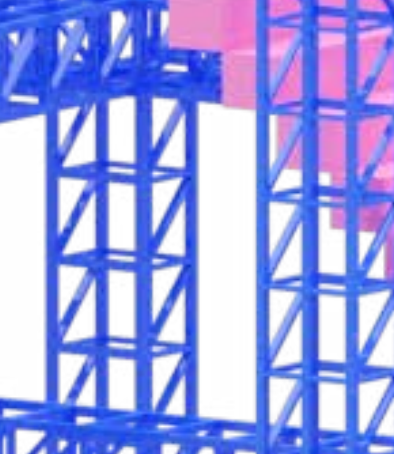

Vi:4

IXYIND:

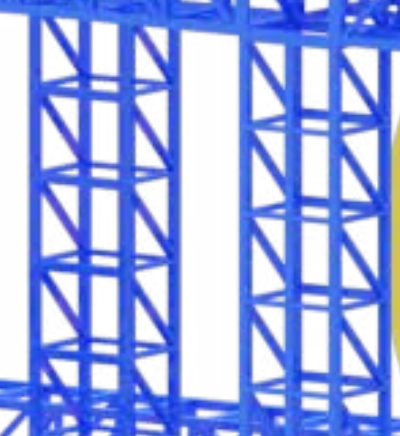

Vi:

$\mathrm{ND}=\mathrm{N}$

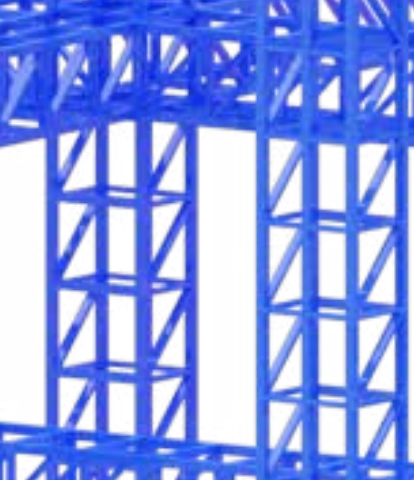

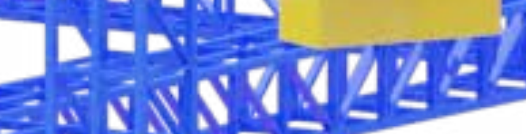

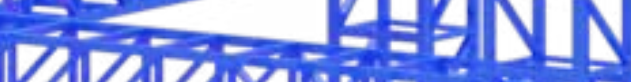
N

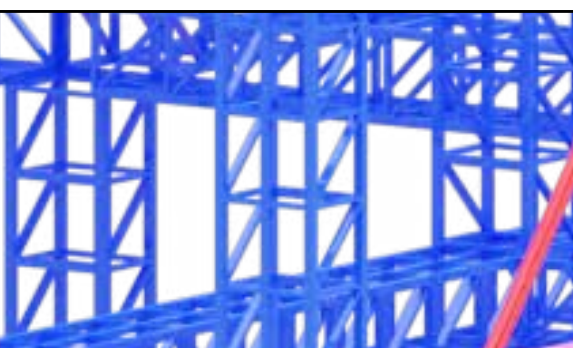

101

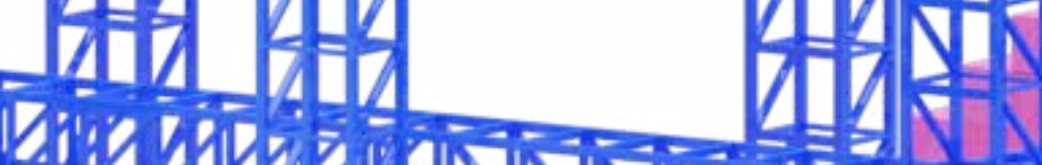

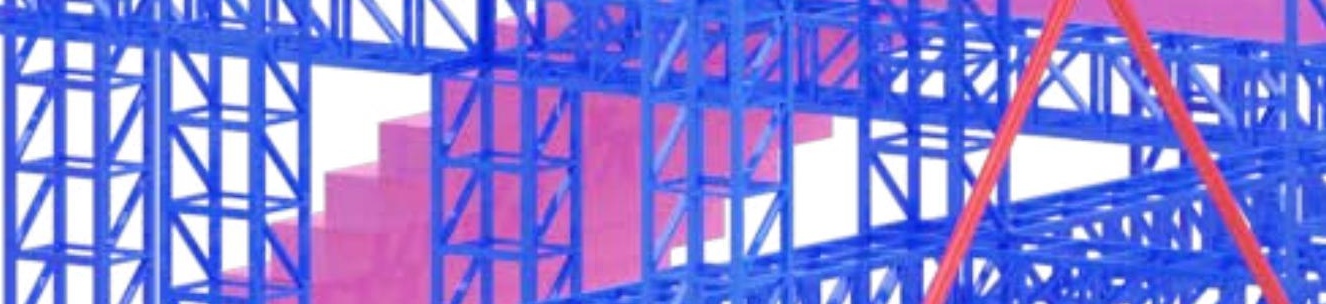

作

प14 14272

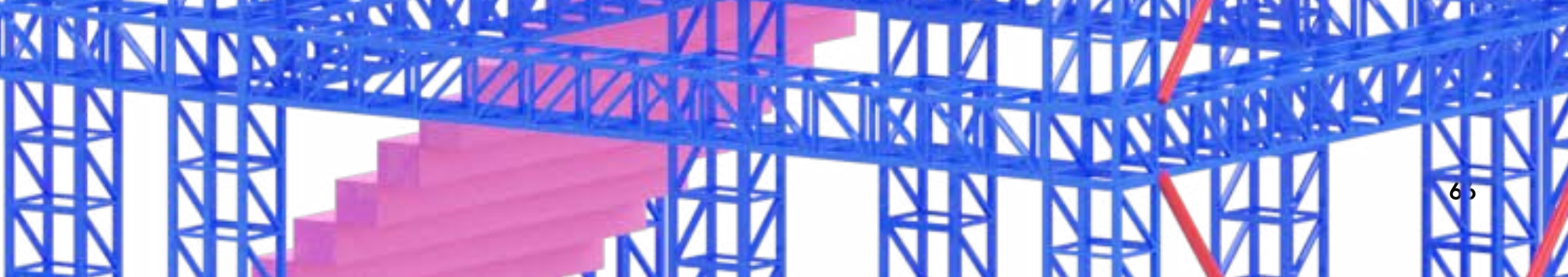




\subsection{EXPLORATION TWO}

\section{Collage}

Early mixed-media collages were created as part of the design process to understand the project tonally, as well as additionally playing around with early ideas of form and theory.

The collages to the right mixed together either old photographic images or watercolour paintings of Dog Island, and watercolours of follies and other concepts. They were then assembled using Adobe Dimension. They aim to get a feel of the atmosphere as a tourist attraction by playing on ideas of visual consumption.

Whereas the previous collage, starts to conceptualise a Camp architectural tourist experience, it uses postmodern imagery and historic photos of the site to provide a logic of what that could be. 


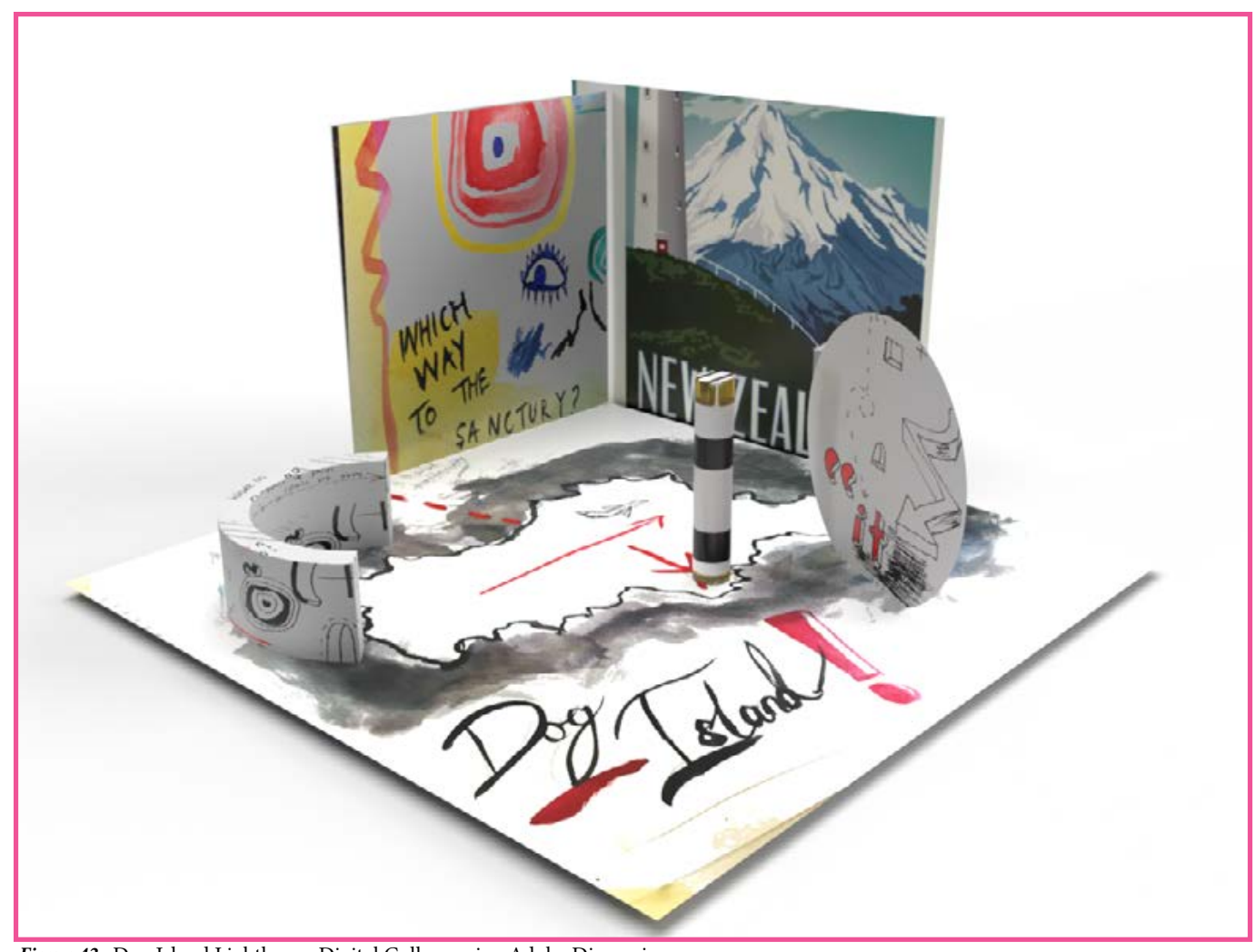

Figure 43 Dog Island Lighthouse Digital Collage using Adobe Dimension

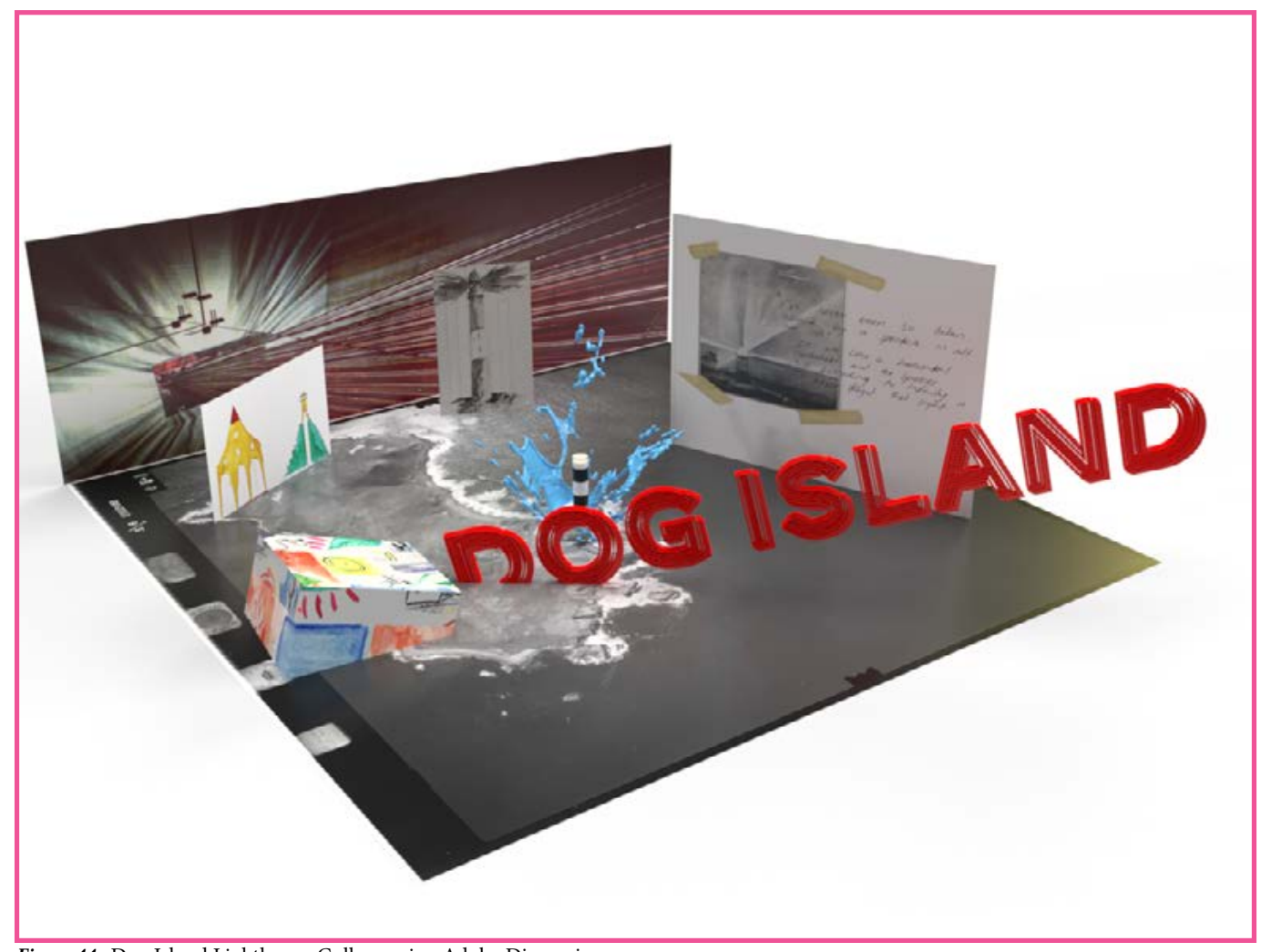

Figure 44 Dog Island Lighthouse Collage using Adobe Dimension 


\section{0,}

\section{DA 140}
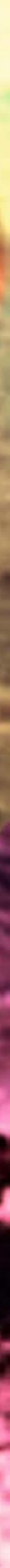


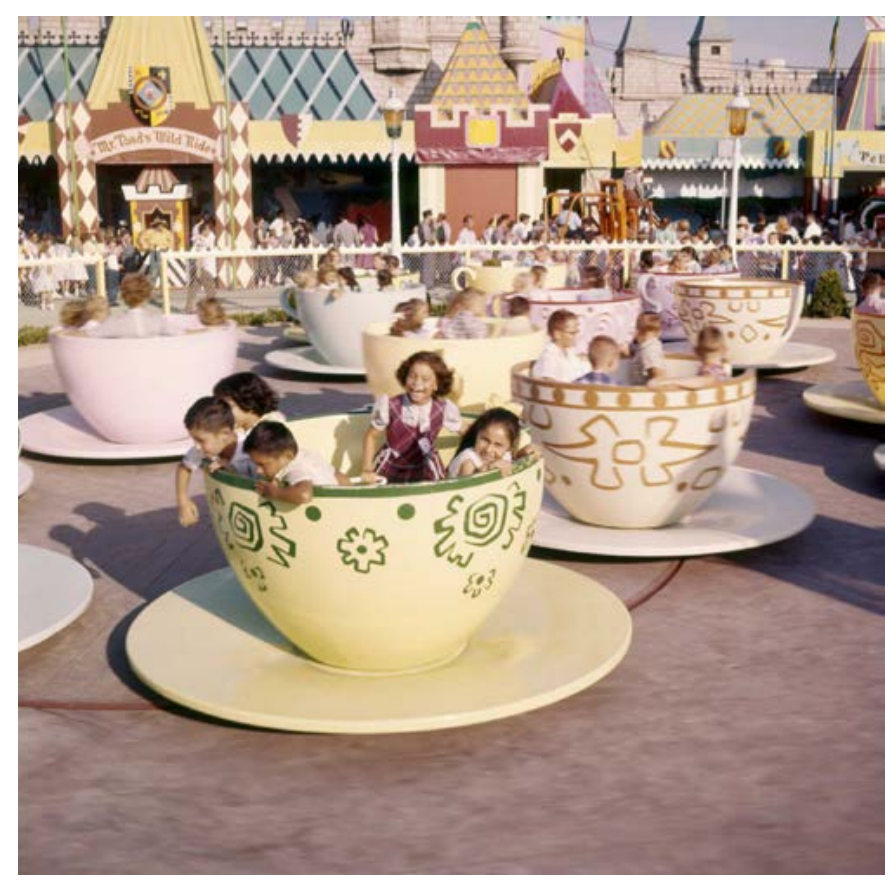

Figure 45 Cups and saucers filled with children at the 'Mad Hatter's Tea Party' attraction in Fantasyland, Disneyland Amusement Park, California. (Loomis Dean/The Life Picture Collection via Getty images,n.d)

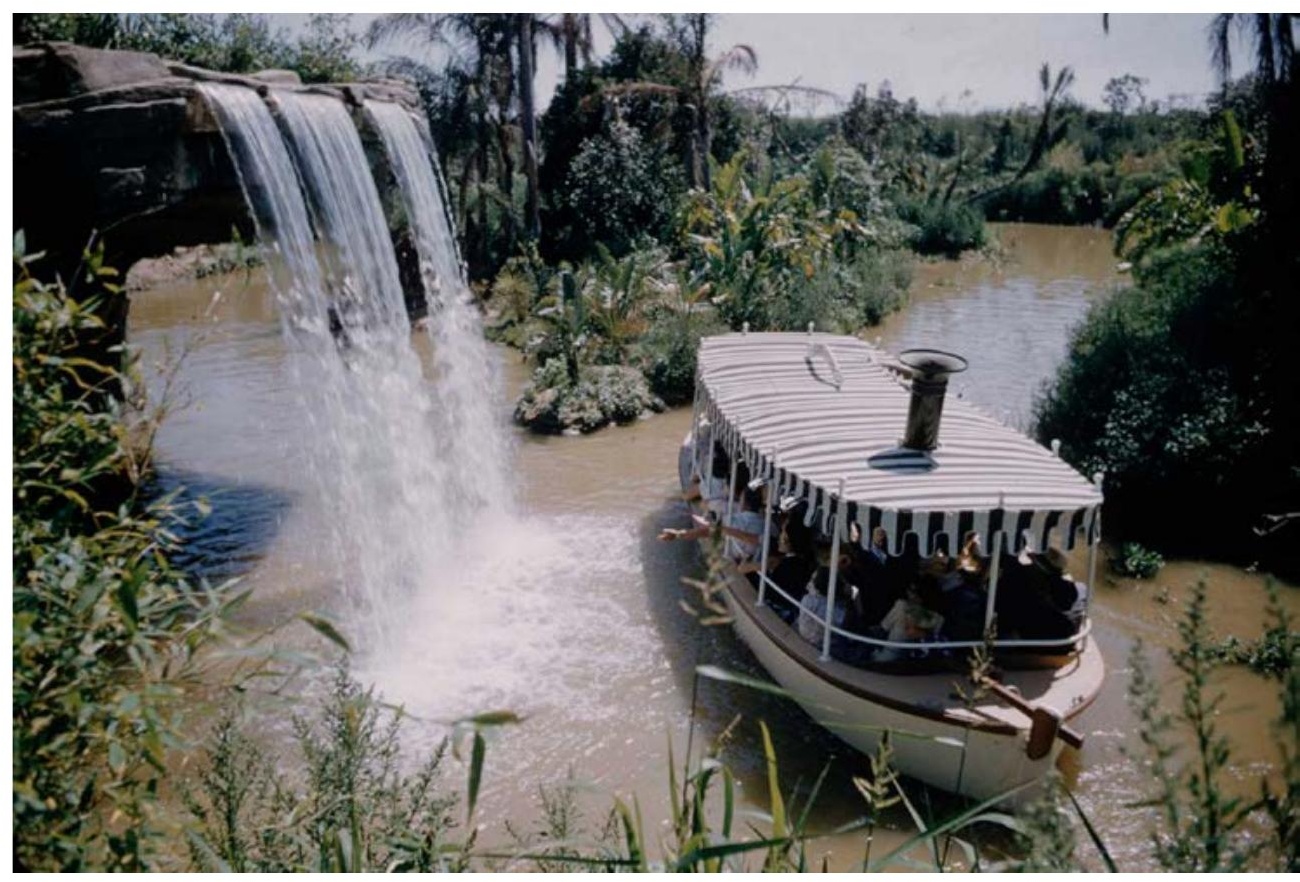

Figure 46 Disneyland's 'Jungle Cruise' featuring animatronic animals, California (Loomis Dean/The Life Picture Collection via Getty images,n.d) 


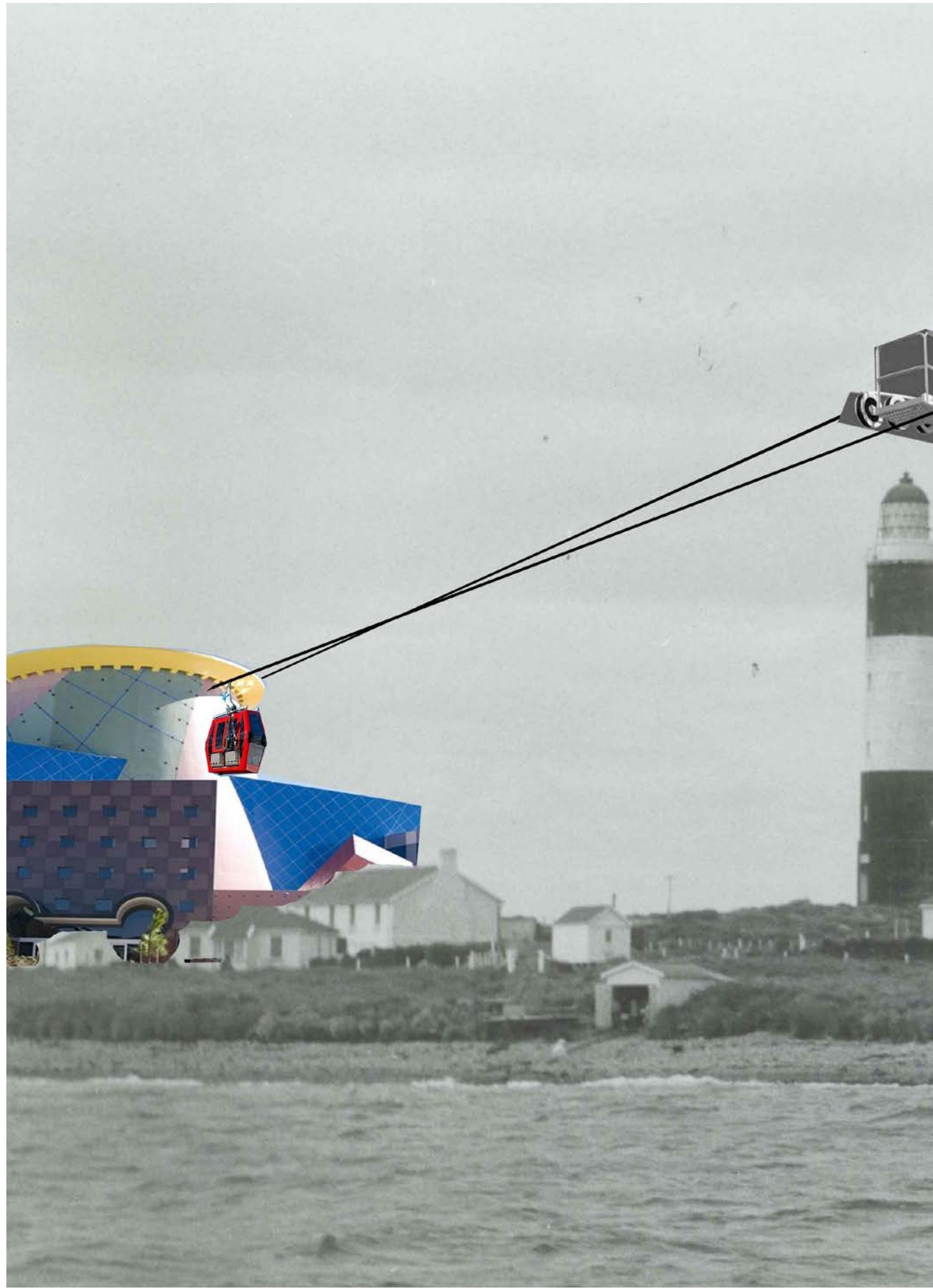

Figure 47 An early digital collage, conceptualising what a 'Camp’ architecture might look like, pulling post modern imagery and historic site photos to create a logic. 


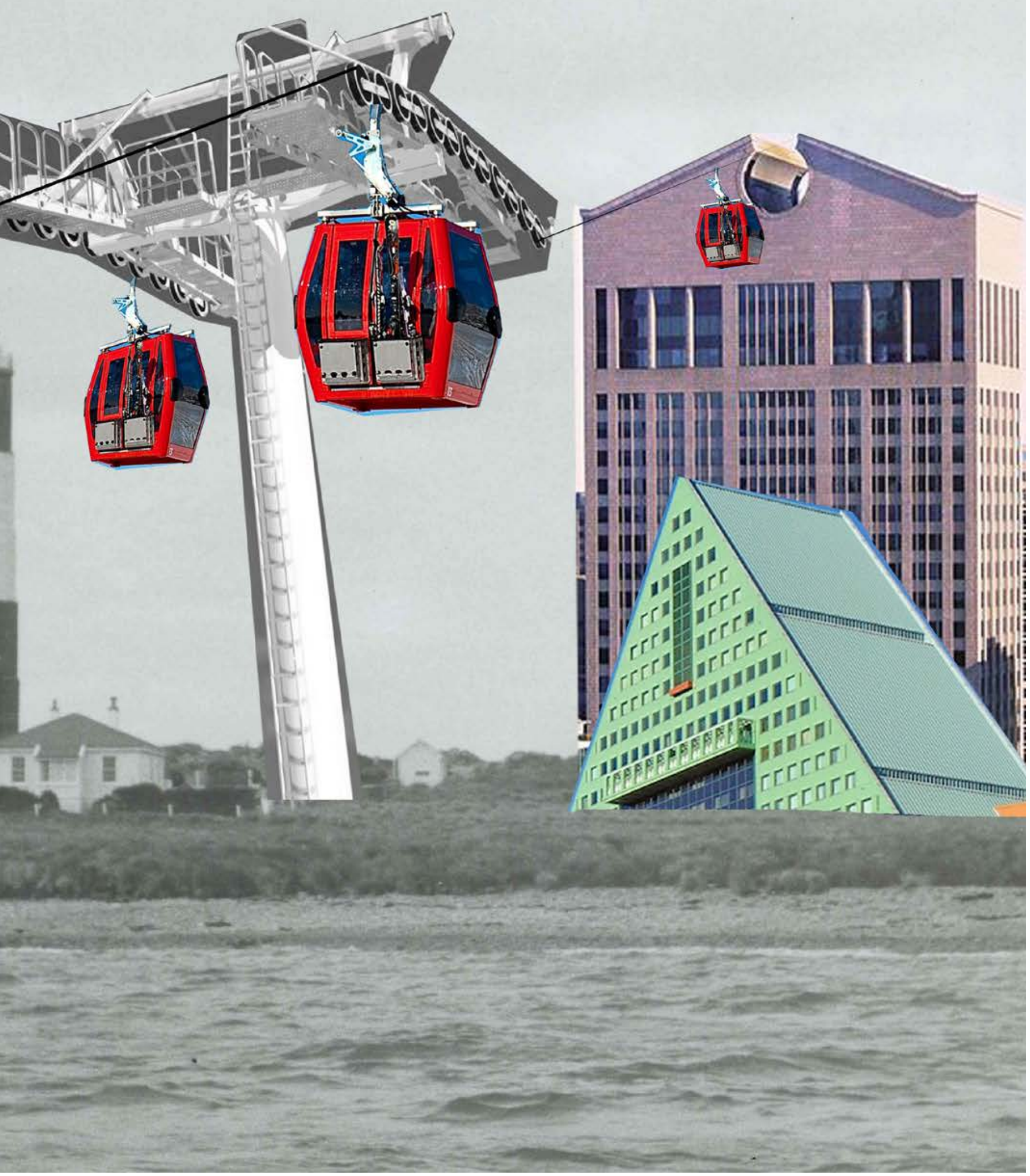




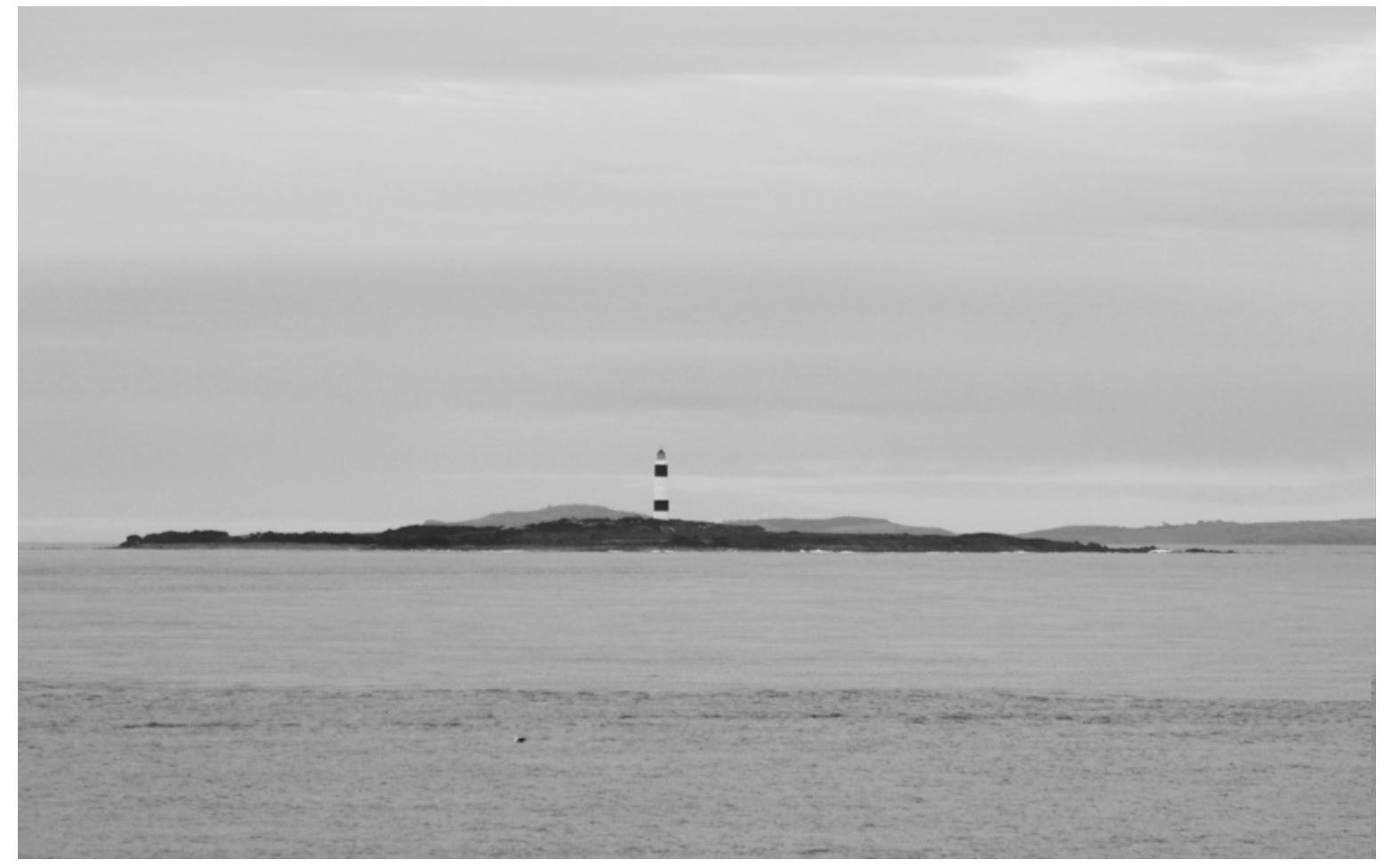

Figure 48 Authors photograph of Dog Island, and it's Lighthouse. Alongside an early collage of the proposed 'design', The Cold Damn Disneyland. 


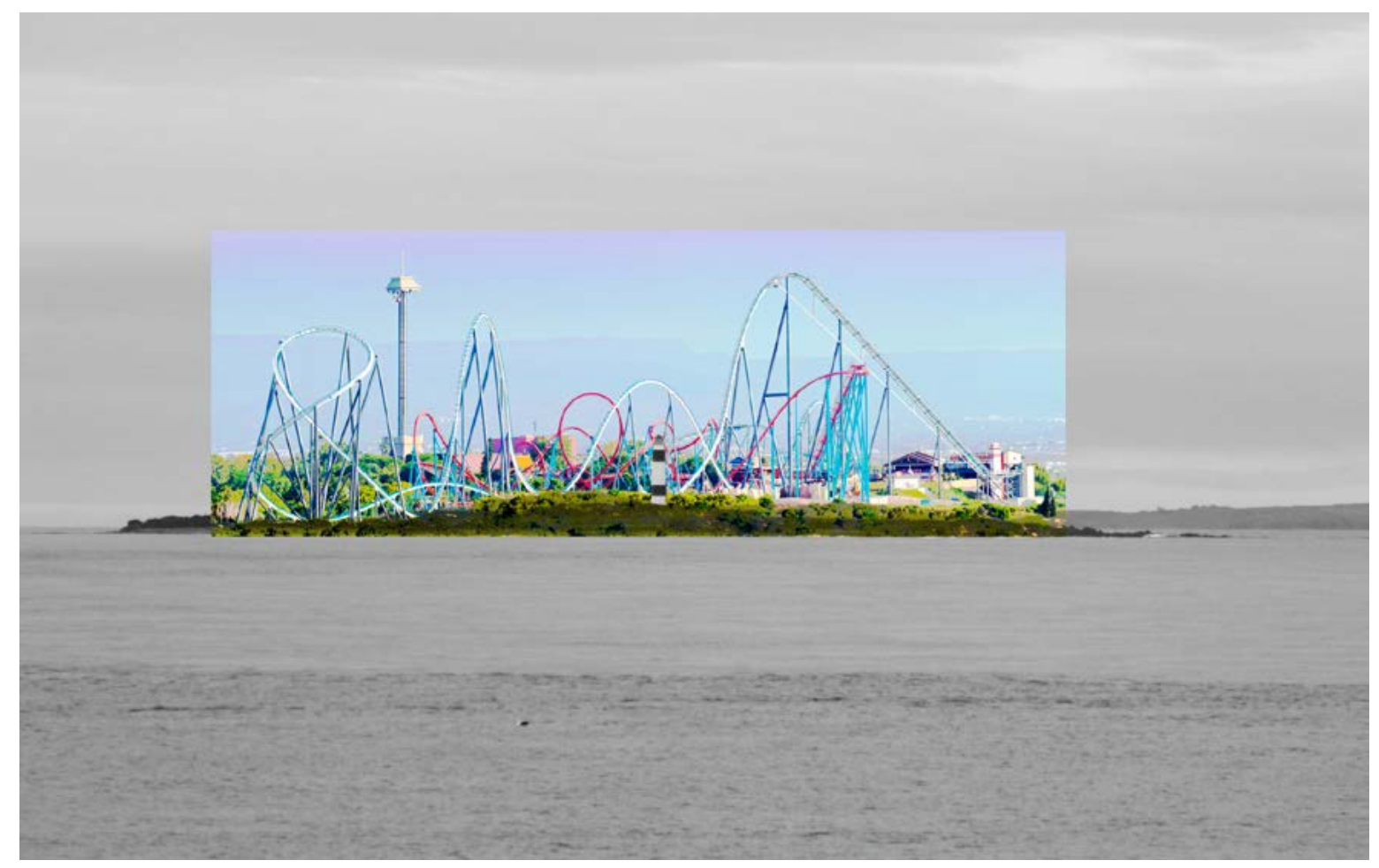




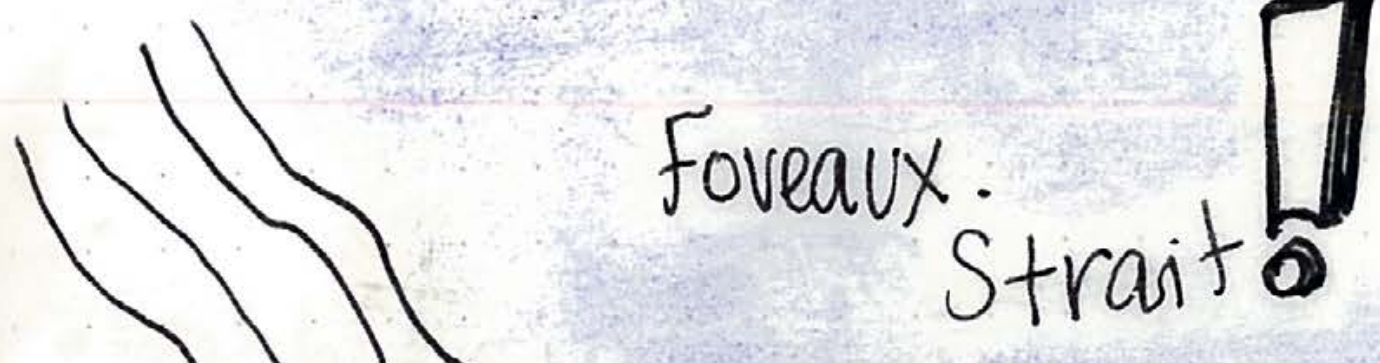

Straito

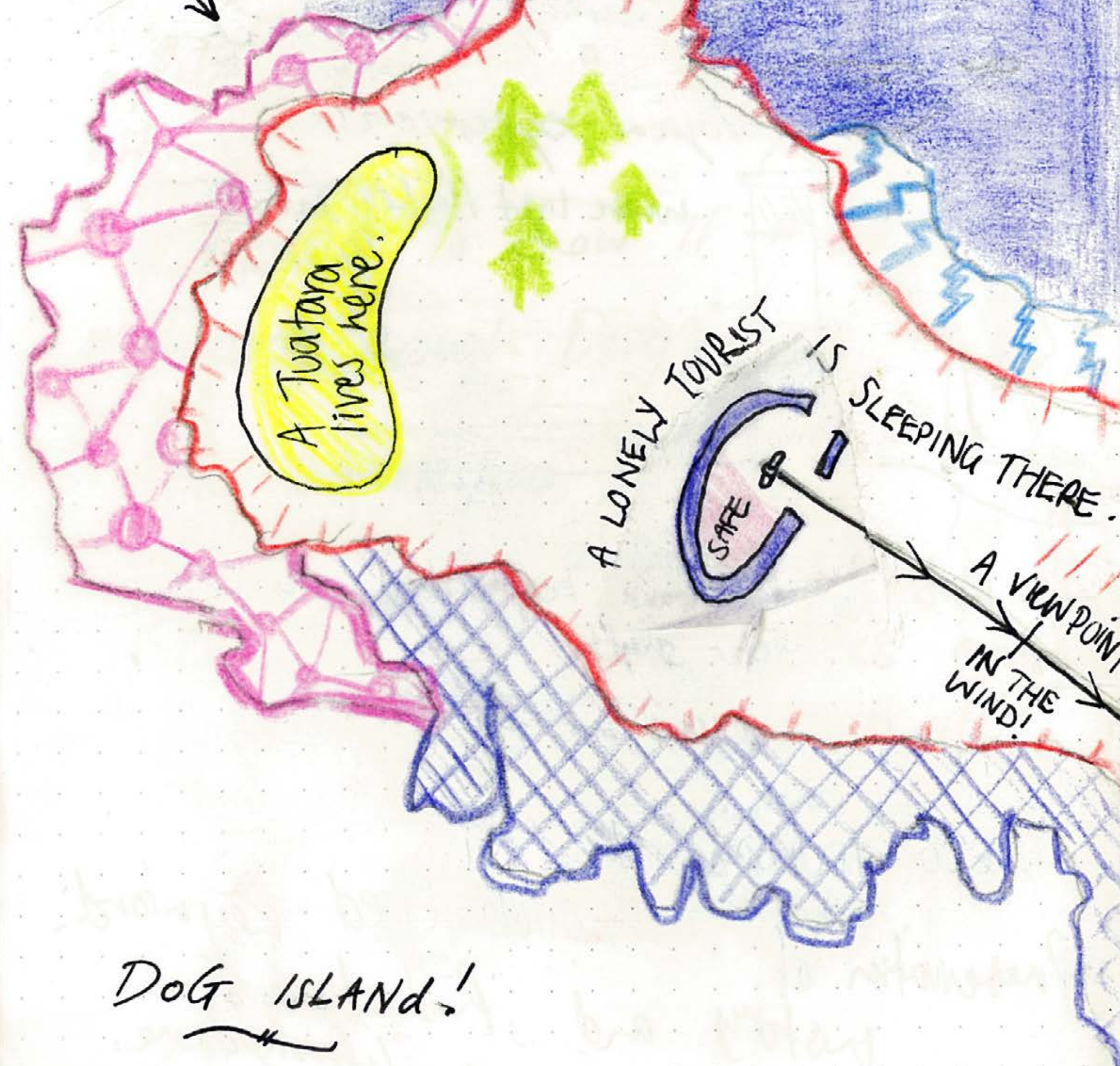


$\theta$
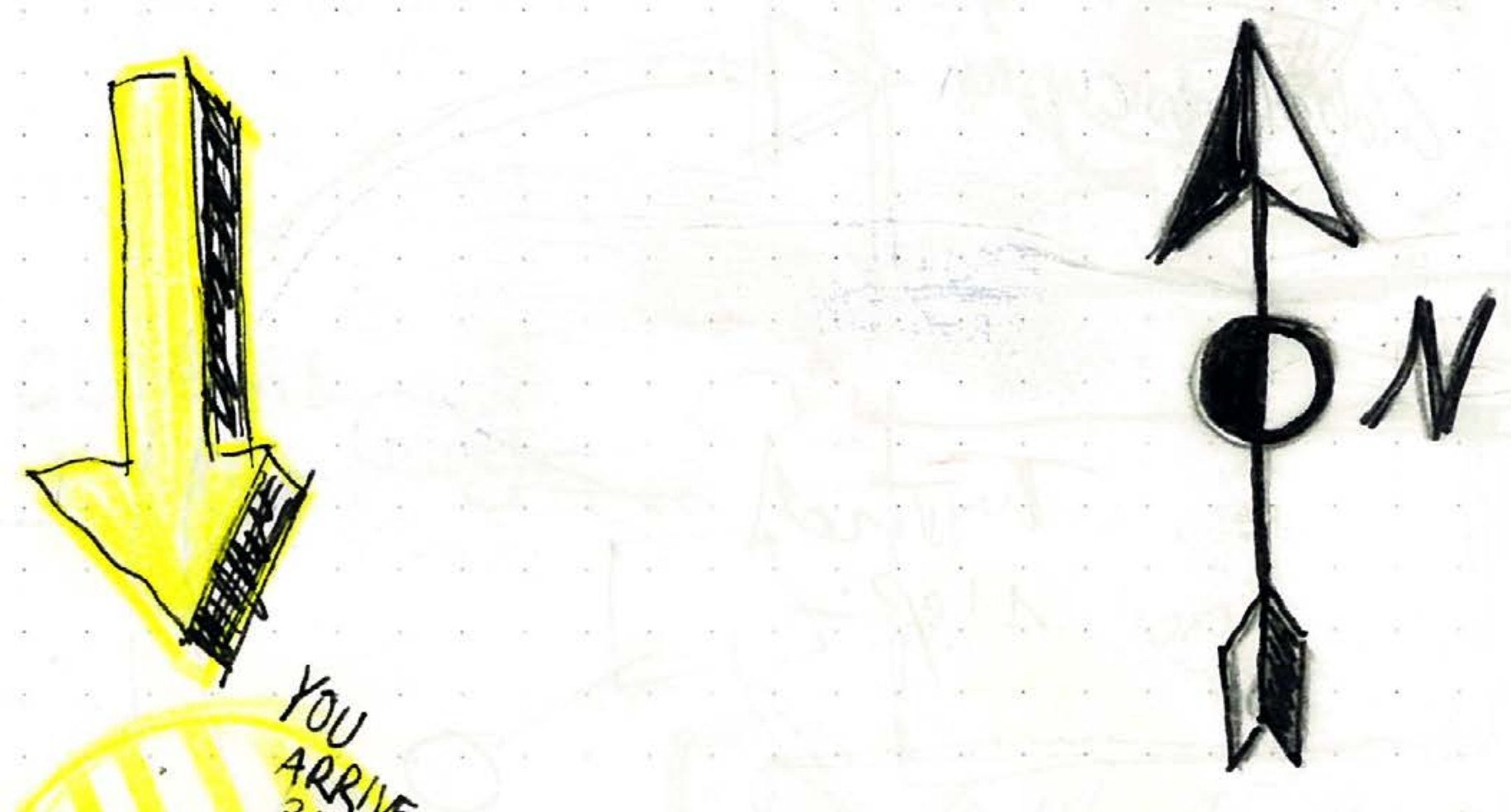

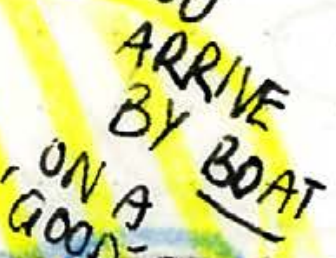




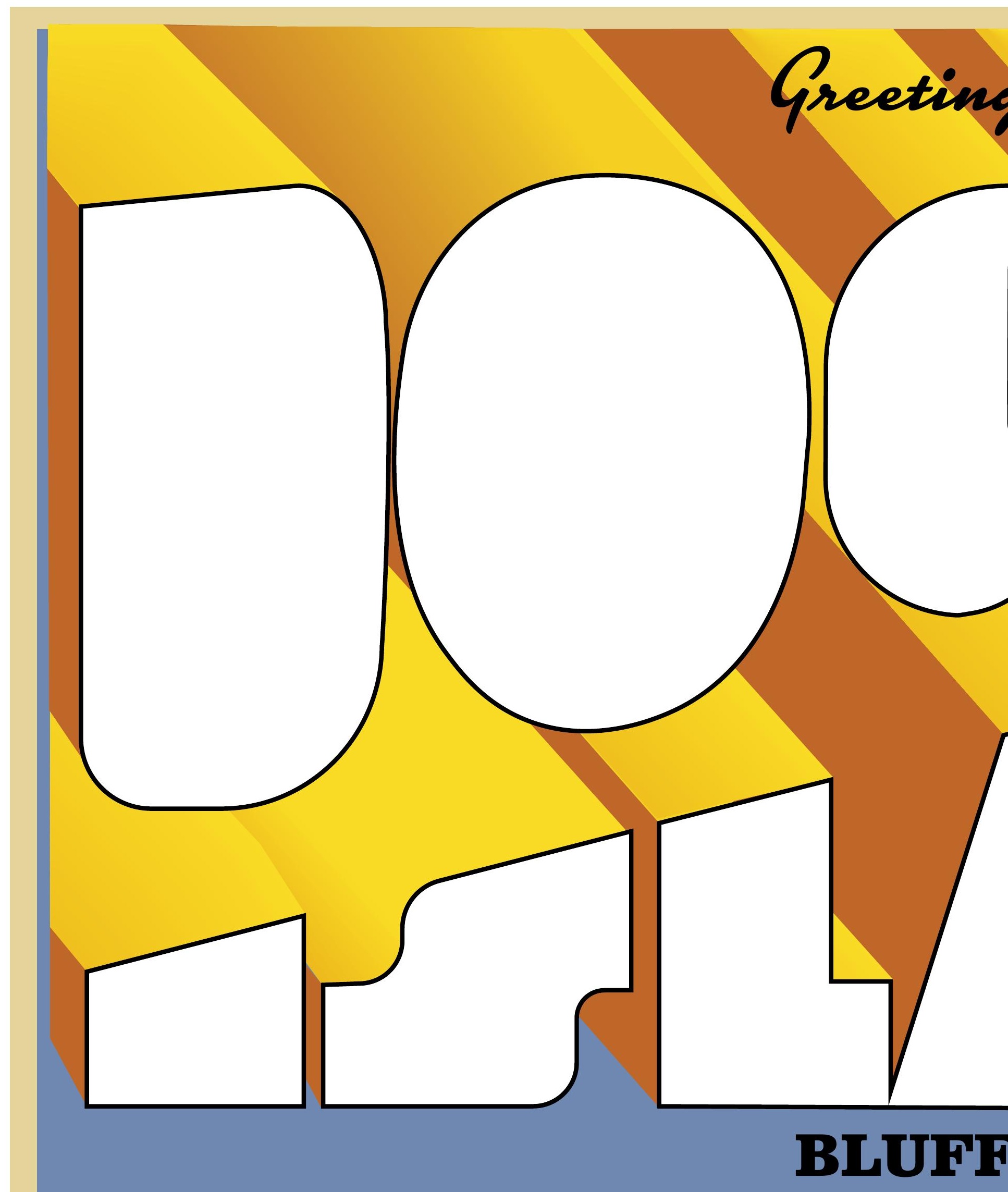

Figure 50 A mock postcard for Cold Damn Disneyland, based off original postcards for Coney Island,USA. 


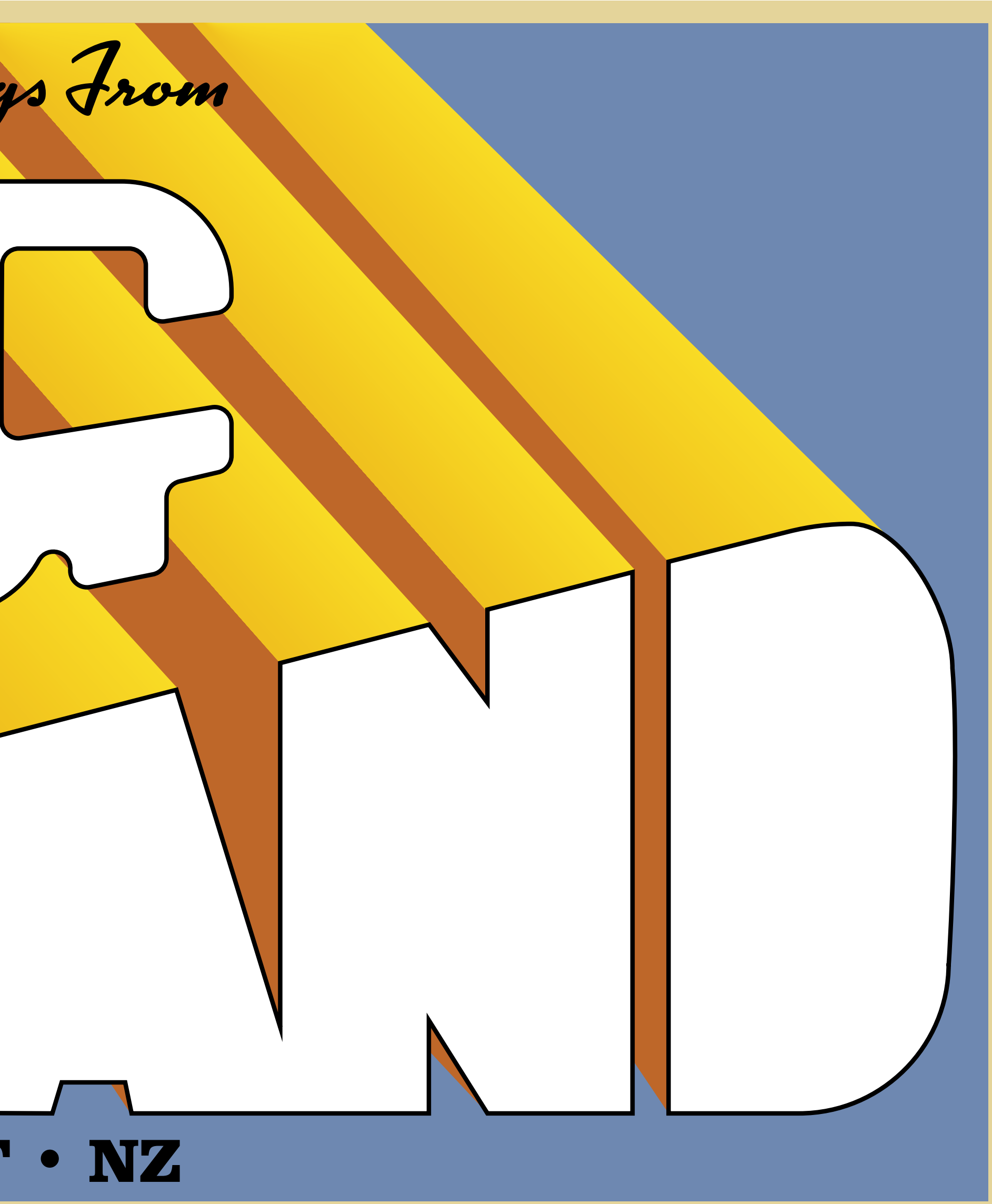




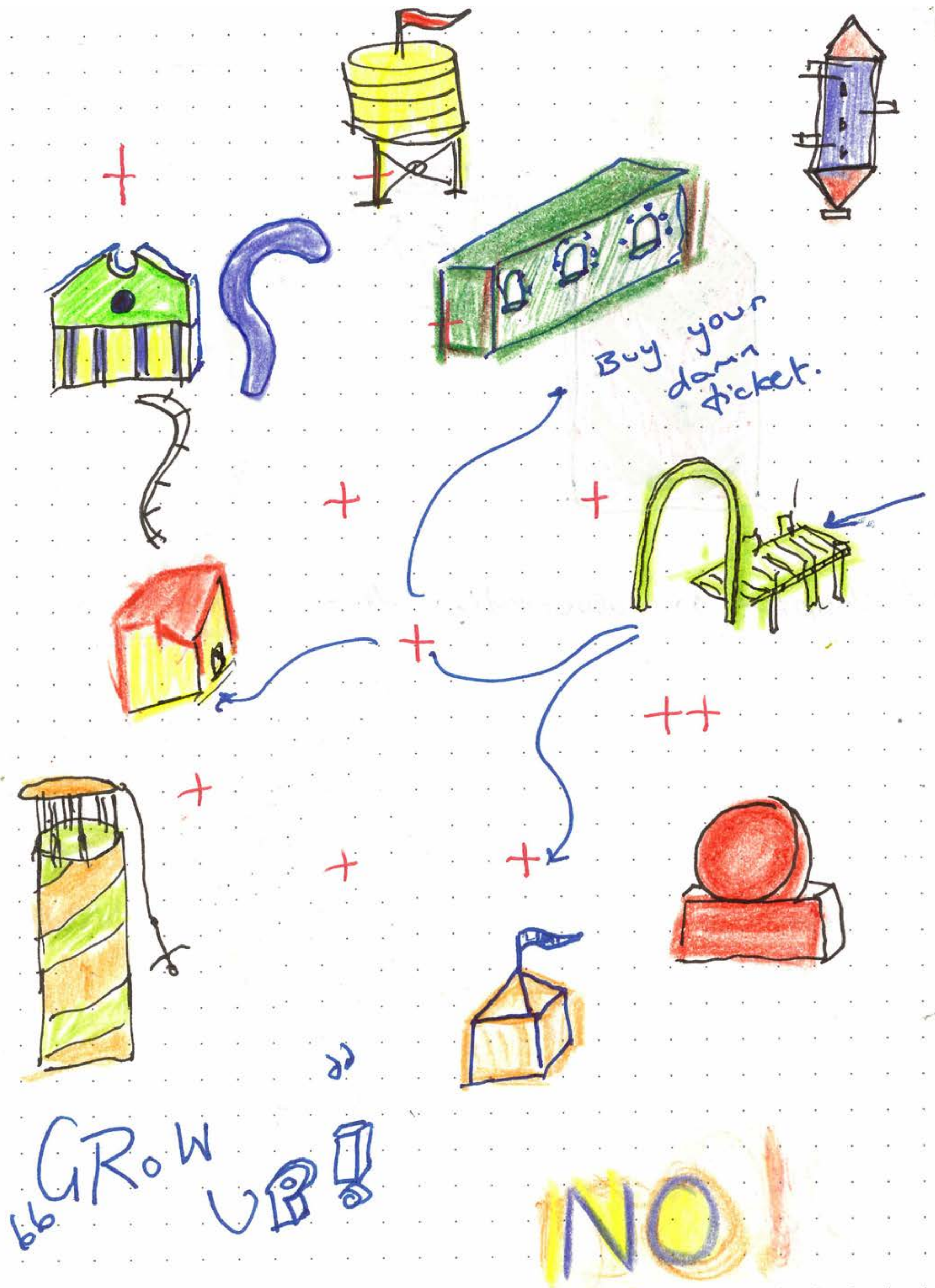




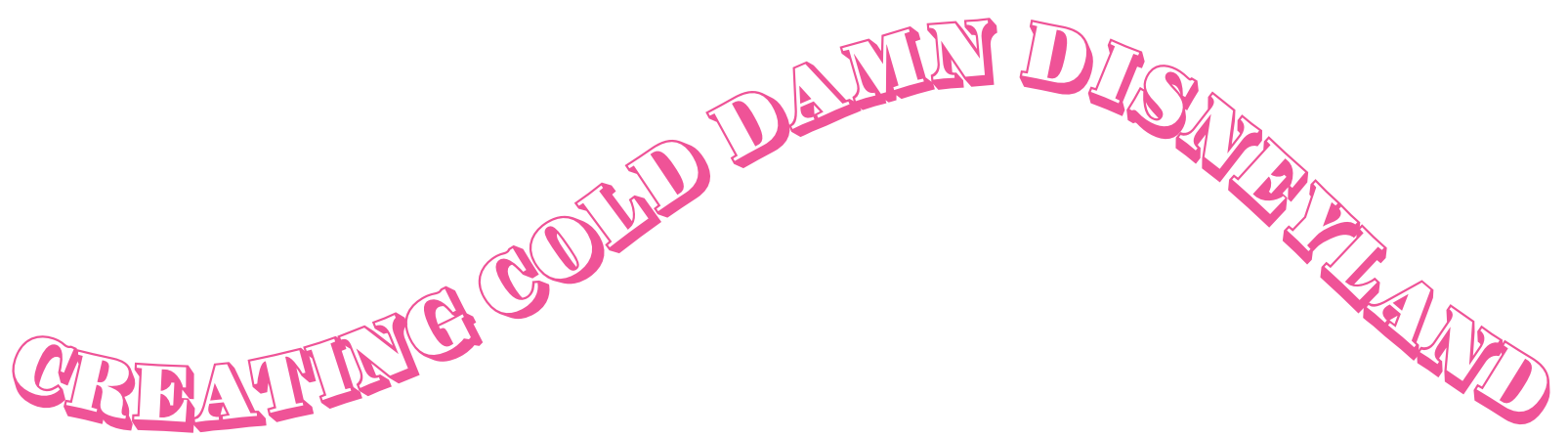

Creating 'Cold Damn Disneyland' started with looking at the folly, at small buildings in a theme park that collectively create an experience. Disneyland is so impressive because of the range, it's almost is a quantity over quality scenario, where the amount of difference, colour, lights creates a sensory overload that leads to the conglomeration, being a 'fun' experience.

This design phase was never a serious one, it was a foray into whimsical structures, that did something, but conveyed its purpose in a 'camp way'. Three of the main structures that were chosen was accommodation, the gift shop and the tuatara pavilion.

The Accommodation, called 'stay the night with the lighthouse keeper' was a satirical whimsical hut structure, the building began as a playful building that rotated according to the wind, it was 'designed' to be accessed via a bottom ladder and was planned to have multiple together. The Second was the gift shop, from the beginning, the term 'exit through the gift shop' was exaggerated to satirically comment on consumer, mass tourism culture. The gift shop was designed as a multi-story pavilion that housed a proposed restaurant at the top, these structures, while very underdesigned, were all created in the hope to collectively be a satirical island theme park.

The third was the 'Tuatara Pavilion' this originally stemmed from the fact that Dog Island was proposed as a predator-free island andaplacewheretuatarawasbeingtransferred. Using camp satirical humour, the advertising becomes the place, see the theme park map.

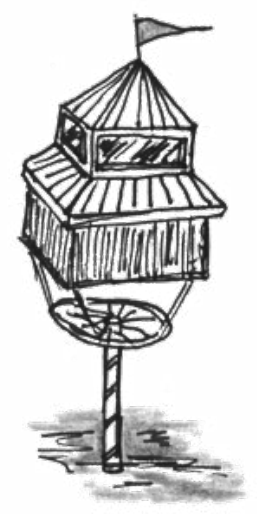

These buildings are for lack of a better word, useless. They act not as individual structures but a collective theme park, It plays on notions, of advertisement, mass tourism, consumption and theme parks and does that by being over the top and ridiculous. 
THE BLUFF FERRY TERMINAL

What began as a serious design intervention to consider how guests would get to the island from the mainland, the Bluff ferry terminal was quickly put on the shelve and the focus was put on the island itself. Still relevant to include,the early work was heavily influenced by the 'consumer' and how through creating space, one is able to manipulate the user to pass through a gift shop or buy a coffee while catching the ferry.
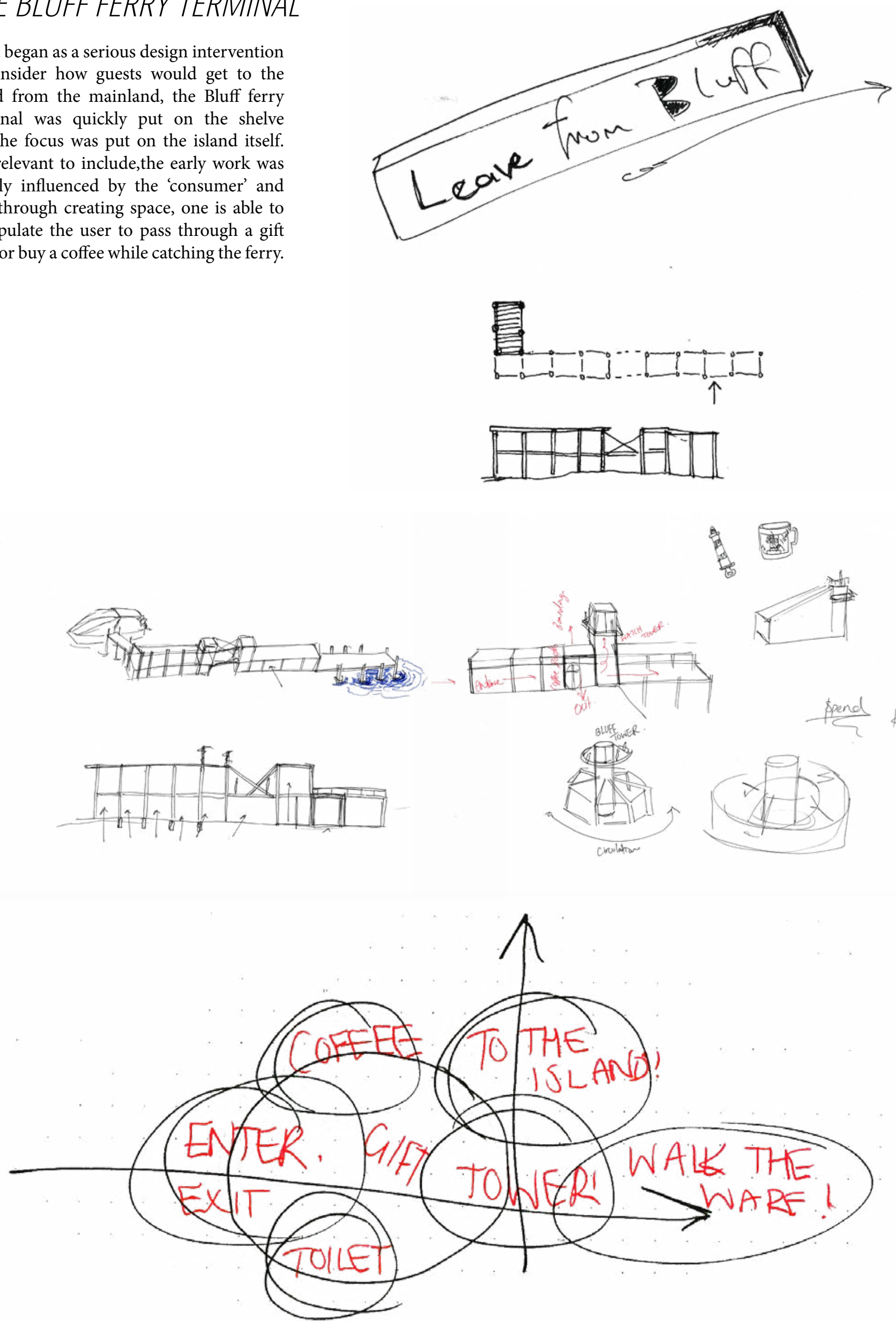

Figure 51 Early design work, creating the ferry terminal and planning space. 
FERRY TERMINAL BLUFF:
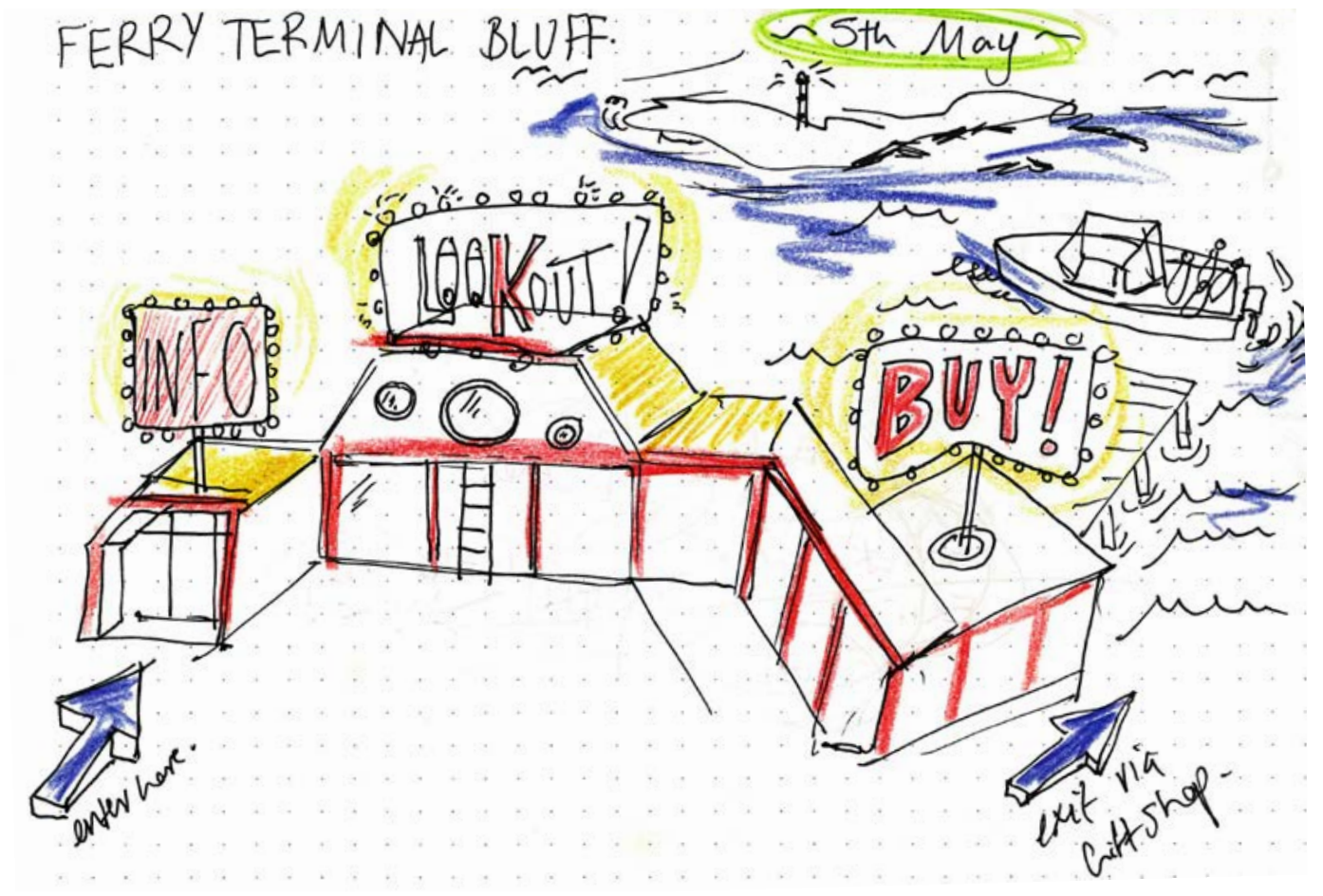

Figure 52 The Ferry terminal

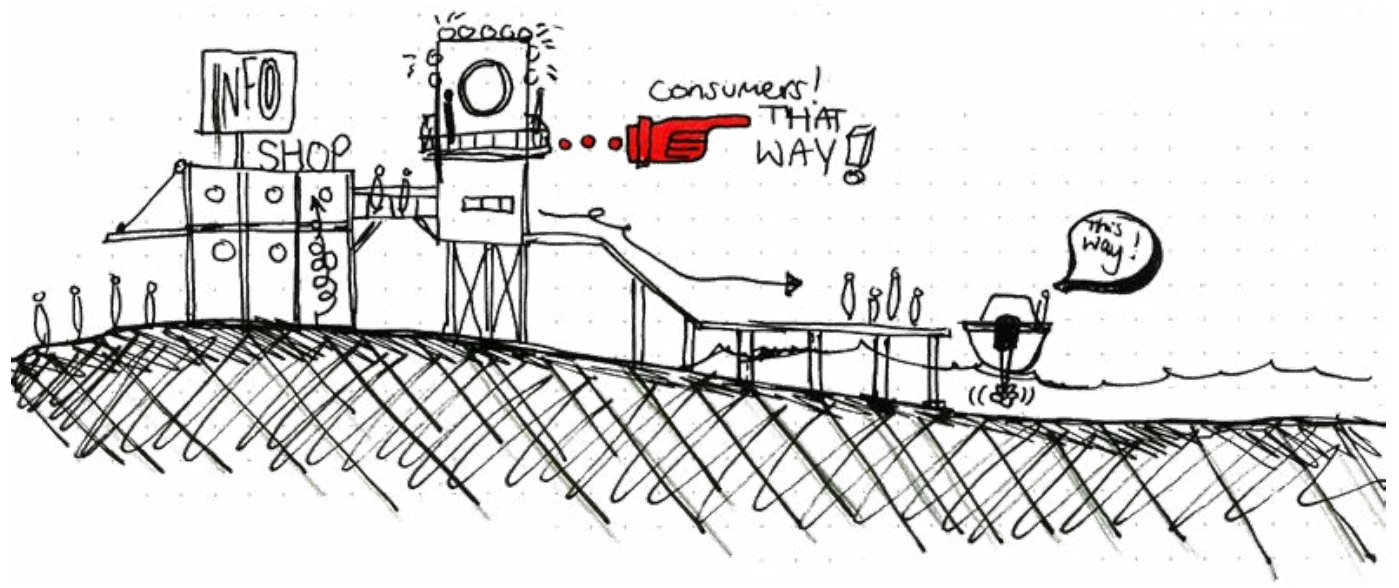

Figure 53 Passangers boarding the Ferry, on-route to Cold Damn Disneyland

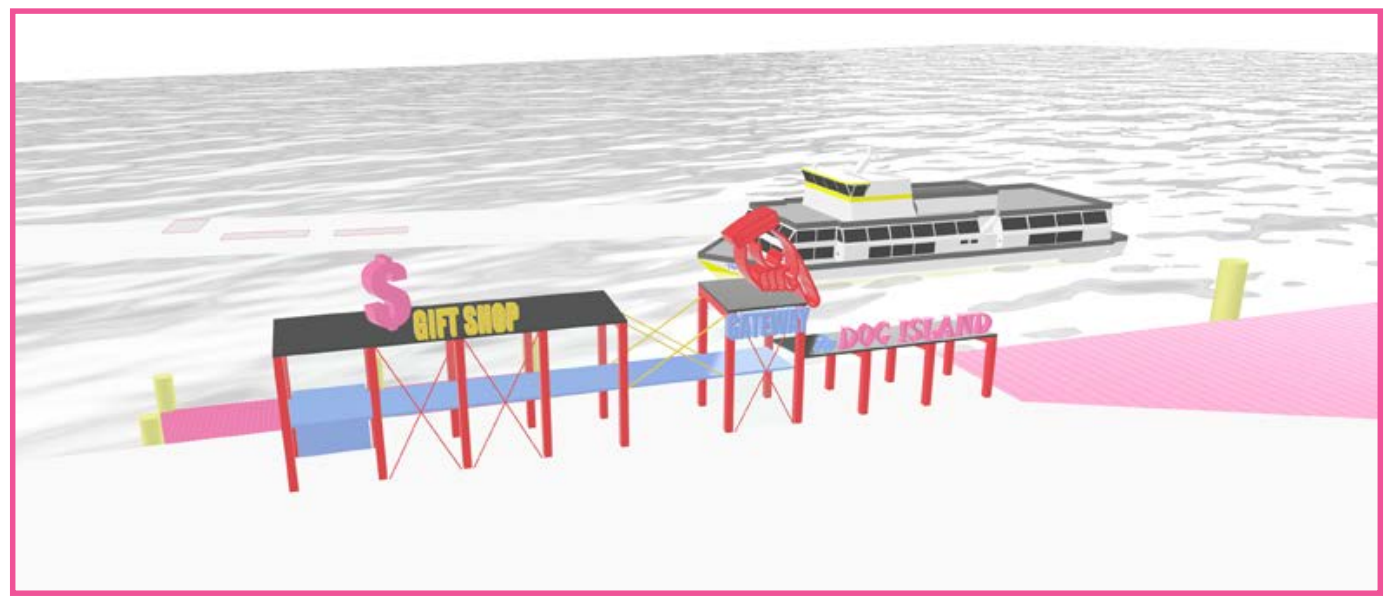

Figure 54 An early render of a concept for the ferry terminal. 


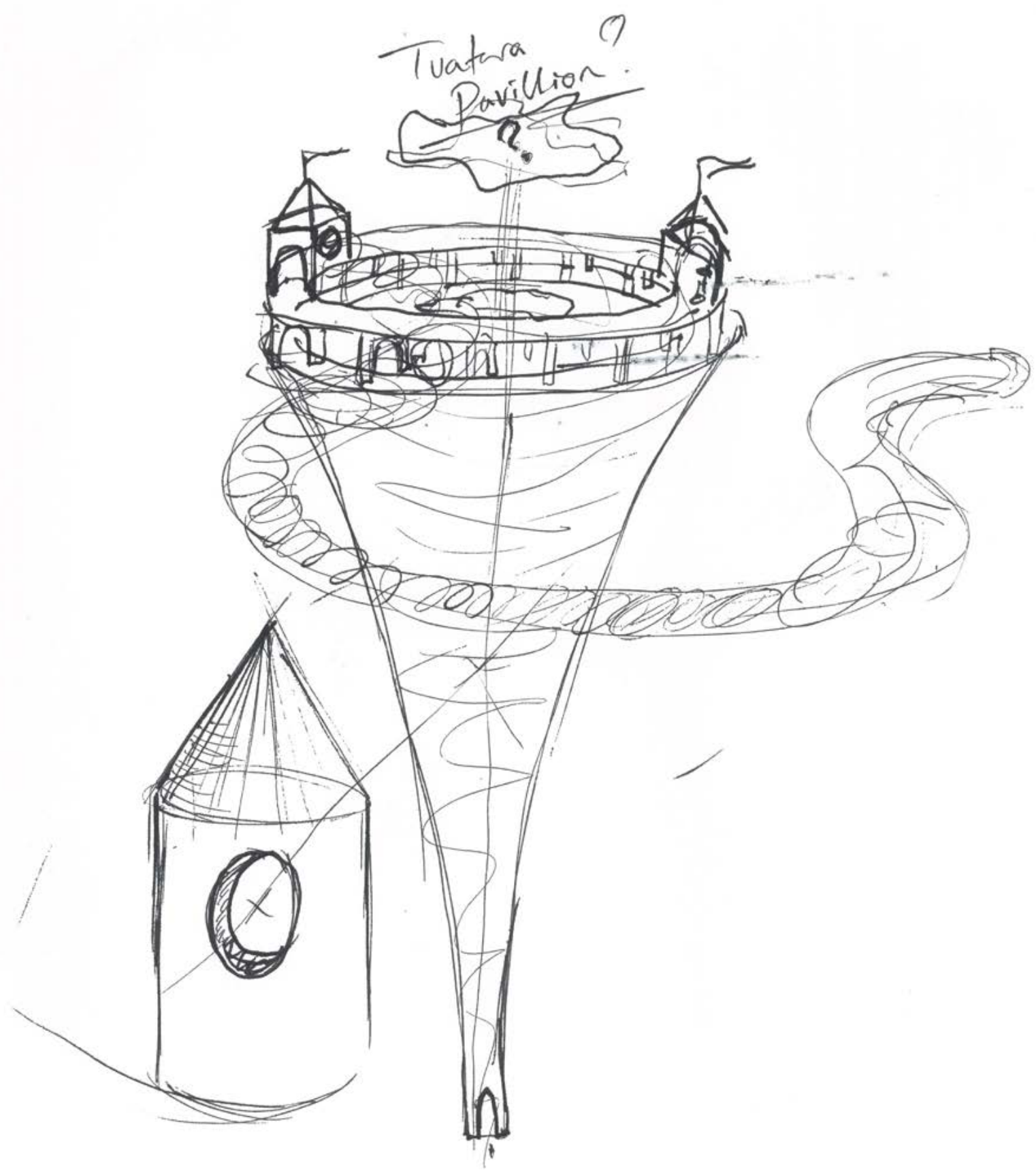

Figure 55 The Tuatara Pavillion concept sketch 

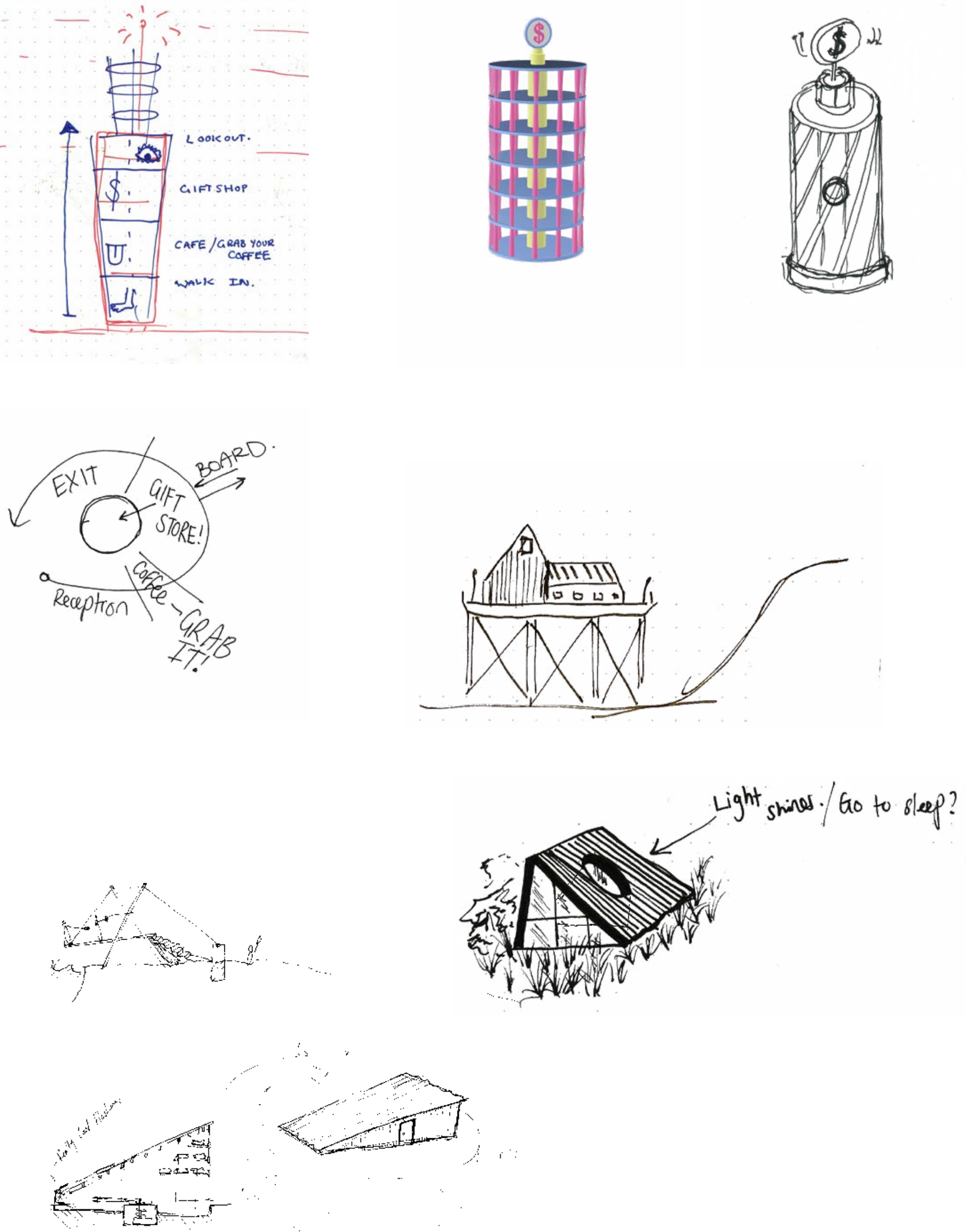


\section{GOLD DANTM DISIYEYMAND}

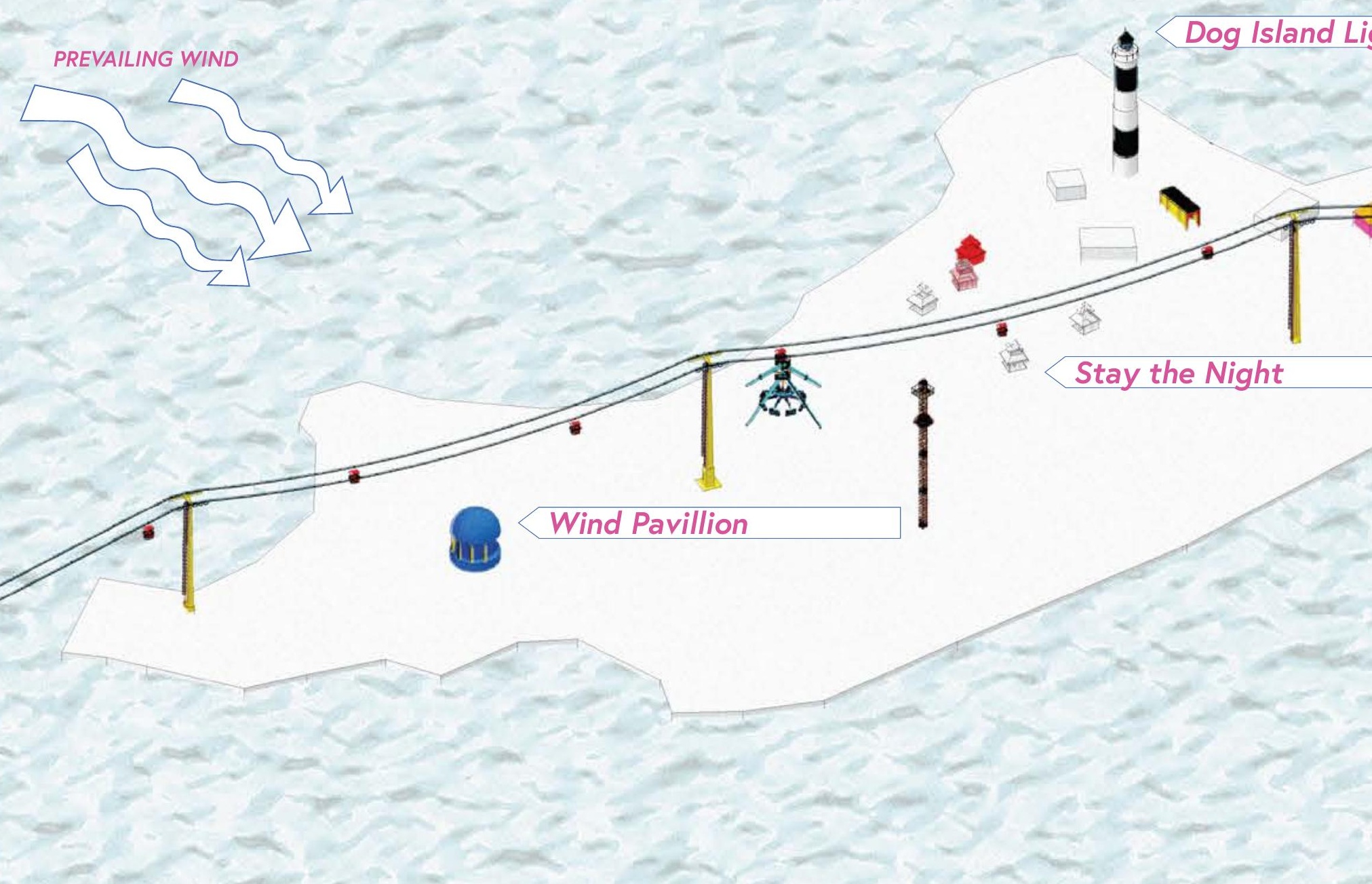

Foveaux Strait 


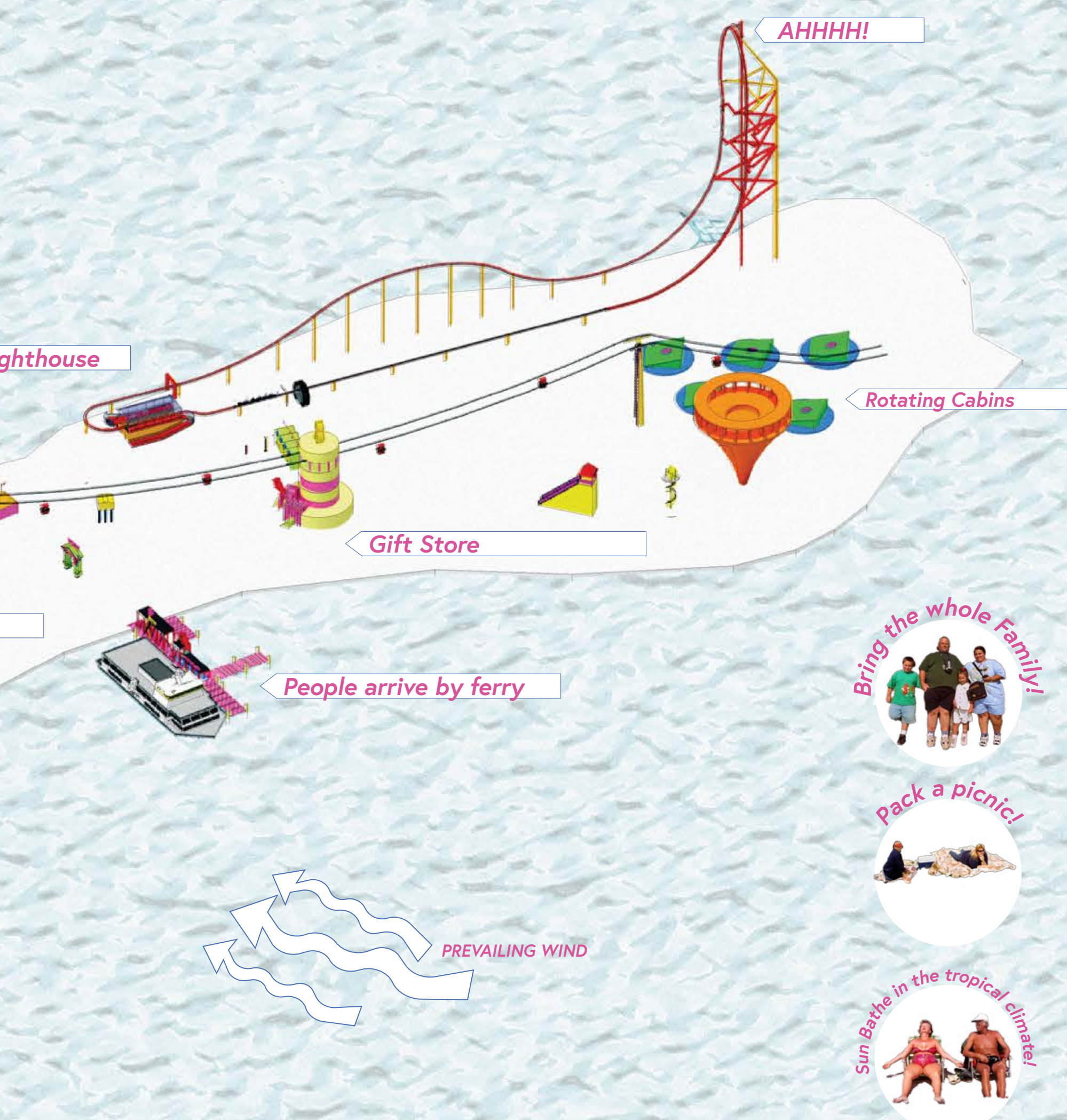

This perspective site plan shows the imagined Cold Damn Disneyland, its attractions, site conditions and how people are to use it. 


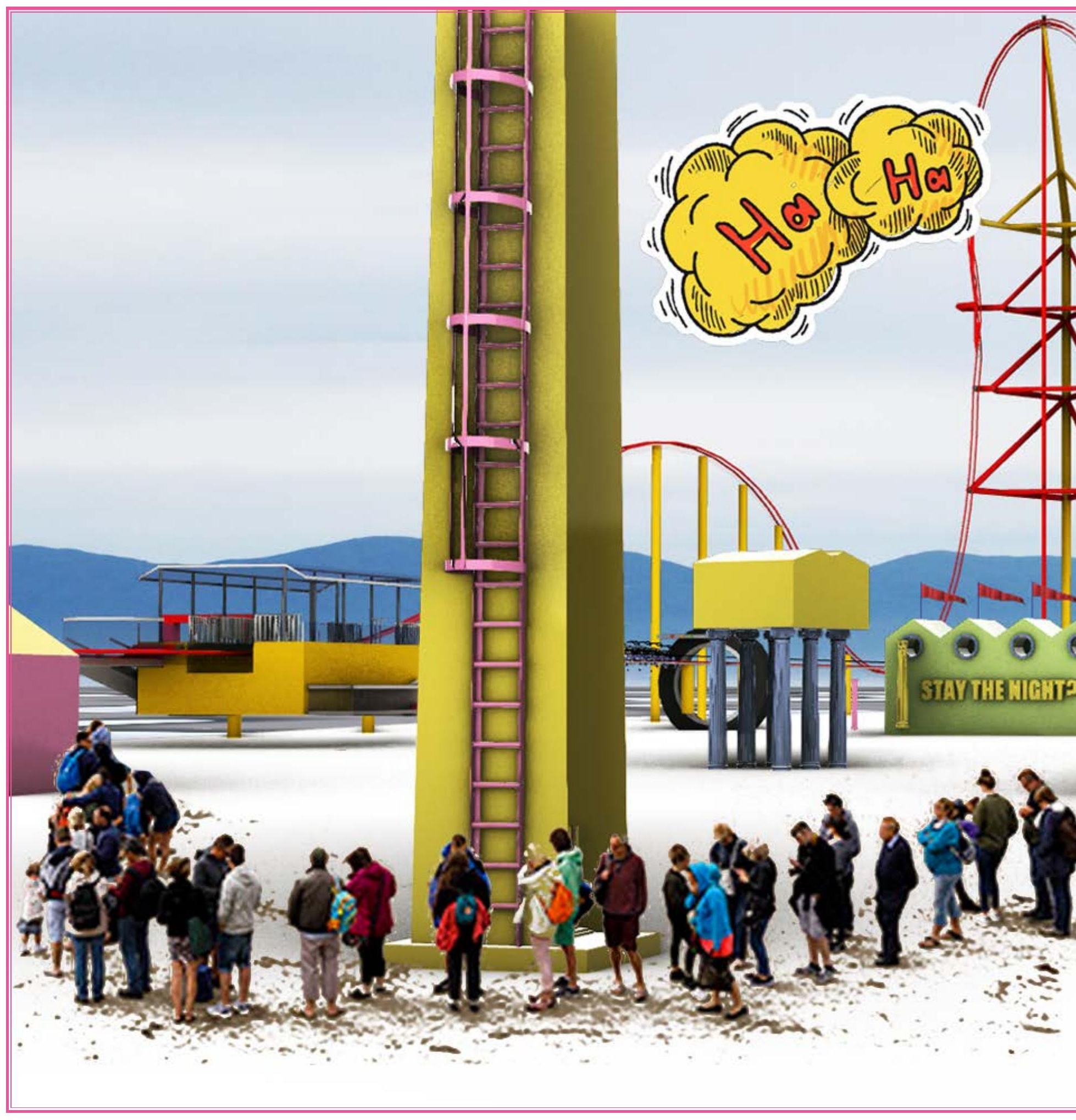

Figure 57 Bob having the time of his life at Cold Damn Disneyland. 


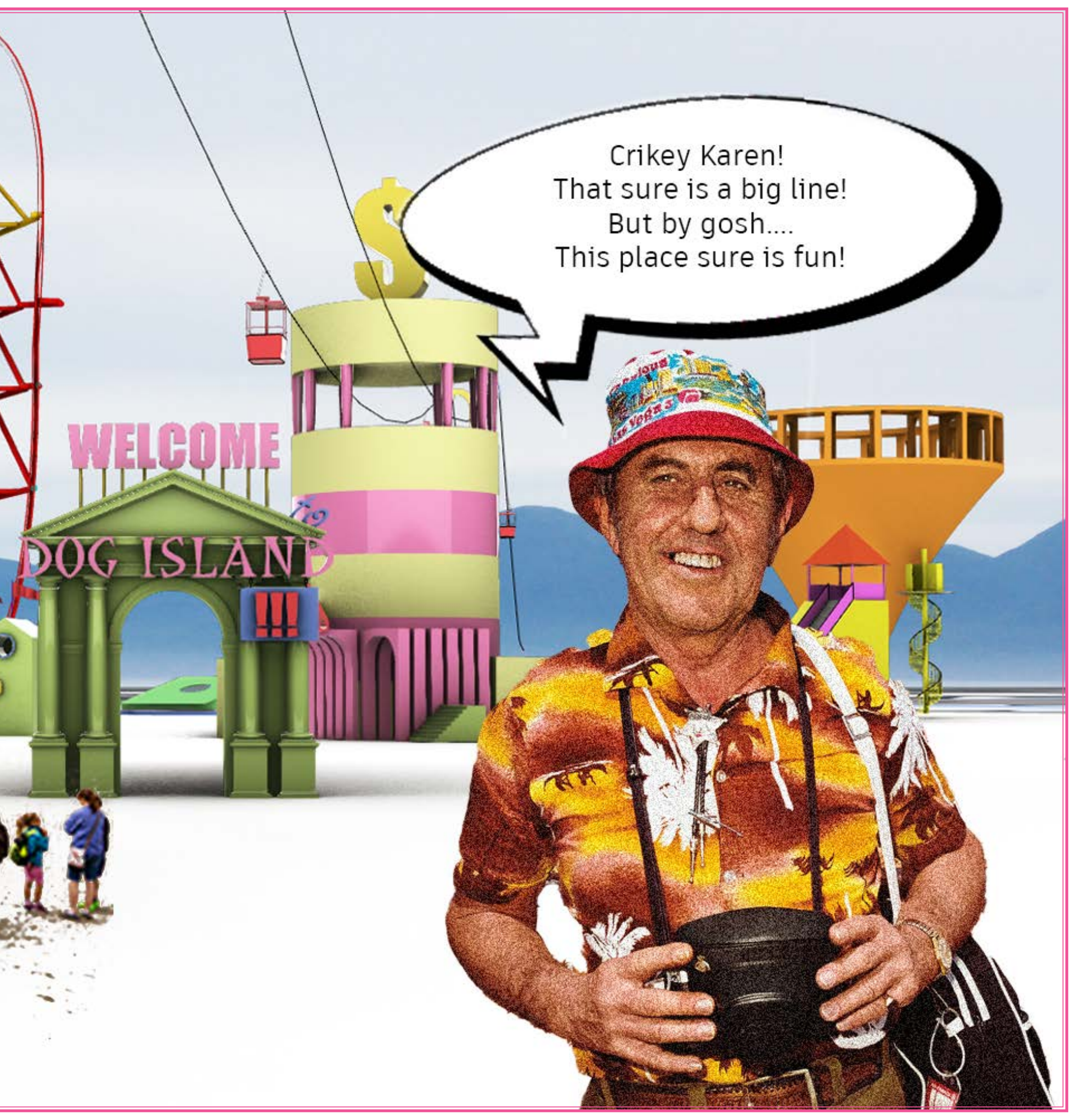




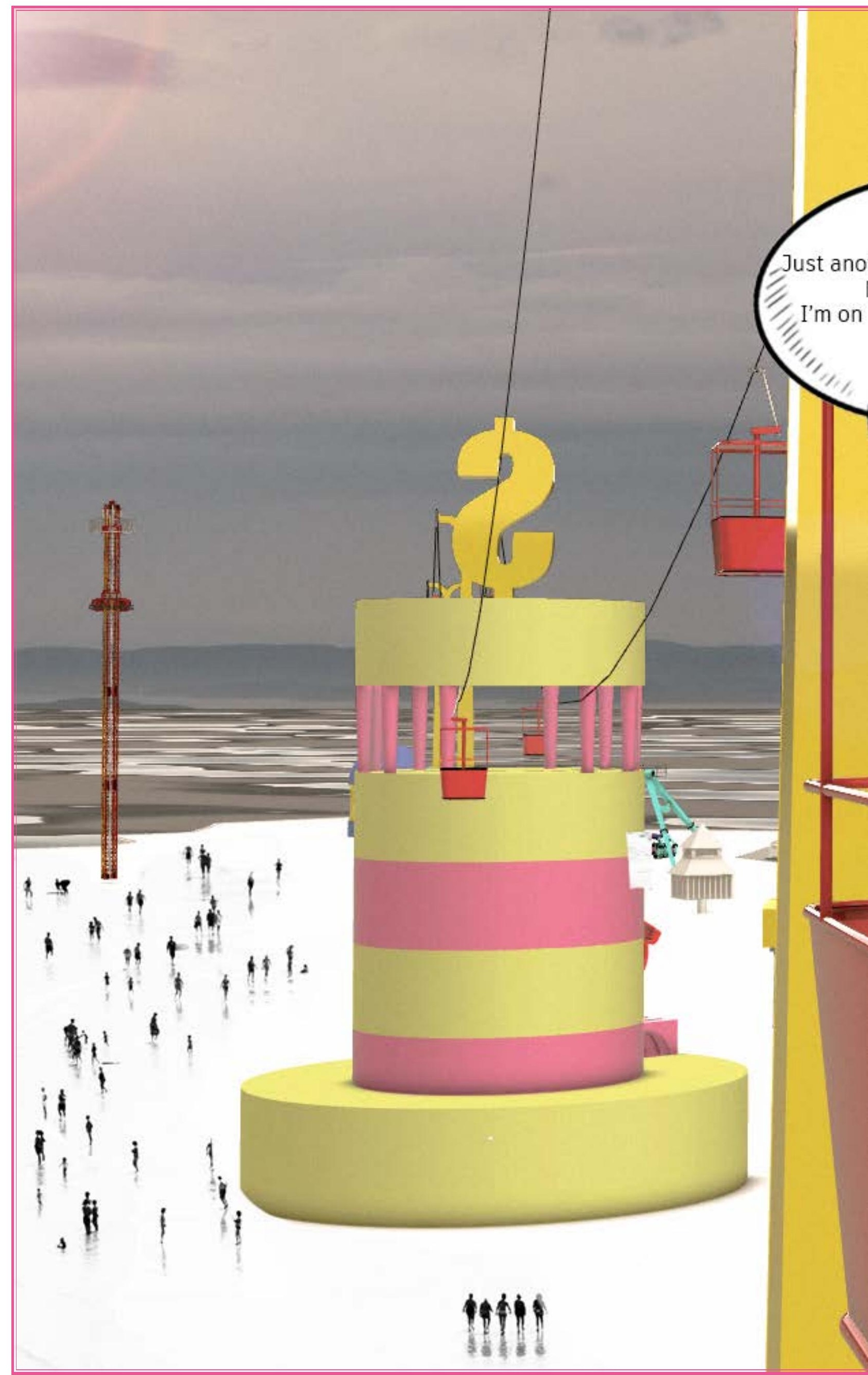




\section{ODARK 5054 IML}

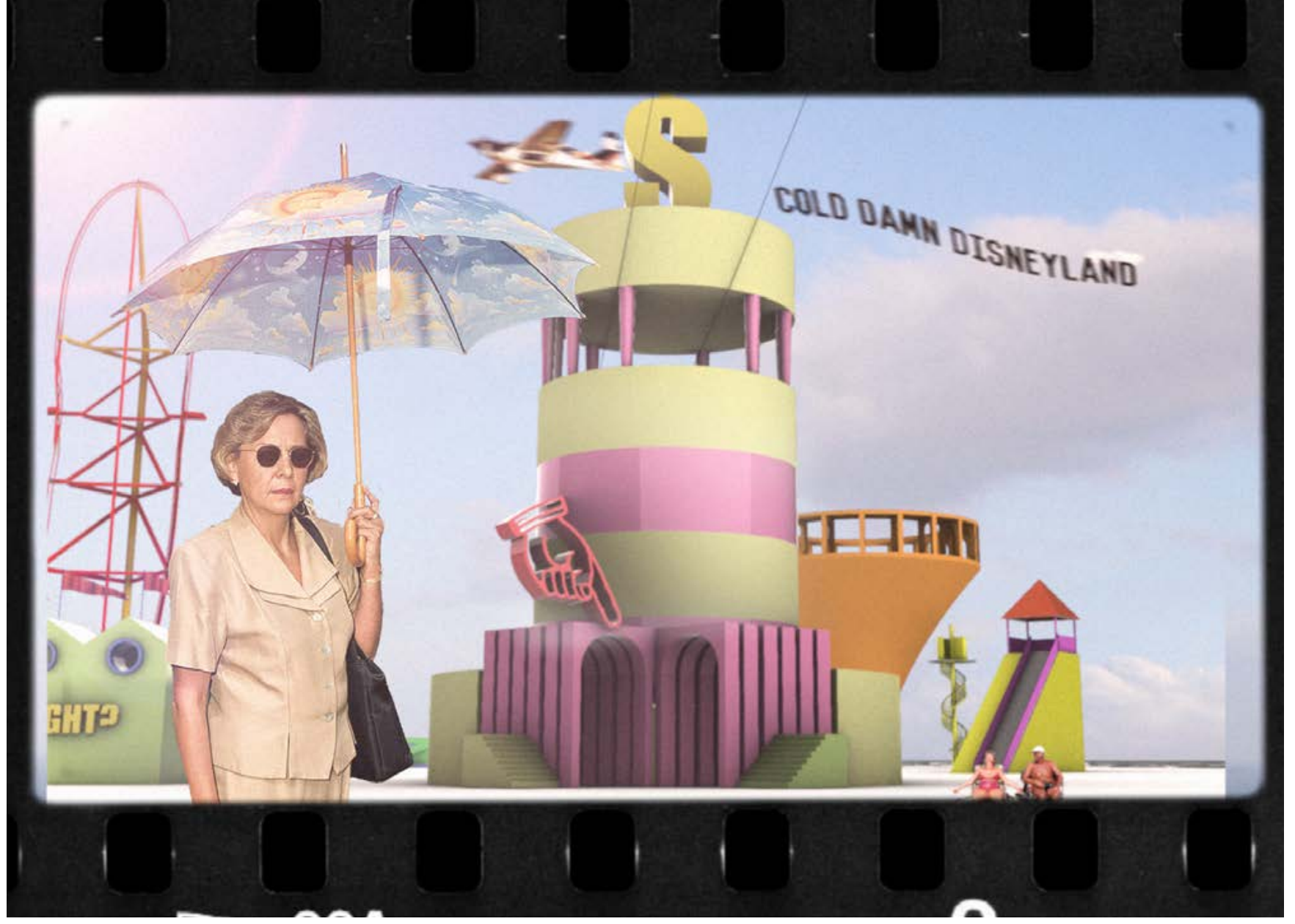

Figure 59 A warmer than usual day at Cold Damn Disneyland, Lisa is having a Blast. 


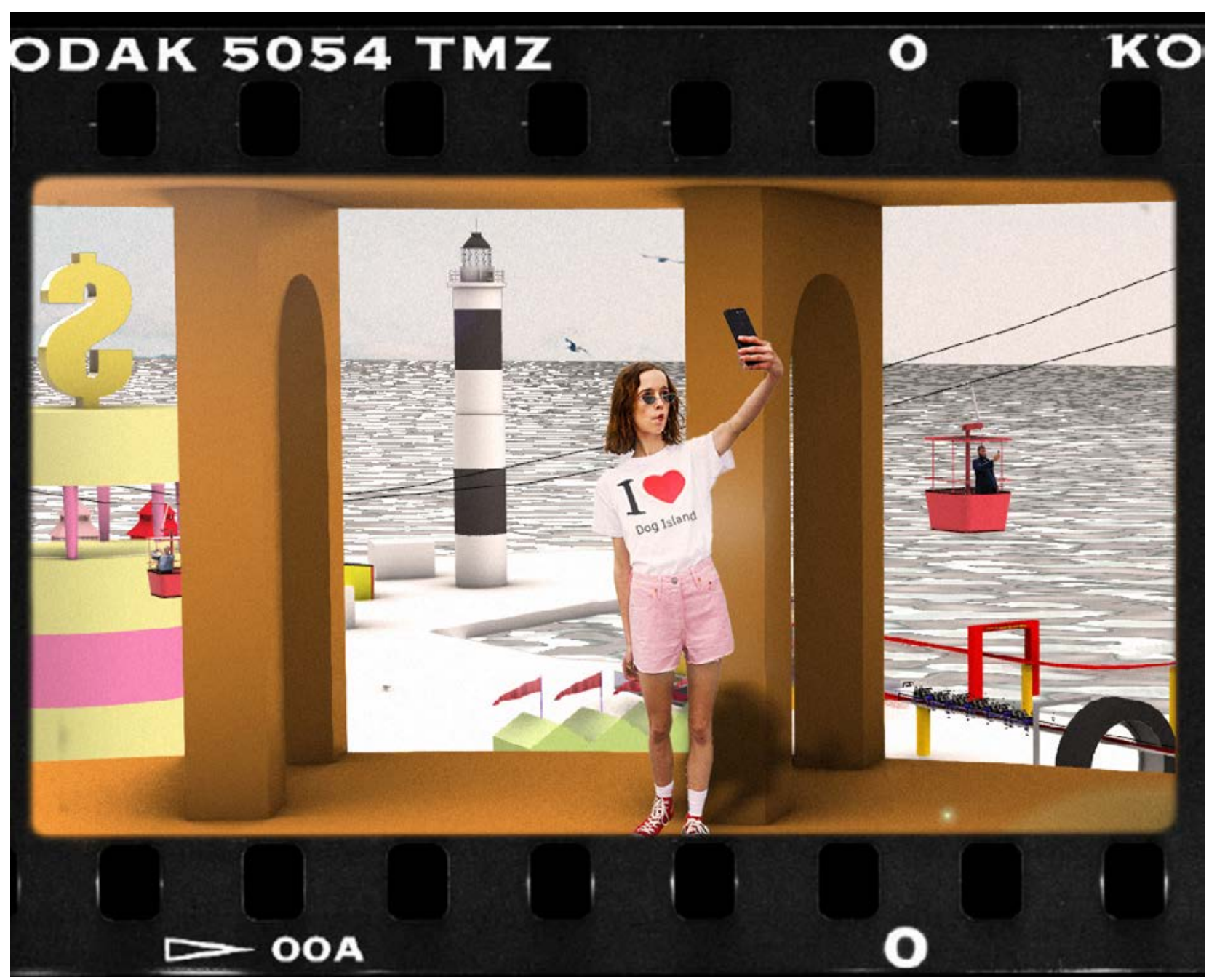

Figure 60 Amber escaped her parents to get a selfie from on top of the tuatara pavillion. 


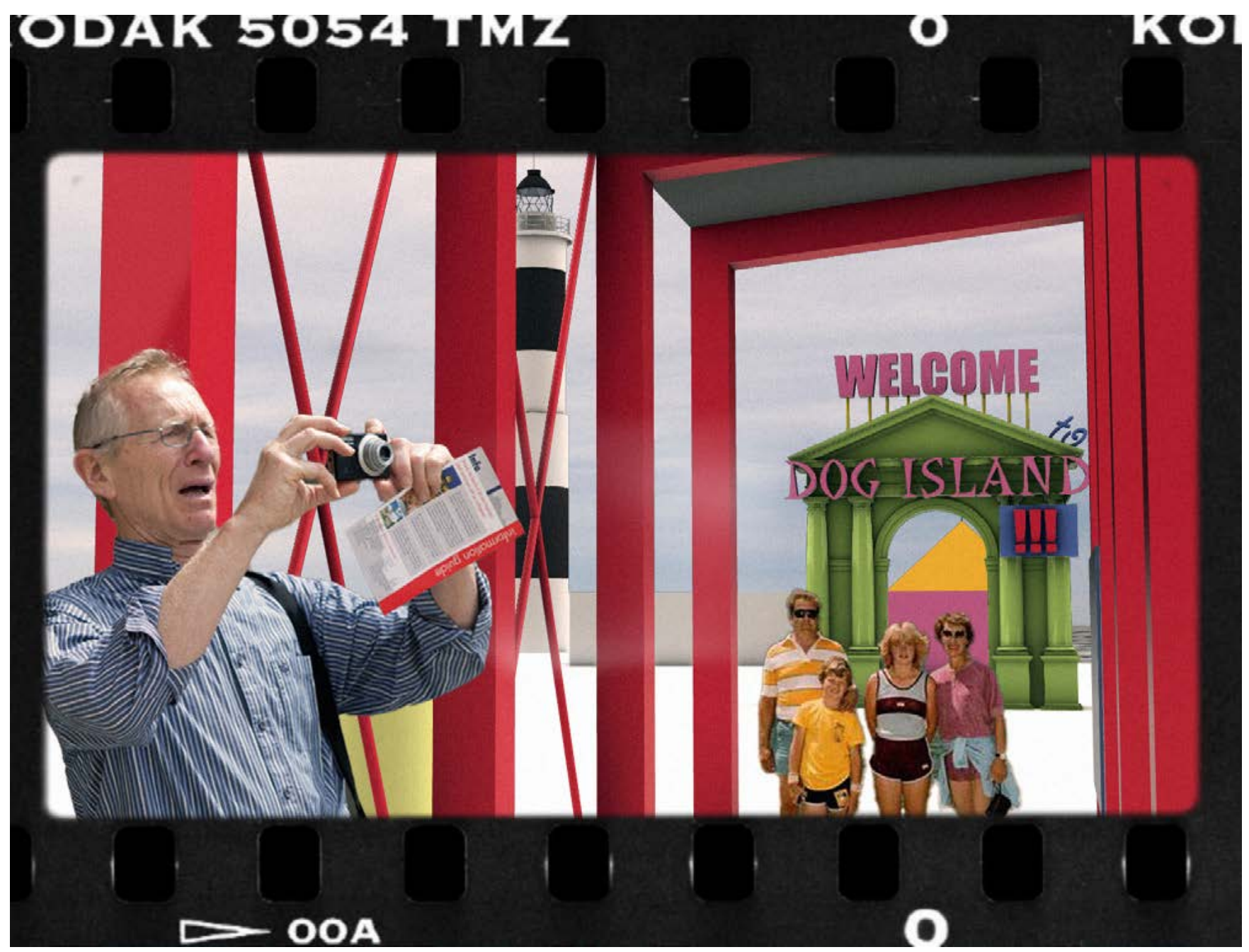

Figure 61 Rodge was asked to take a photo of this lovely family arriving at Cold Damn Disneyland, but got distracted! "Ahh, the serenity" he says. 


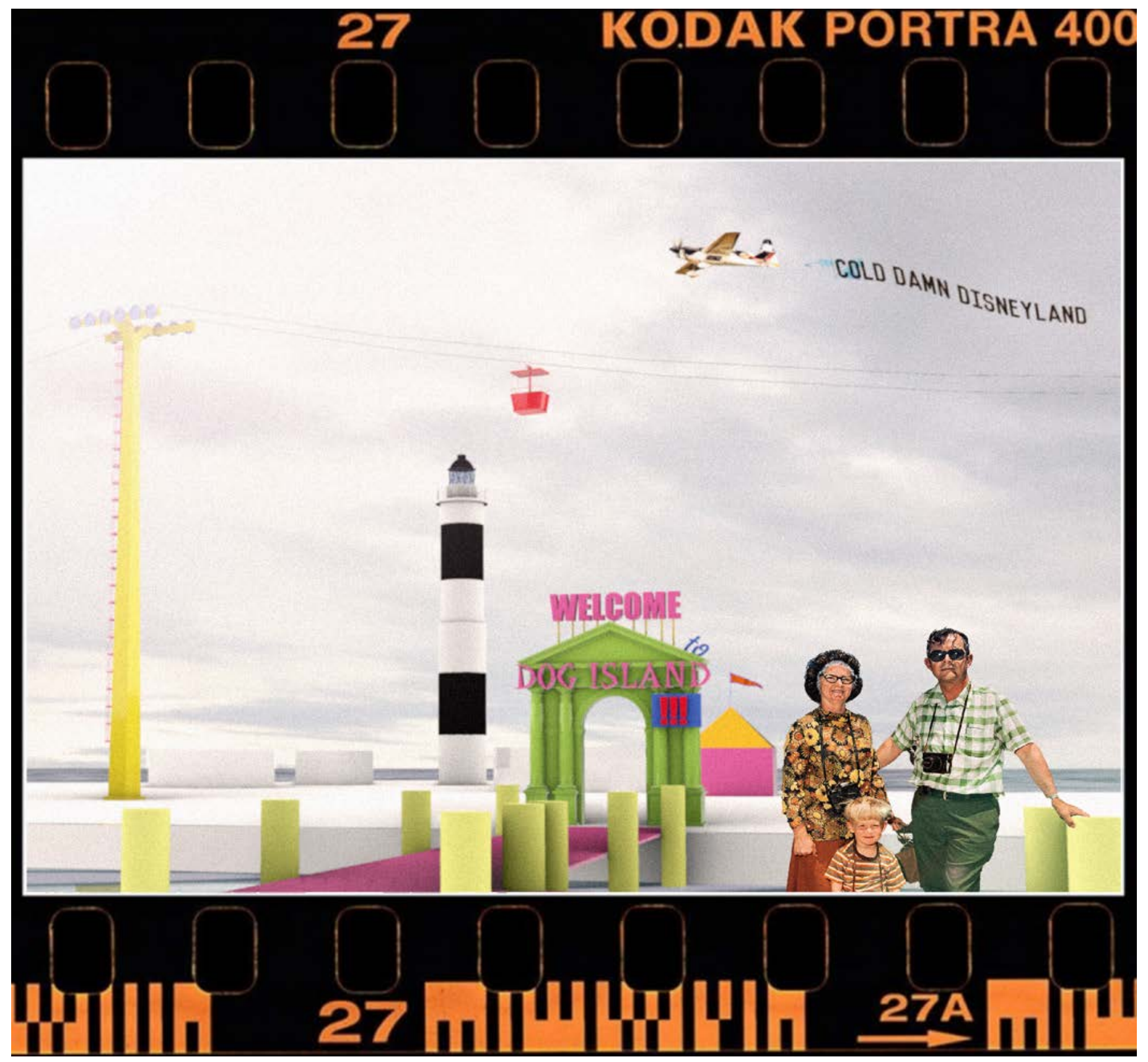

Figure 62 Susie, Nigel and Timmy, on a lovely family outing. 


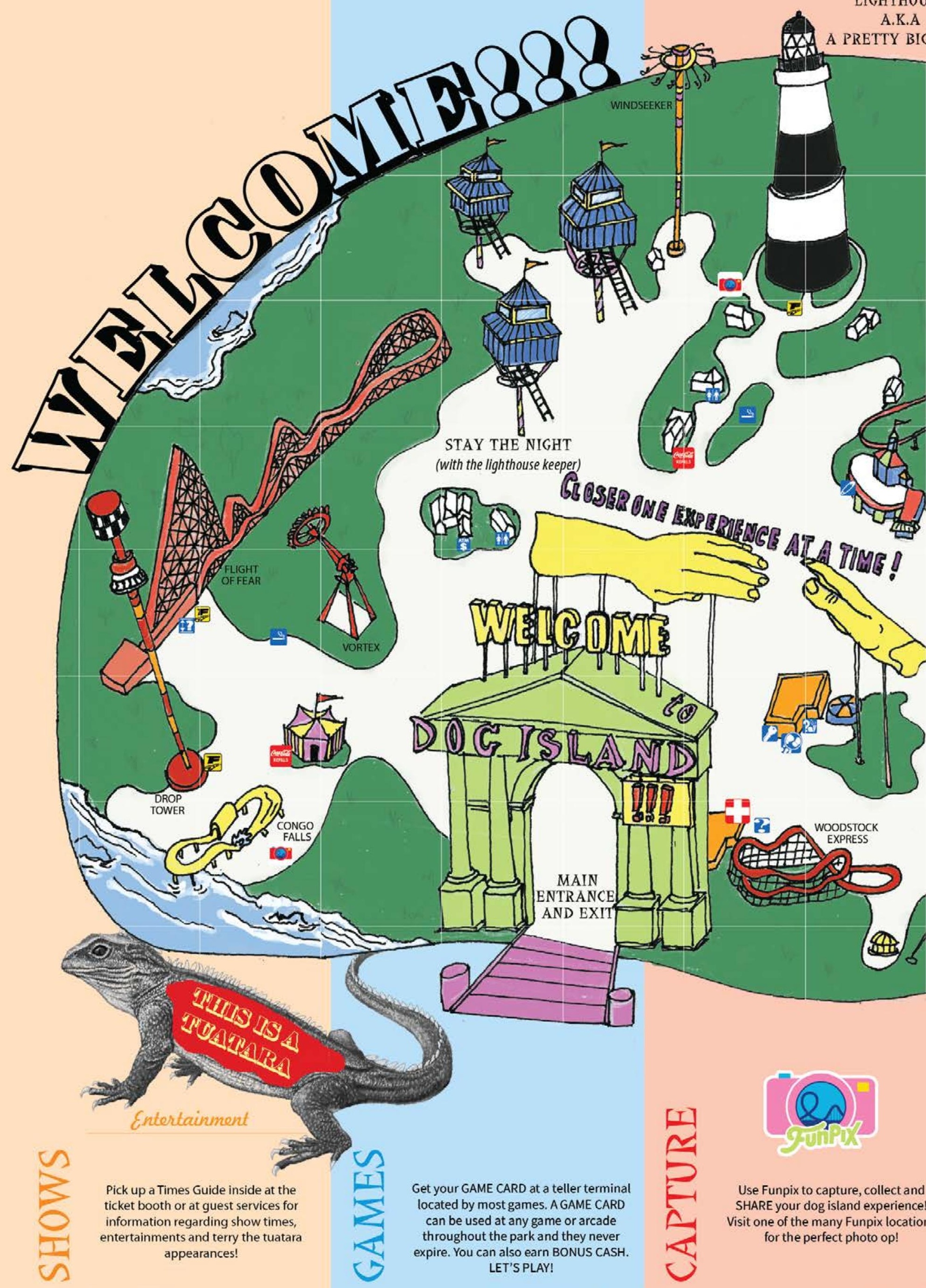



island mobile app includes ride wait times, special event information,
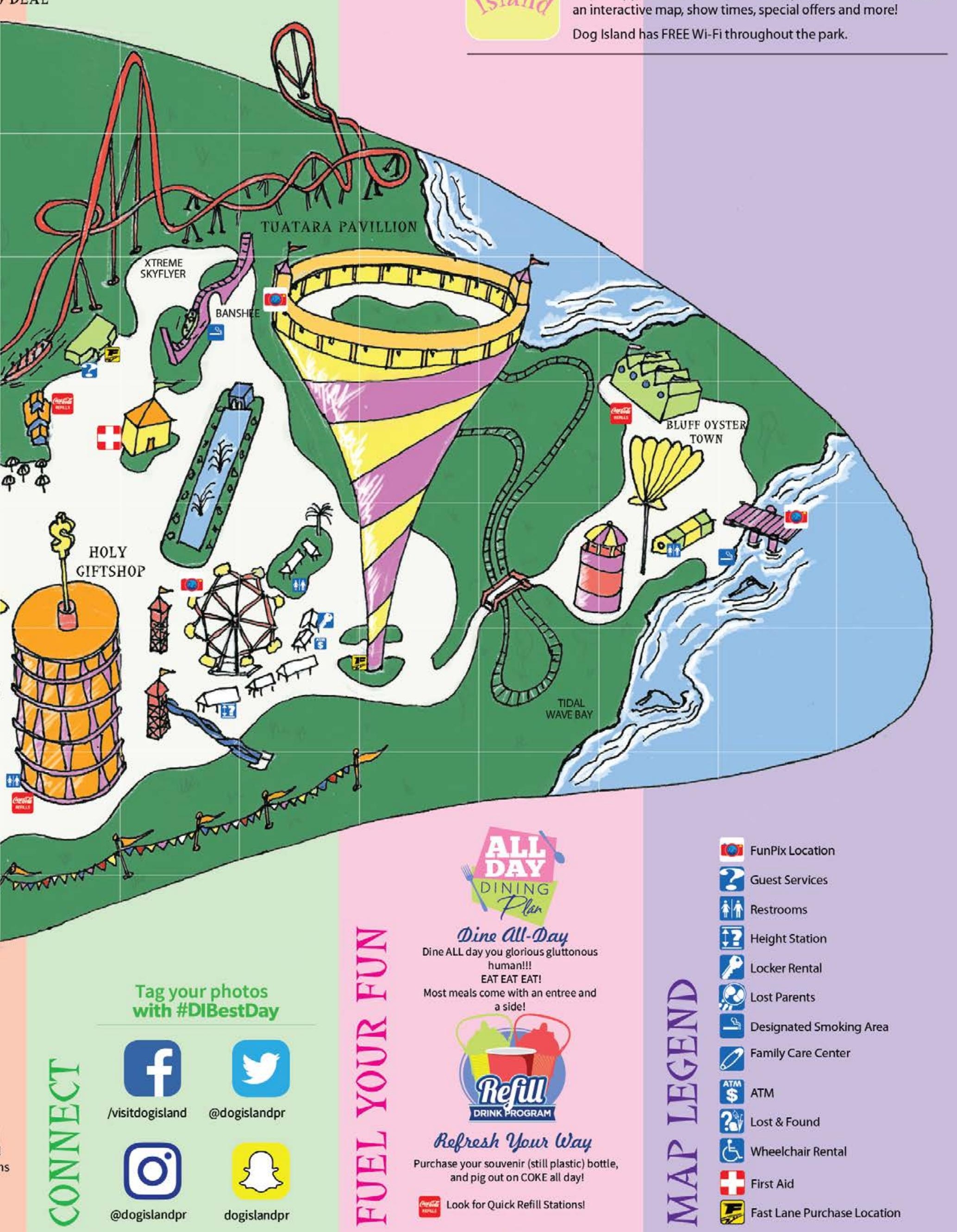



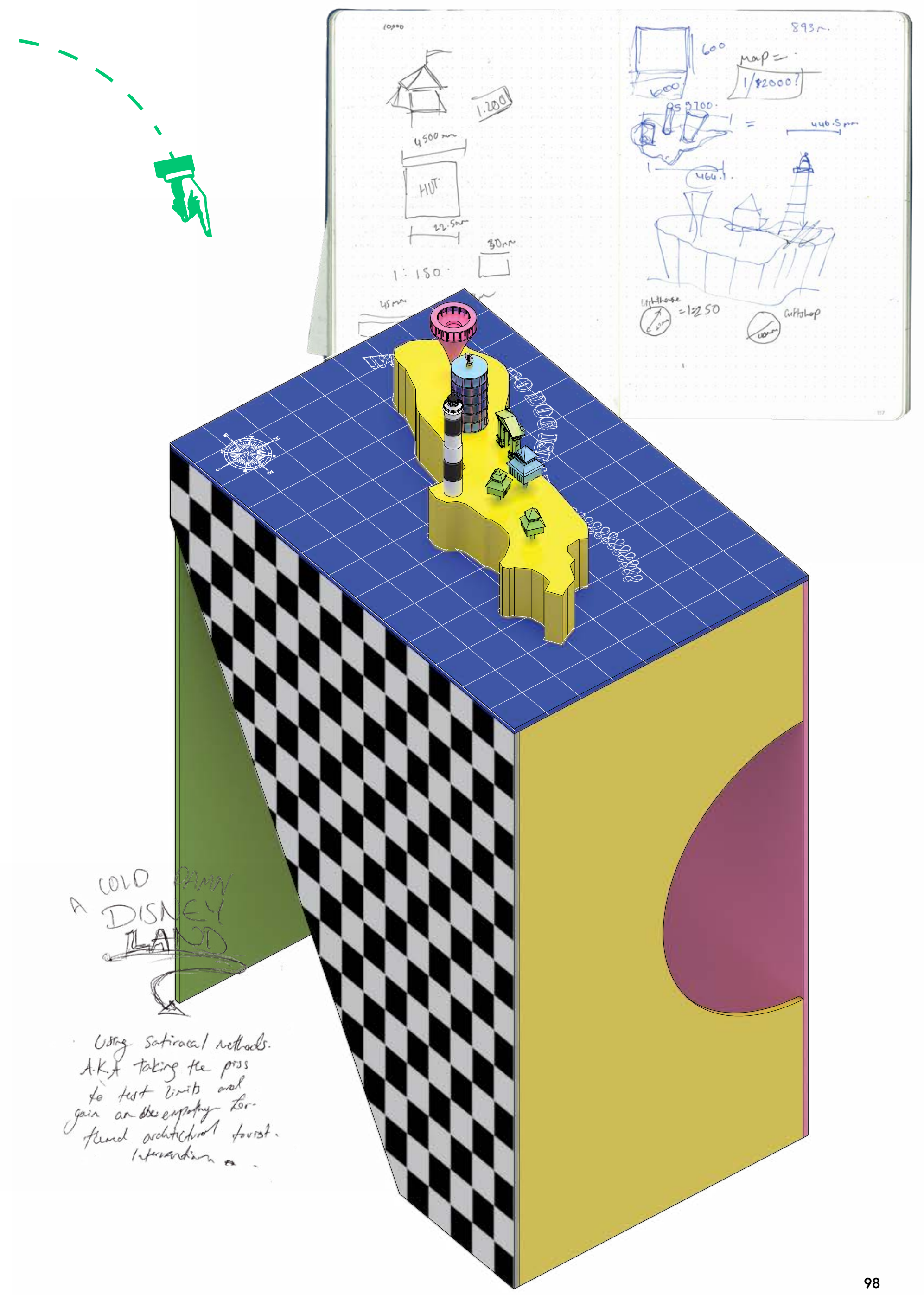




\section{A tourist visually consumes Cold Damn Disneyland...}

\section{IHITS IS $A$ TYUAPARA}

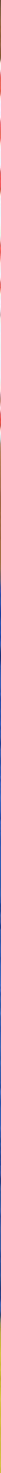





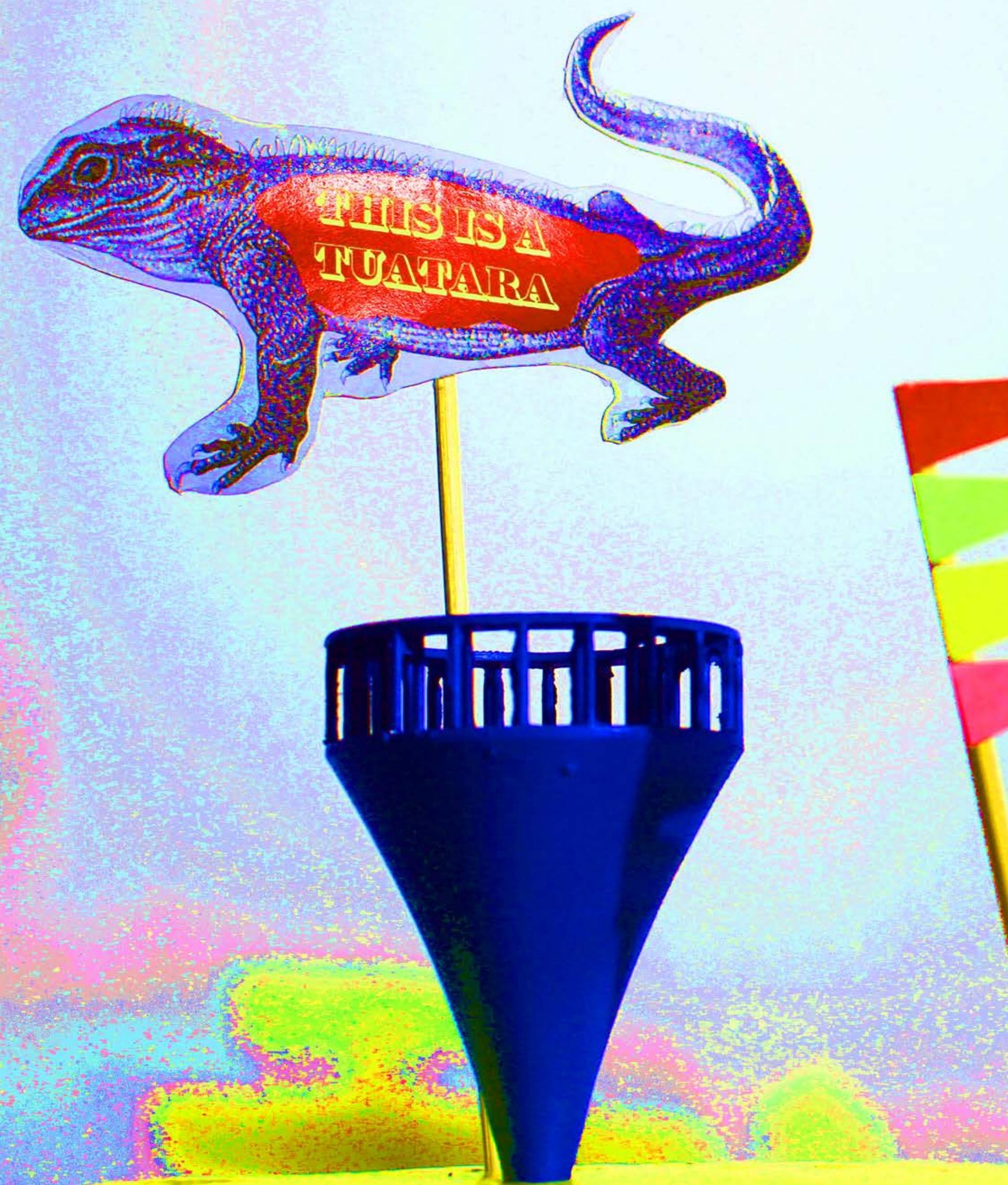




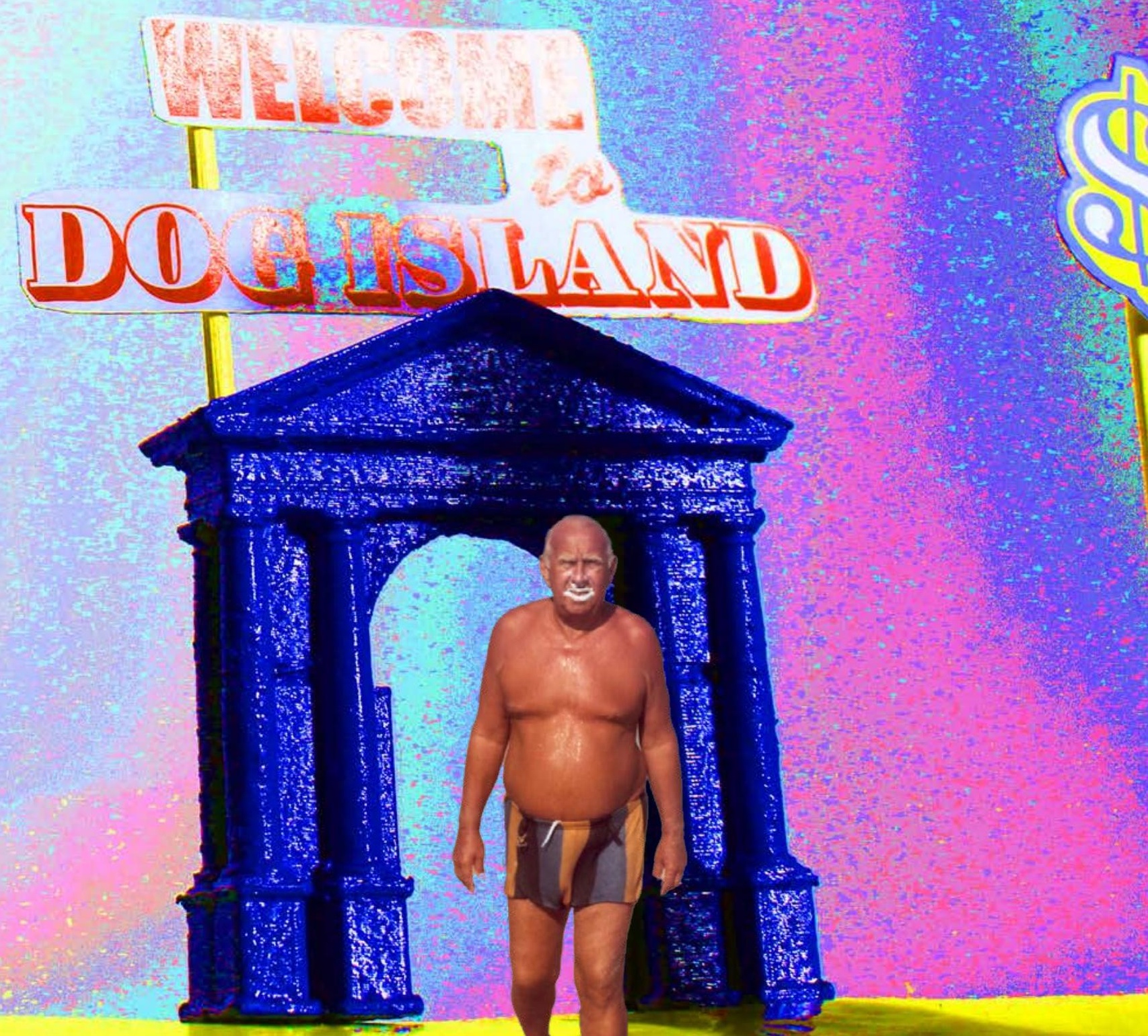



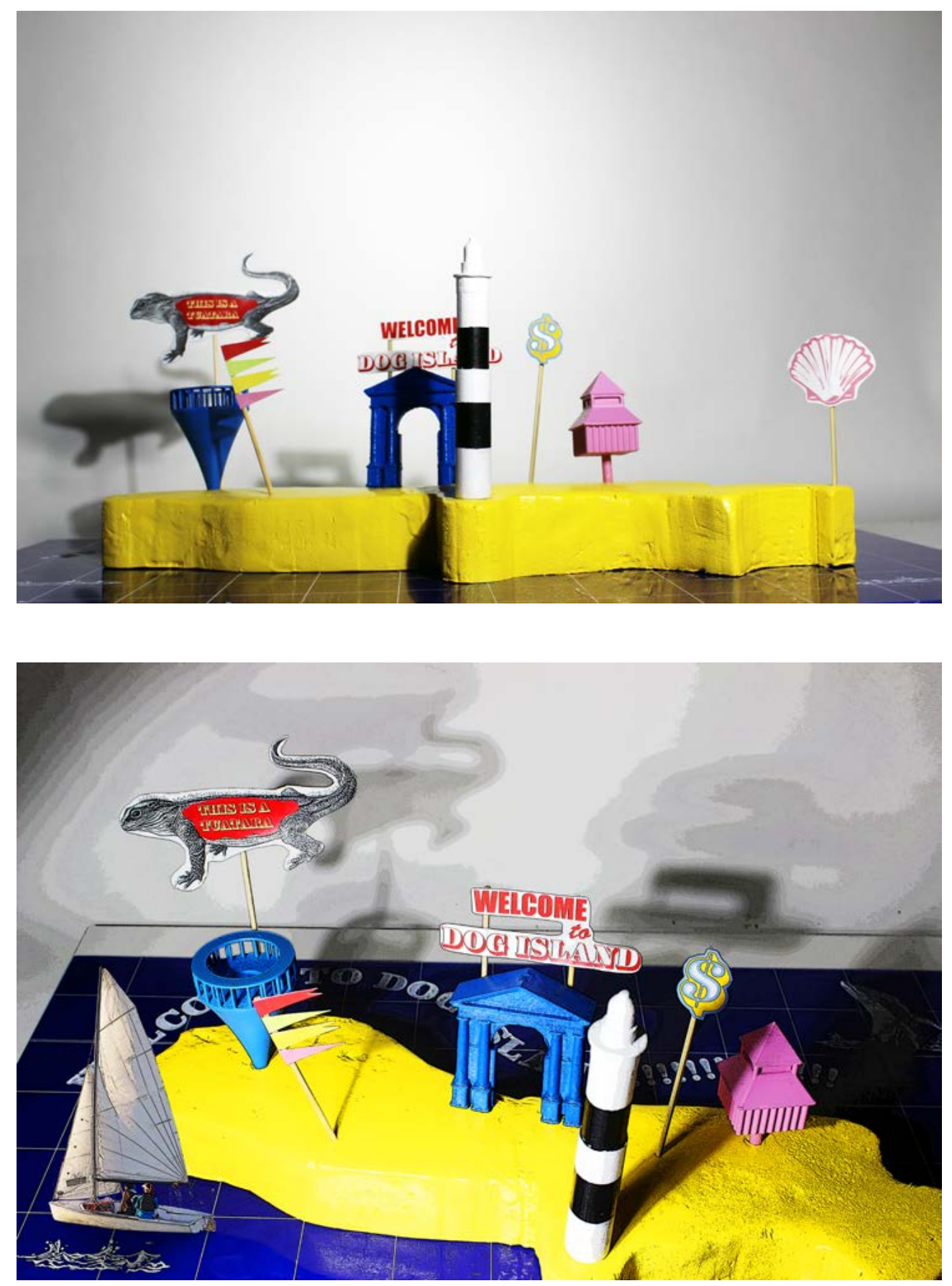

Figure 63 Photos of the physical model of Cold Damn Disneyland, captured with spotlighting, as if it was on its own stage. 

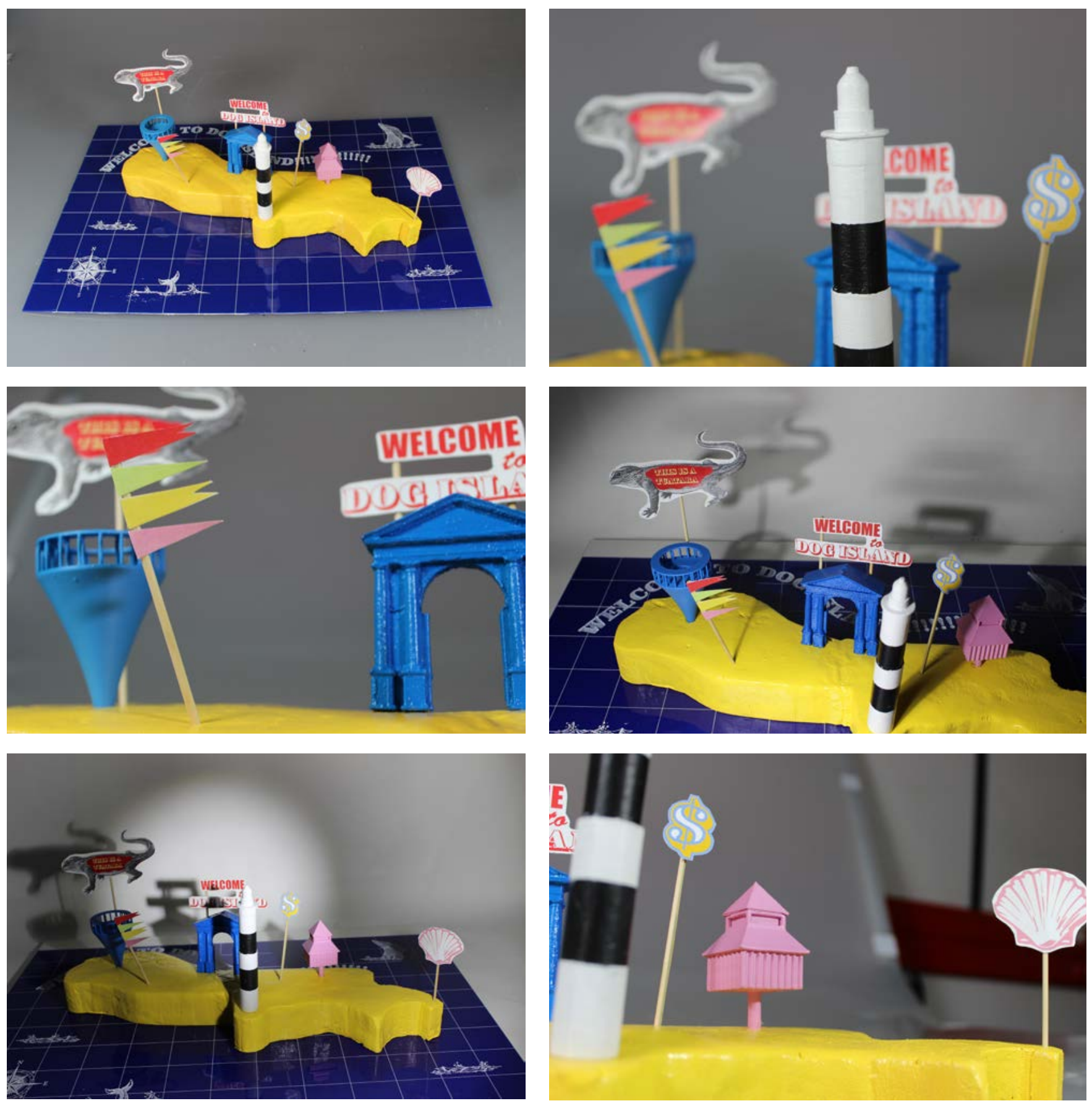

Figure 64 Photos of the physical model of Cold Damn Disneyland, captured with spotlighting, as if it was on its own stage. 

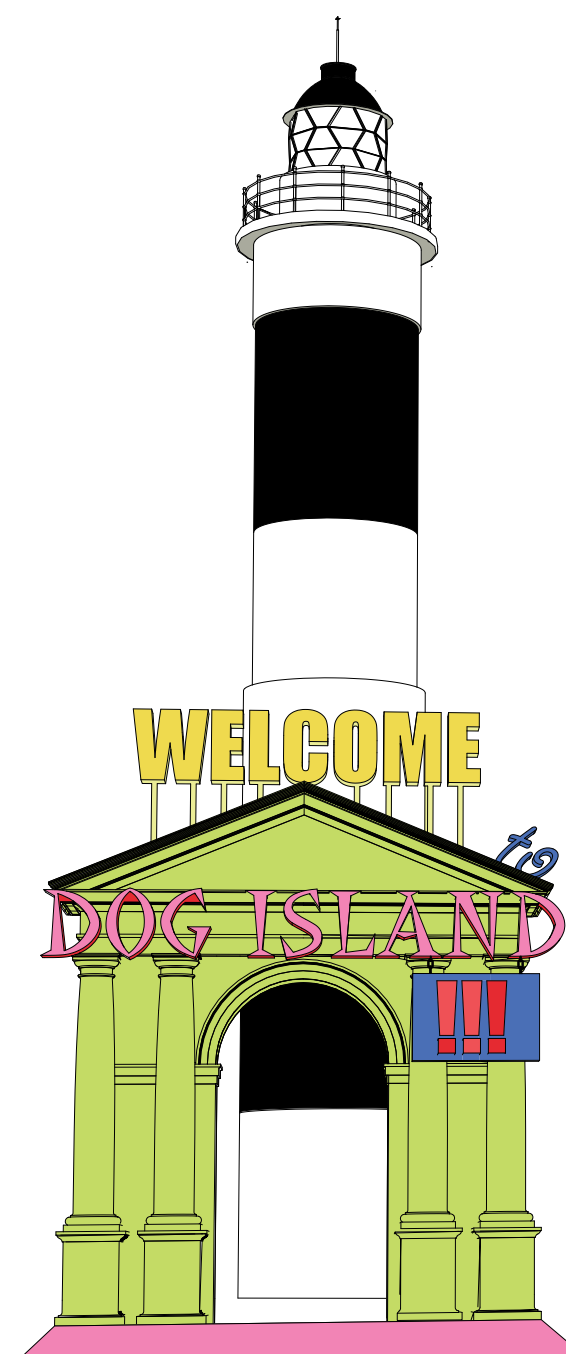


\subsection{CONCLUSION}

For centuries Dog Island has been a vital component of survival in the Foveaux Strait. Fisherman pass the island daily, Lighthouse keepers and their families once occupied the island, now it is a predator-free DOC run island, with one of New Zealand's oldest lighthouses sitting in solitude, waiting. This design phase if anything has been a fun exercise in speculating the ridiculousness of creating a tourist experience at the bottom of the earth in one of the coldest, windswept places in New Zealand. The camp lens has helped explore ideas of globalisation, mass-tourism, Disneyland type experience, and offered options for activating the lighthouse. Drawing on other whimsical, folly like attractions to create a camp stage for tourists to perform. Collage, visualisation techniques and a model has helped realise a fantastical imaginative world, where fun is paramount, where artifice is prioritised and where the tourist is given a stage on which to perform.

The first design exploration considers and interrogates the lighthouse as an object in a collective kitsch/ mass tourism approach. By using tools of exaggeration and satire this visual collection of collages, renders, drawings and modelling can express a 'what-not-to-do' approach under the lens of camp.

The body of work looks at how places such as Disneyland currently operate- then mimics it. Where the place is not only a waypoint on a journey but a destination itself. These destinations tend to never be about one singular 'attraction.' But a conglomeration of small stages to make up one experience. This design phase attempts to speculate how a lighthouse would adapt to this form of context.

This design outcome is undeniably "over the top" but it does achieve its goal of camp, through the silliness. In this design exploration, I am asking the person consuming this design to look past and see the irony of touring and place. It prefers a situation where the tourist is supposed to be observing the lighthouse, but instead, they are only seeing it as another attraction in the whole conglomeration of 'stuff'. While using camp, a degree of flaw is required. The work does not offer much to the viewer about the lighthouse however, in a way lacking a proper authenticity behind its manifestation, in that sense, I believe the design fails at being a proper camp architecture.

Moving forward into the second logic, we now attempt to remove the camp lens and begin looking at the lighthouse more seriously without the artifice to question the camp lens. Once the crux of the lighthouse has been identified then the camp may be put back and a final design can be completed. 
at the end of the world, I found.....
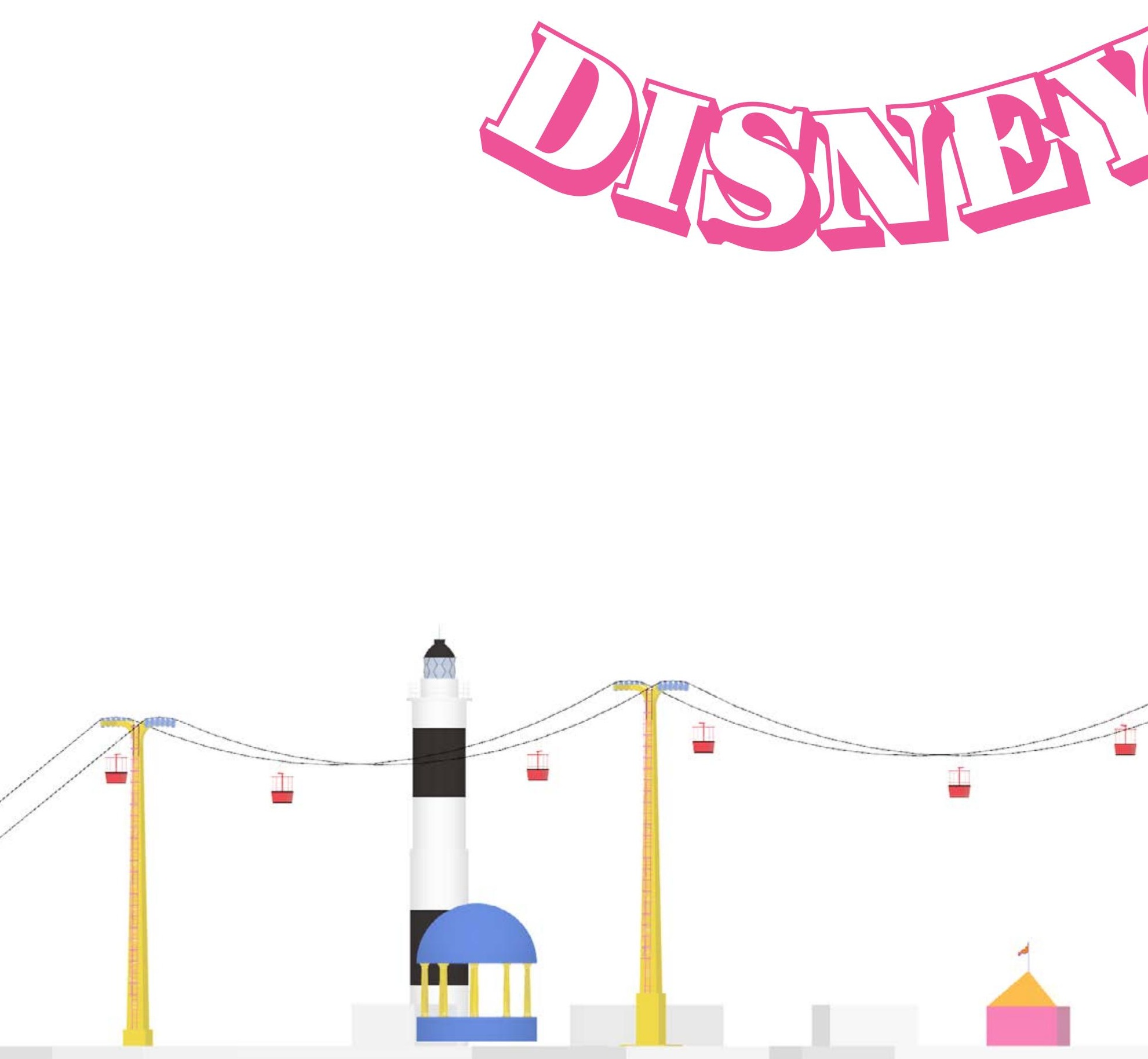


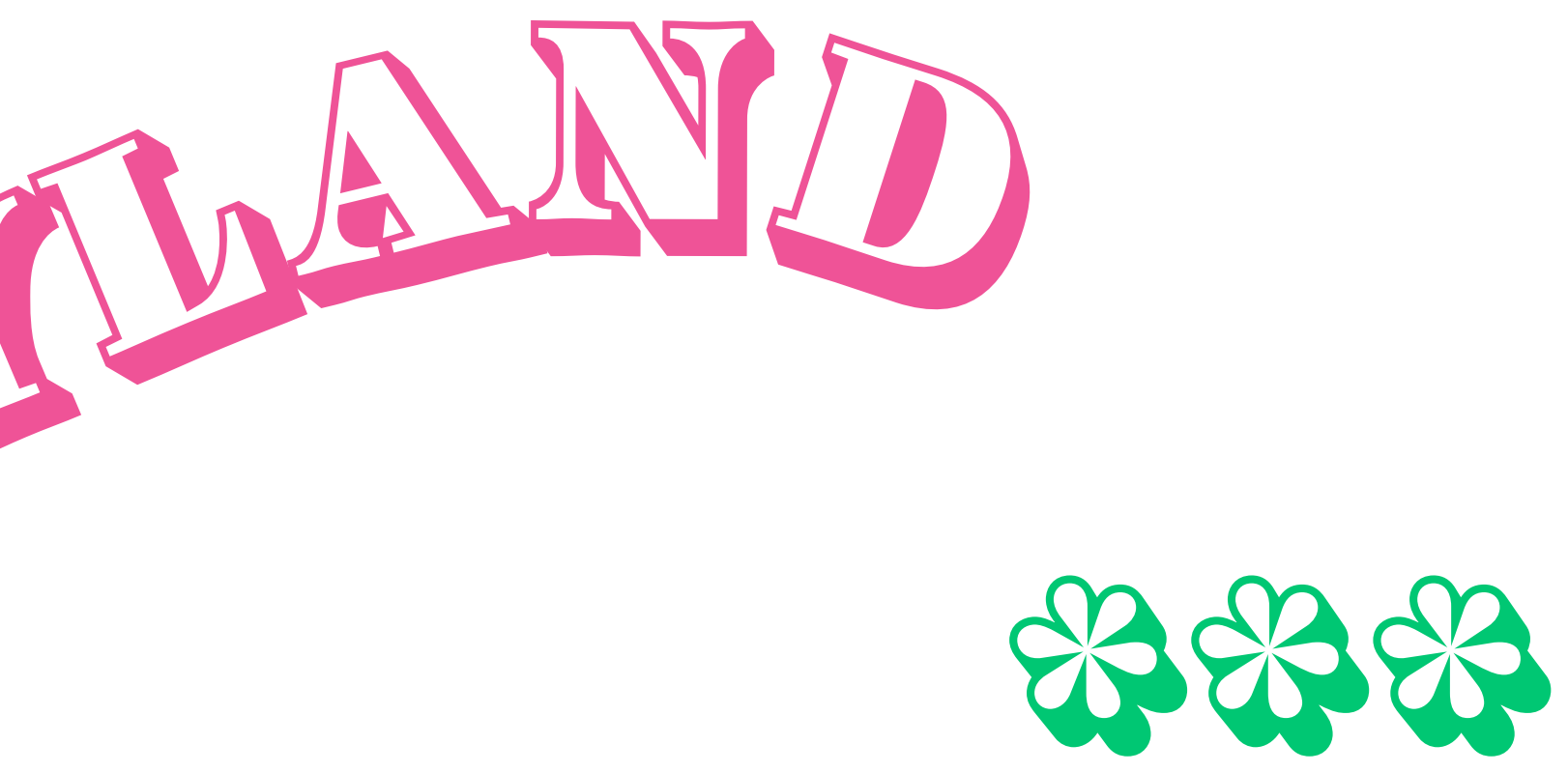




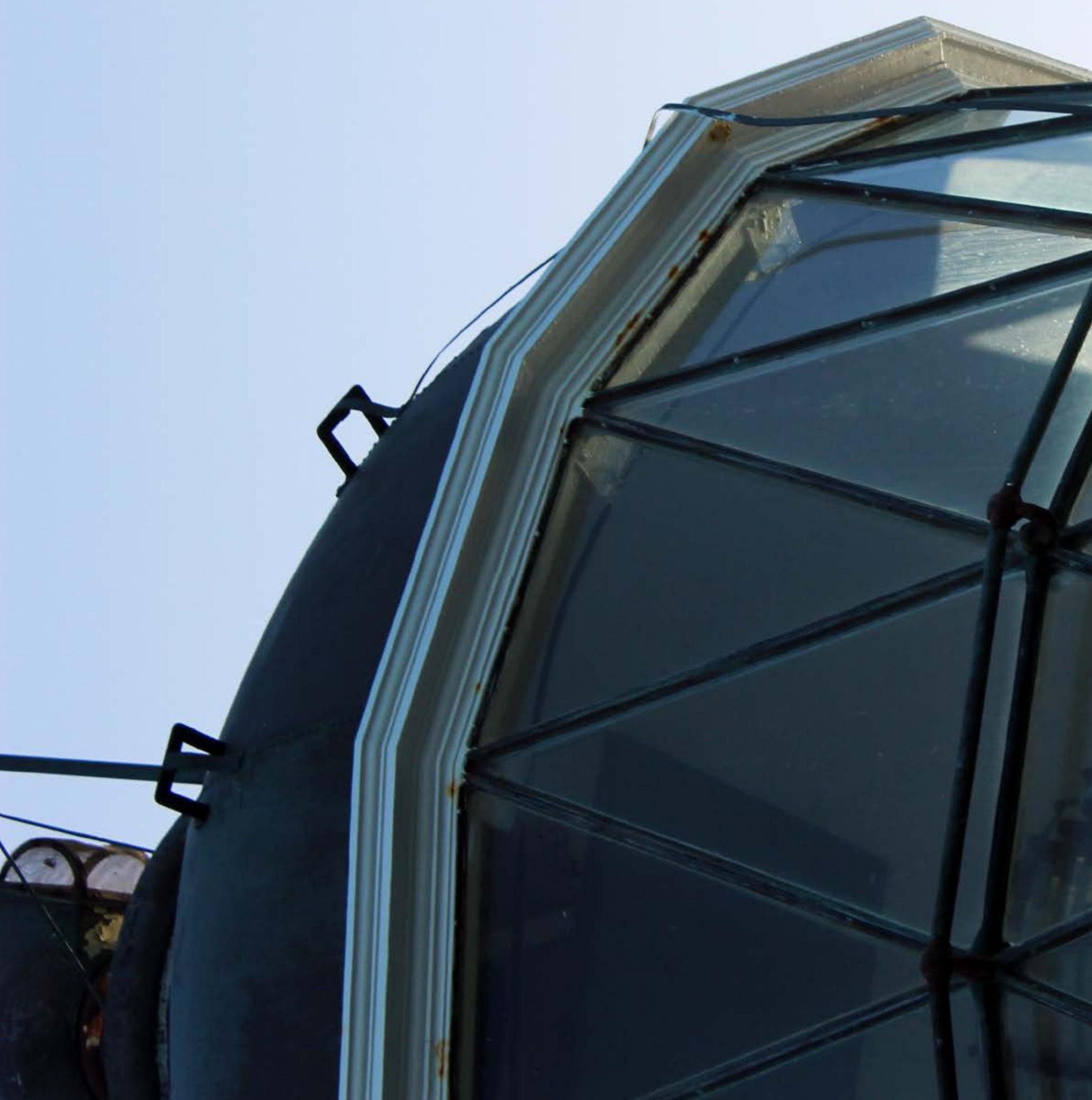




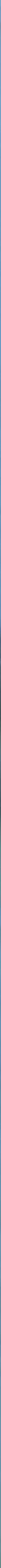




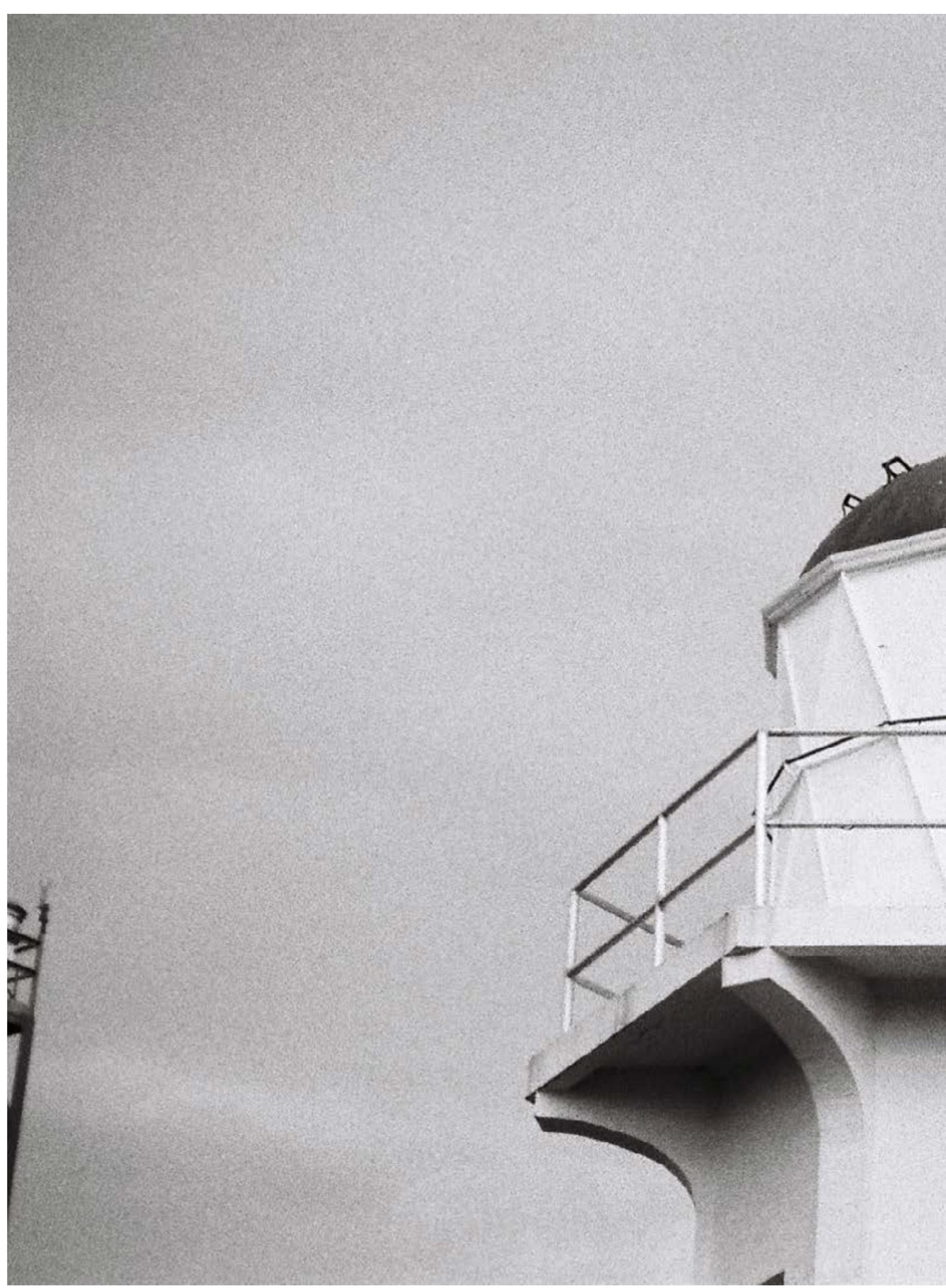




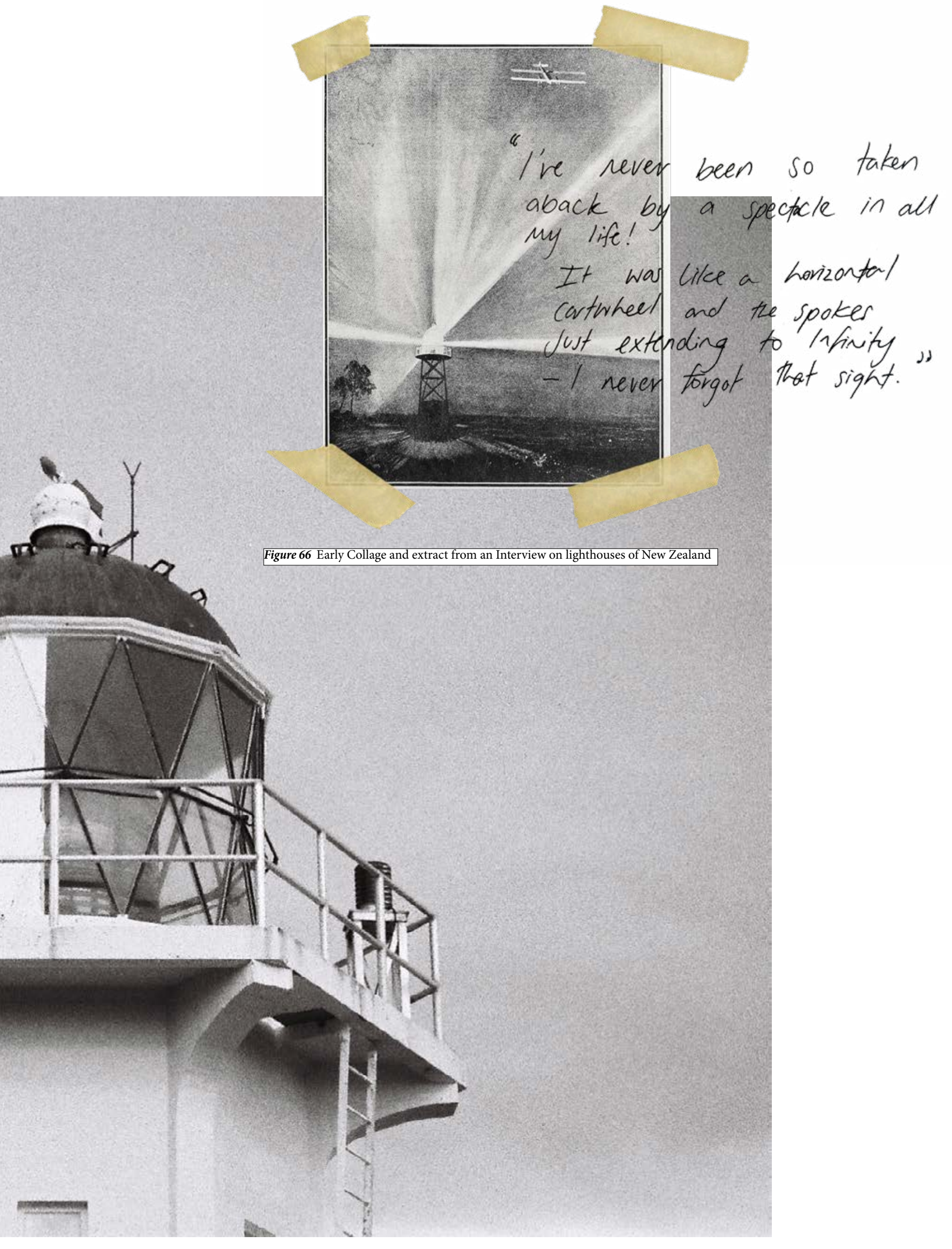




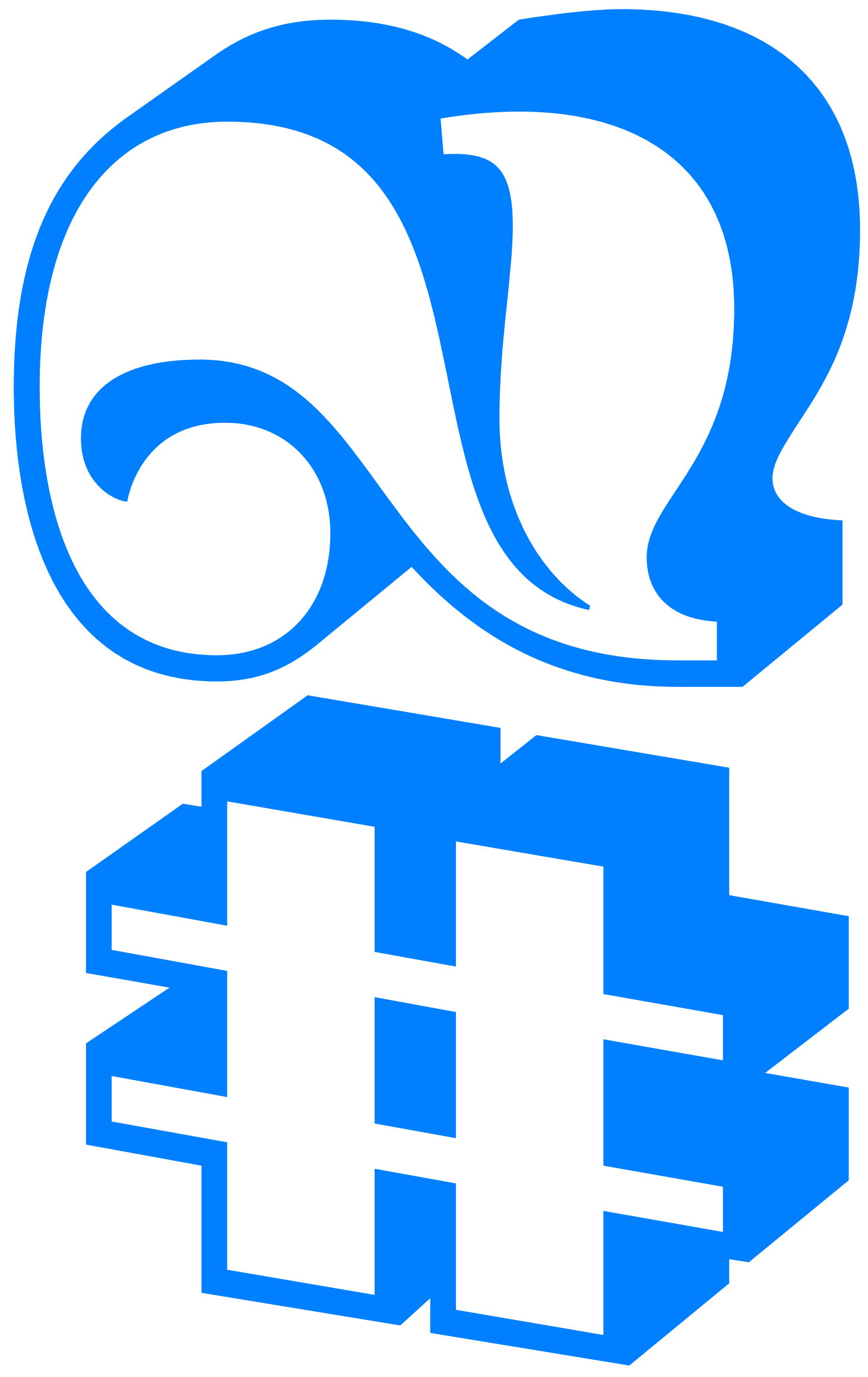




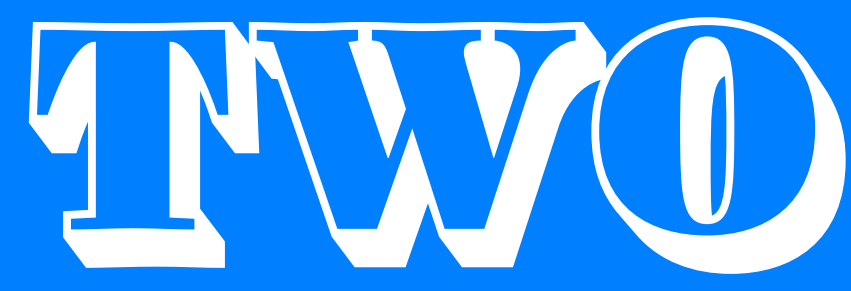

\section{"The Light Device"}

The Camp lens is removed, the lighthouse is revealed without artifice, a.k.a anti-camp. 


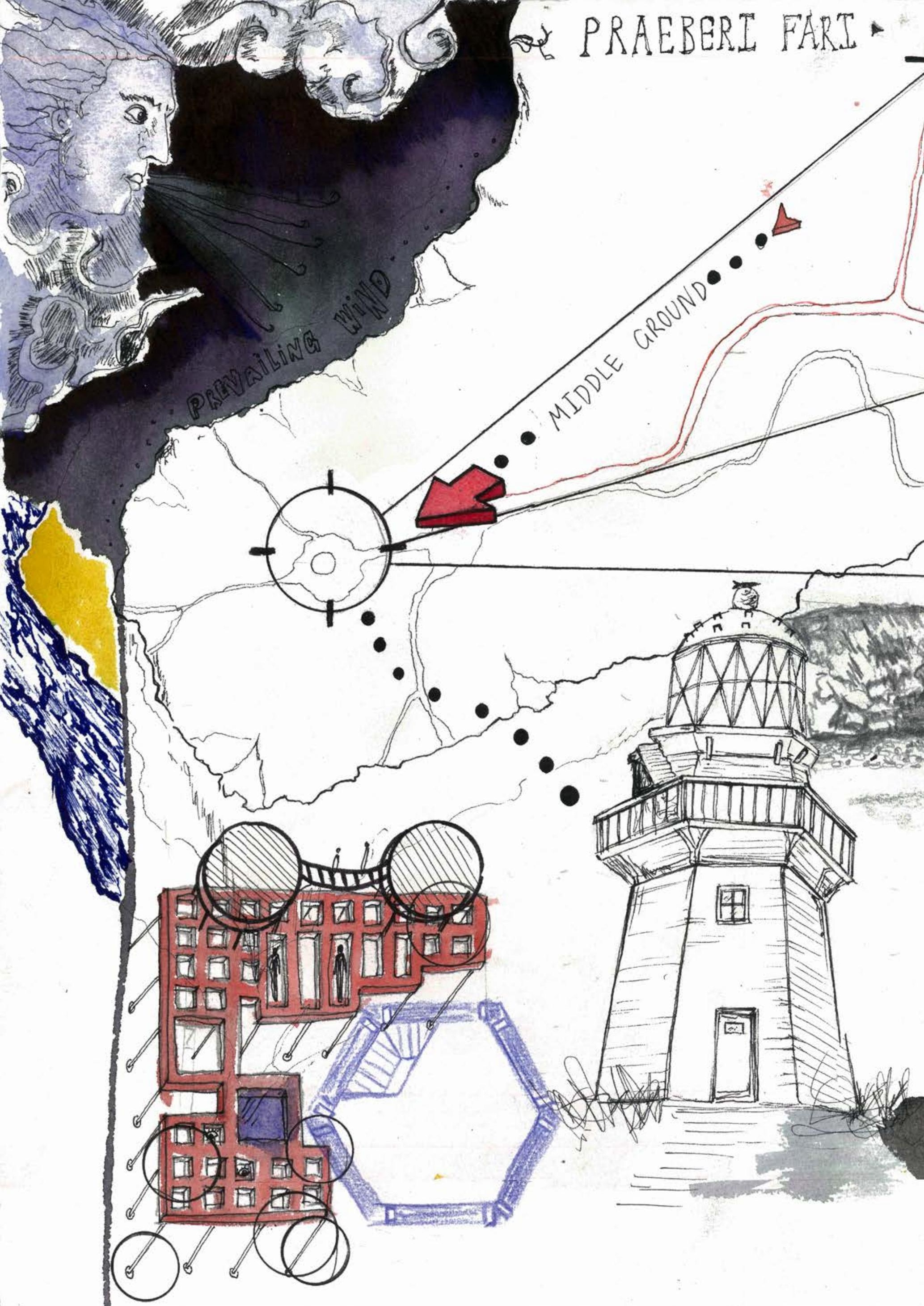




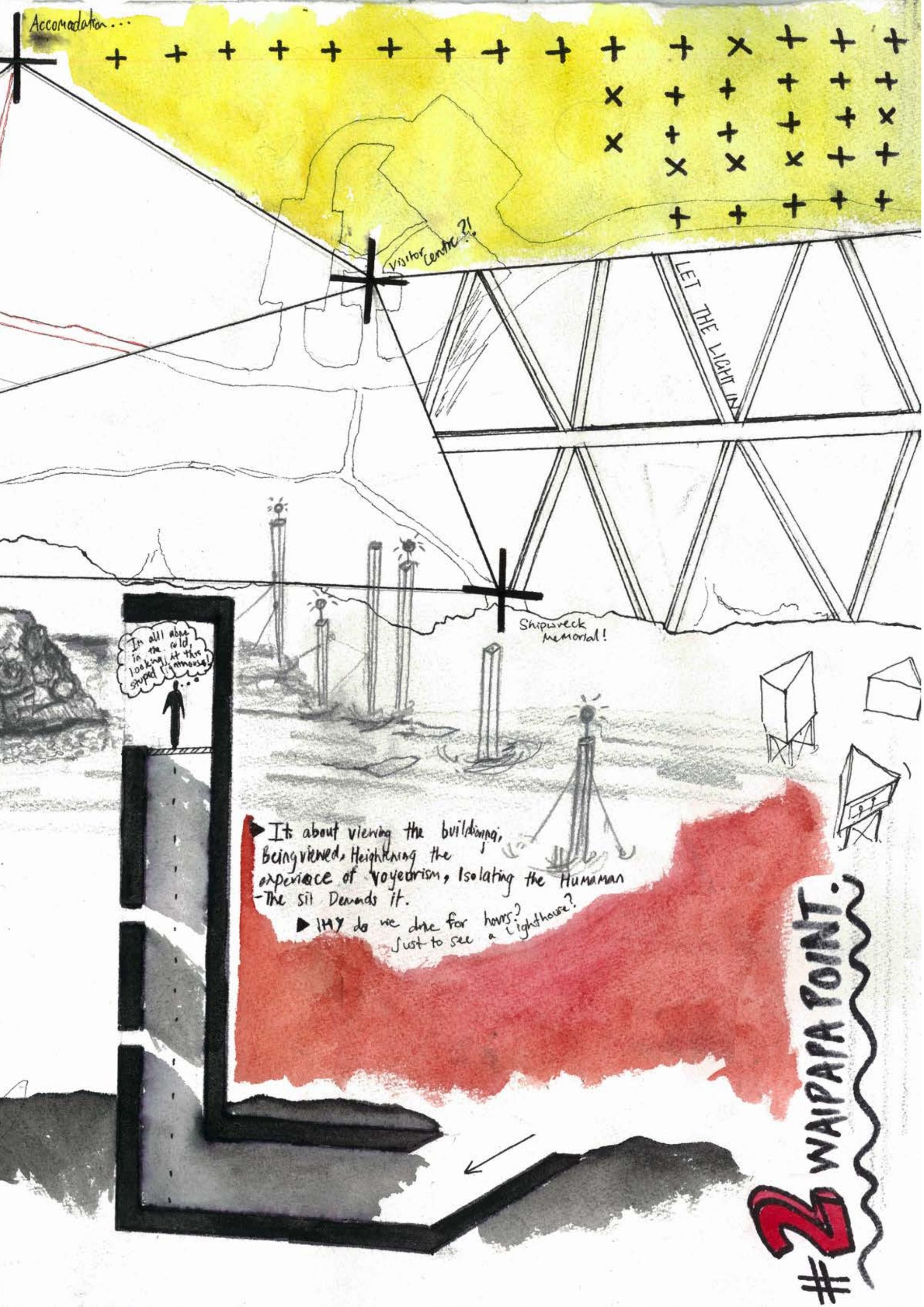




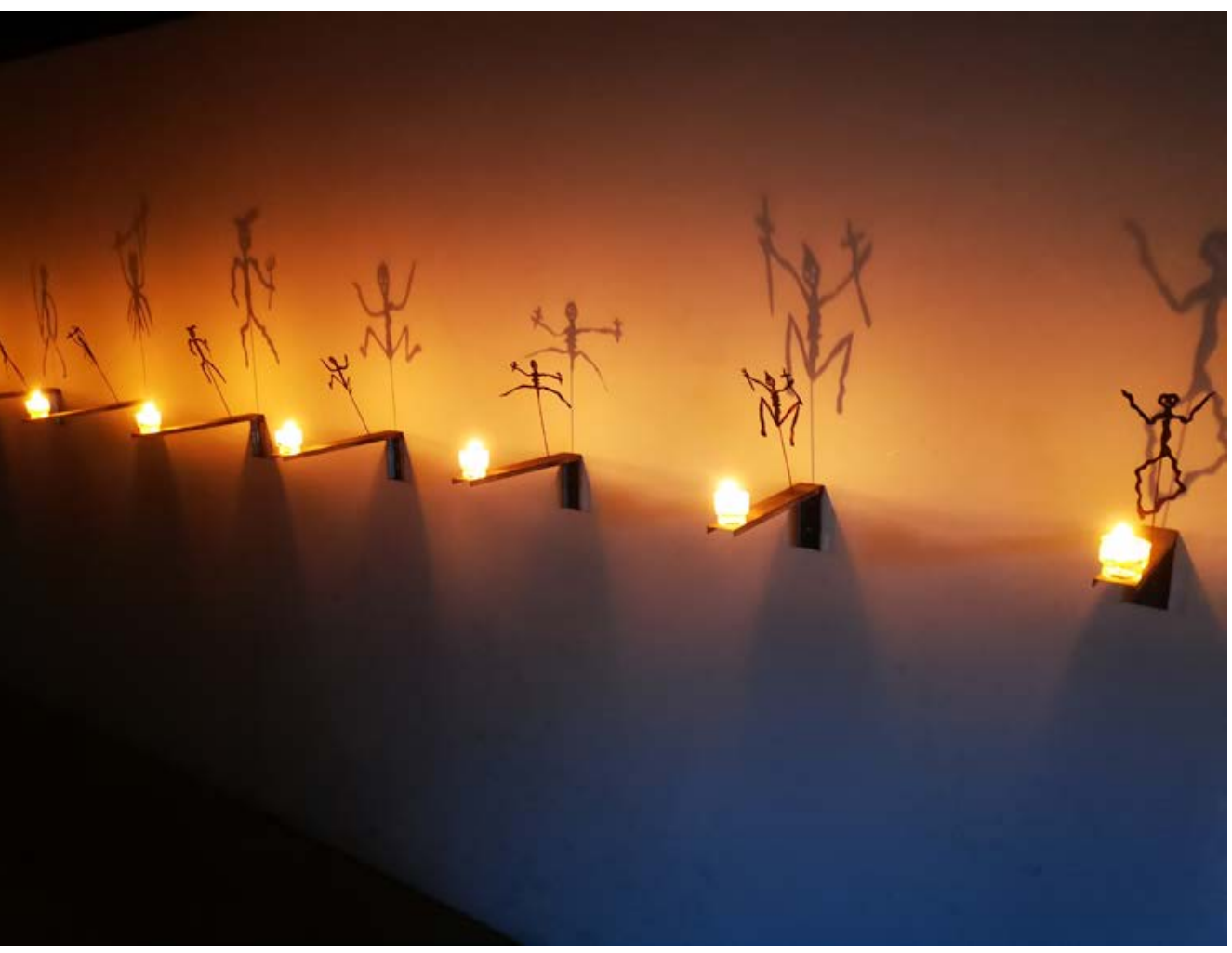

Figure 67 A shadow play by Chrisitan Boltanski, "Vanitas" within the crypt of Salzburg Cathedral, 2019 


\subsection{INTRODUCTION}

In this next phase of design, I challenge the camp lens and remove the artifice, turn the lights off to hide the whimsy and focusing on what makes the object (the lighthouse) so unique. The anti-camp is used to explore the light of the lighthouse and the act of the tourist gazing and performing. Phase Two is an interrogation into the aspects of a lighthouse, its crux, a closer look at the elements that run throughout this whole body of work.

The act of the performer, which in this tourism context is generally taking the photo and visually consuming through the photograph is explored. Light and the photograph is the primary elements while the visual nature of the lighthouse's architecture is reduced, and what is left is just its light source. Photography in this thesis is a direct record of things in the world, a method to register the forms of desire. It is a process of two way looking: looking at, and being looked at. Phase two uses photography as the documentation process and to experiment with darkness and light. To take photographs is not to take the world for an object, but to make it an object, to exhume its otherness buried beneath its alleged reality, to bring it forth as a strange attractor and pin down that strange attraction in an image.

This section consists of 3 design exercises, each building on, but looking at using architecture, and representation methods to convey the idea. The lighthouses light was examined and architectural ways light is manipulated was explored. The end goal of these exercises was to look at architecture and visually consume, without the filter of 'Camp'. By doing so the explorations collectively offer a deeper look at the light, and how to bring it through to the final design phase when the camp lens is reinstated.

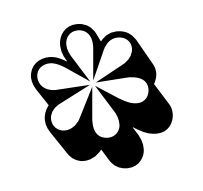



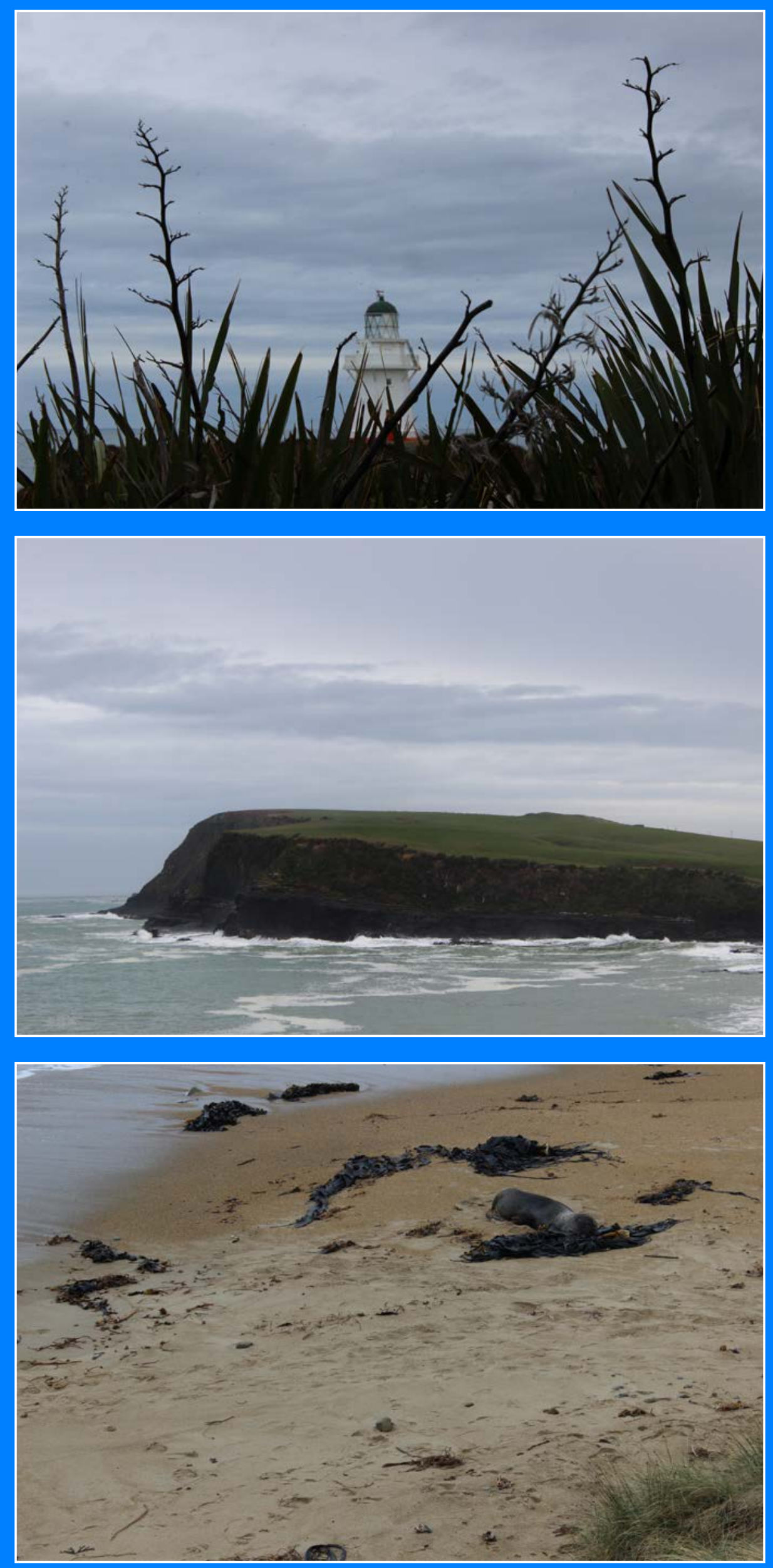

Figure 68 Authors photos as part of an earlier field trip, showing site conditions of Waipapa Point 

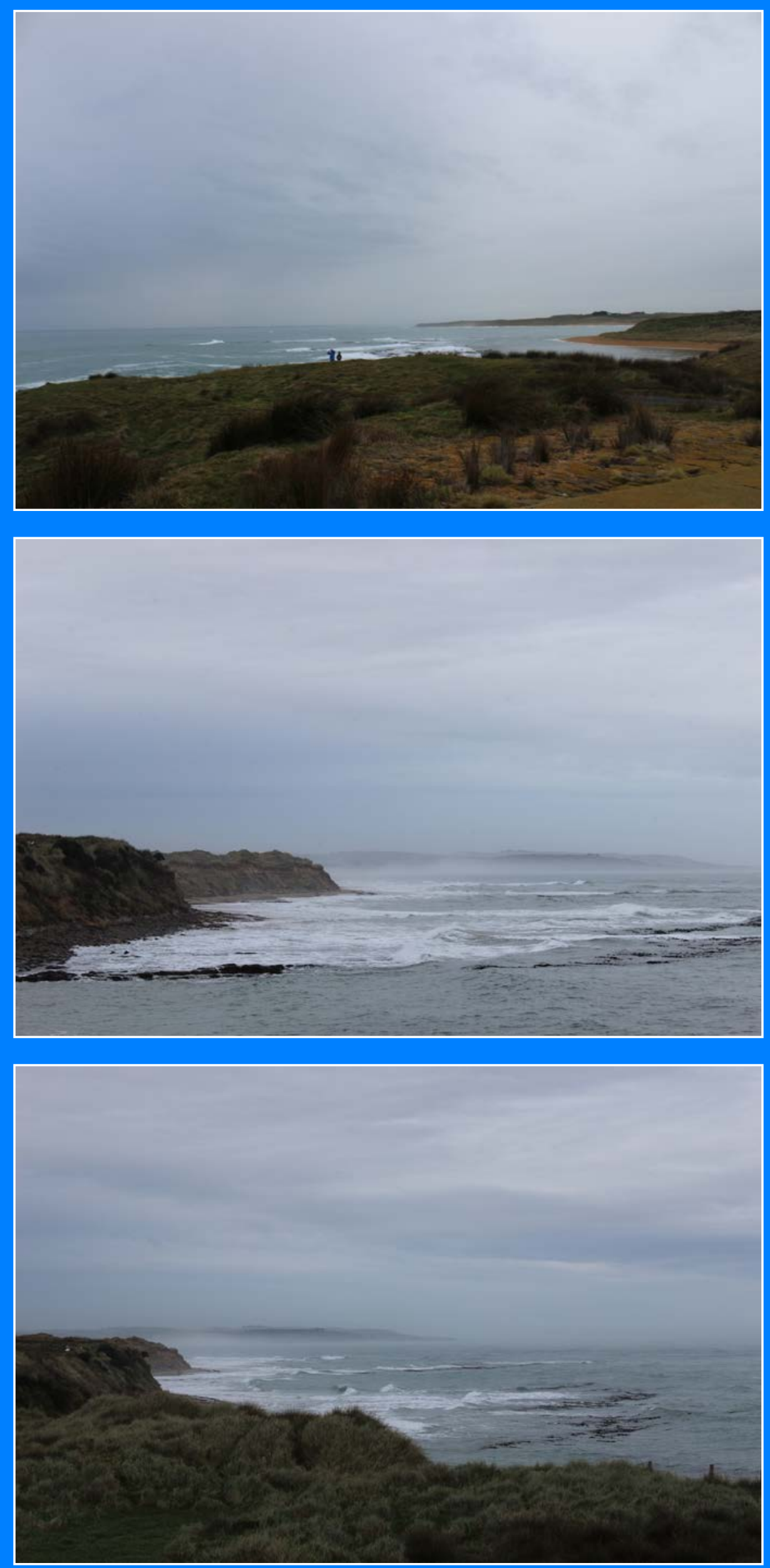

Figure 69 Authors photos as part of an earlier field trip, showing site conditions of Waipapa Point 


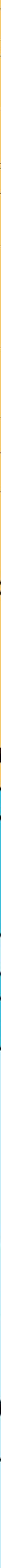




\subsection{WAIPAPA POINT}

Waipapa Point marks the eastern entrance to Foveaux Strait, originally not considered a place to establish a lighthouse. Following, one of New Zealand's worst maritime disasters, in 1881, The Tararua hit a reef off Waipapa Point resulting in the death of 131 lives, there was a change of mind and in 1884 the wooden lighthouse was erected (Churchman, 1989). The site, like most lighthouse locations, is isolated, an hours drive away from any established settlement. Here there is a sense of wilderness still, the sea is relentless, its sky is always overcast and the only sign of life, a colony of sea lions, roam the sand dunes and rocks.

\section{A note on site:}

Site throughout this thesis has become less and less about geographical location and more about the place. This site is the lighthouse, everything else is secondary. The aspects of the site, the tangible and intangible elemental qualities add to the human experience of the observation of a lighthouse.

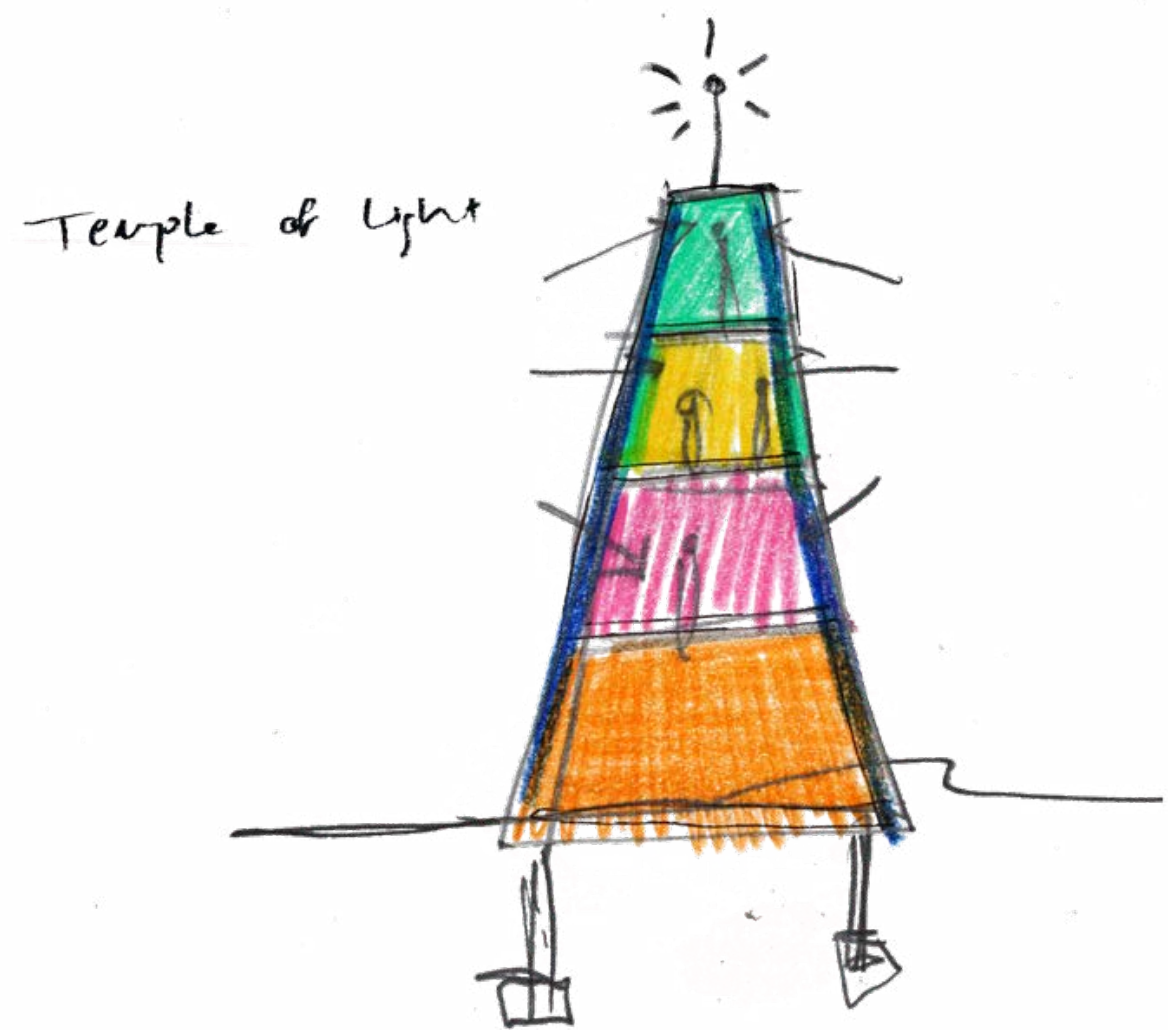

Figure 70 Temple of Light. A preliminary sketch of an imagined building that projected its own light. 


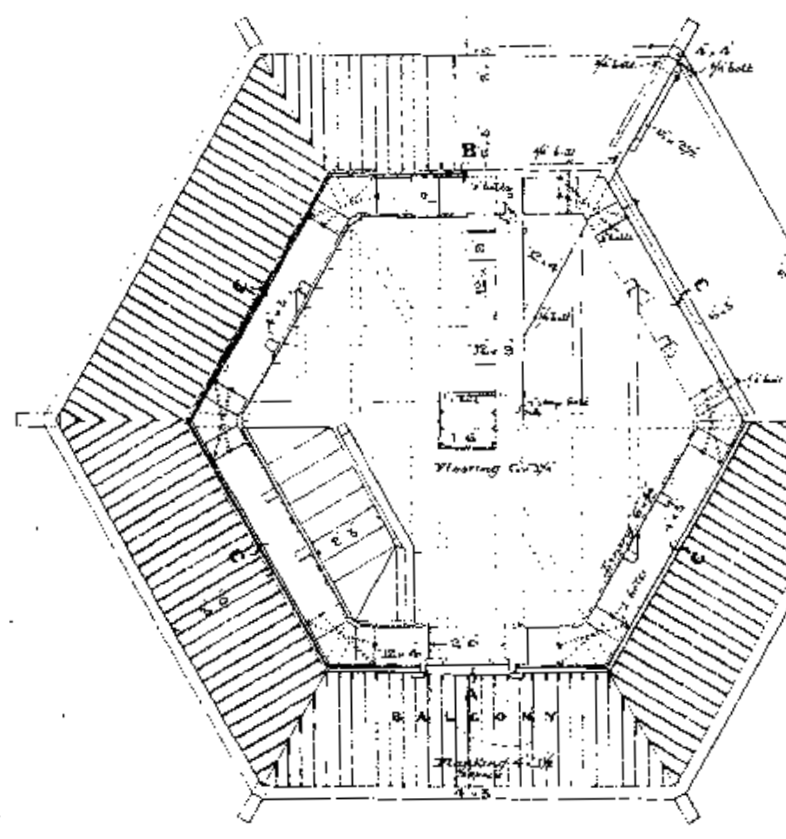

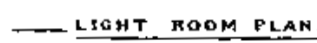

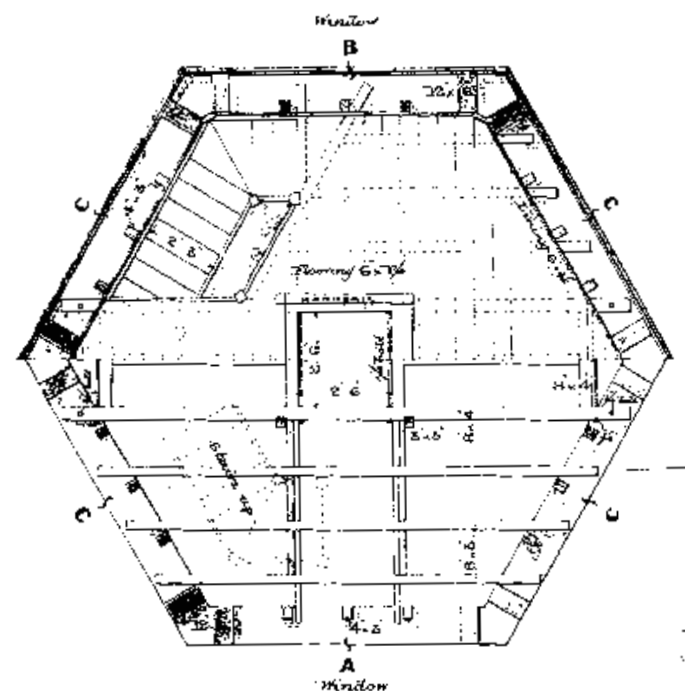

- FIRST FLOOR PLAH. -

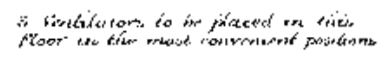

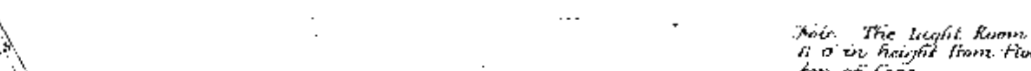

bo of ropor
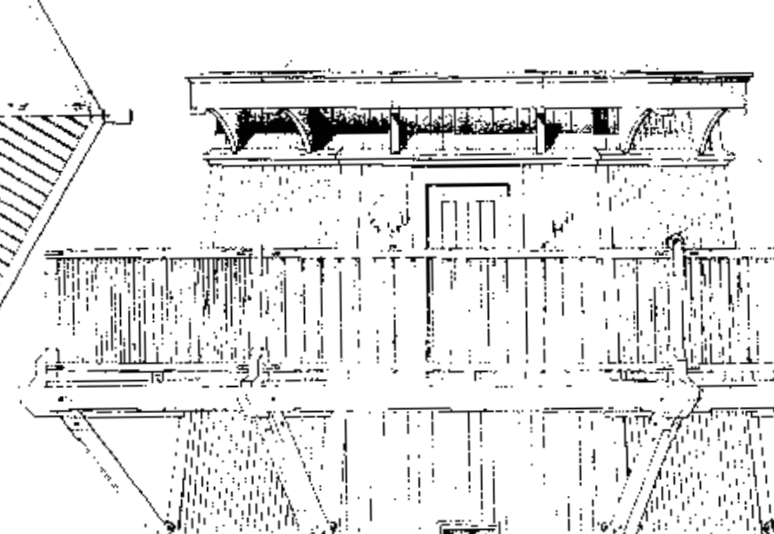

1.
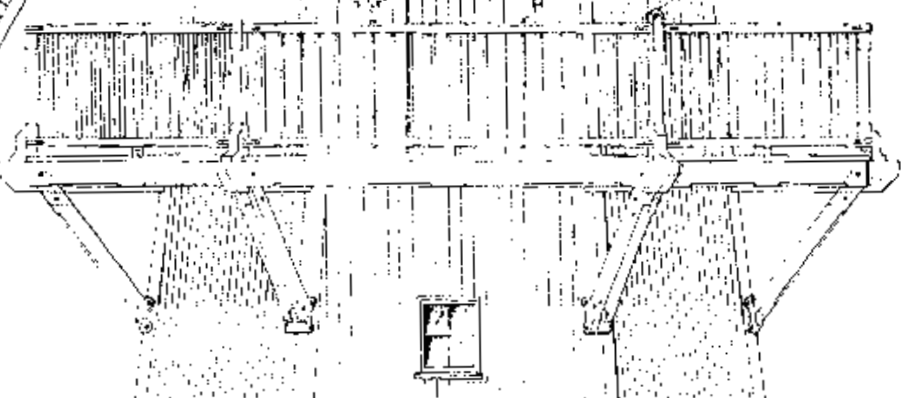

$\because$

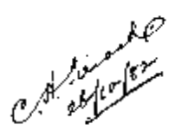

- o.eober $2 A B 2$
-

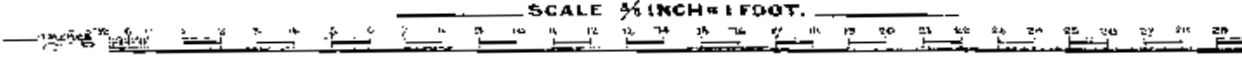



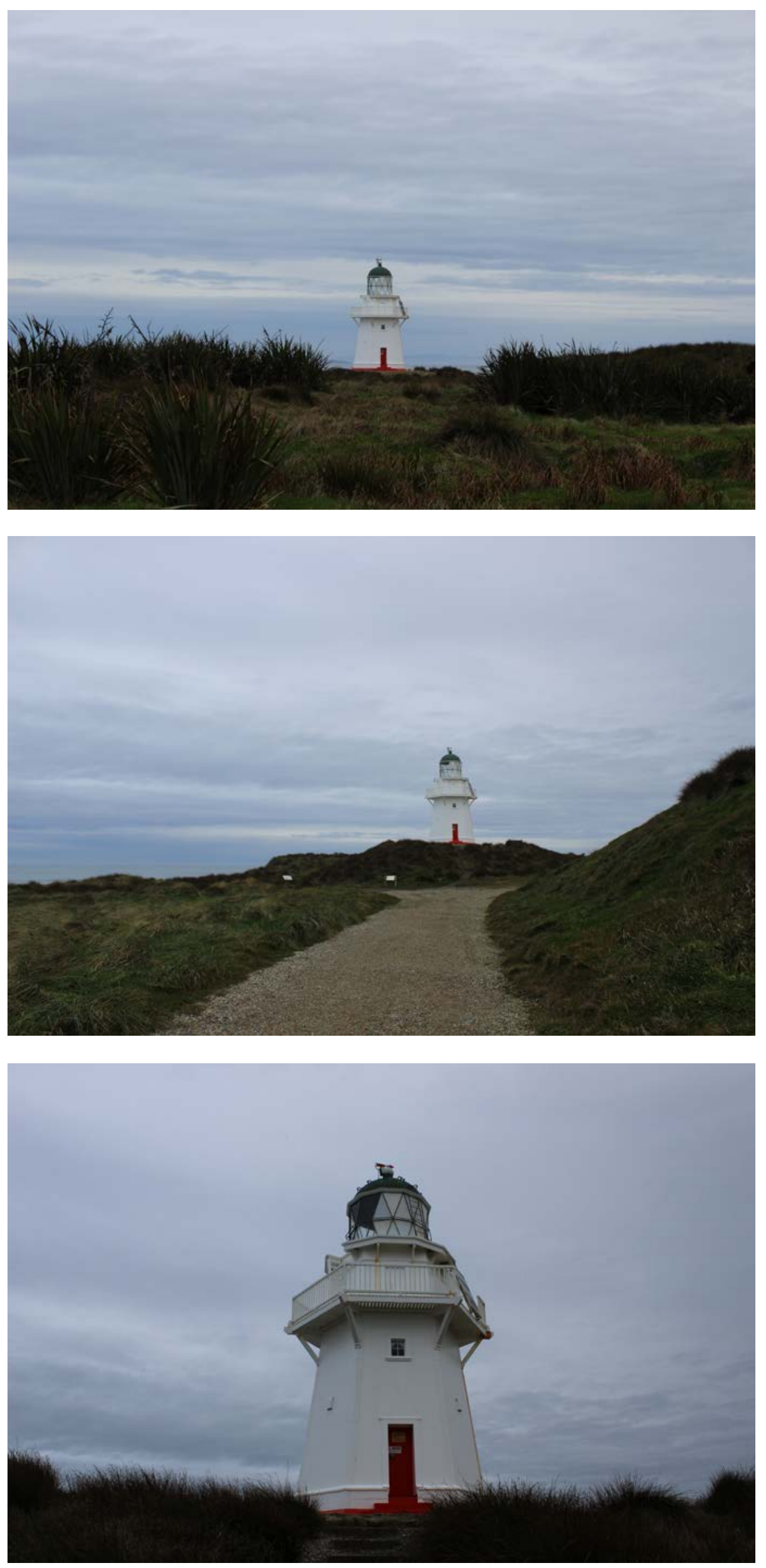

Figure 73 Authors own photos of Waipapa Lighthouse on an overcast day 


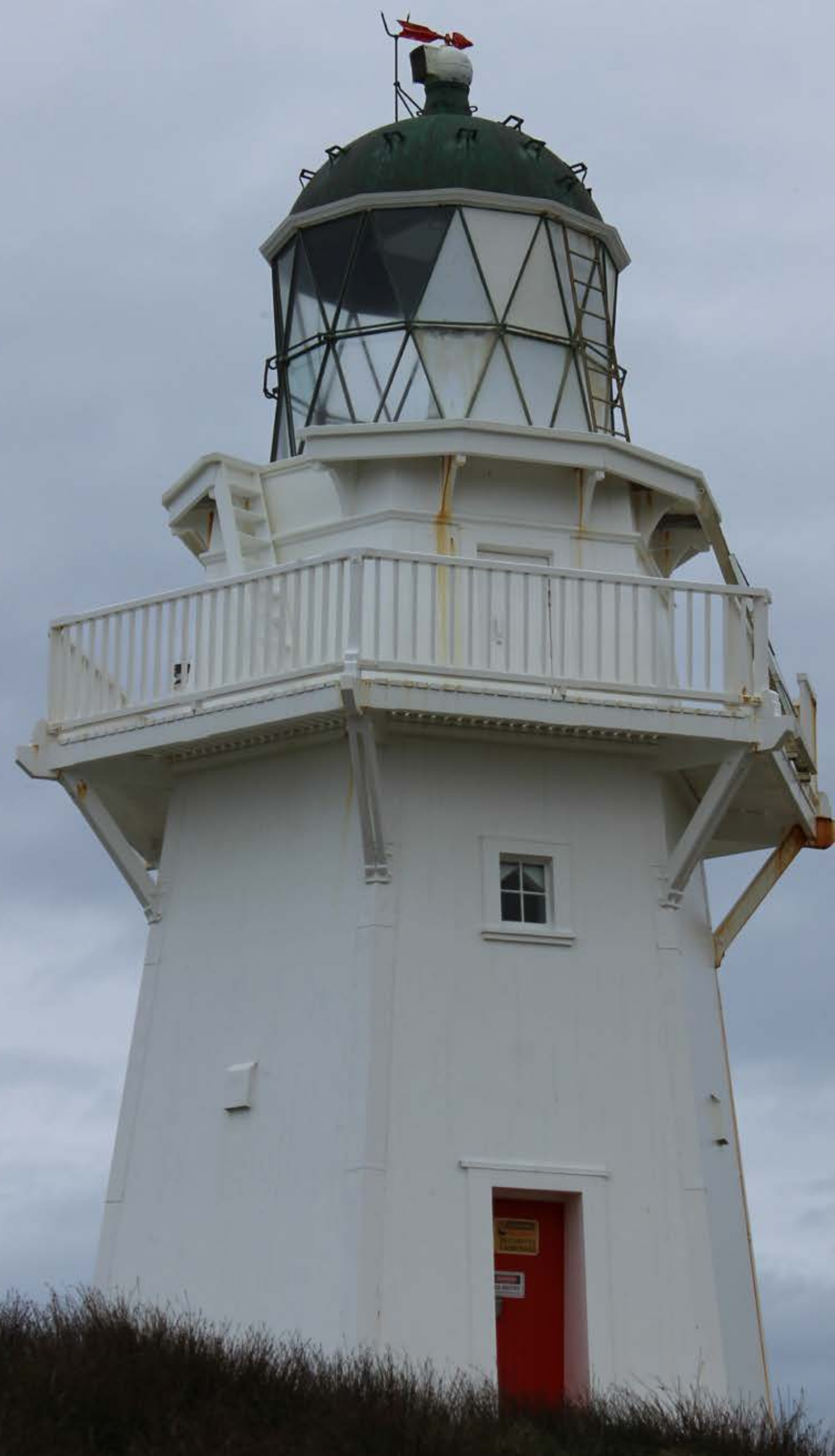

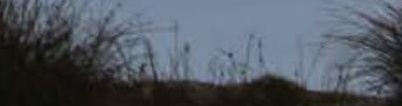




\subsection{KEY THINKERS}

Two key thinkers, Anne Noble, a New Zealand photographer and Diller + Scofidio, New York architects are the theorists that grounded these explorations.

\subsubsection{ANNE NOBLE 'ICE BLINK'}

Anne Noble is one of New Zealand's most notable and widely known photographers. Her substantial body of work spans landscape, documentary and installation. Sheoften works in series, enabling her to explore the medium and its possibilities in great depth (Anne Noble | Arts Foundation Laureate, n.d.). Since 2001, she has been researching and photographing Antarctica. In a project that has taken her to Antarctic centres all over the world as well as Antarctica itself, she explores the cultural construction of place and how our knowledge of such places is shaped through representation and imagination. Her images challenge the traditional depiction of the Antarctic landscape as heroic, picturesque or sublime and seek to suggest some of the current complexities that underlie the region's beauty. She compiled a selection of her works in a book titled 'Ice Blink' (Noble et al., 2011).
"When we look at Antarctica, from the deck of a ship, or in a make-believe tableau, and fix it in our gaze, what we see is a figment of the imagination. The sight we encounter is a sight already seen, image upon image fixed in the shadow of our dreaming by the medium of photography itself" (Noble et al., 2011,p. 126).

This content is unavailable.

Please consult the figure

list for further details. 
Noble's Ice Blink' plays on notions of simulation and simulacra, a copy of the original without the original, which is seen when she juxtaposes a photo of Antarctica against a photo of the Antarctica Centre in Christchurch. Her work asks questions of authenticity, what is a real representation and most importantly through the visual method of photography. Noble toured Antarctica and what we are seeing is Antarctica through the eyes of her, and we know when we look at her images what it felt like for her, we get a sense of what we think it sounds like, the chill, the white.
This content is unavailable. Please consult the figure list for further details.

This content is unavailable.

Please consult the figure list for further details. 
TURN THE LIGHTS OFF!

The Lighthouses light is examined and architectural ways light is manipulated is explored. The end goal of these exercises was ultimately to influence how the final design manipulates the light using architecture to create an experience, a stage for tourists to perform upon. Shadow and light play was the main driver along with photography and manipulation tools to discovering the crux of the lighthouse, and find an authenticity, without the camp lens. Turn the lights off! 


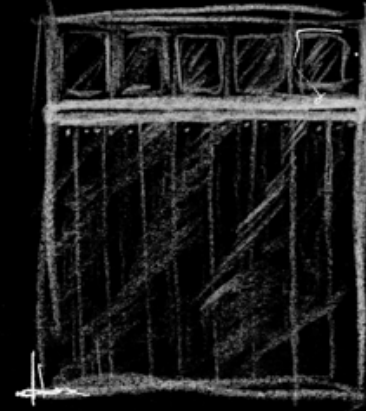
light blocks, in a timber
(glass) (bricks) bed room.

- dissipate the lisht. Second hand. -let ve sleep.'

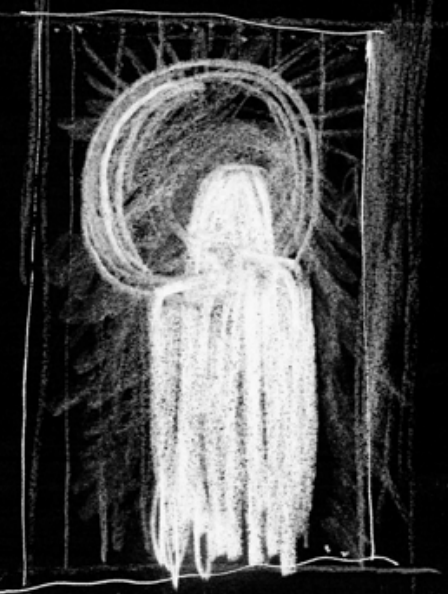

I'm not soved.
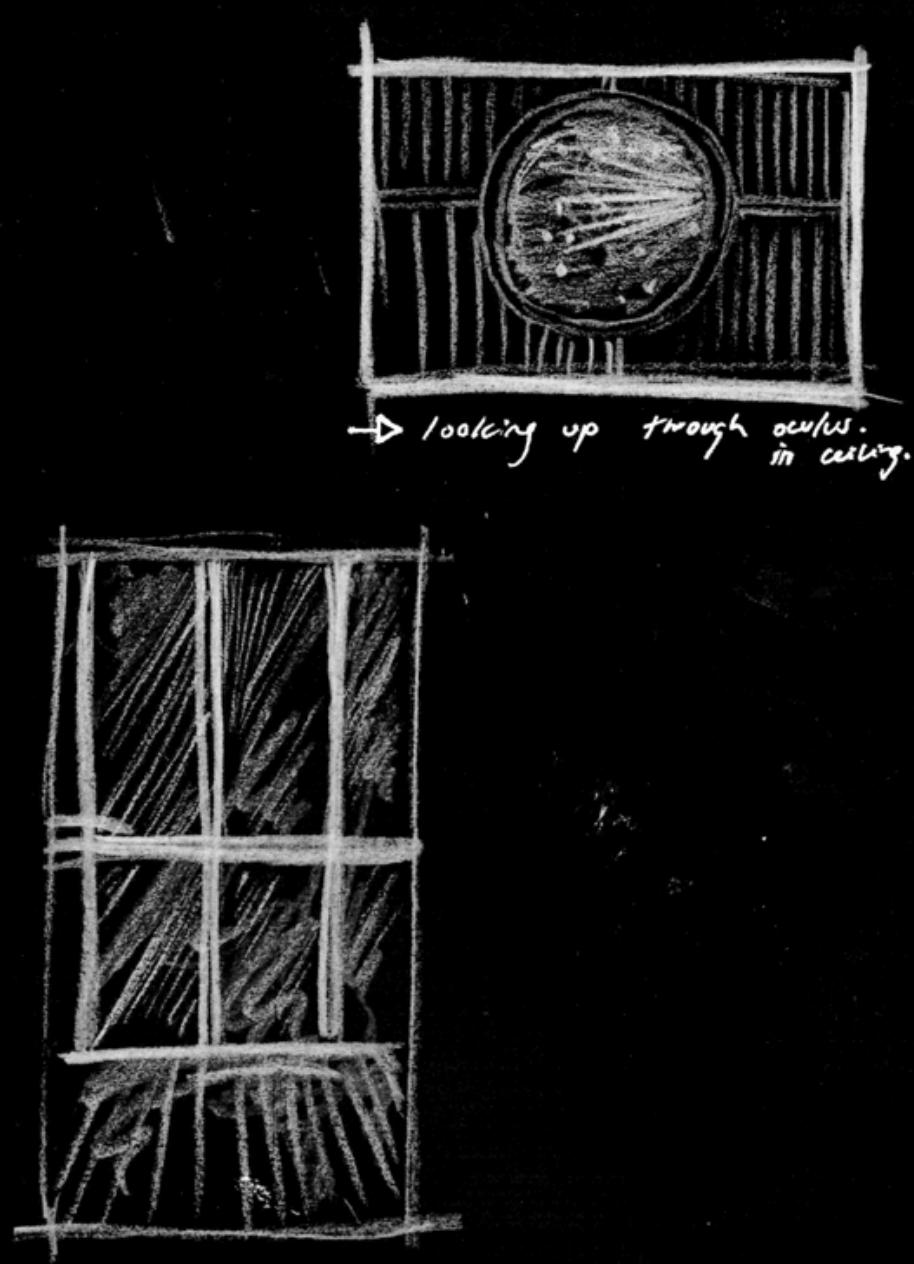

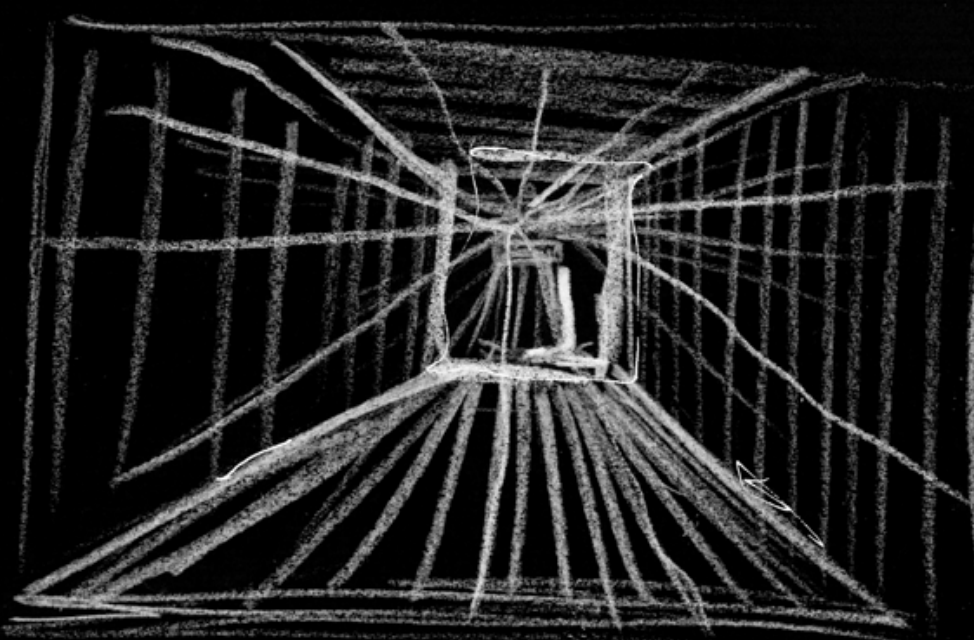

a timber viening shelter.

- absorb the light.
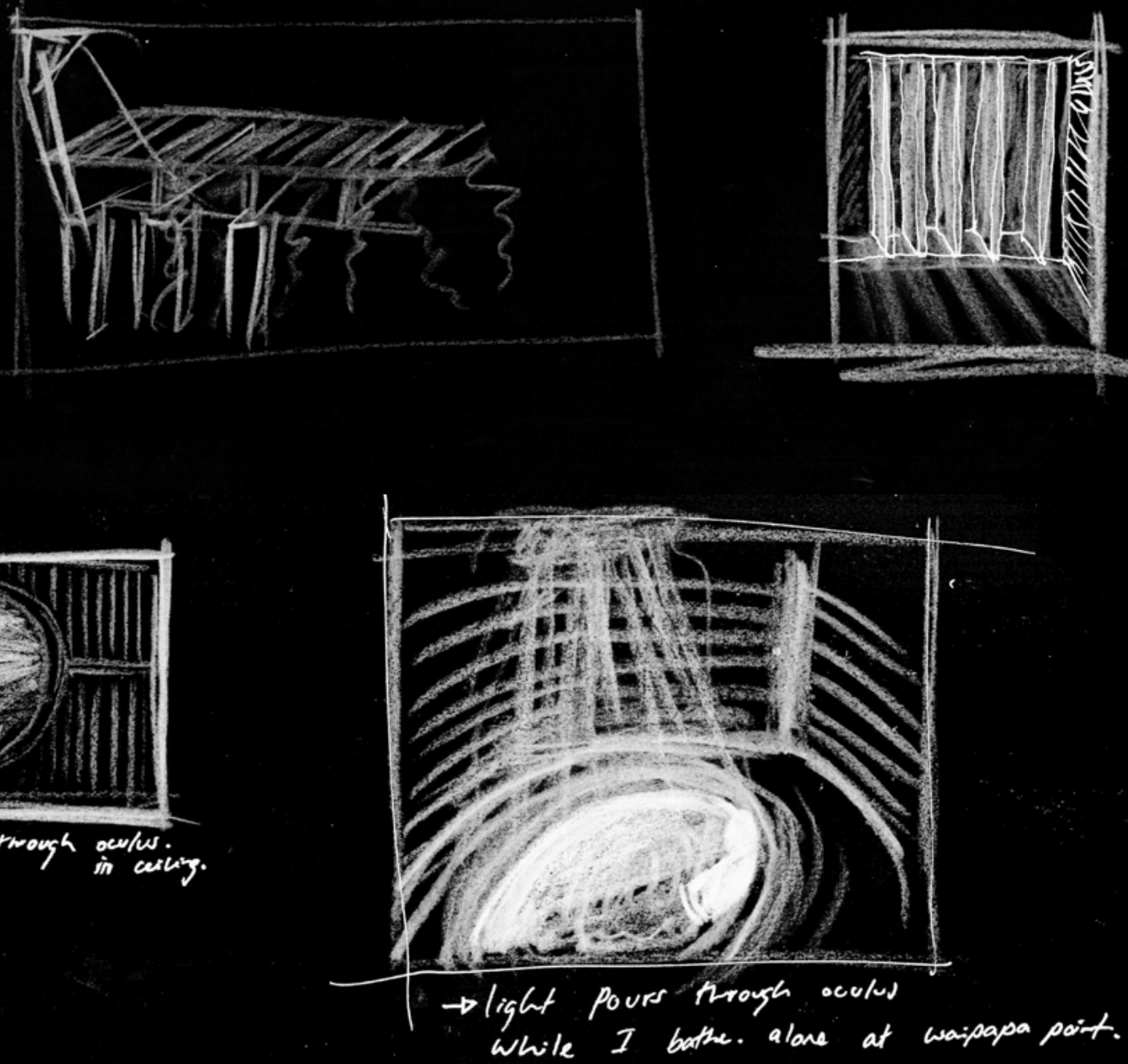


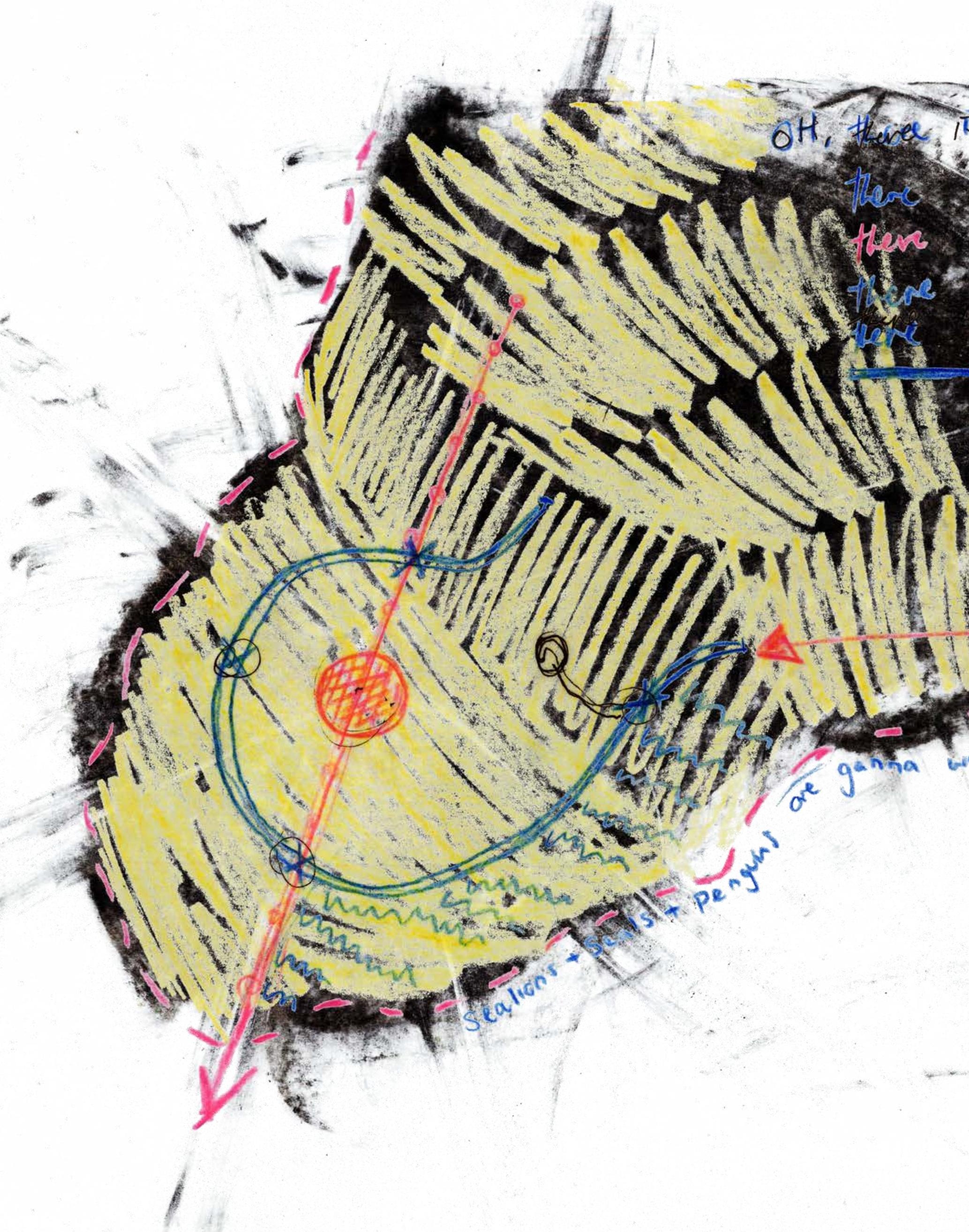




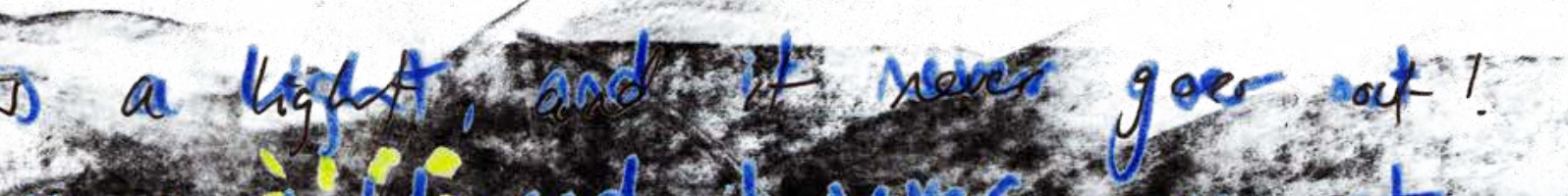

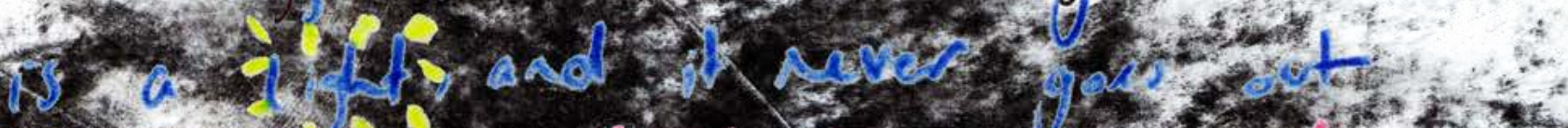

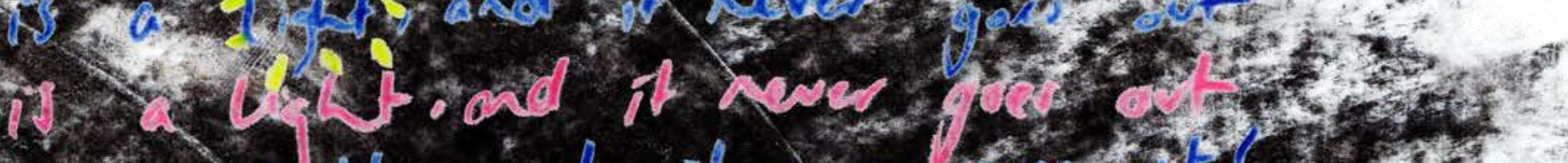

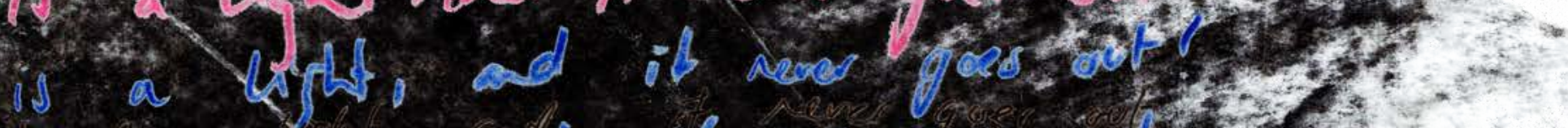

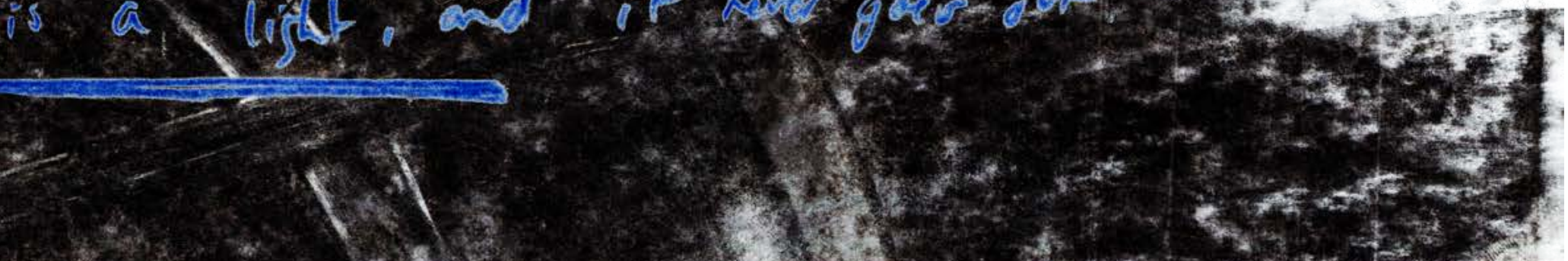

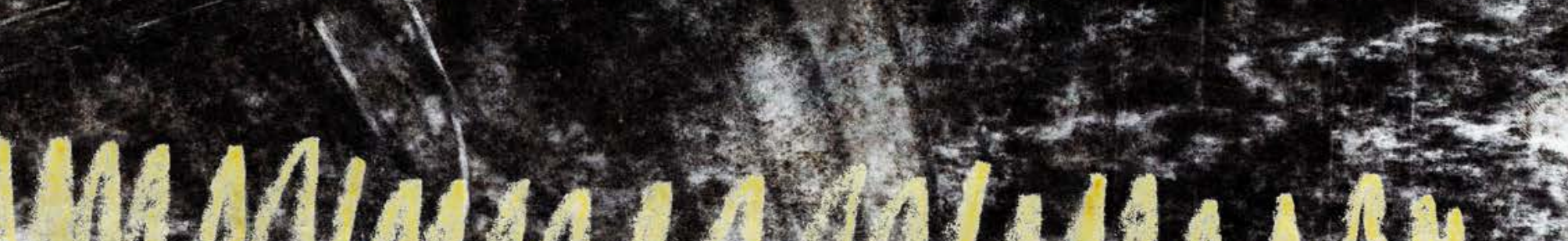
HII SWM

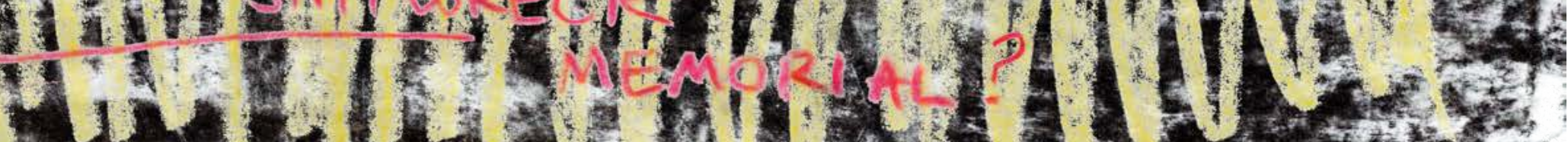

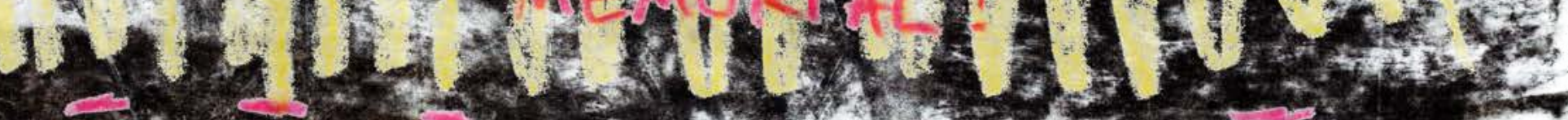

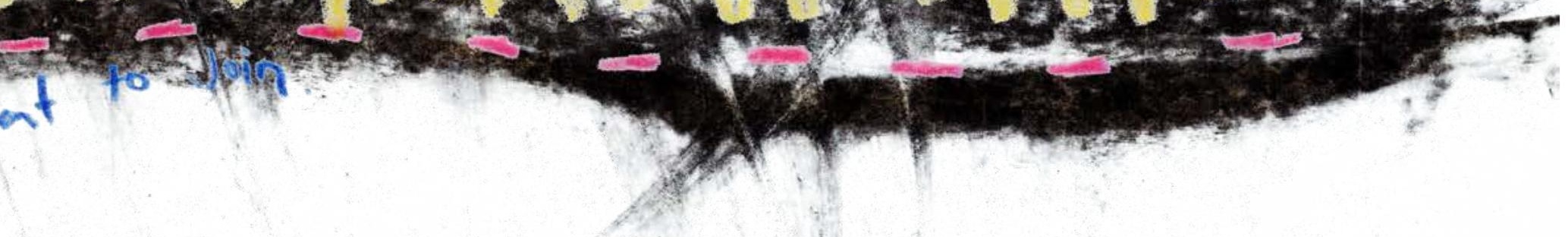




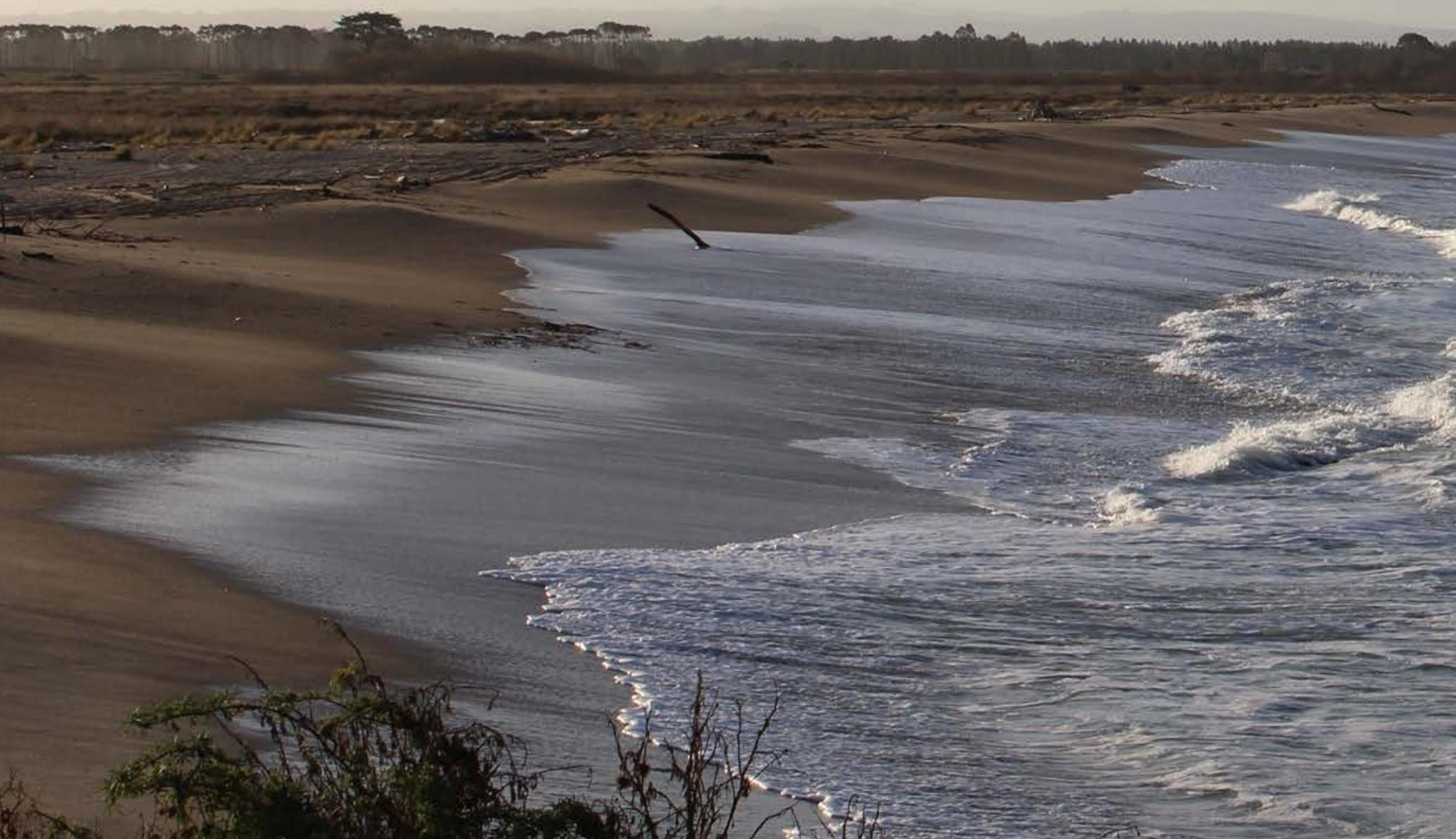




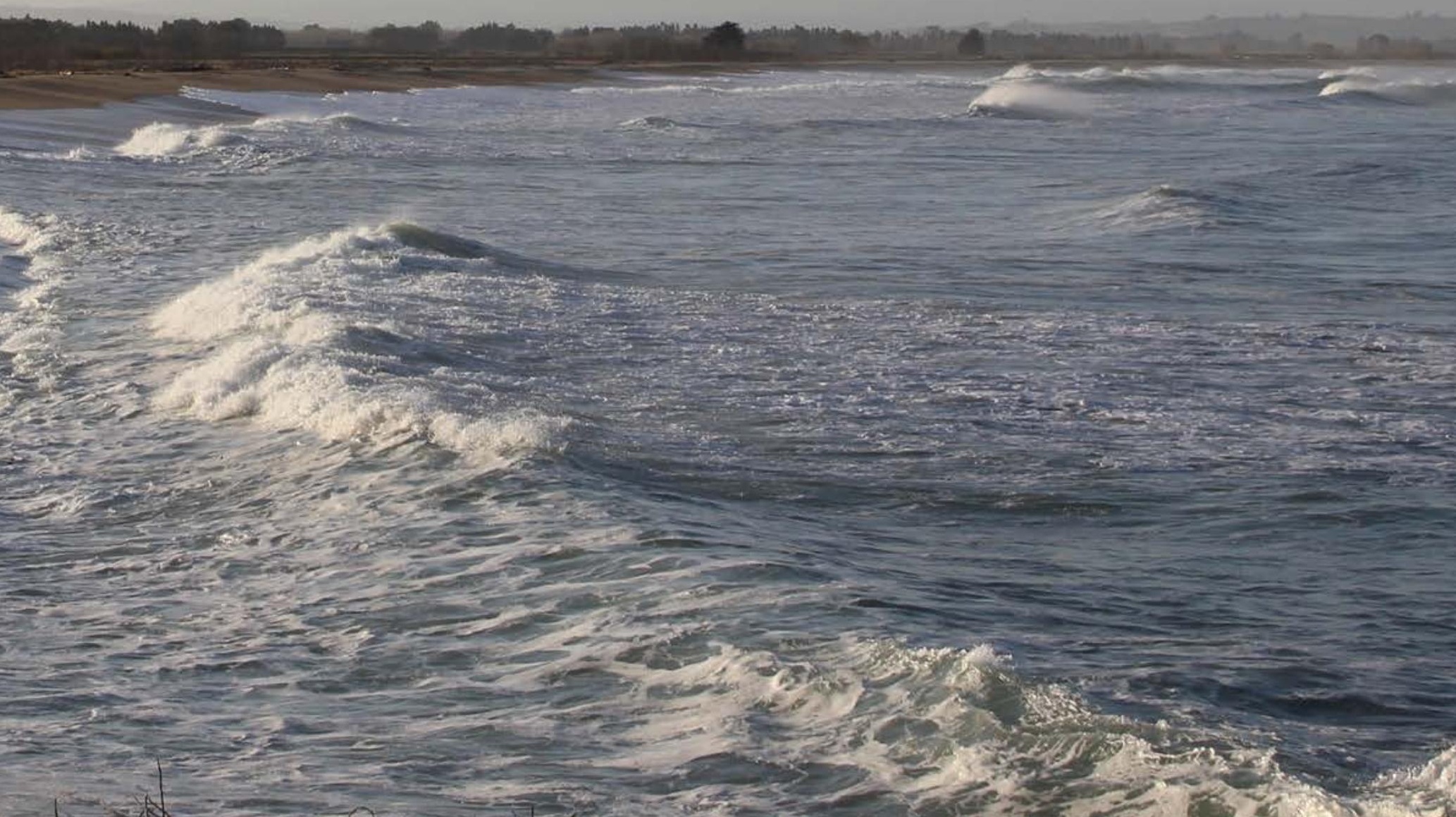


This content is unavailable.

Please consult the figure

list for further details. 


\subsubsection{Diller + Scofidio 'SLOW HOUSE'}

Collaborators since 1979, Diller and Scofidio have made the relationship between architecture and technology a pervasive theme in their work (Slow House, n.d.). For decades, the eastern reaches of Long Island, N.Y, America, have been a spawning ground for architecturally adventurous weekend houses. But none of them displayed the conceptual audacity of the Slow House, intended for a waterfront site in North Haven. What Elizabeth Diller and Ricardo Scofidio, proposed was essentially a habitable device for examining the site's prized sea view. In simplest terms, say the architects, it was "a passage ... from a door to a window." Remaining unbuilt, Diller + Scofidio's slow house is an experiment in three different types of viewing, the real, the framed and the virtual (Slow House, n.d.). Using different representation methods from model making, cutouts, and mechanics, this concept is realised. Instead of the house itself, the view and the representation become their primary interest.

The Slow house stands as an example of architecture around a focal point, in this case, the view, but applied differently what would it be to create a house around a light, or challenge the view. Their representation methods of collage and the model are important for my practice. To understand an idea, it relies on lived experience or proof to grapple with the concept. They have links to Nobles in the way they deal with the virtual and adds to a commentary of looking. This was specifically important for the second phase of the light device, what is trying to be achieved, is with the removal of camp, a focus on the gaze and performance of the tourist becomes paramount.
This content is unavailable.

Please consult the figure list for further details.
This content is unavailable.

Please consult the figure

list for further details. 

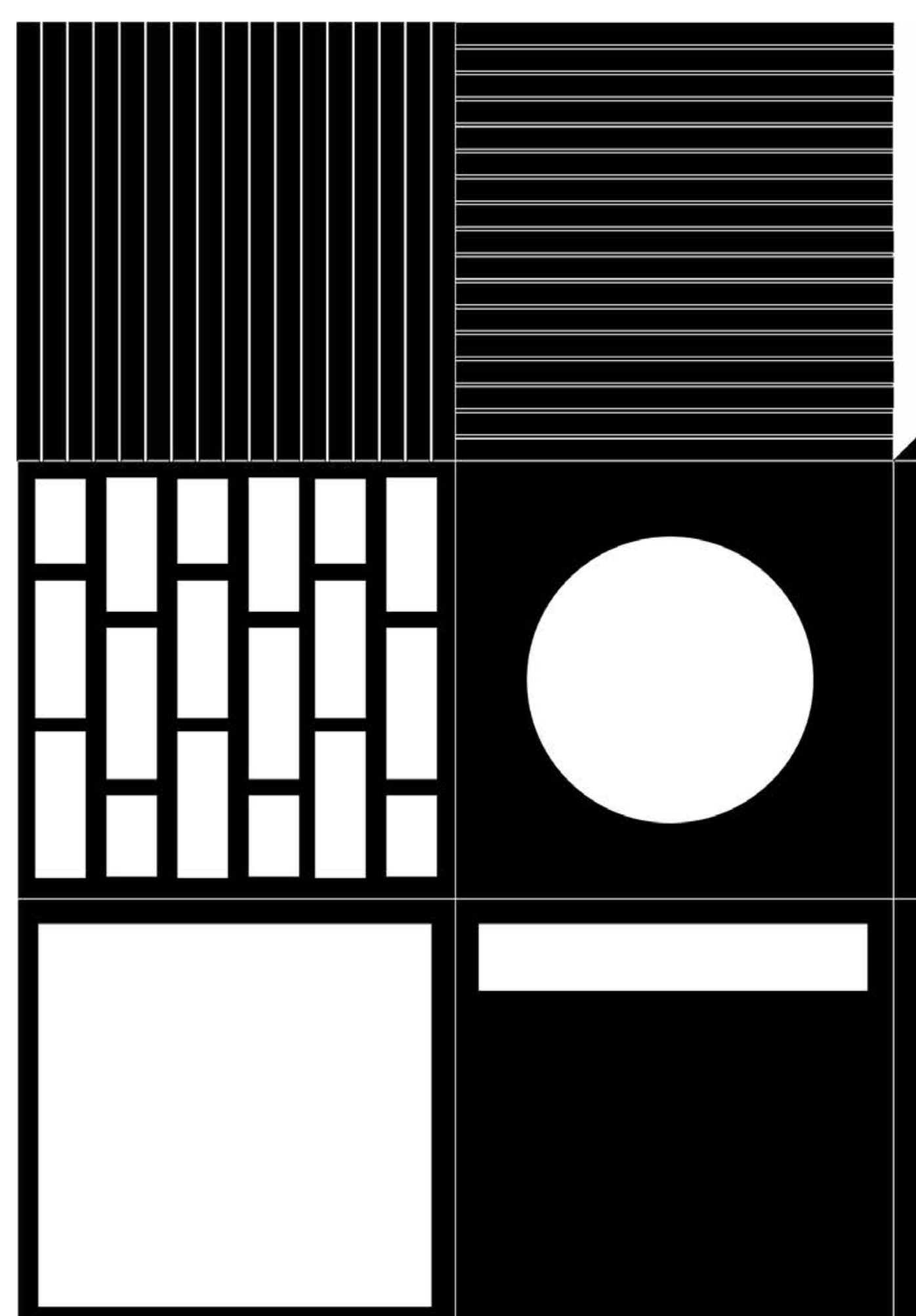

\section{0
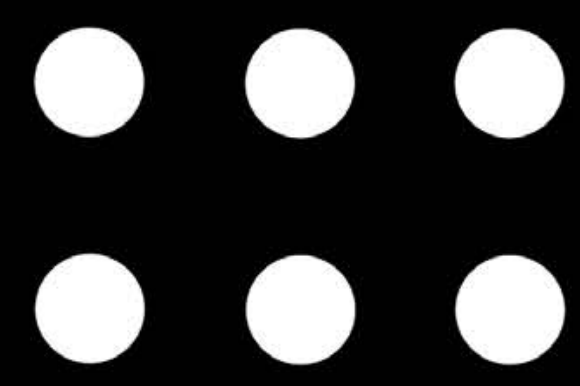
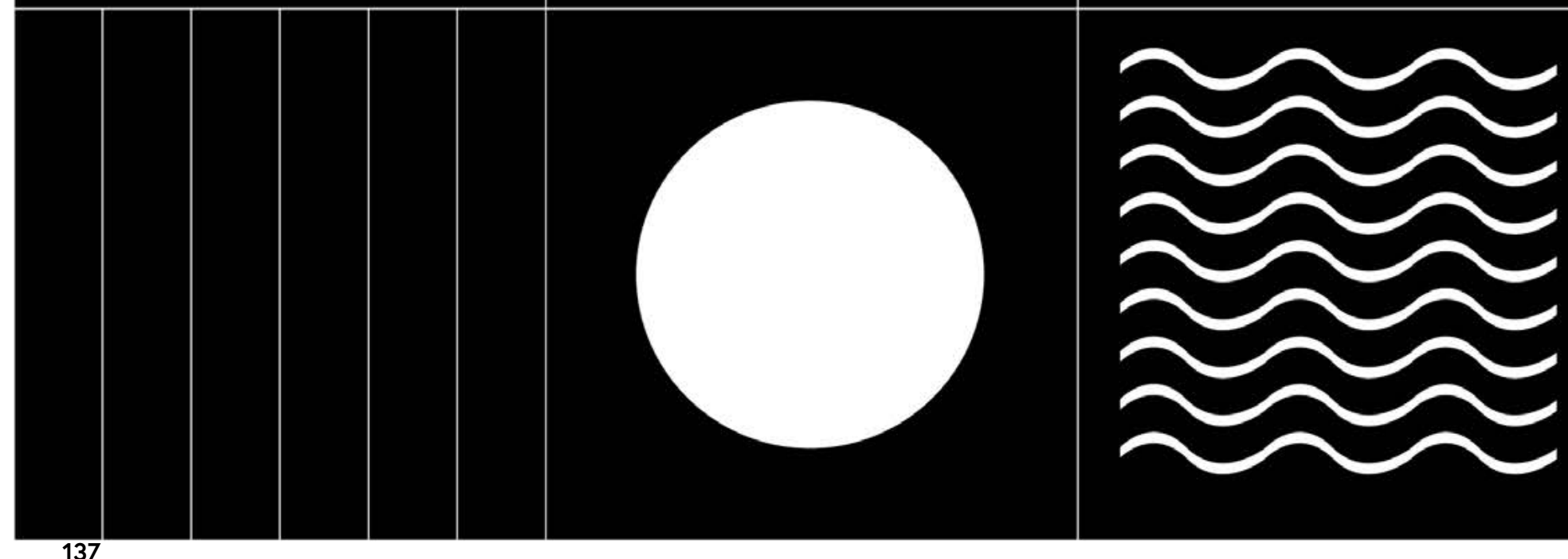


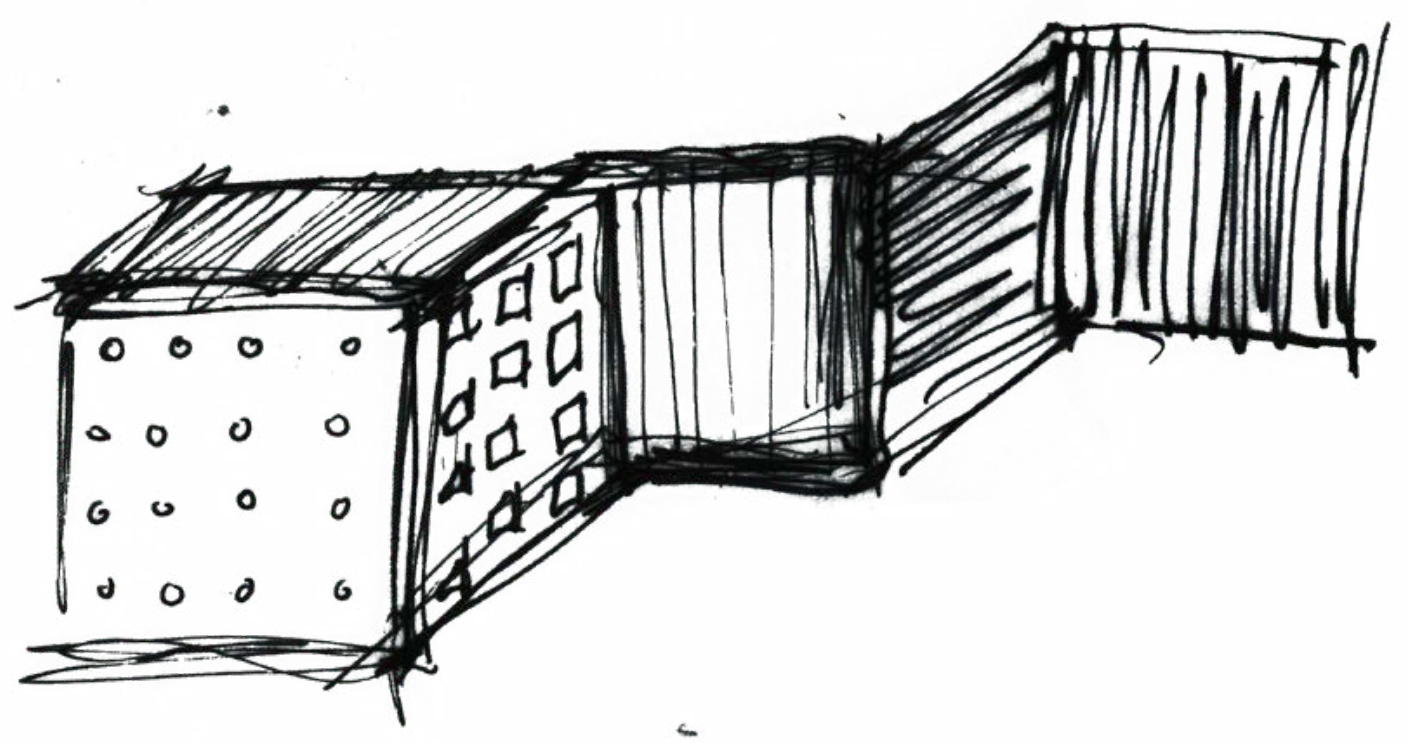




\subsection{LIGHT MARQUETTES}

The first design experiment was to make light maquettes, using a LED light as the 'lighthouse' and laser cut card, these were then stuck together to create 100x100x100mm 'rooms', experimenting with space on a small scale, as well relying heavily on screens as the architectural device to manipulate the light of the LED. By taking photos of the light that I manipulate in the design experiment one, I am making the light an architectural device, something that helps create a stage and something tourists must navigate when experiencing.

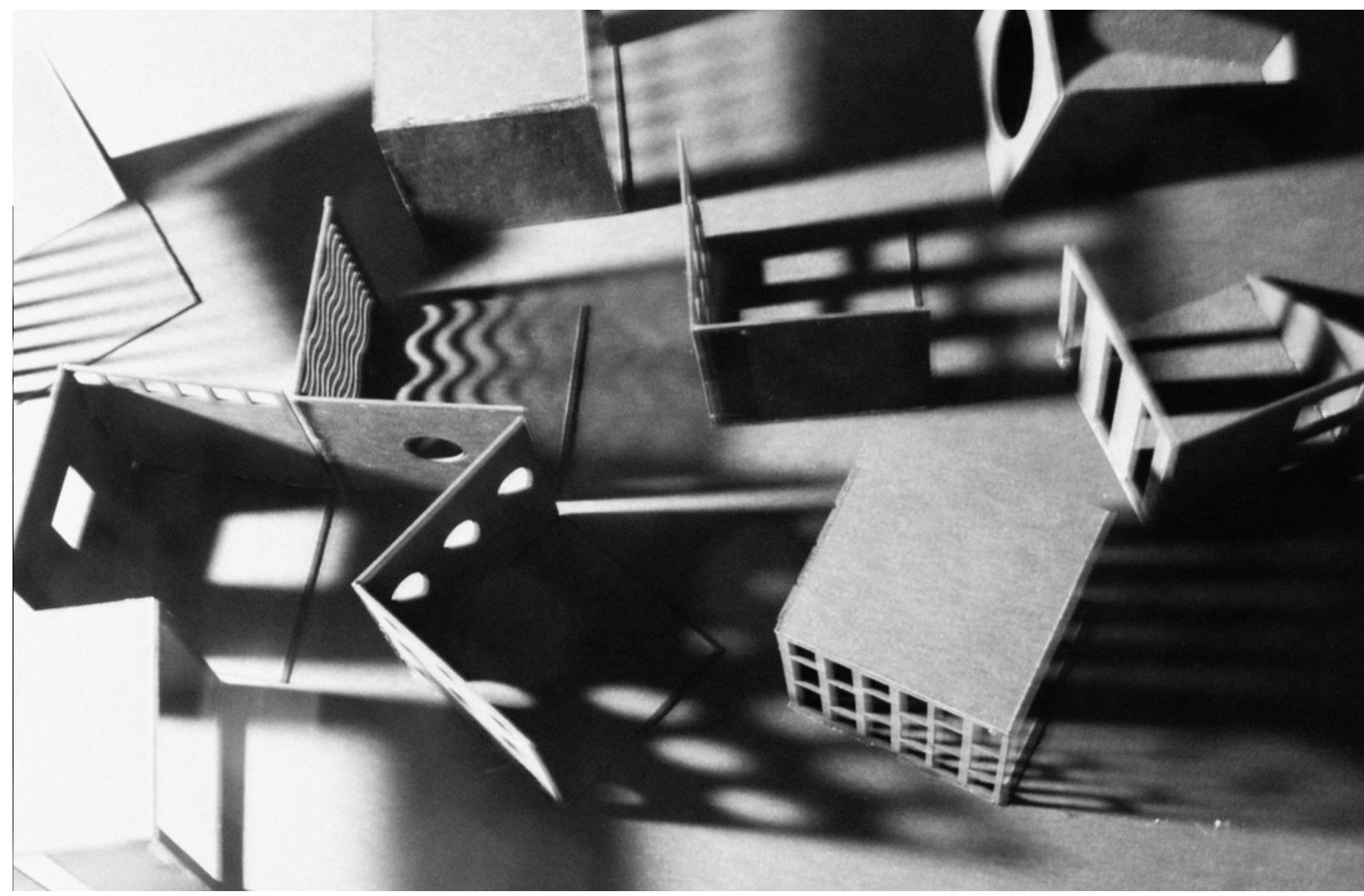

Figure 80 The light marquettes assembled together 

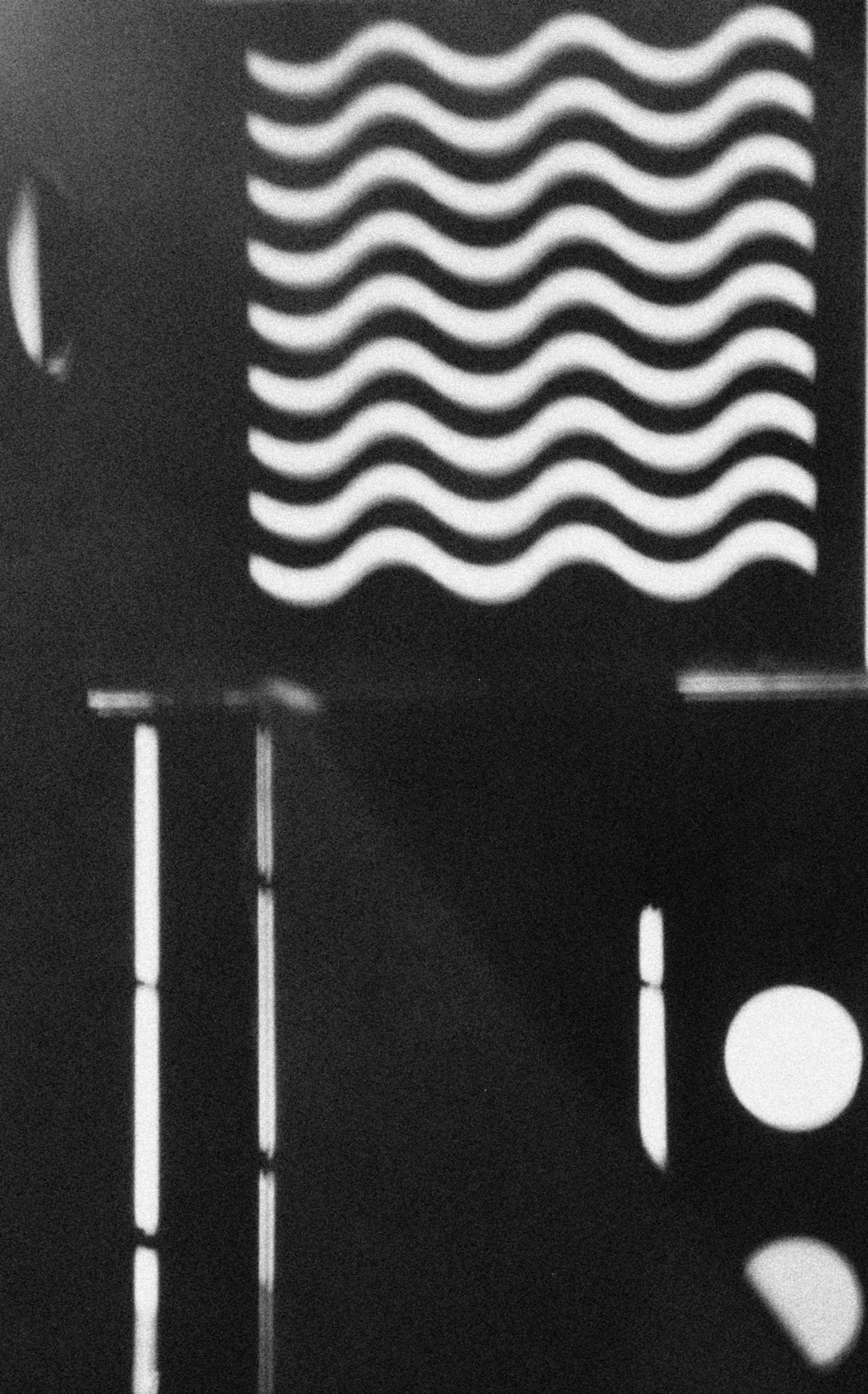

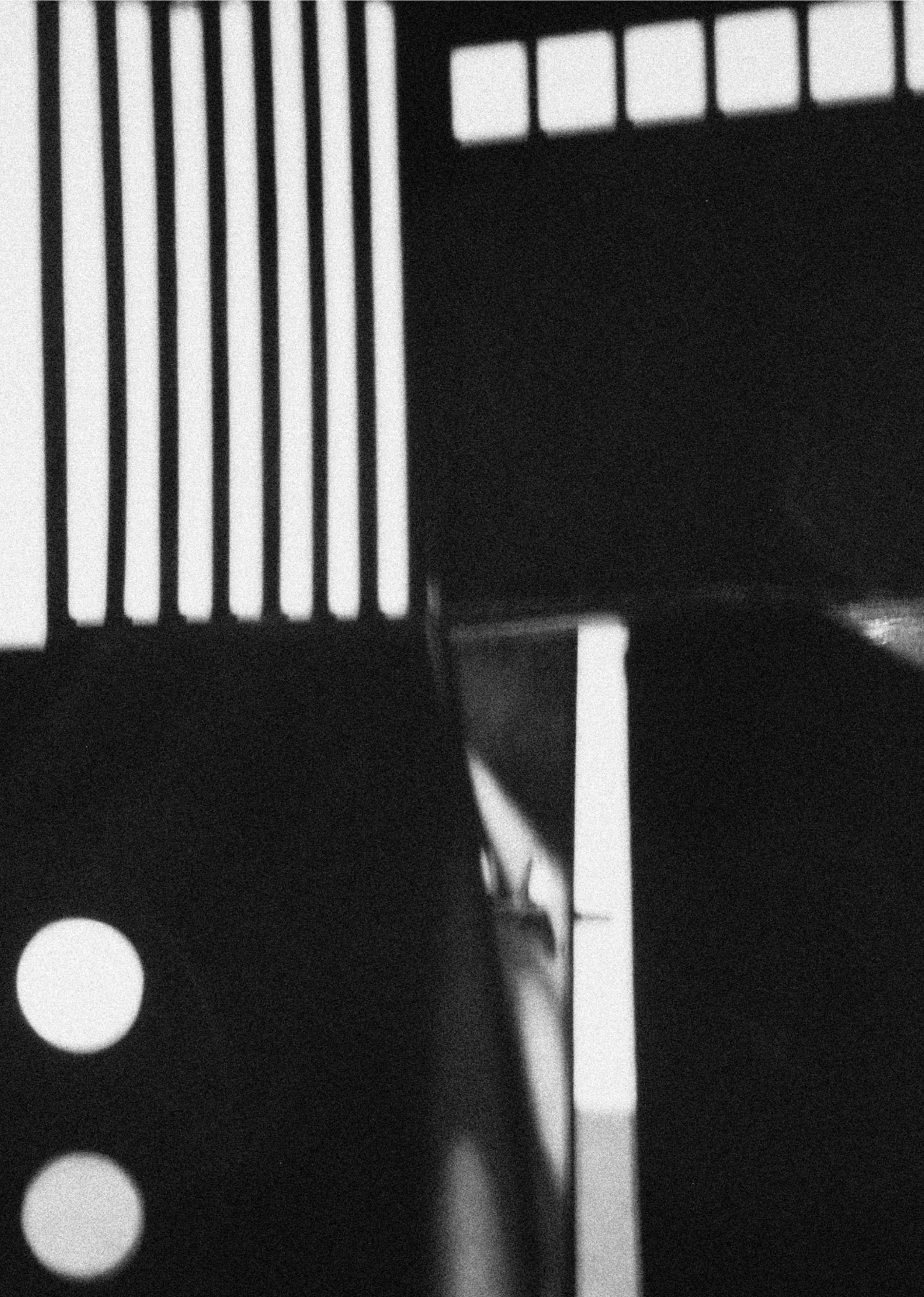

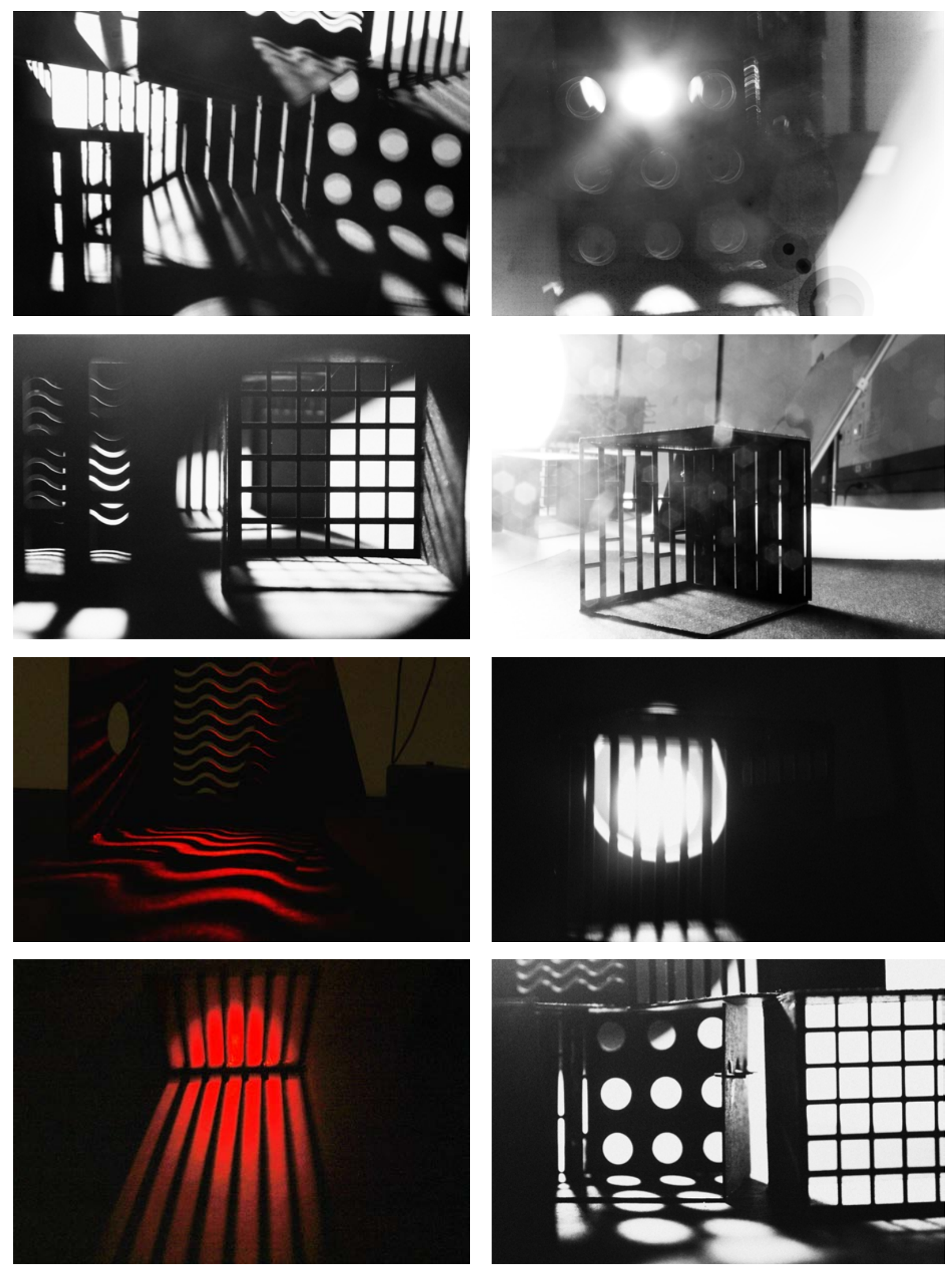

Figure 81 A selection of the photographs from the light marquette design experiment, Note, the variance in light textures, shapes and overall varied conditions. 

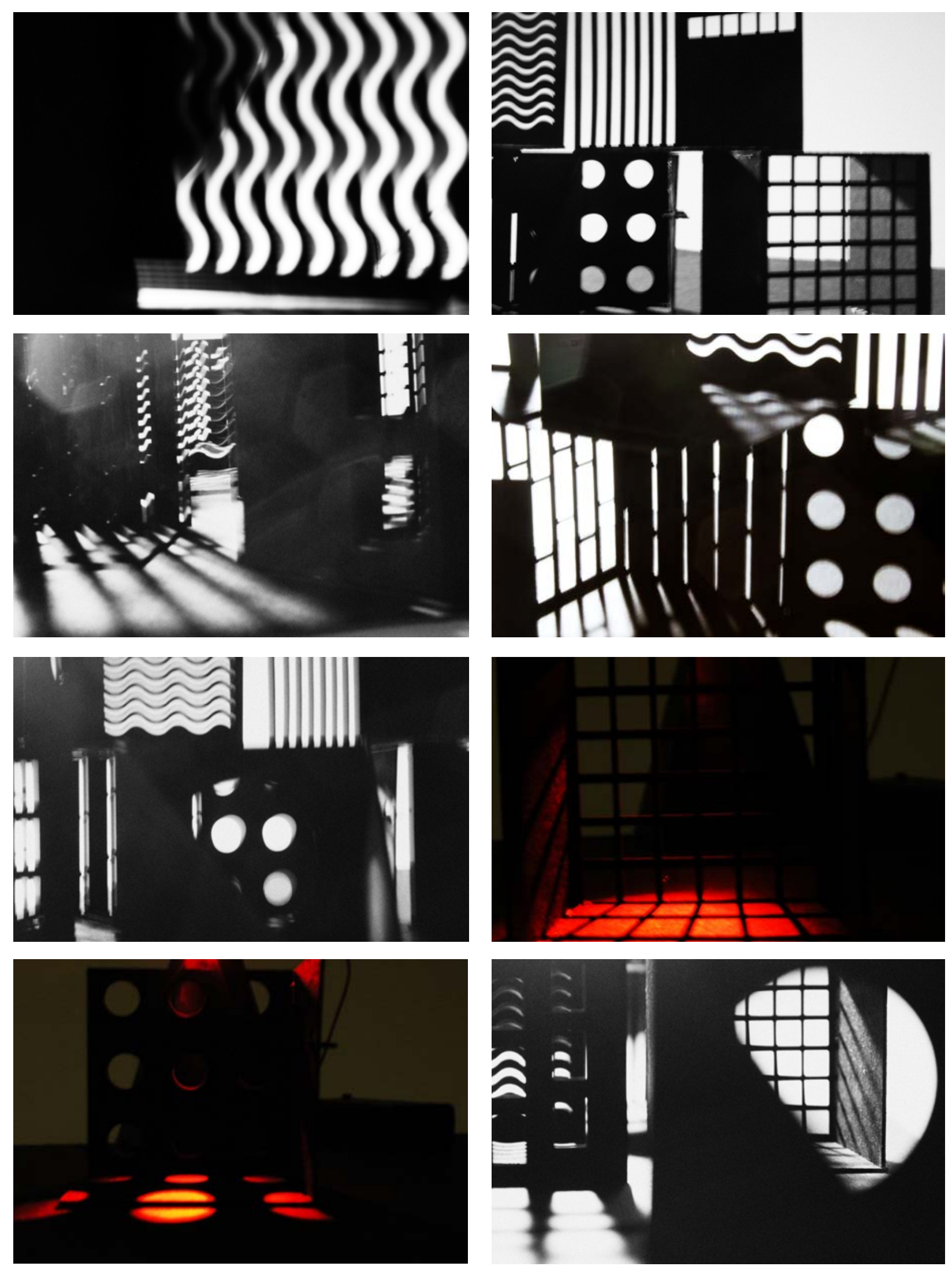
First a lighthouse was created, or a light source, this is to be the focal point from which the light play experiments and photographs formed, ideas of layers, screens, apertures and controlling light come into play. 
The laser-cut screens patterns were designed randomly, with the only parameter being that they must have variance and alter the amount of light and shape that light will pass through, some screens represented a wall stud, a circular window perhaps, louvres and sunshades, but for the most part, it was a way to mix whimsy into the darkness. These shadow/light studies offer moments for one to imagine as if they were in these spaces how the light one feel. The only let light present an in which the look outthe back and between the and tourist, performer, being seen.

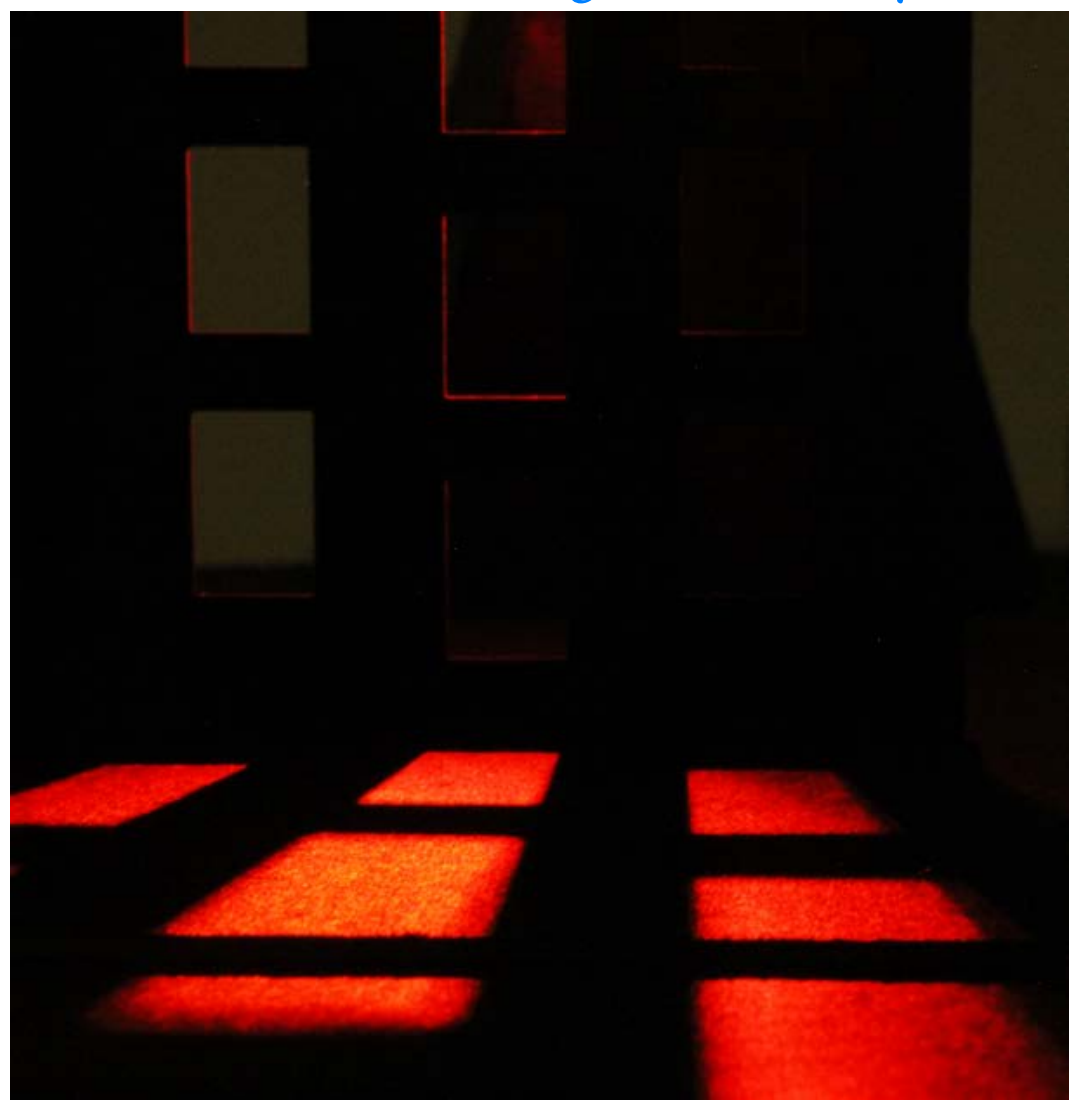
would make openings not in but also opportunity tourist would maintaining forth dialogue lighthouse stage and looking and 


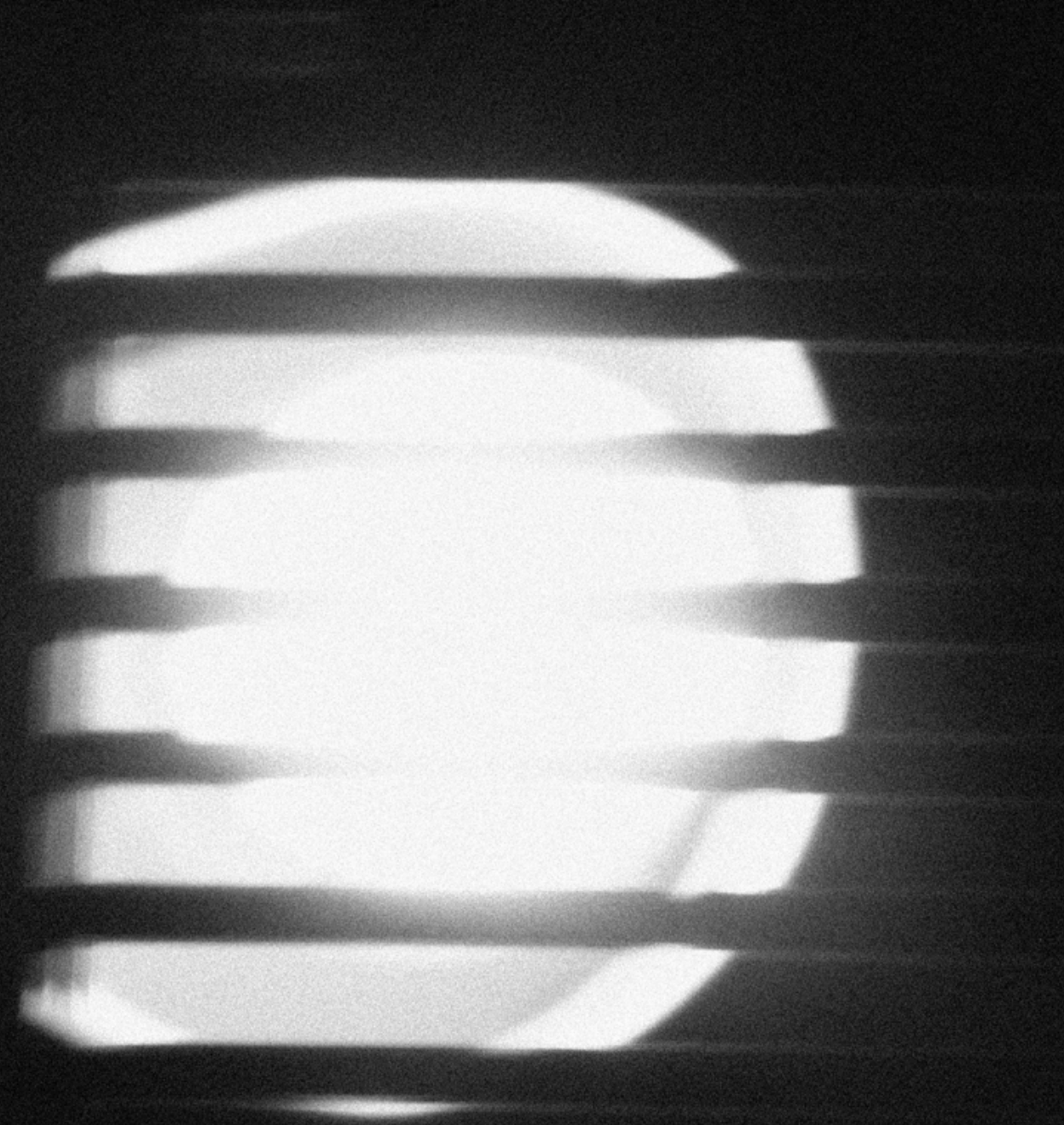




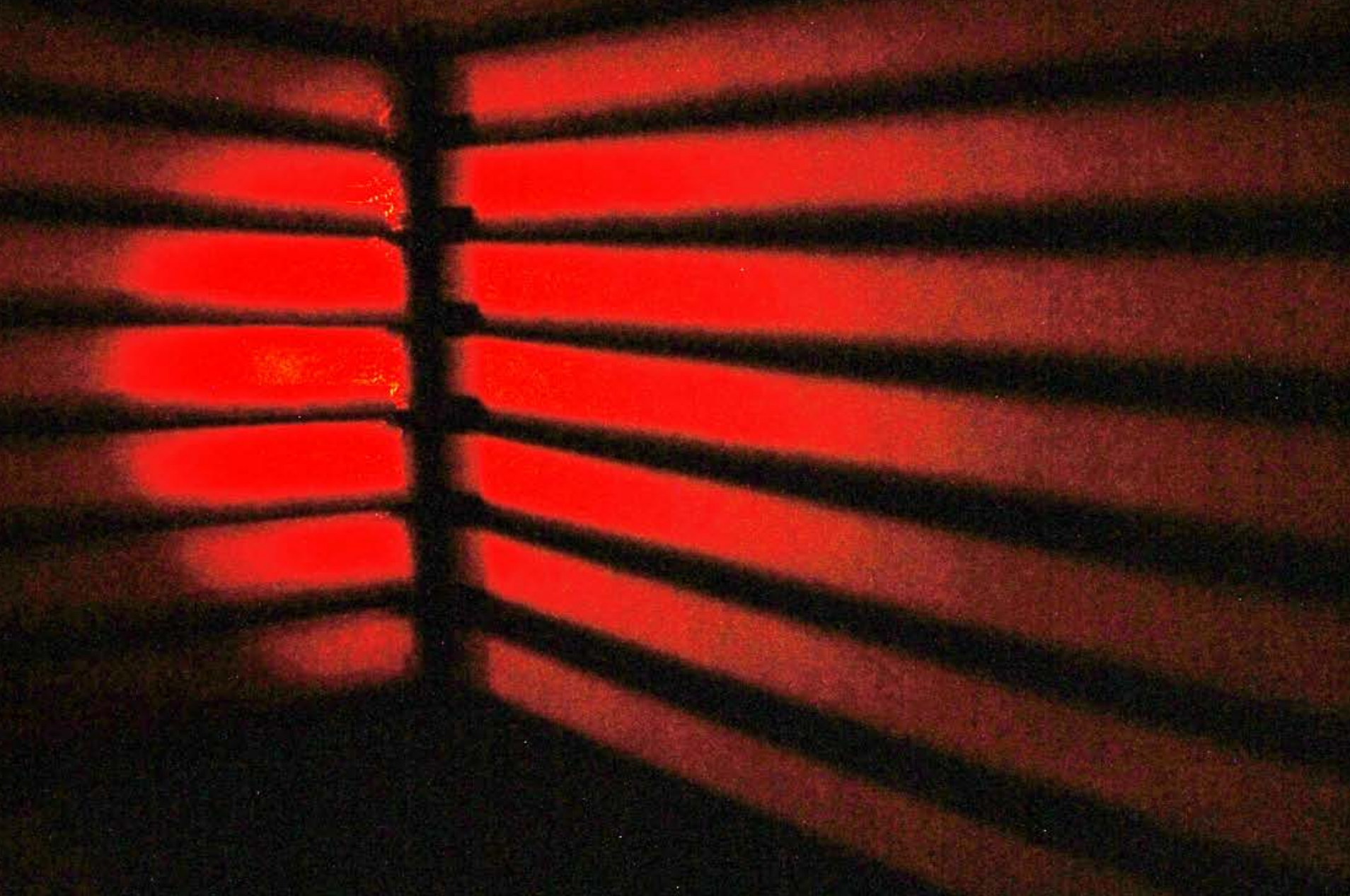


As a final conclusion to the first light experiment, the screen 'rooms' have been assembled to form a light tower, a conceptual structure that responds to the lighthouse, creates an atmosphere and plays with the shadow and light, it is the anti-camp tower, the light tower, a preliminary device and stage for the tourist to occupy and look in at the light. In opposition to the theme park in phase one this object is singular. The conversation of the observer with the lighthouse. There is no facade or artifice, its honest, it wants to understand the lighthouse. This helps influence the third experiment where an architecture is proposed. 

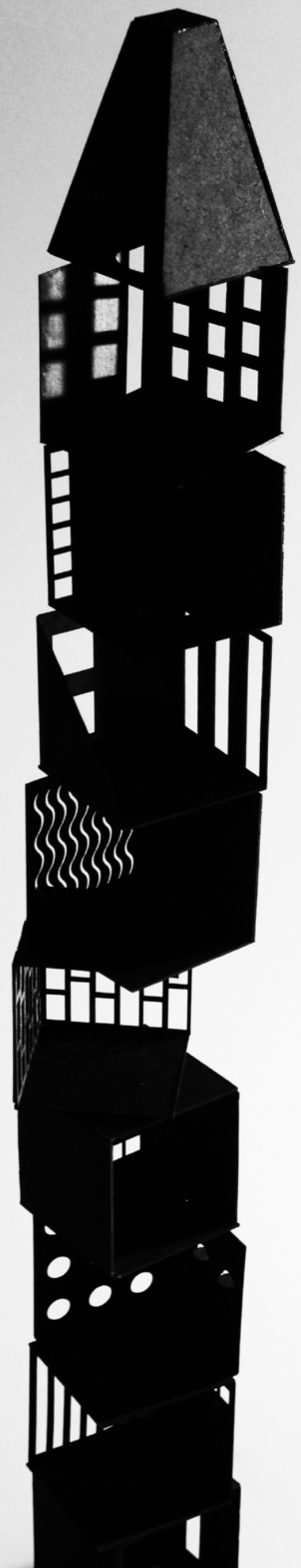



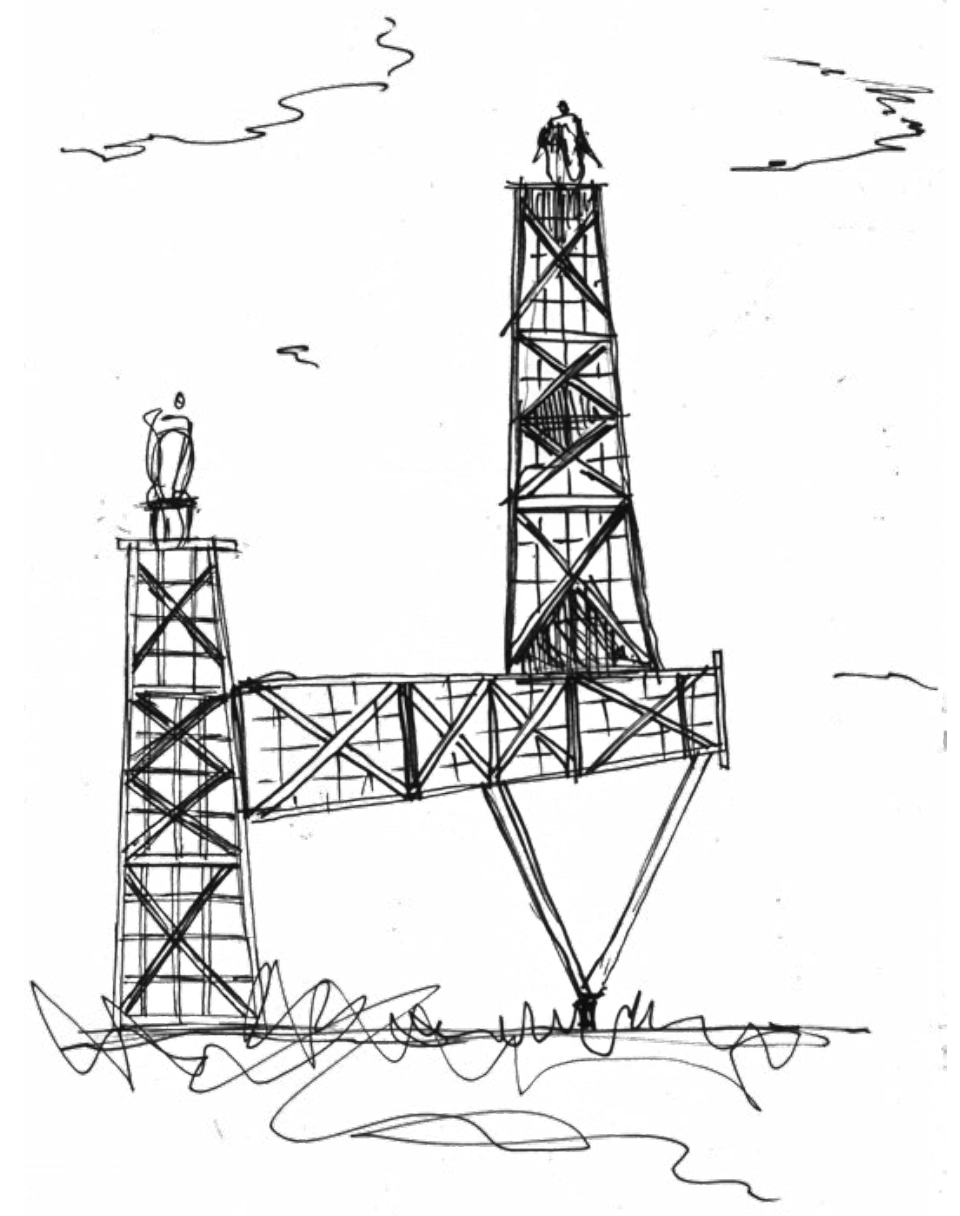

Figure 82 Concept sketch of a supplementary architecture to go beside Waipapa. 


\subsection{ATMOSPHERIC STUDIES}

An atmospheric study forms the third design experiment within phase two. A design process using collage techniques, photography and photo manipulation, a visual form of the atmosphere is created for the speculative building, which plays on the notion of the photograph. What we see is not necessarily what is. The final four images give a sense of an interior space or as if they are looking from the perspective of the lighthouse, looking outward, in ways it signals back to the time, the lighthouse was a solitary architecture, watching over the seas, protecting. This exercise ultimately was a test in seeing if a photograph has the potential to evoke other emotions, notions of site condition, lights, tactile senses etc. The atmospheric studies act as a study in what the speculative building is seeking to achieve. The building which is developed as the third experiment 'worshipping the light' is a conclusion to this chapter of anti-camp and it next applies these atmospheric studies and translates them into a building. 

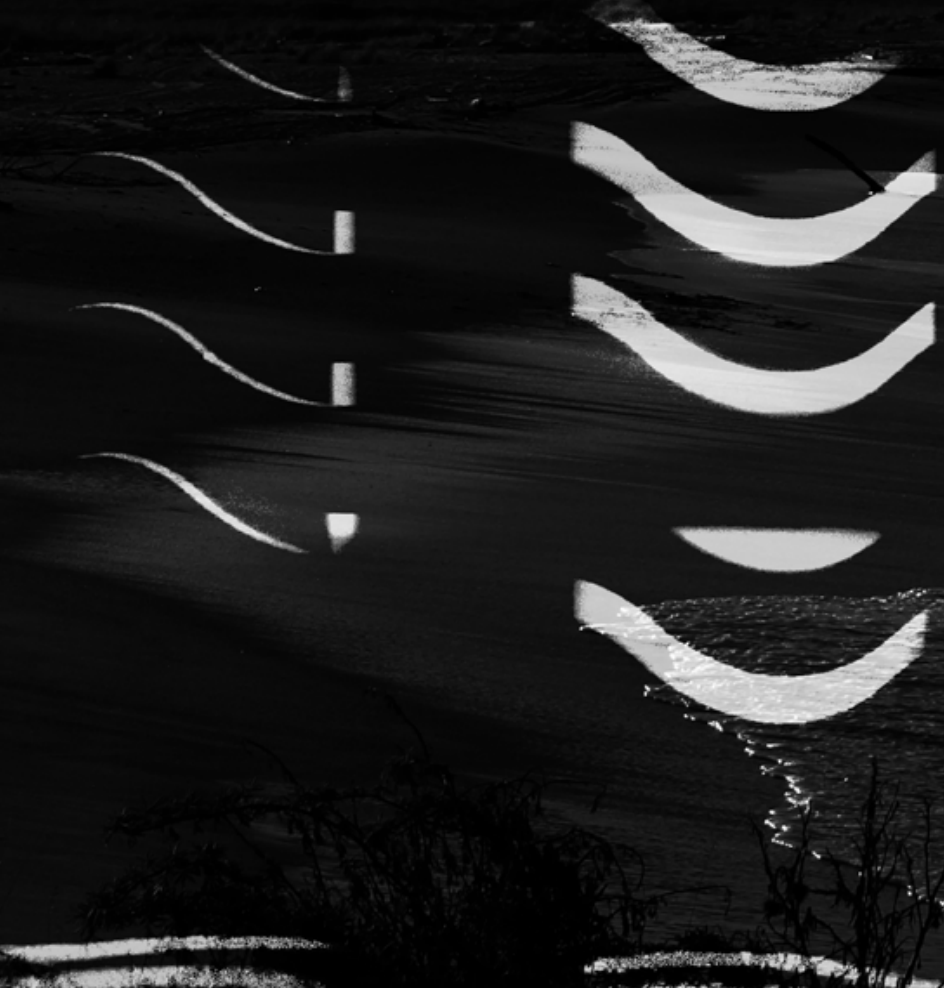

X...

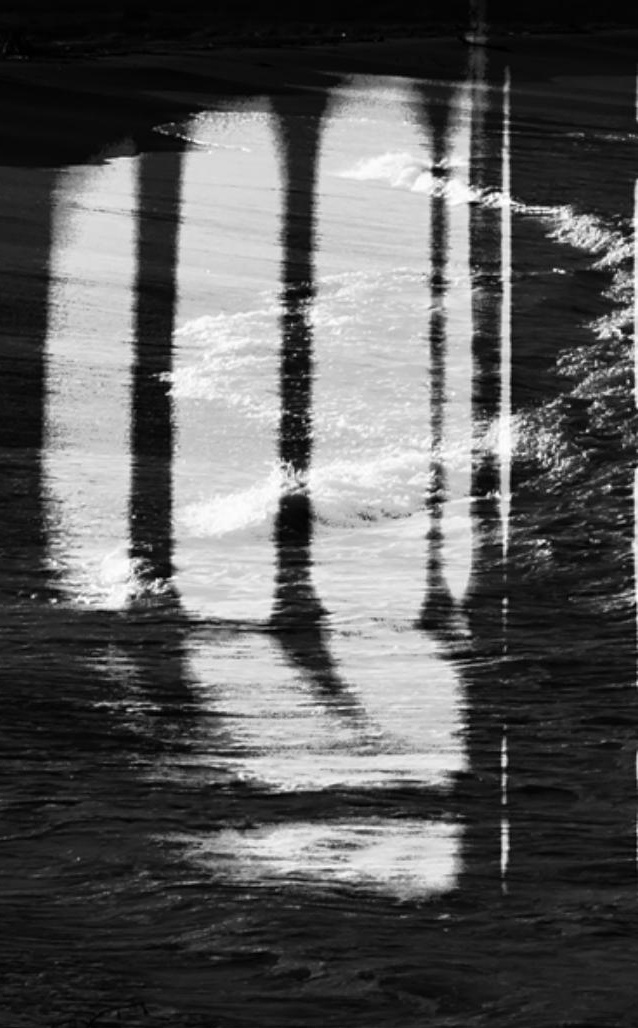




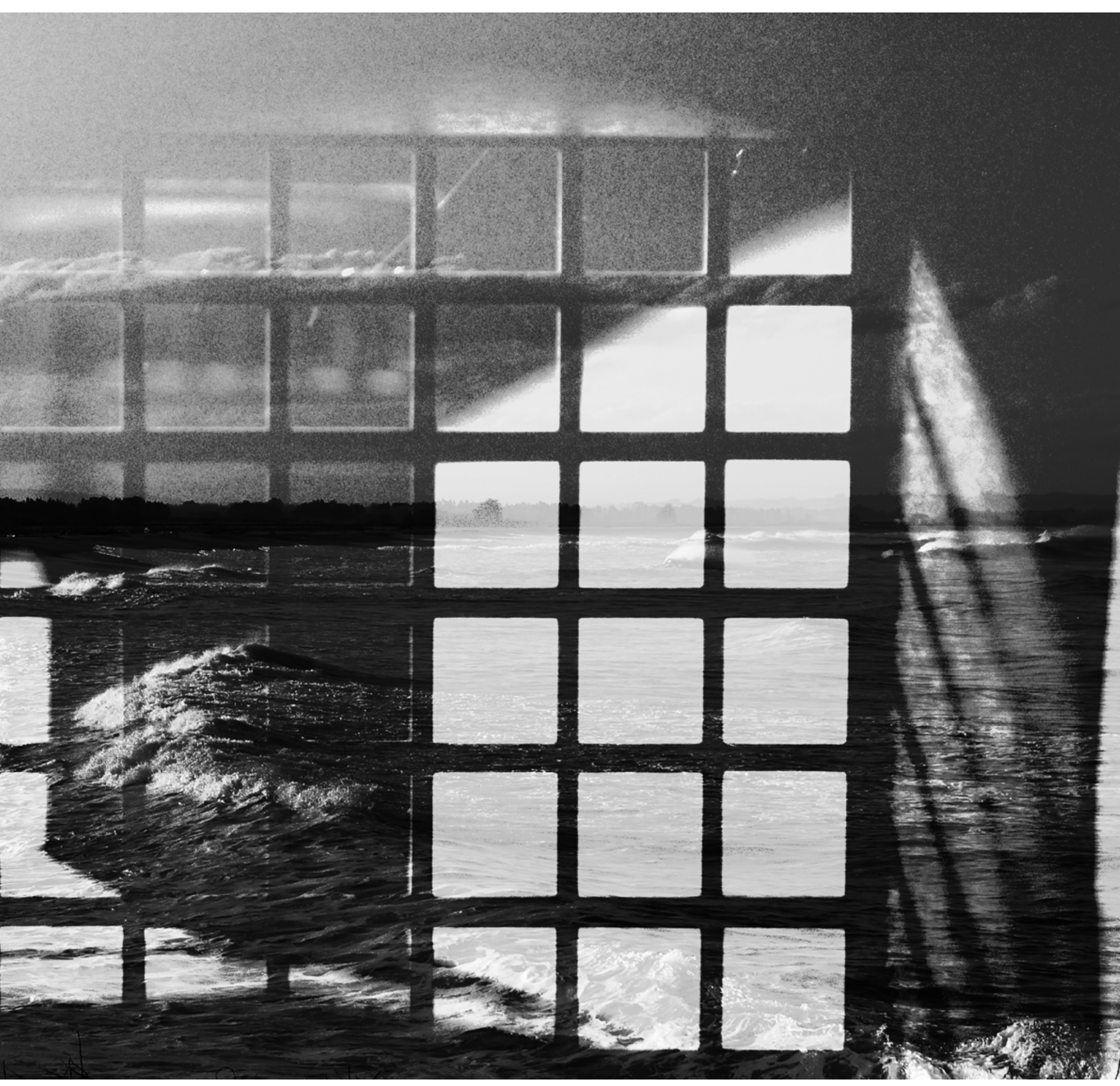

Digital collage, authors photo of Molyneux Bay manipulated with the photgraphs of the light marquette's. This study is an experiment on the combination of light, apatures, screens, and site condition 

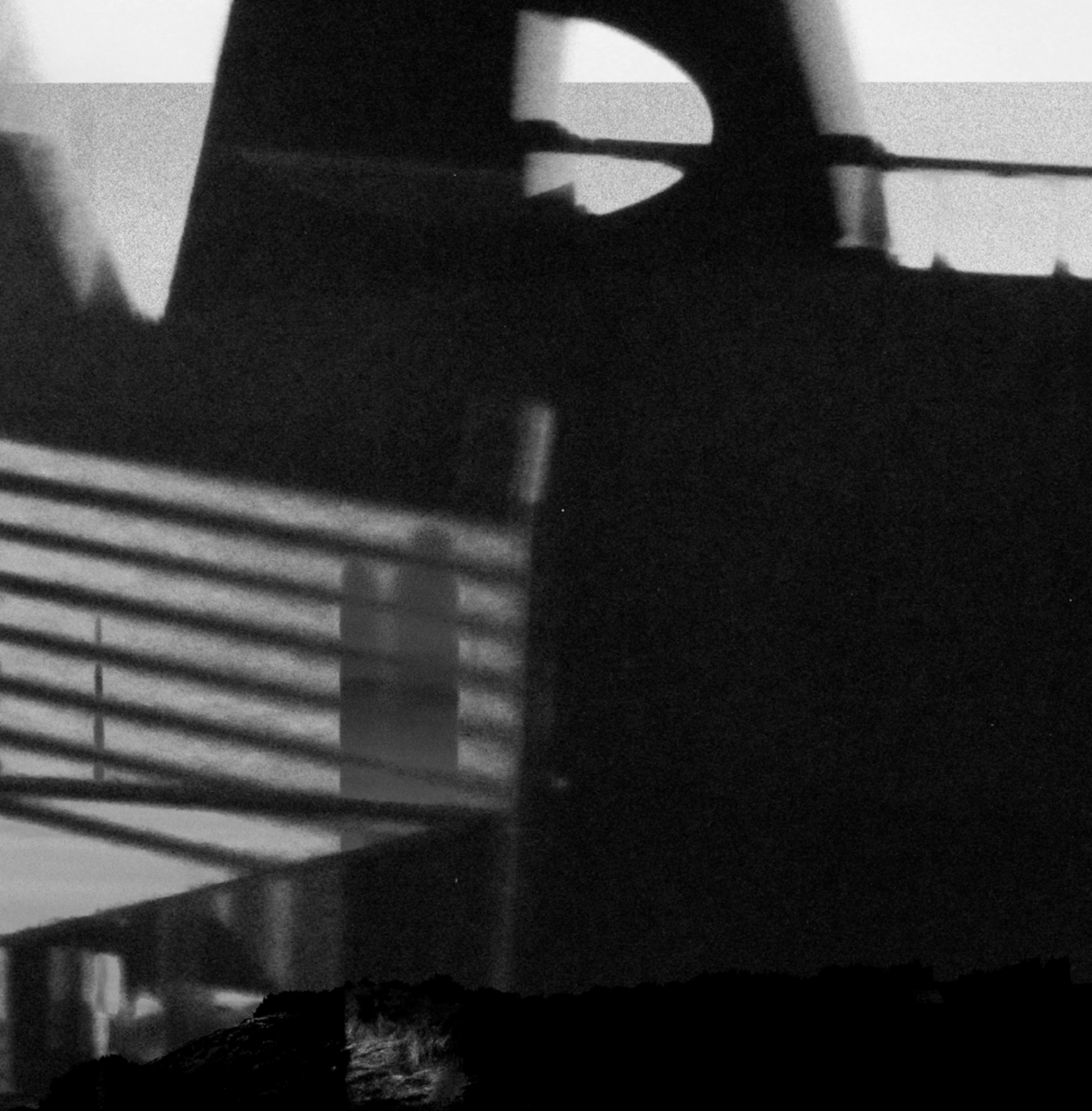

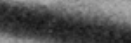


Digital collage: Authors photo of Waipapa Lighthosue manipulated with the photgraphs of the light marquettes, the LED light study. This image looks at screening, looking onwards at the lighthouse from the protectionof an interior space, while watching other tourists perform.
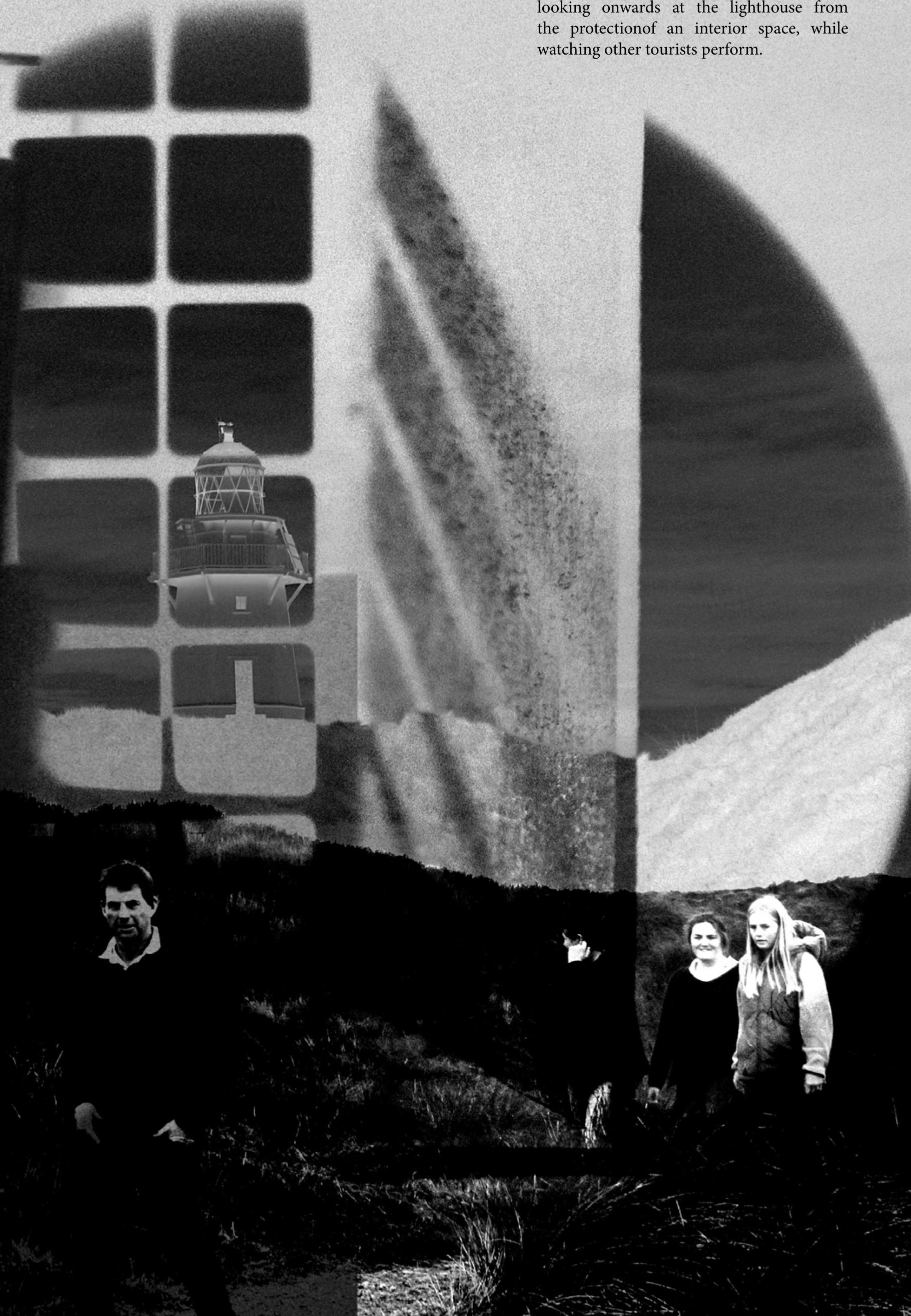



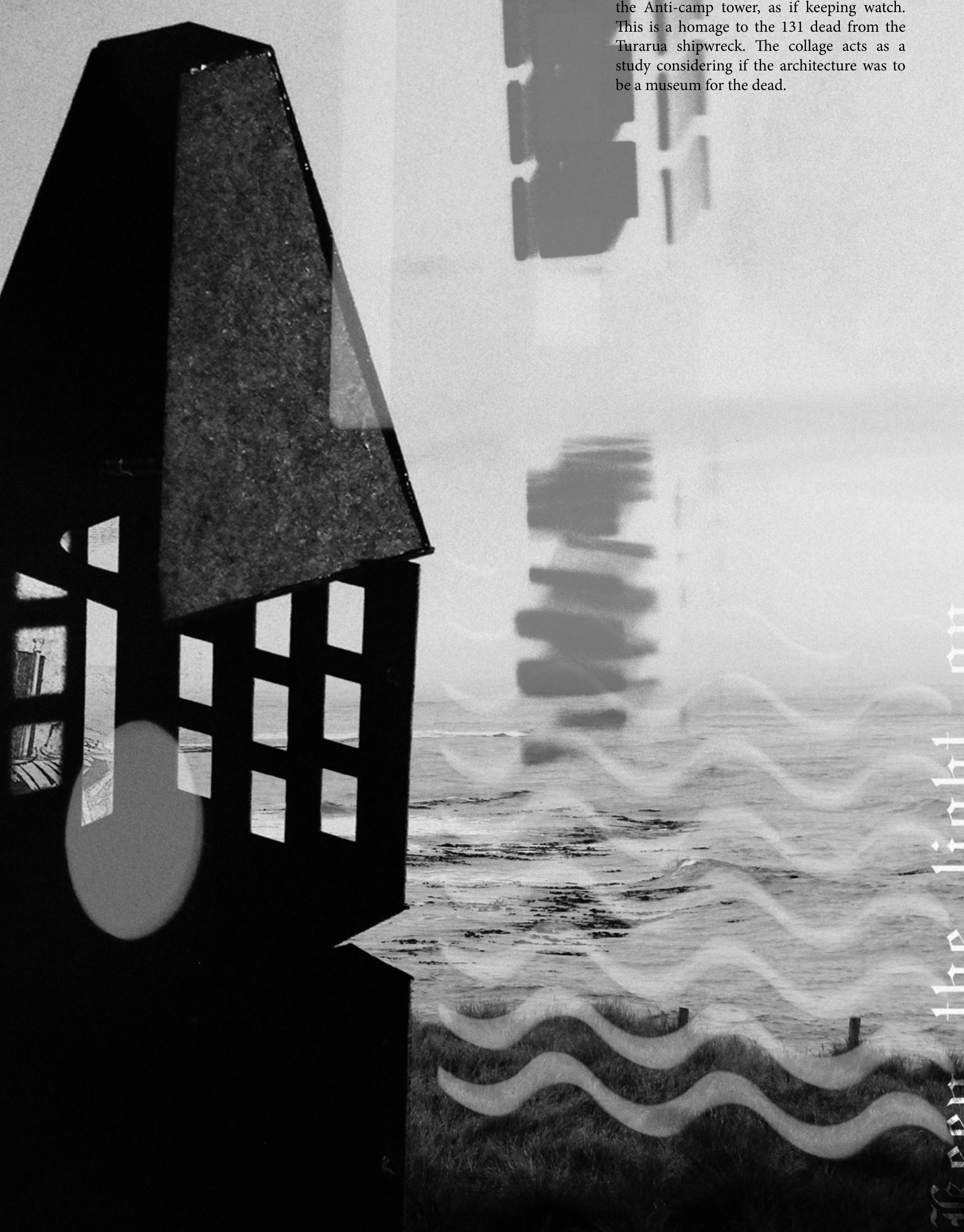




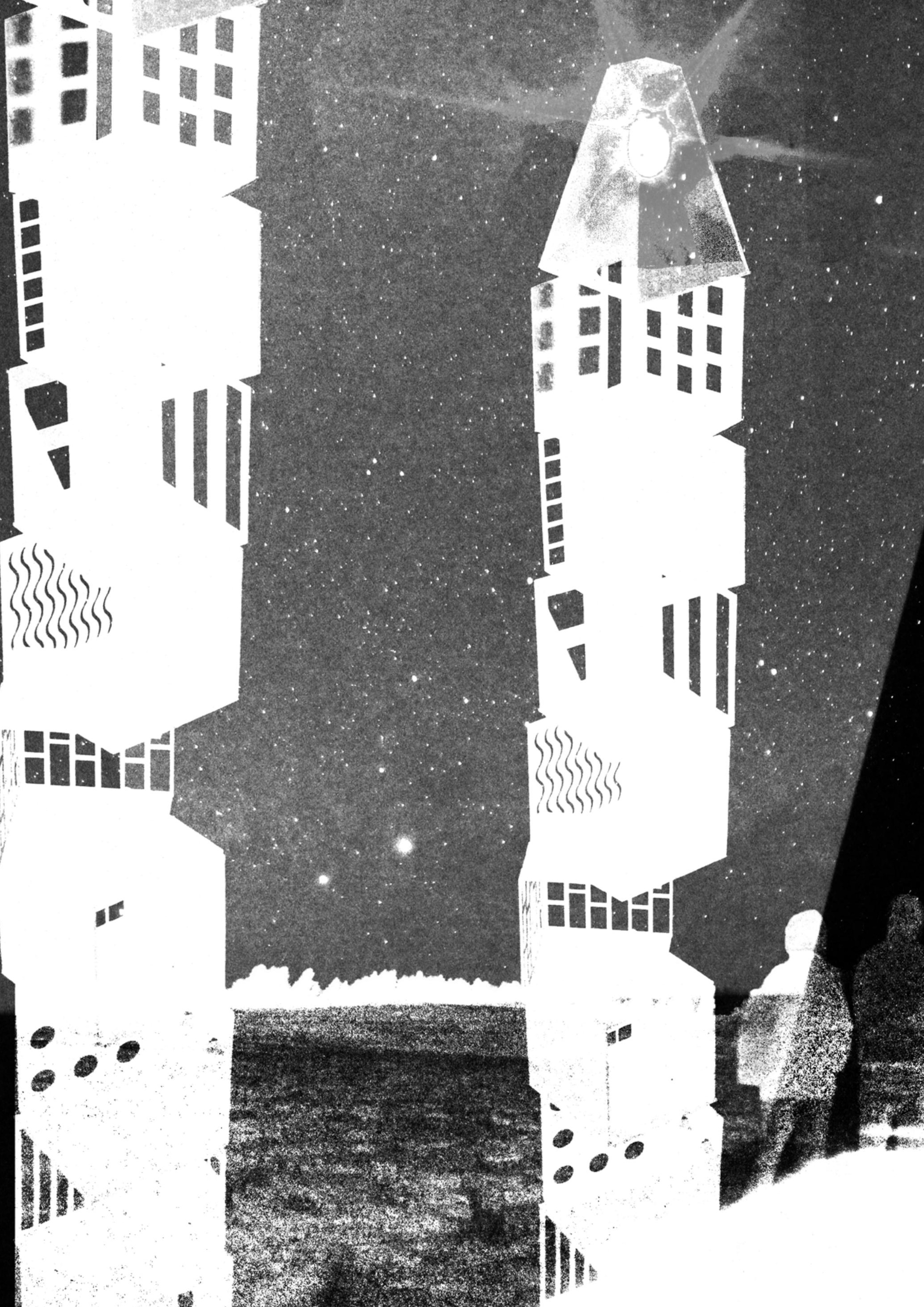




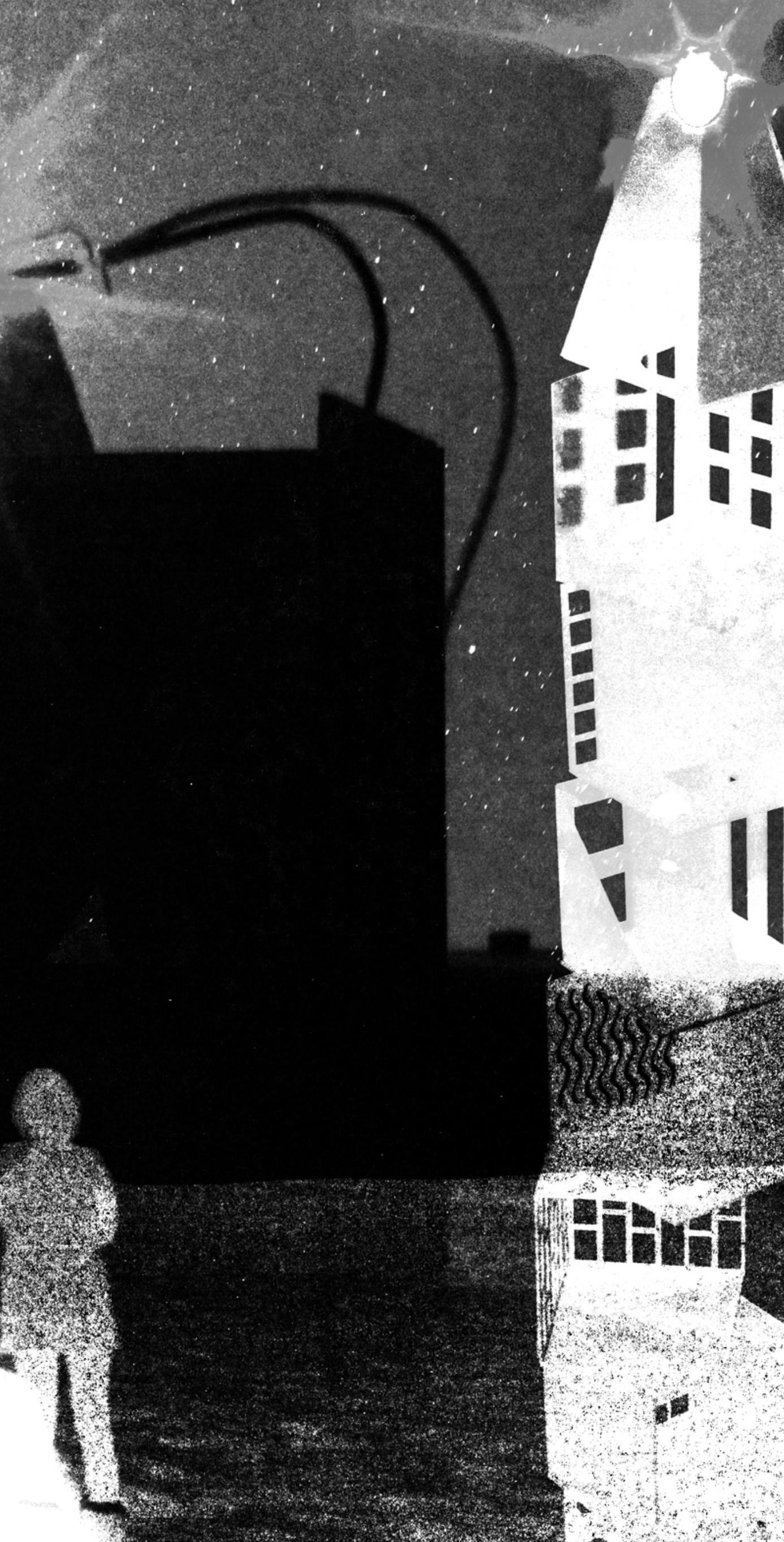




\subsection{WORSHIPPING THE LIGHT}

The last design experiment is a more developed design approach than the previous two. It builds on atmospheric studies and the shadow/light play and uses these design outcomes to manifest the first concept of a structure that surrounds the lighthouse. The designing for the structure draws on the ideas of Diller + Scofidio's 'slow house' to create a narrative based 'stage' where tourists circulate the space vertically, finally reaching the top via a spiral staircase to a platform where they are face to face with the light [of the lighthouse].

Where camp emphasis is on the artifice and the appreciation of 'things-being-what-they-are-not' (Rubin, 1974). Worshipping the light seeks to be an honest, anti-camp expression with an open serious with little 'bullshit' in the way of what's to be achieved. This is about the experience of experiencing the lighthouse, creating a stage in which one understands the lighthouse as an object of fascination differently. 


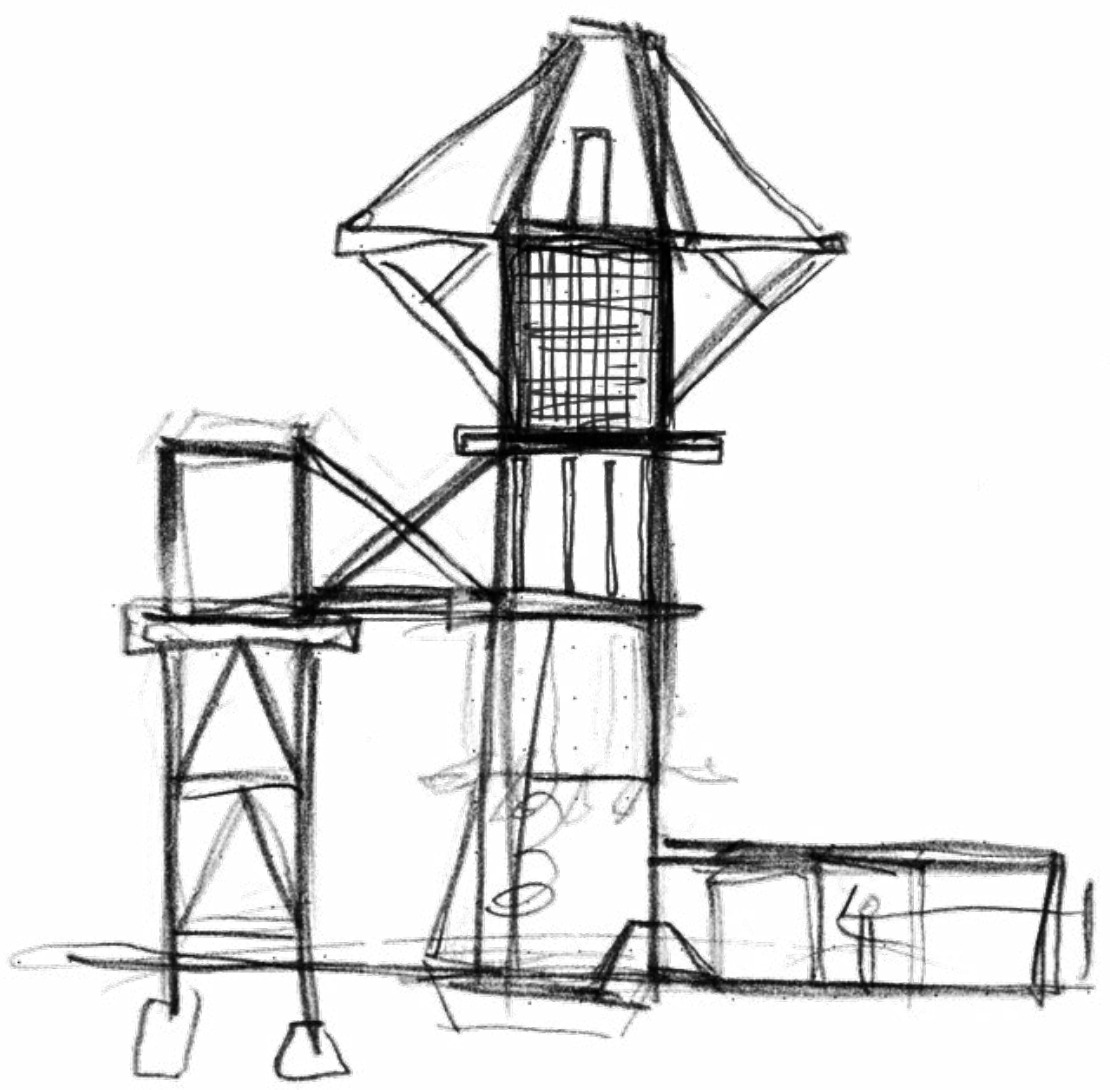

Figure 83 Early Concept work of the Light Device, seen above is a notion of veritcality and movement through space.

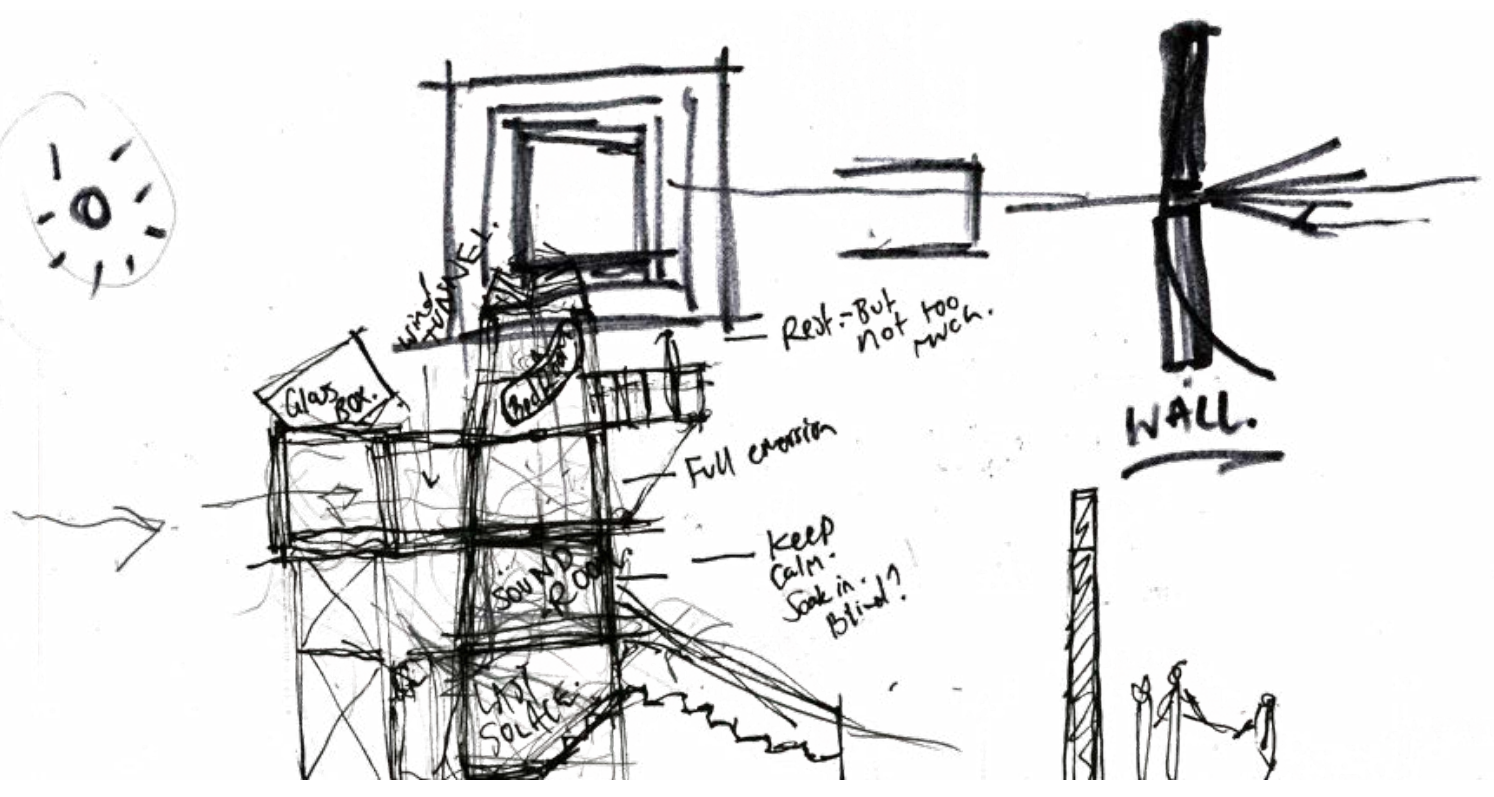

Figure 84 More developed concept work, of the light device, how would the performer navigate the space and what would the experience be. 


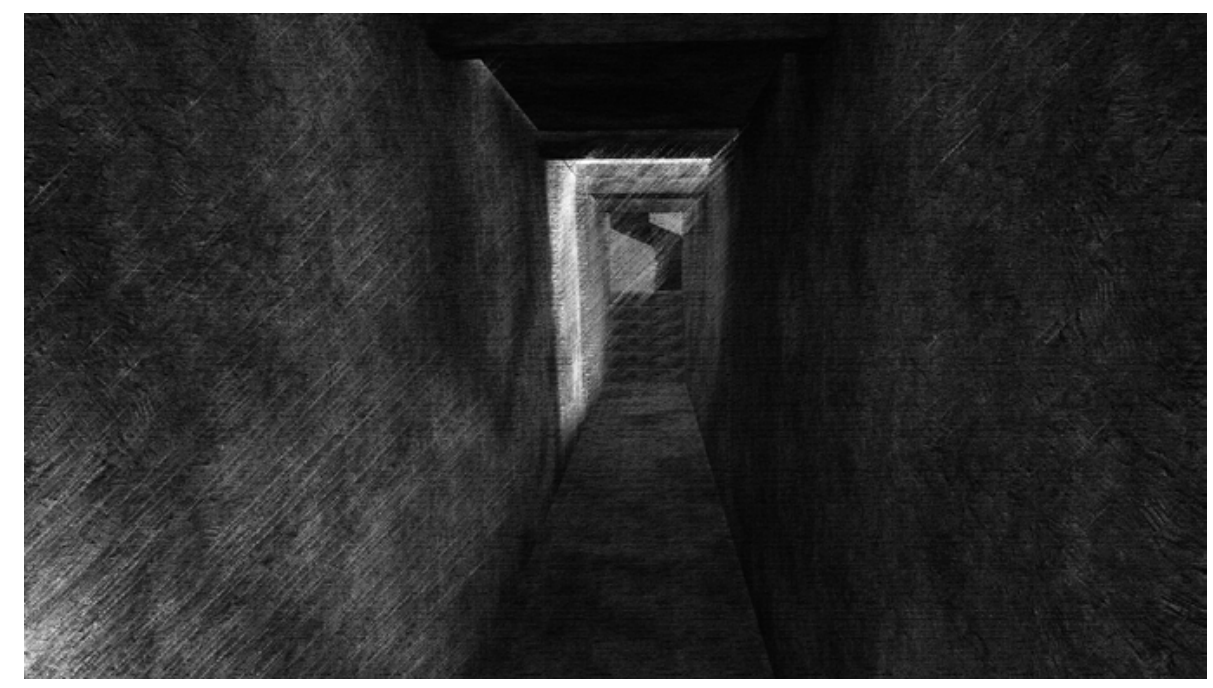

The tourist begins performing through a narrow concrete entrance, where a stair case brings them first up then down into a concrete room with light only from the top of the wall.

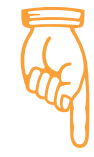

Small openings allow light to pour through into the space but are not at eye level to the performer, creating an intrigue and a desire to venture higher.

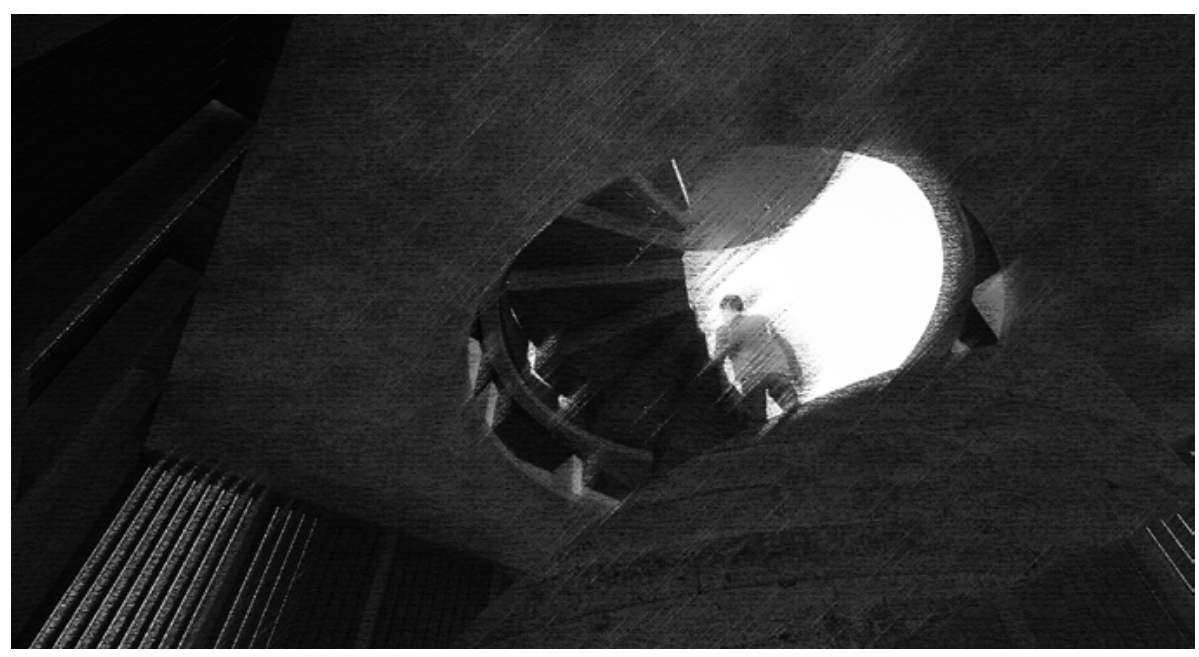




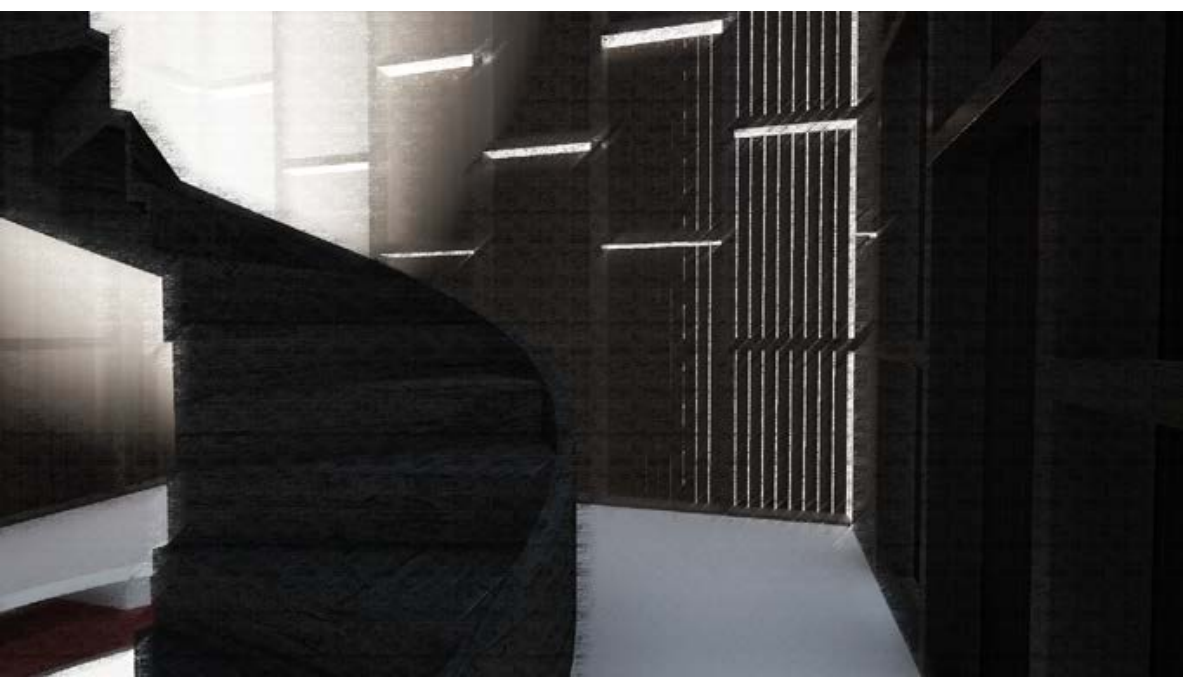

The performer will climb the staircase upwards. The next room is one with exposed studs. The light pours through the cladding, much the same as seen in some of the screen tests in design experiment one. The light from the lighthouse is stronger now but it still is not clear where the light is coming from.

The performer continues their journey up into the next room here they are encased in a fully glass room, the light is intense and it consumes them. The light is too intense to see the lights source, but the feeling of full immersion is unique. This is the most intense the light will be, at eye level with the light.
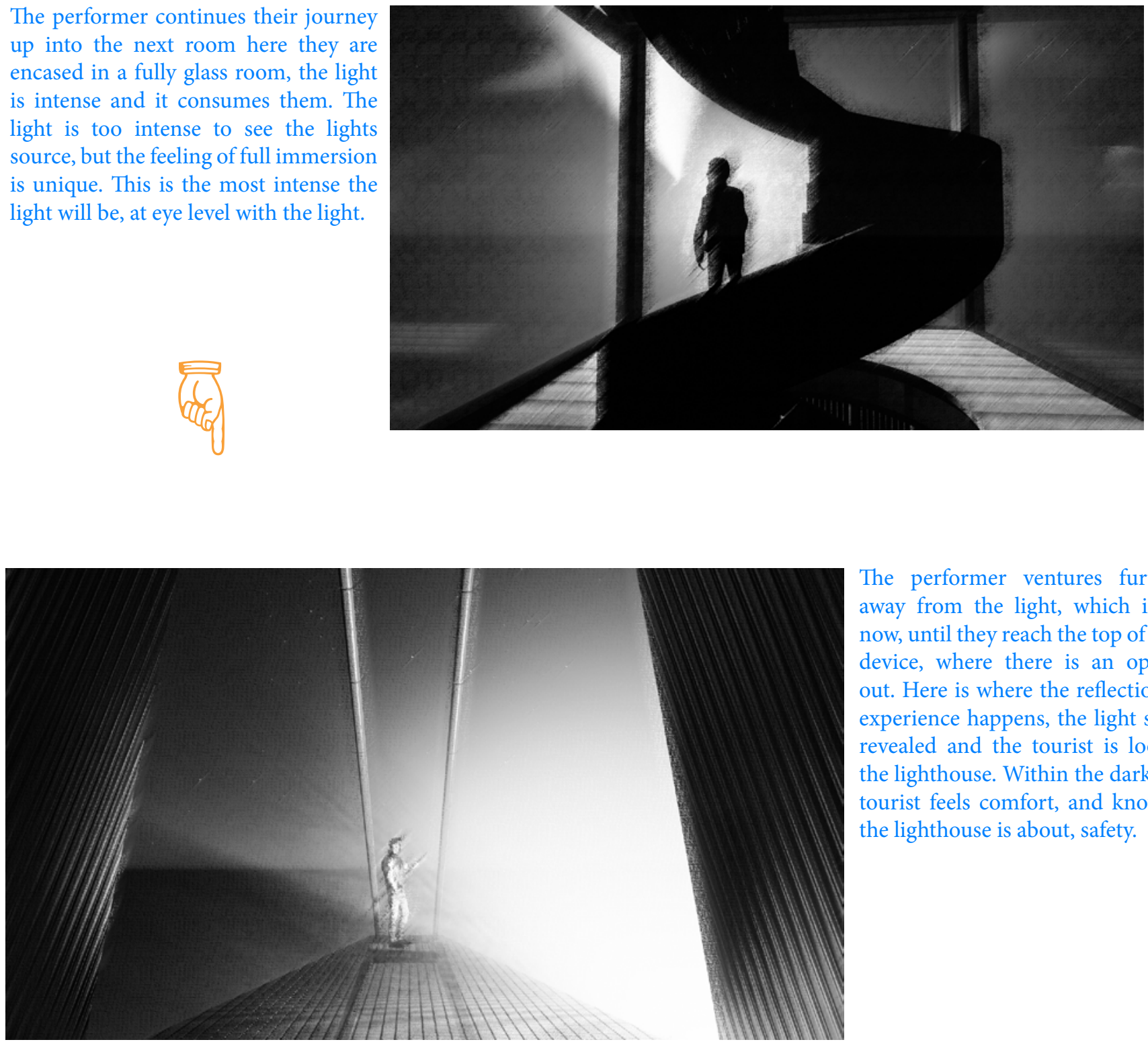

The performer ventures further up away from the light, which is fading now, until they reach the top of the light device, where there is an open look out. Here is where the reflection of the experience happens, the light source is revealed and the tourist is looking at the lighthouse. Within the darkness the tourist feels comfort, and knows what the lighthouse is about, safety. 


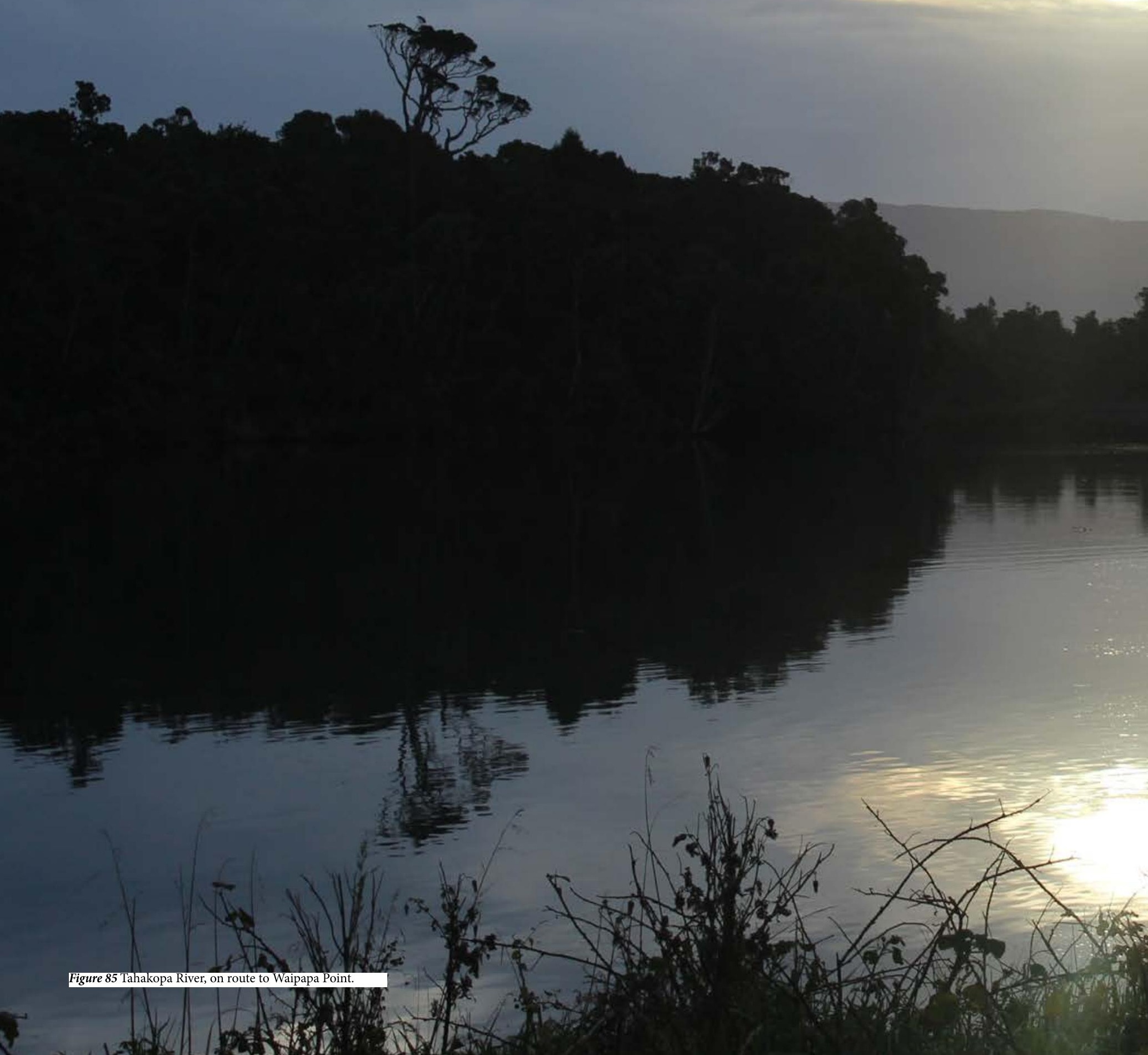



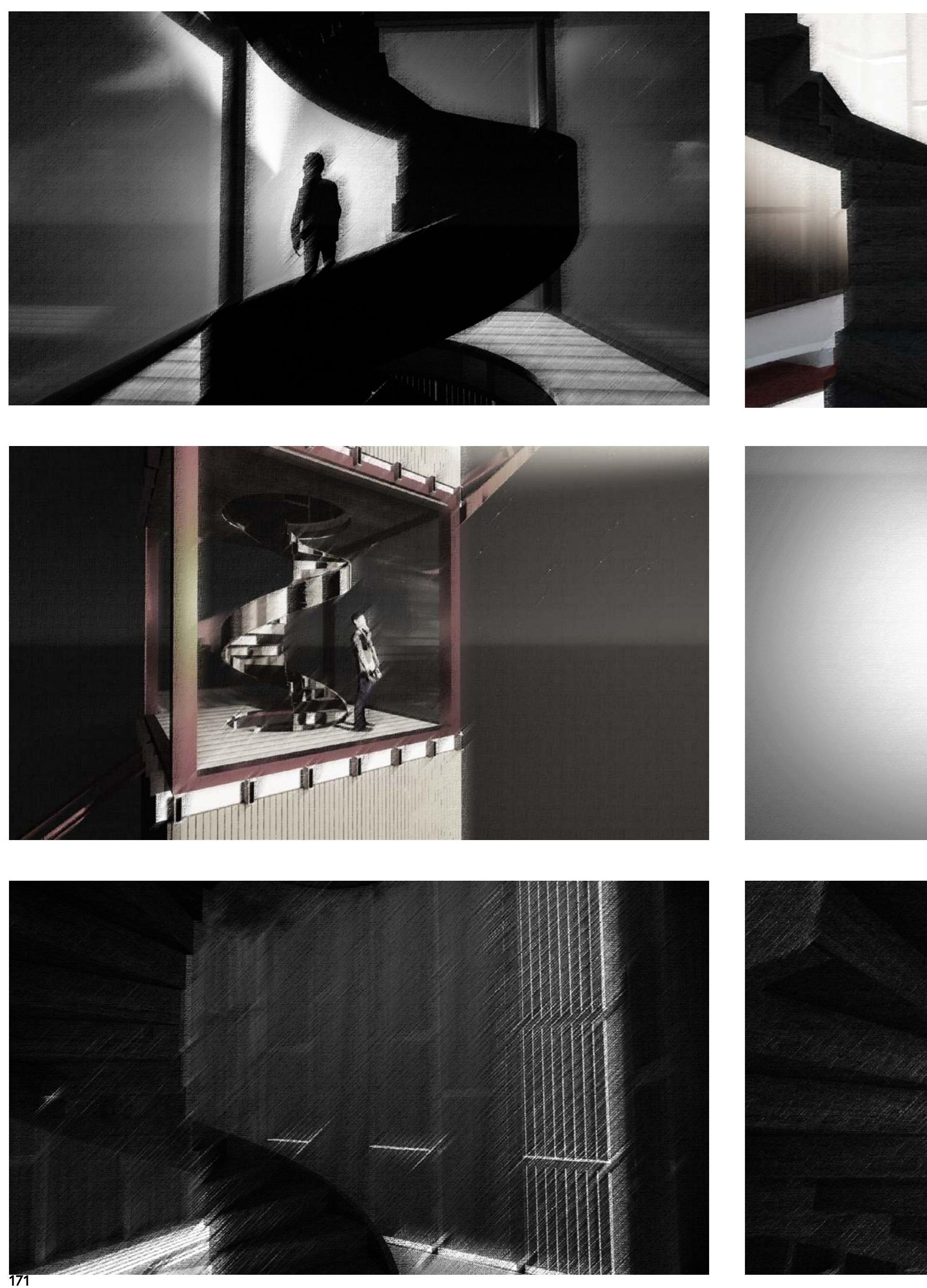


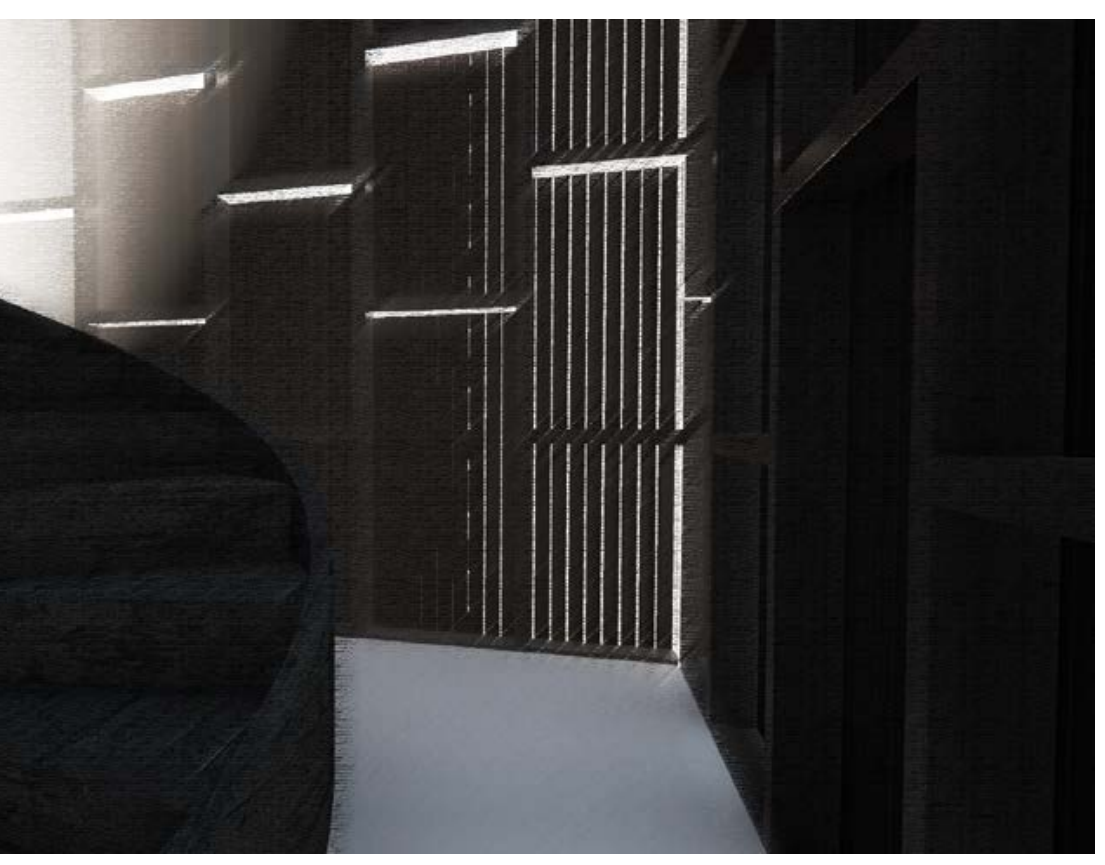

Additional renders from the light device, showing the balony, the glass room and the timber room, Light condition and atmospheric conditions of the light.
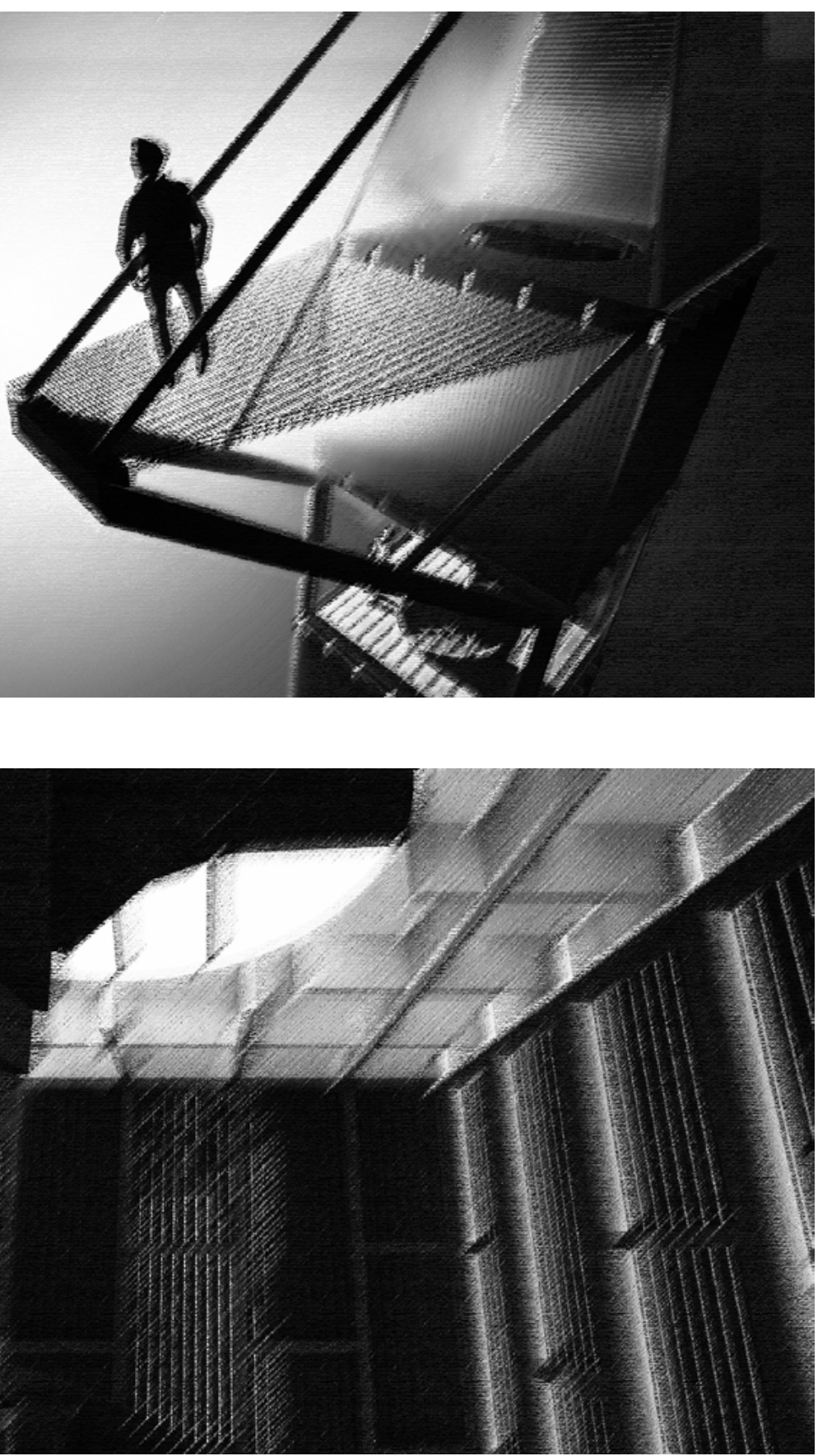

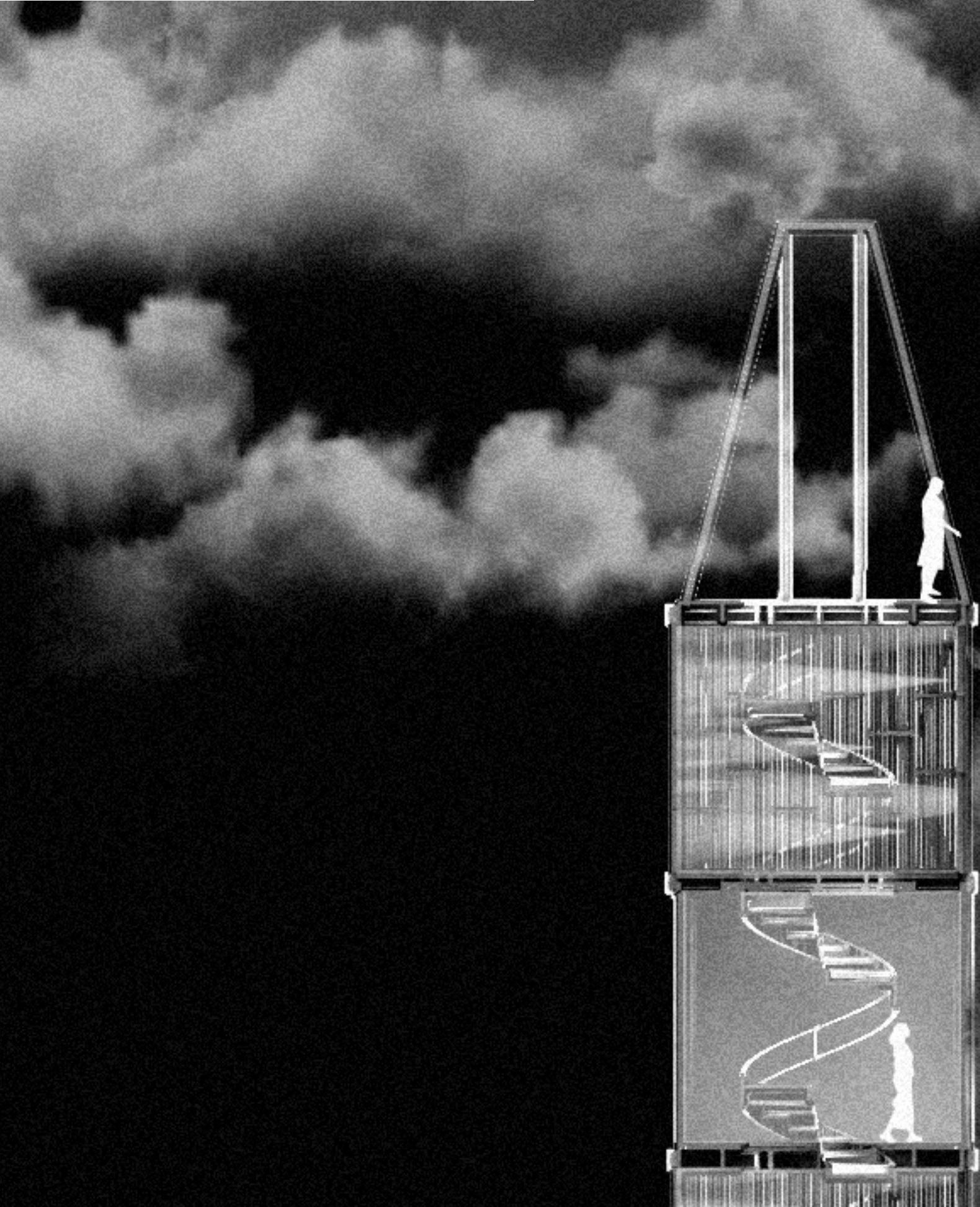

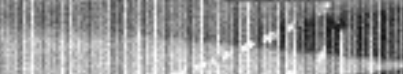
3.

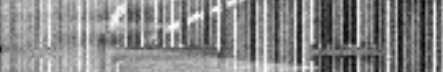
(1)

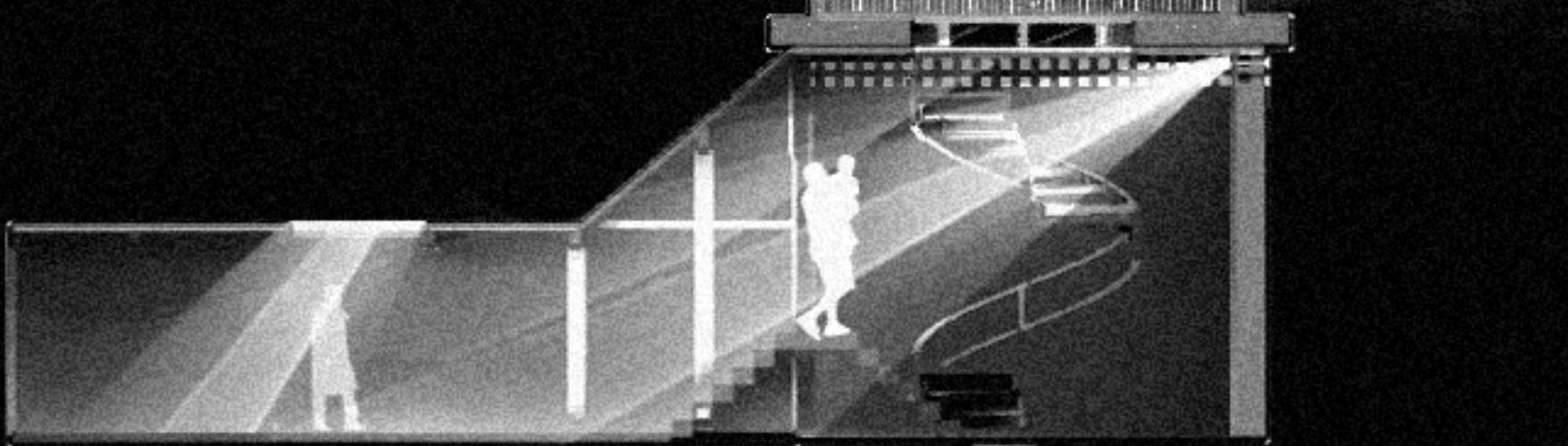



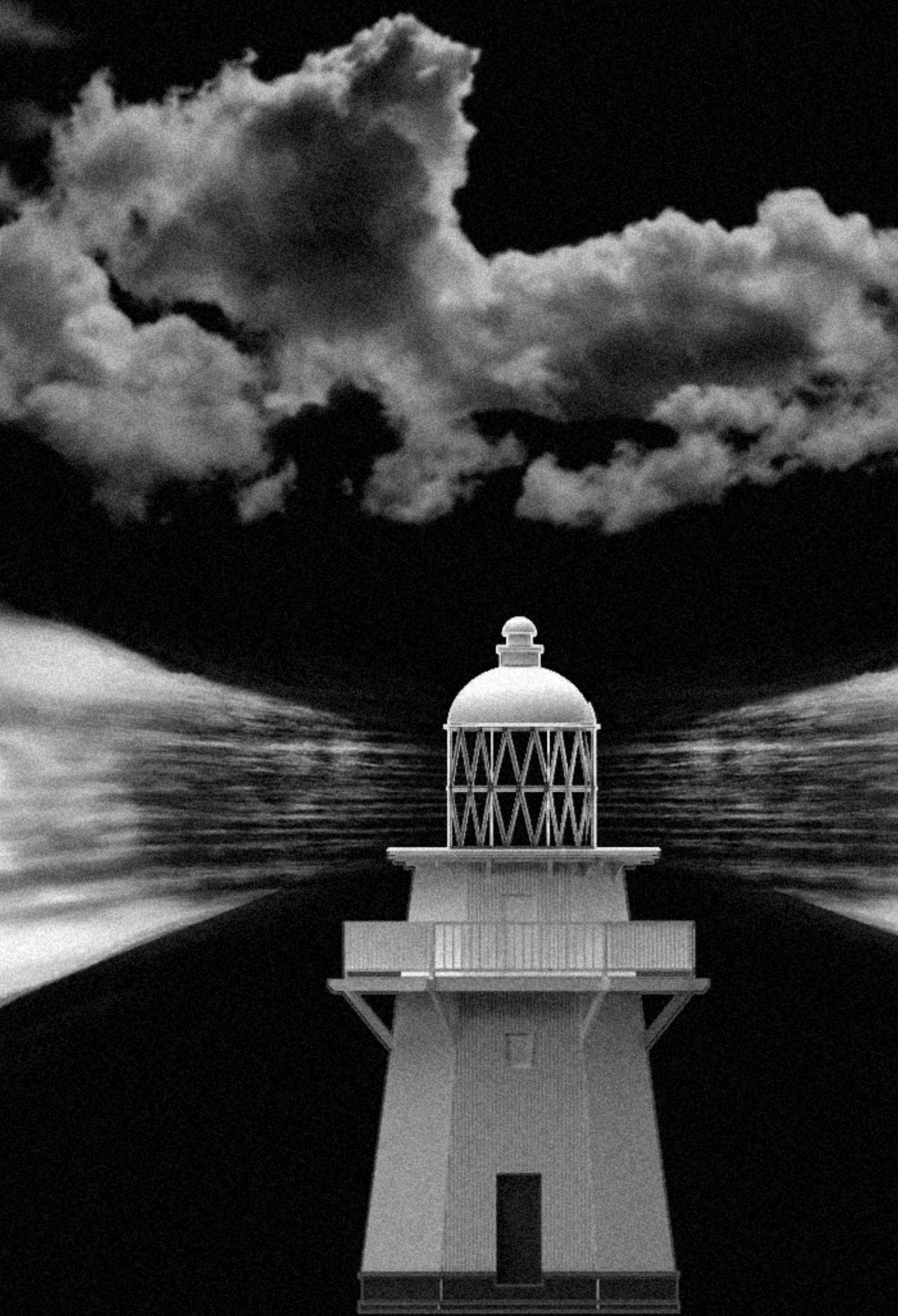




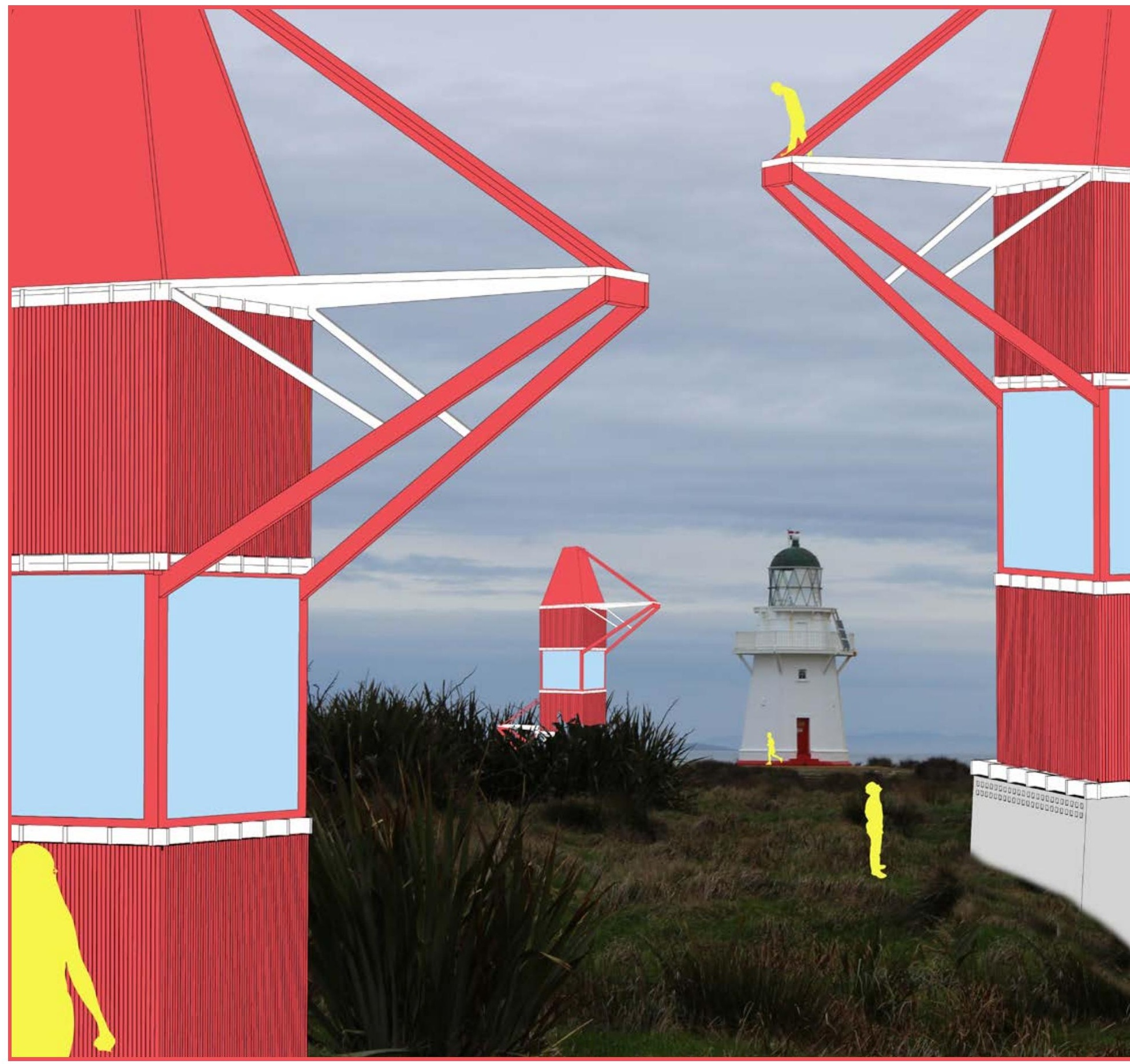



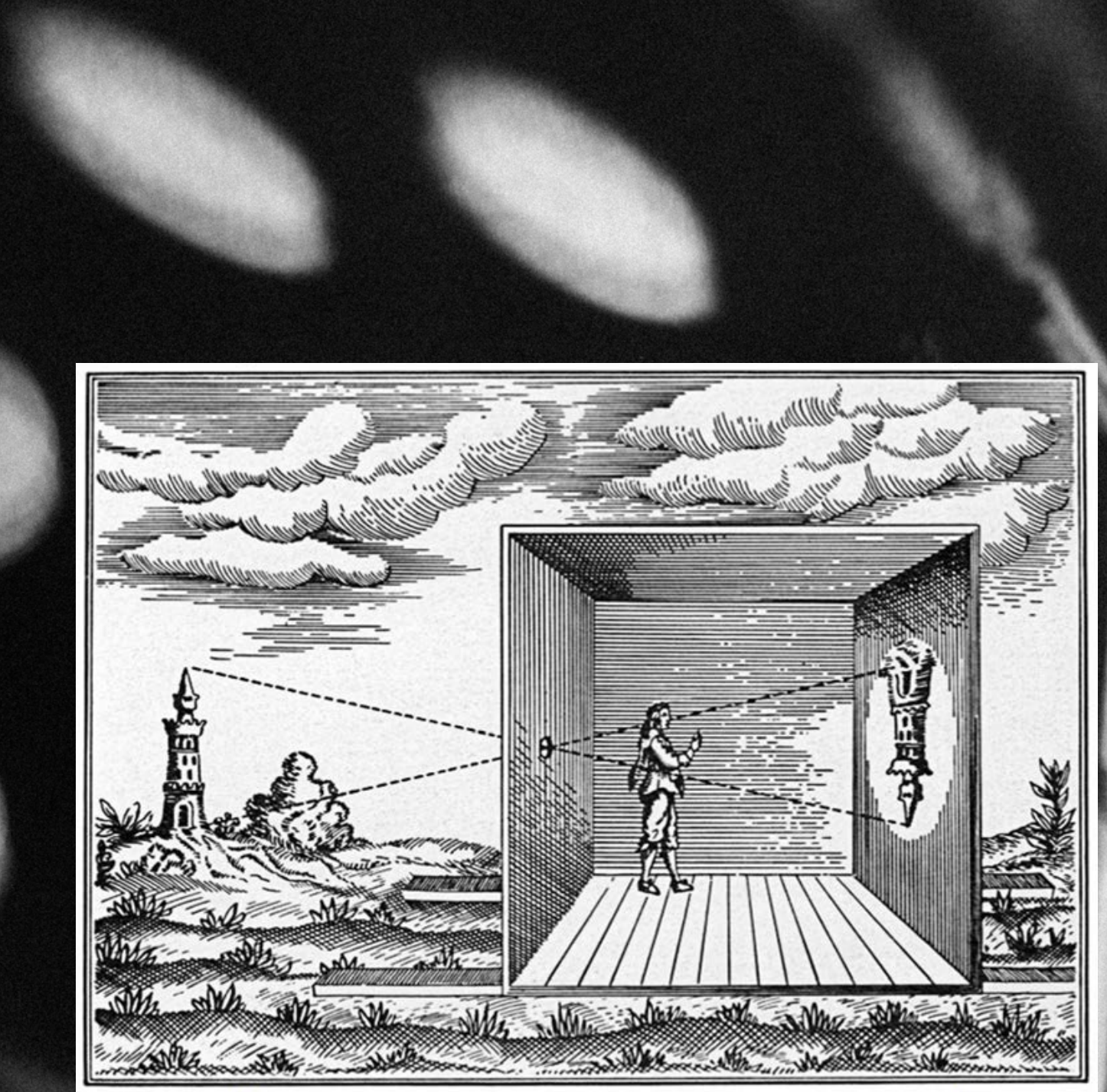

Figure 89 A Camera Obscura

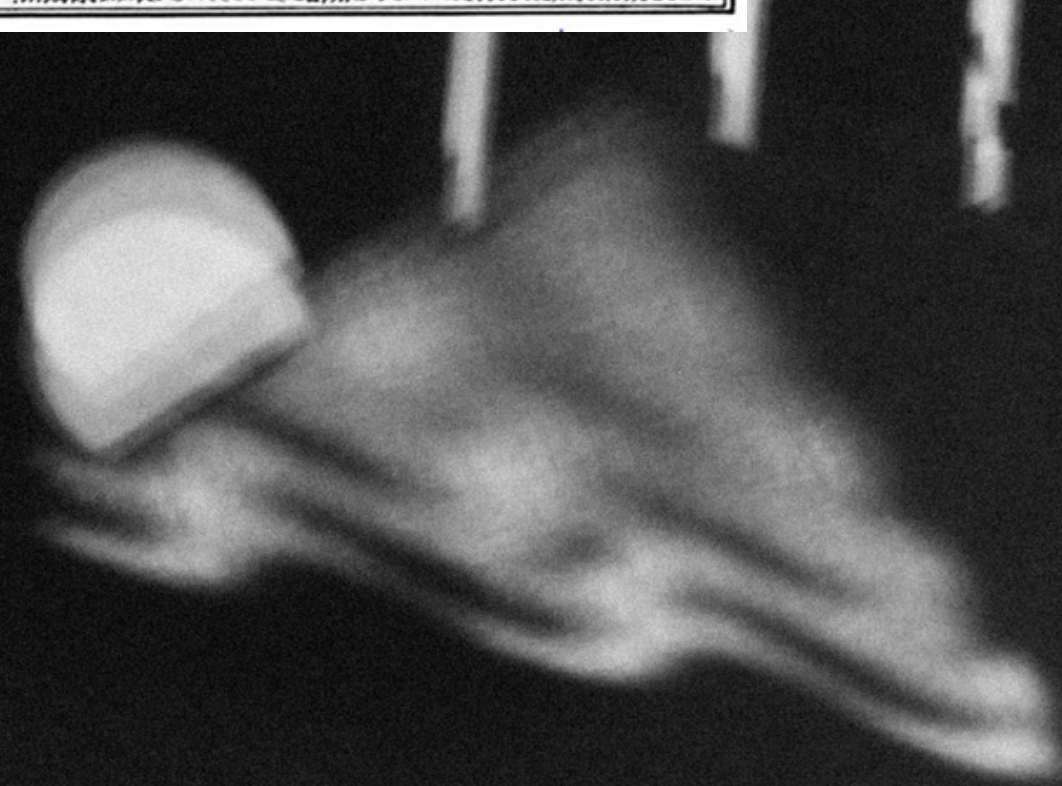




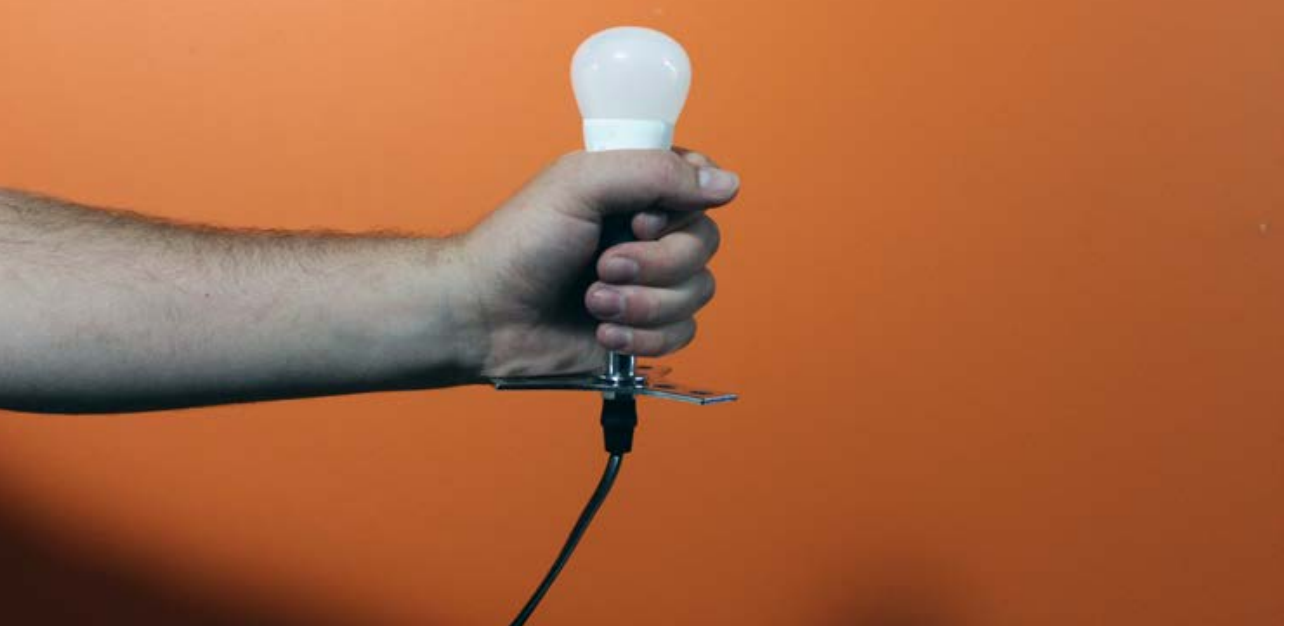

Figure 90 Author with lightsource- off 


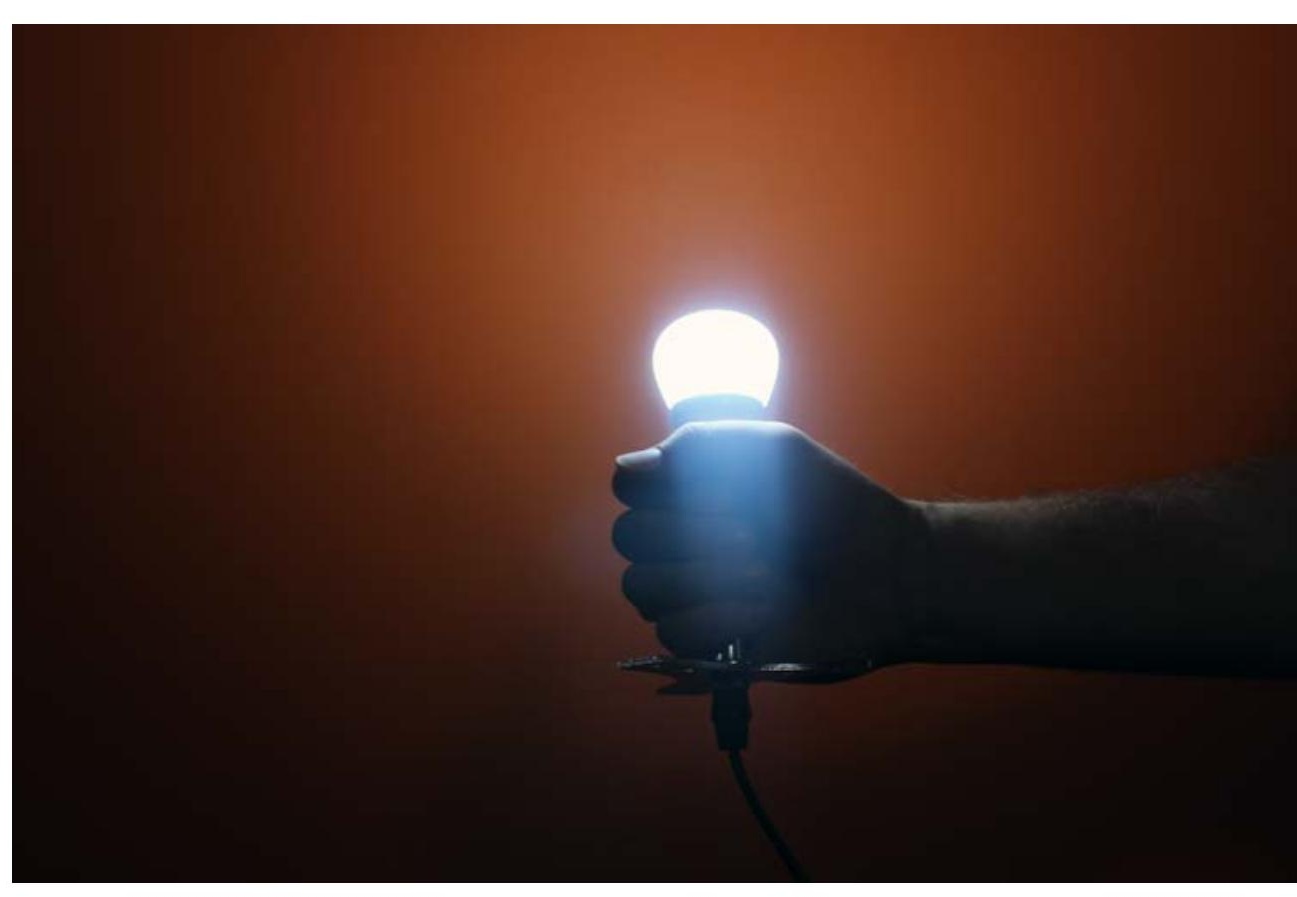

Figure 91 Author with lightsource- on 

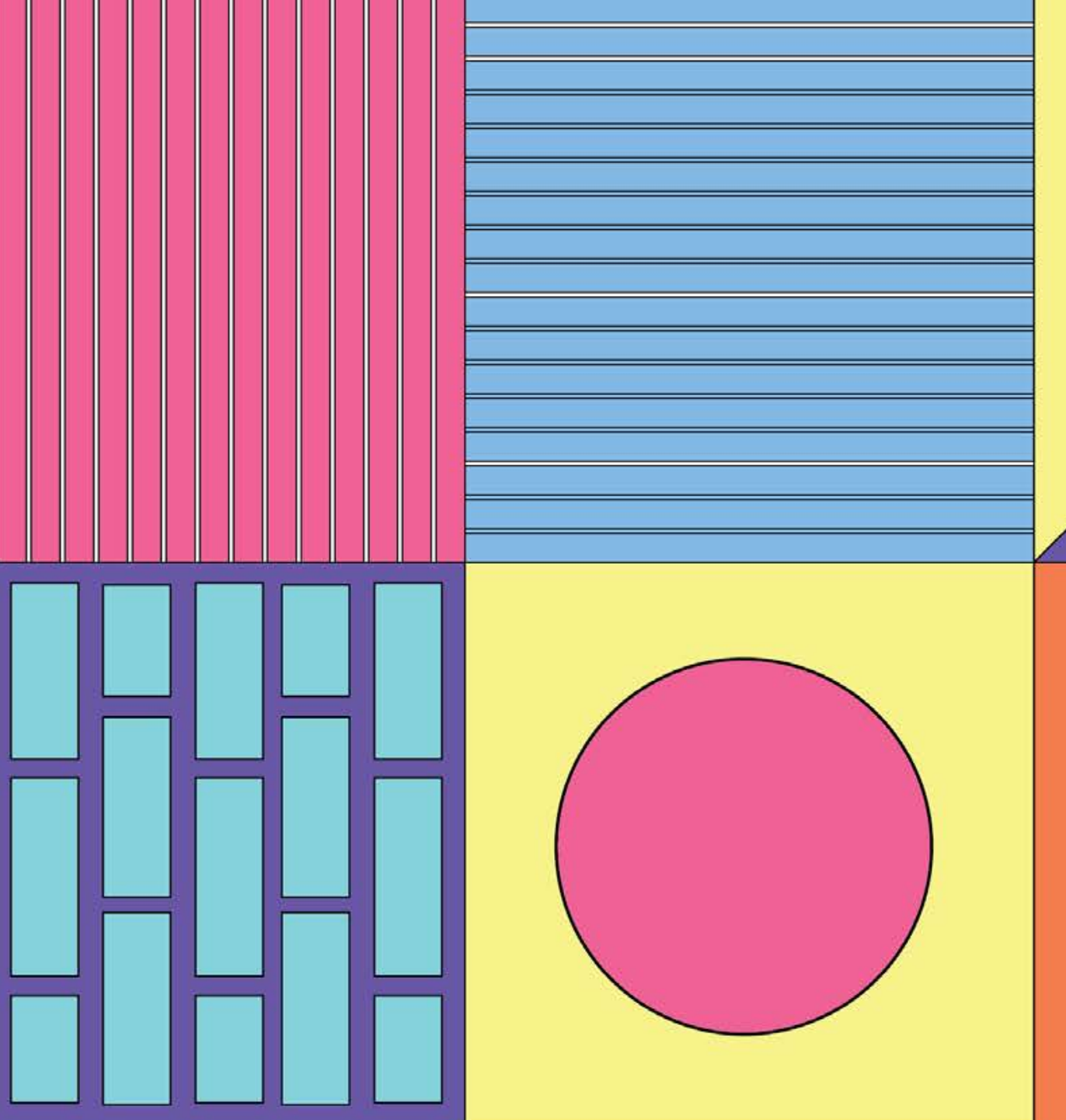

$0 \bigcirc 0$

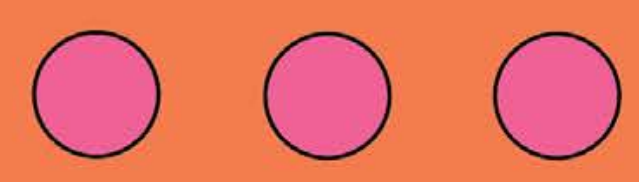

$0 \bigcirc 0$
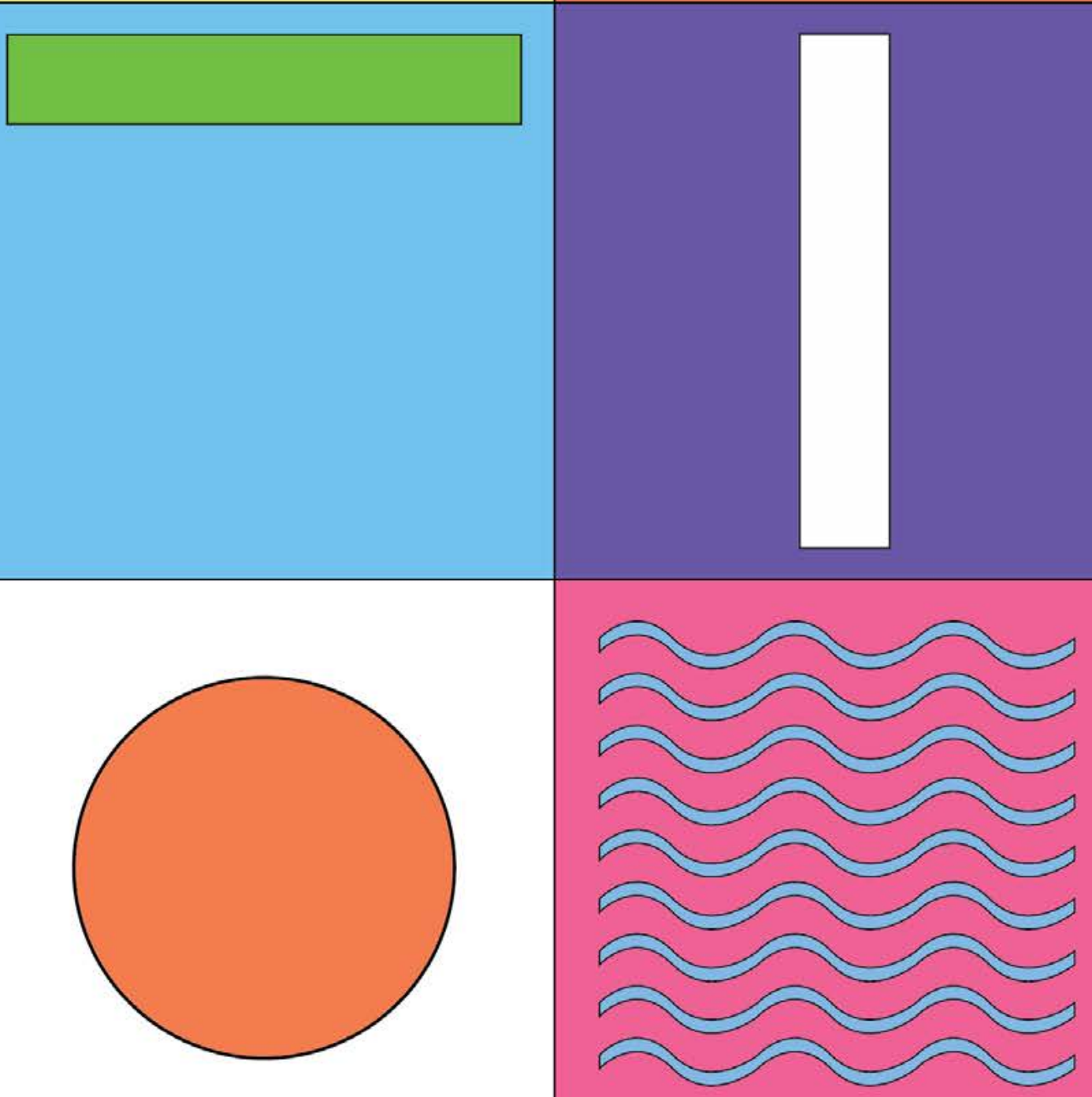

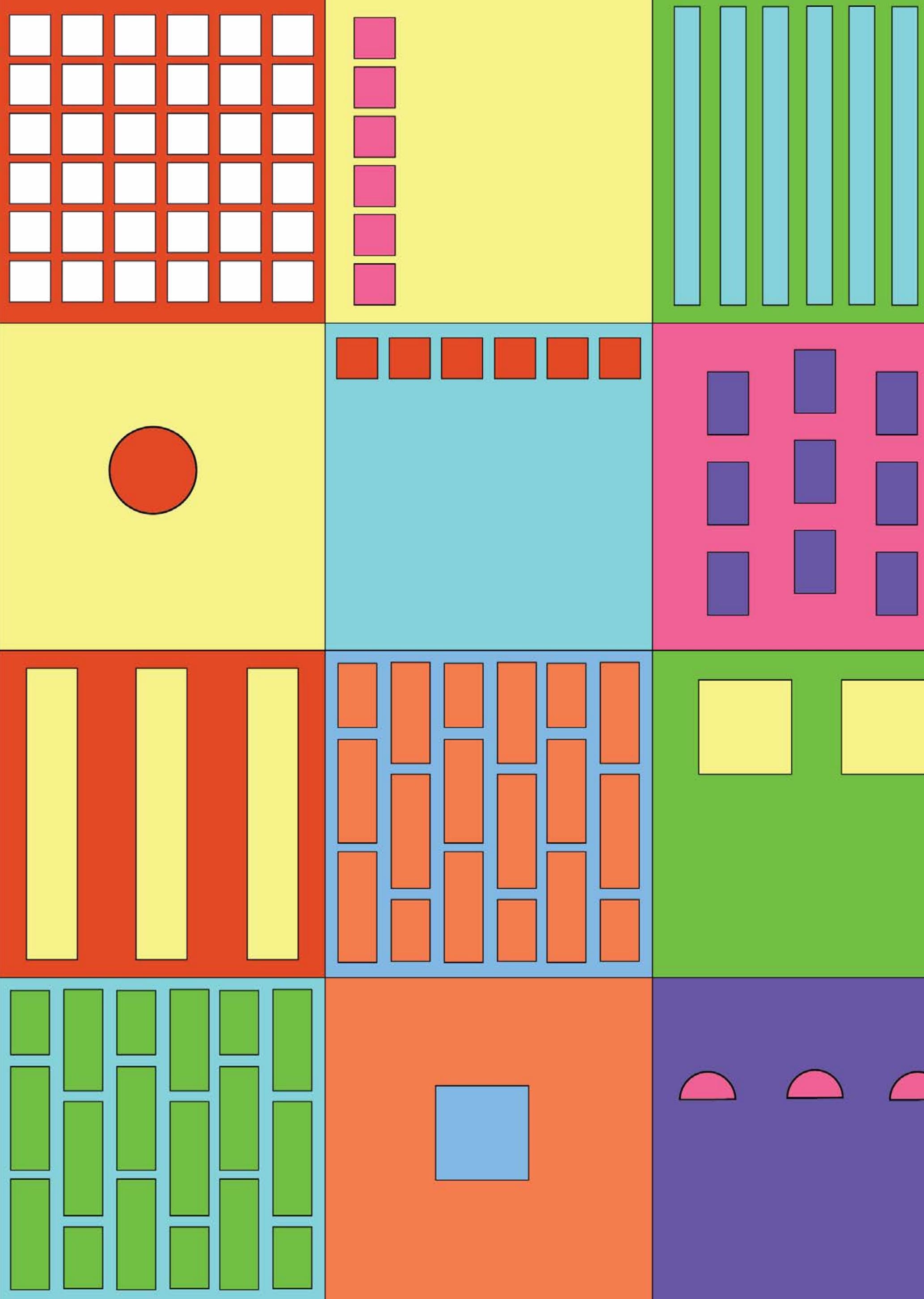

$\bigcirc \bigcirc \subset$ 


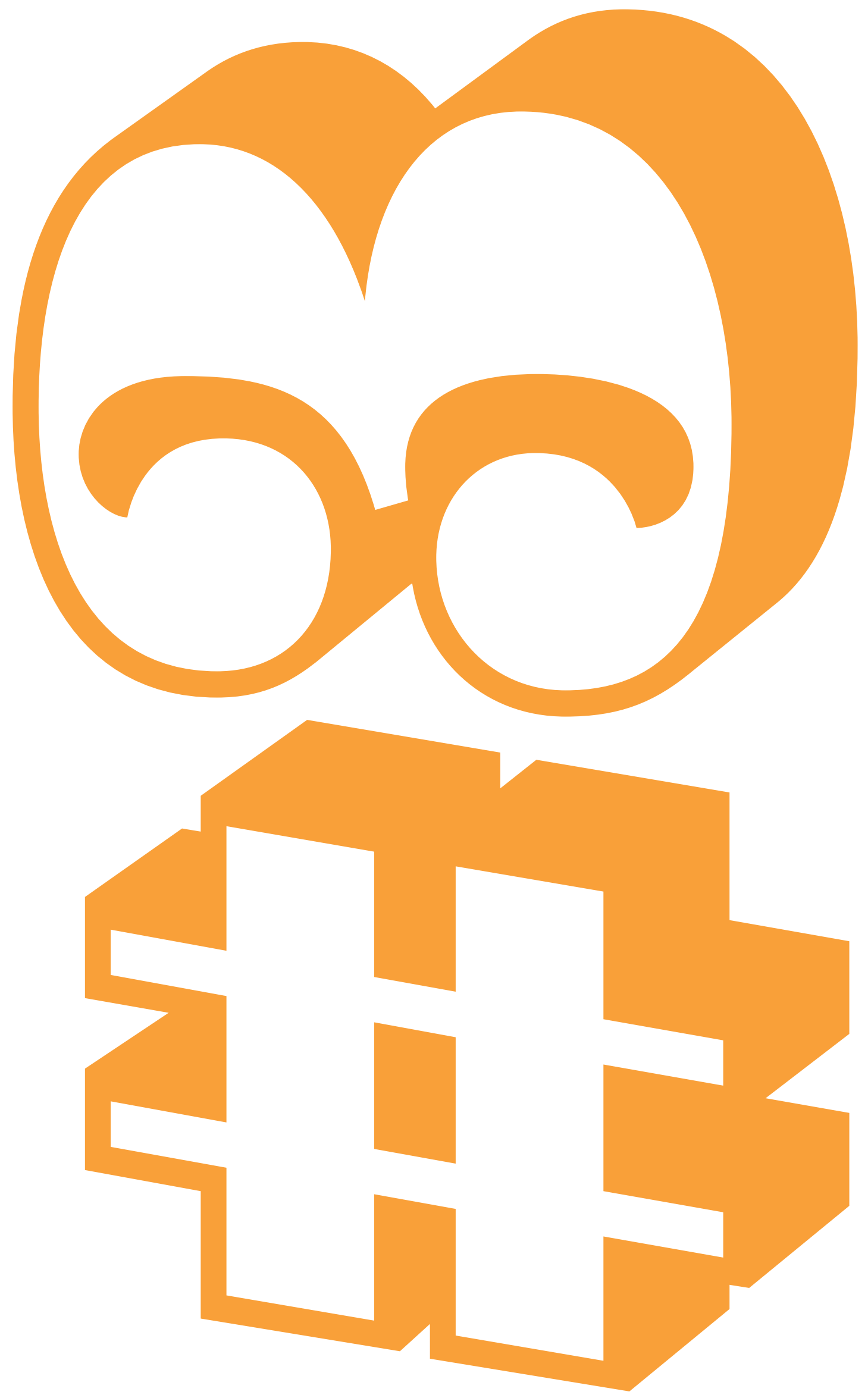




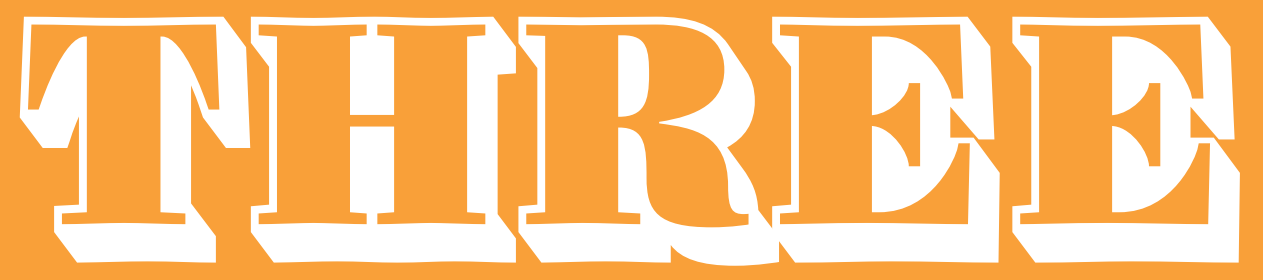

"The Stage Complete"

The Camp lens is reinstated, but is refined, the design is a stage, showcasing the crux of the lighthouse. 


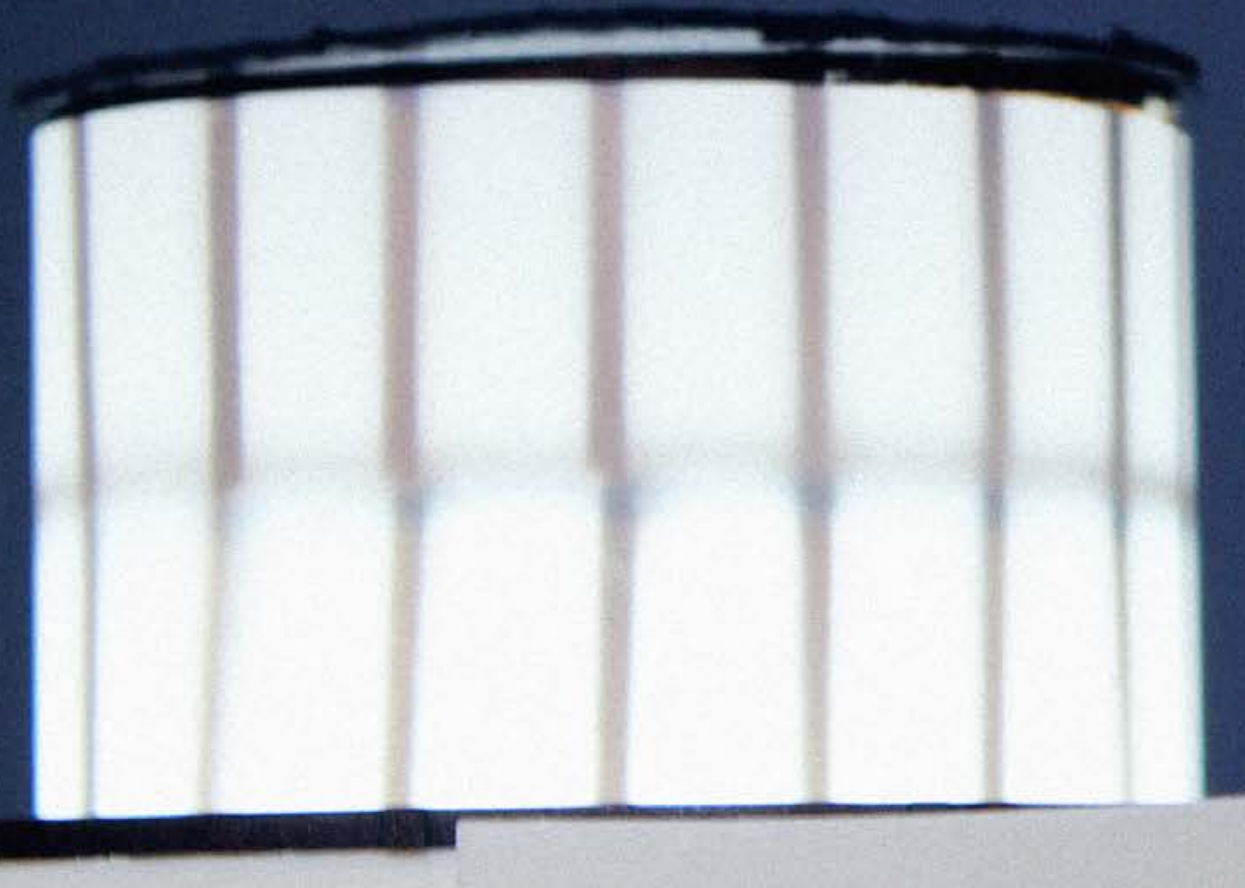

$-7$ 


\subsection{INTRODUCTION}

The third and final logic of this thesis aims to create an architecture that facilitates the experience and enables the act of the performance of tourist, creating an exposé on the lighthouse. Here the lighthouse is enclosed, keeping it safe while showcasing it to those who enter the building. Unlike Phases one and two 'The Stage Complete' is designed to be experienced both day and night. From the analysis of the past two phases, a design architectural framework was developed from what was successful in both. This framework, along with the site and program will inform the research through design. A concept phase, using digital modelling methods and analogue sketch design is formed from which there a final developed design will be formed. This final design is an architecture for the lighthouse, with its one program being to showcase the lighthouse and its site.

A stage is hereby created, in which people can engage with these lighthouses differently, for an experience that teaches, makes them feel.... (without sounding moralistic). And create an experience worthy of a checkpoint on a journey. The end design is a commentary on the tourist landscape, the theories of seeing and experiencing, it reveals the absurdity of consumption, the sensibilities of camp, the experience industry and how we visually consume objects. 
Figure 92

A developed concept sketch of one of the proposals. The design aesthetic is a mix of functionalism, a direct reference to the weather station at Baring Head Lighthouse, and Camp. If anything the constructive nature of the architectural elements is used to establish its direct functional requirements which are mainly circulation. It uses as little facade and artifice as possible but retains colour as a nod to the whimsical nature of lighthouses. Within the sketch are visual references to the work of the likes of Cedric Price.

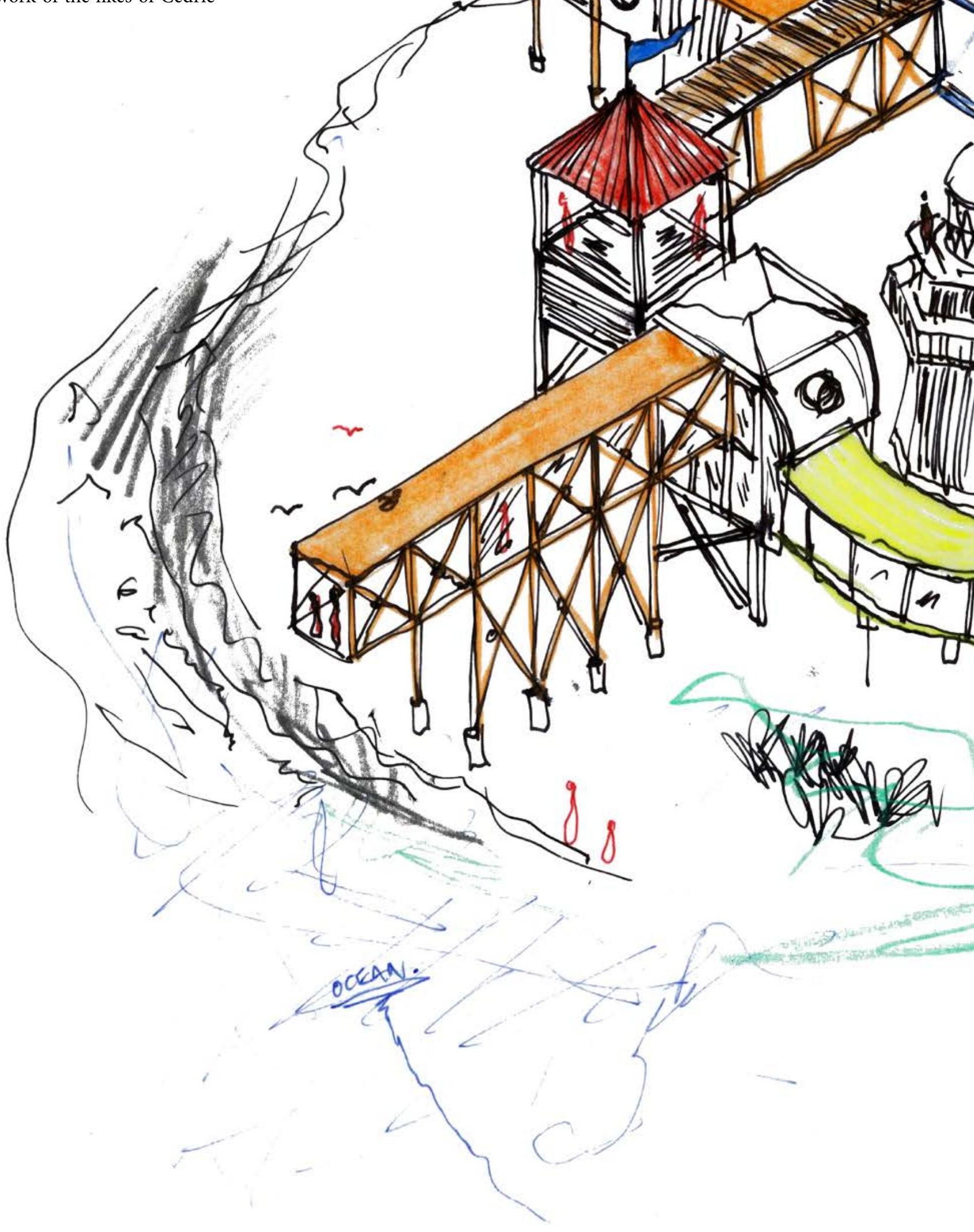



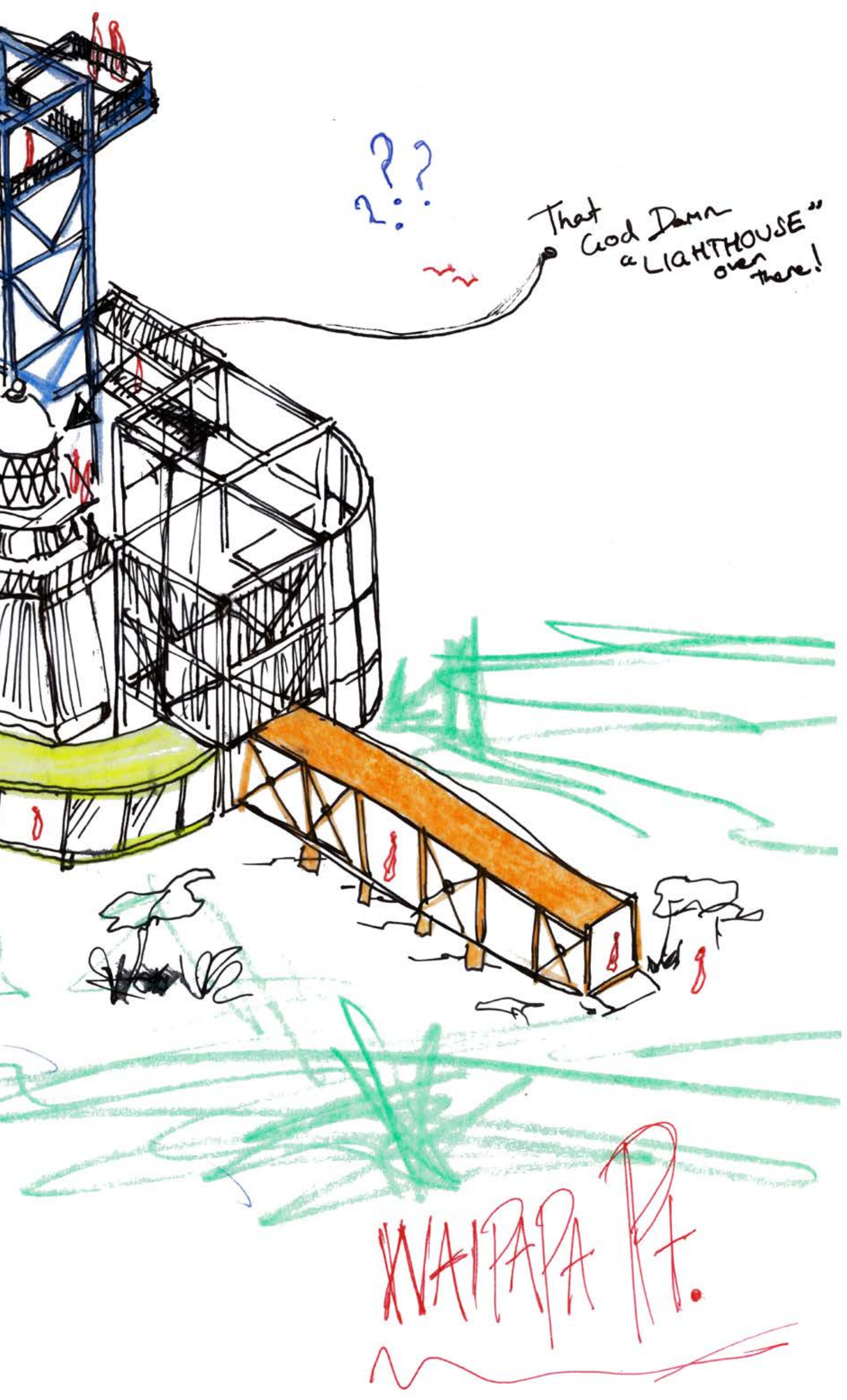


\subsection{DES/GN REASON/NG}

The constructivist aesthetic of the developed and concept of the design derives initially from, First, a personal design language I engage with and enjoy using and, second, from a memory of an earlier trip to Baring Head lighthouse at the start of 2020. When approaching the Baring Head Lighthouse, a supplementary vertical structure captured my attention, a bright blue weather station. There is no reason for a weather station to be painted bright blue, other than possibly preventing rust. This supplementary whimsical architecture overshadowed the lighthouse and in a way became the focal point of the trip. This raised the question of when something overshadows the former, what is a tourist object? 'How cool would it be if it wrapped around the whole lighthouse?', this and the notion of these structures "stealing the limelight" and hiding the lighthouse created a design objective and way of designing. By creating a distraction, or a marker for people to explore attracts those into what is hidden within- the lighthouse.

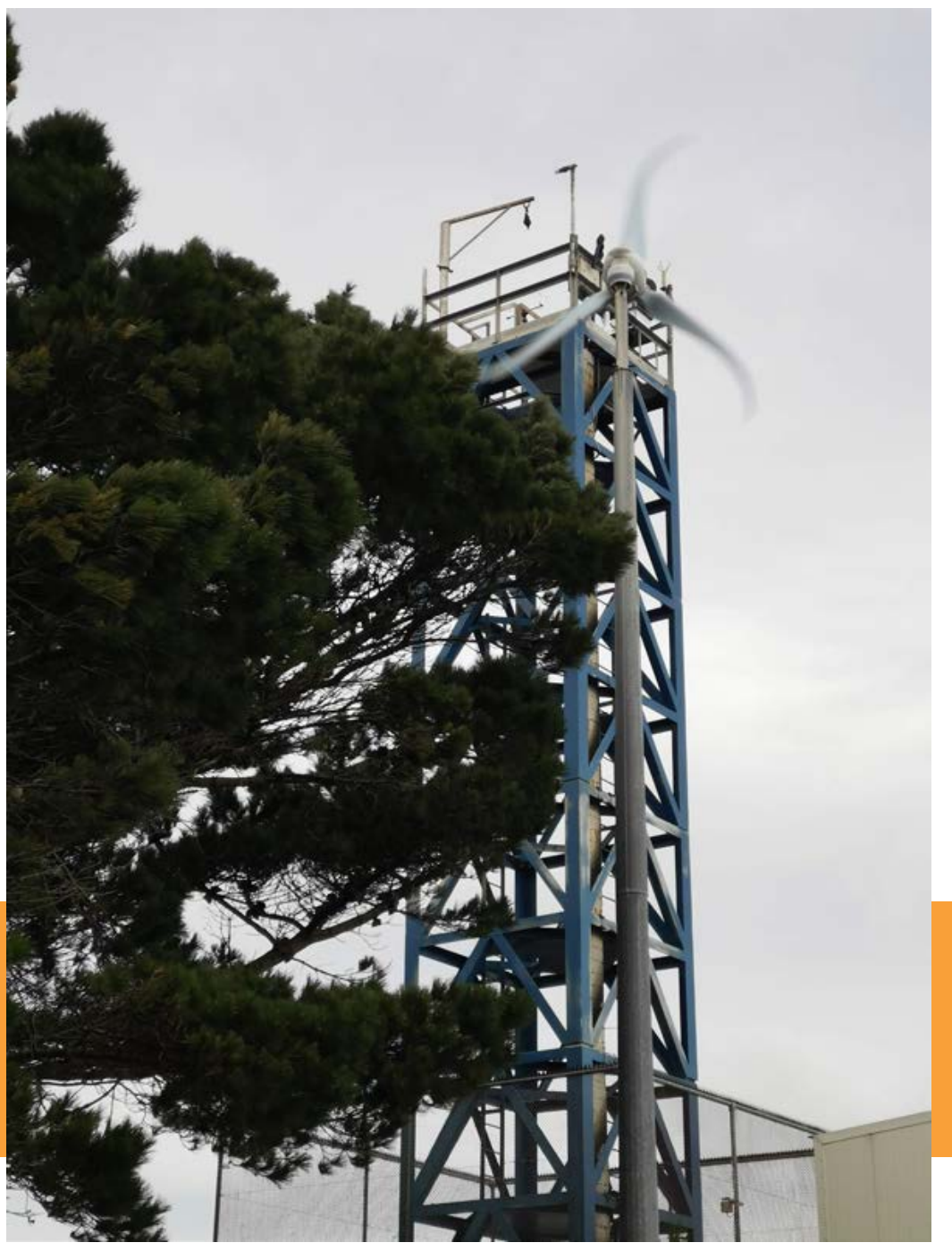

Figure 95 The weather station and wind turbine 


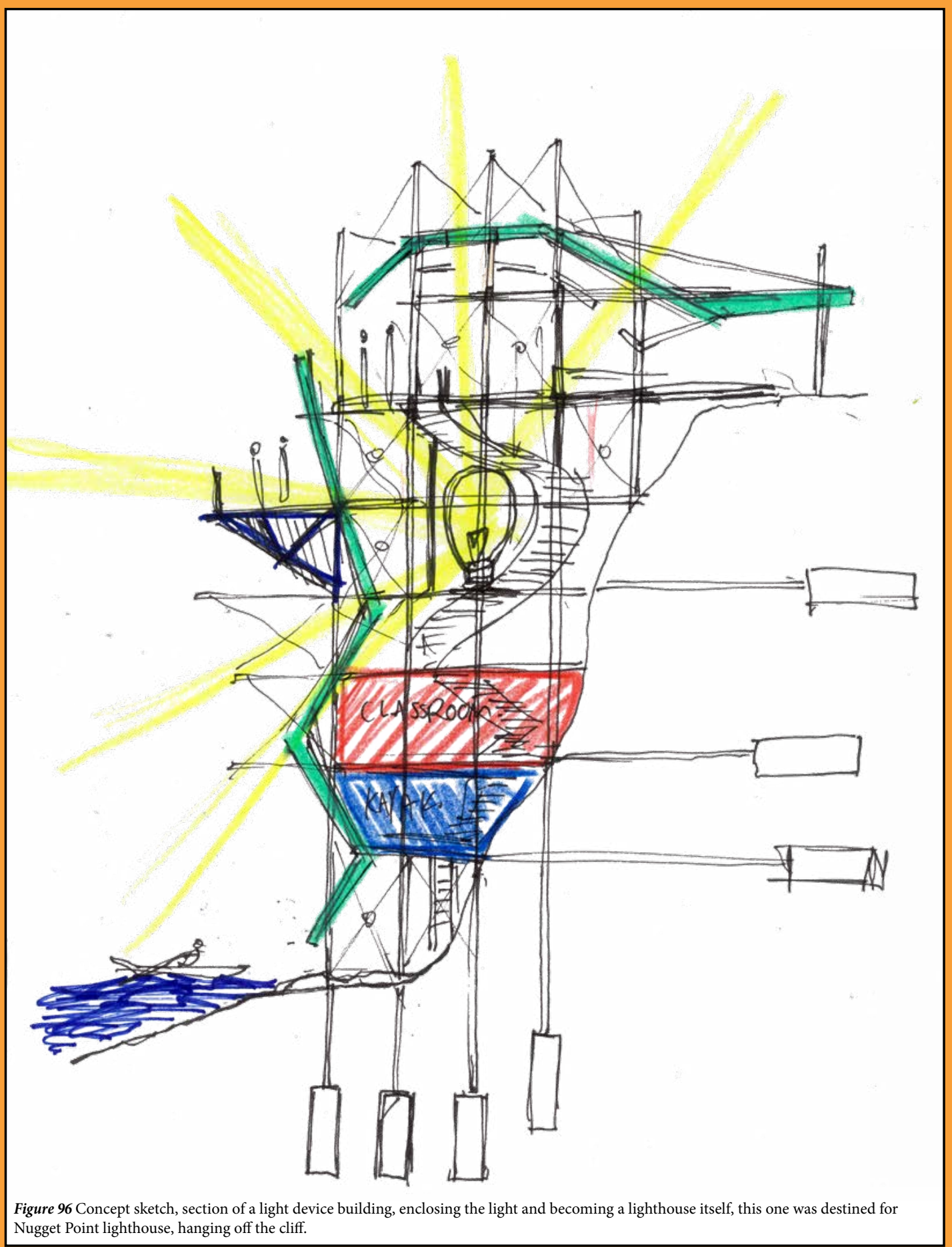




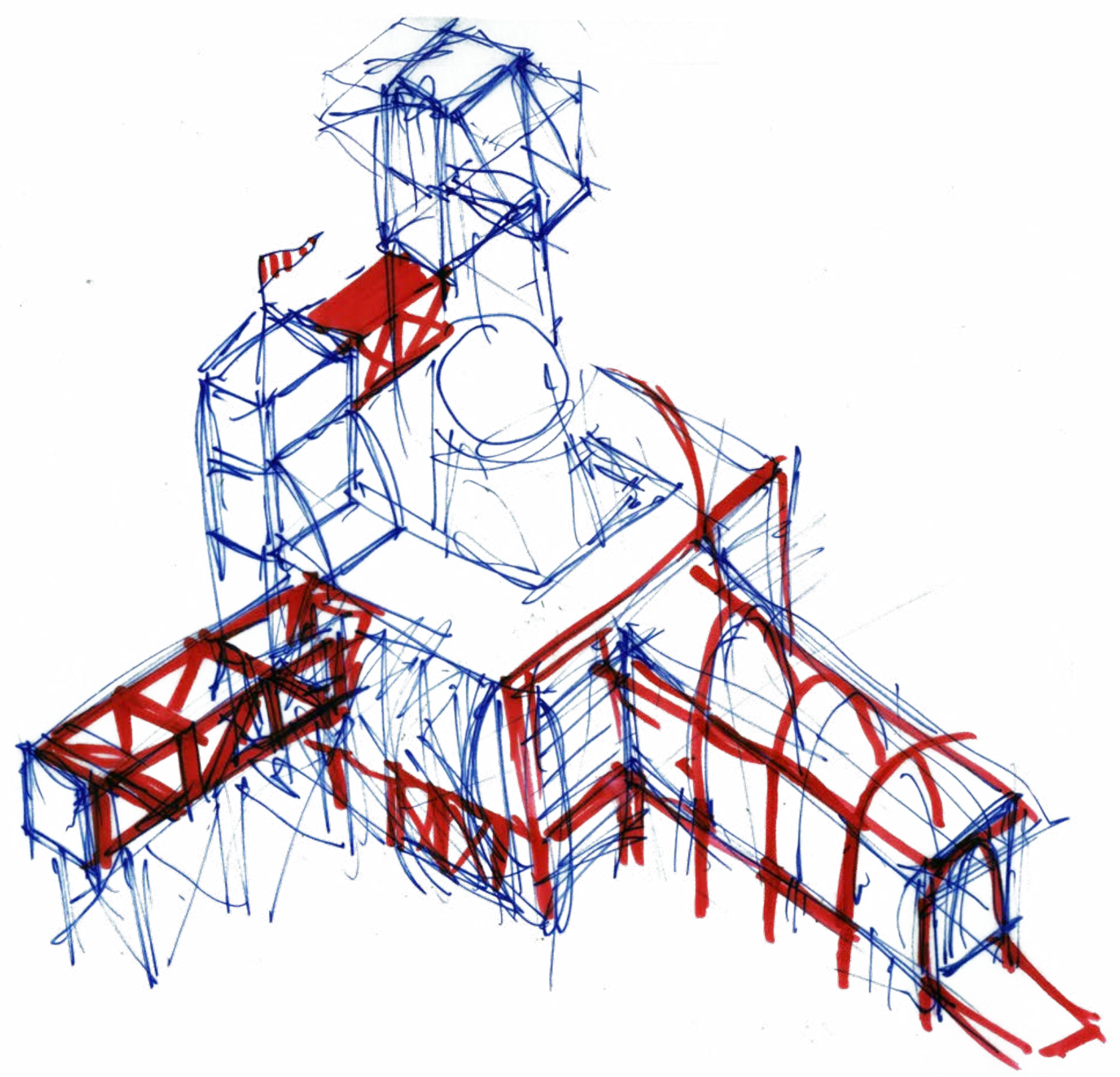

Figure 97 Concept sketch, starting to look at multiple components of design, structure and how to wrap around and ultimately enclose the lighthouse. 

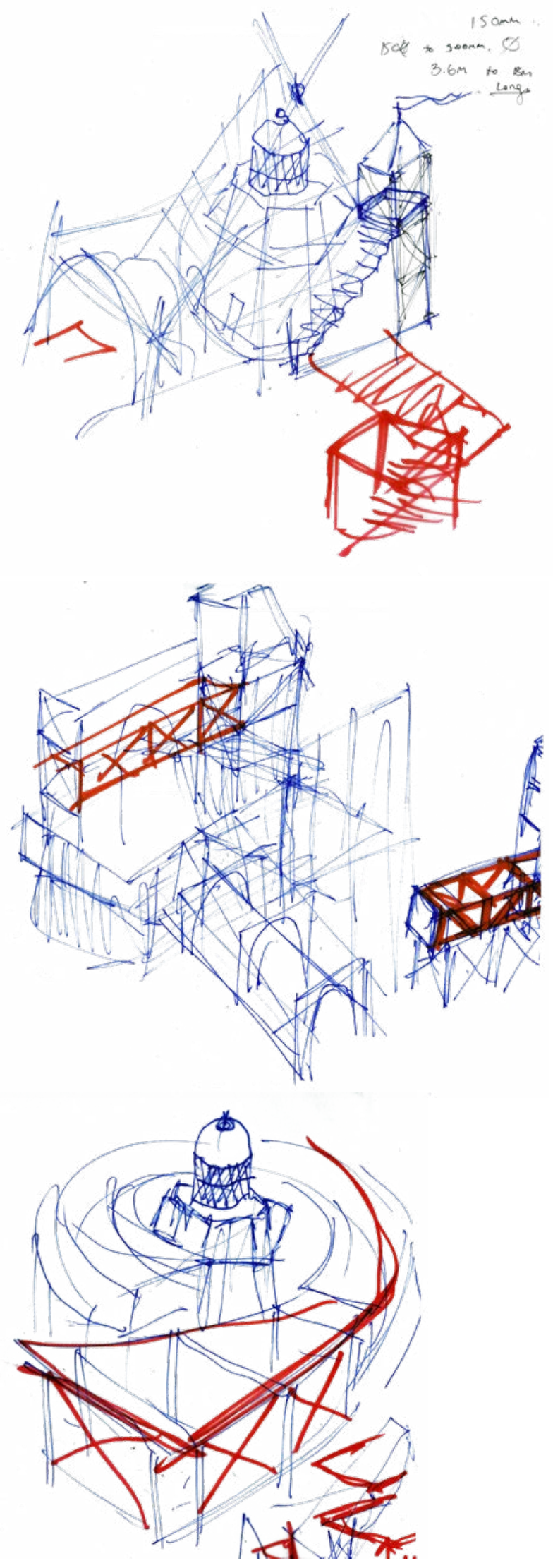


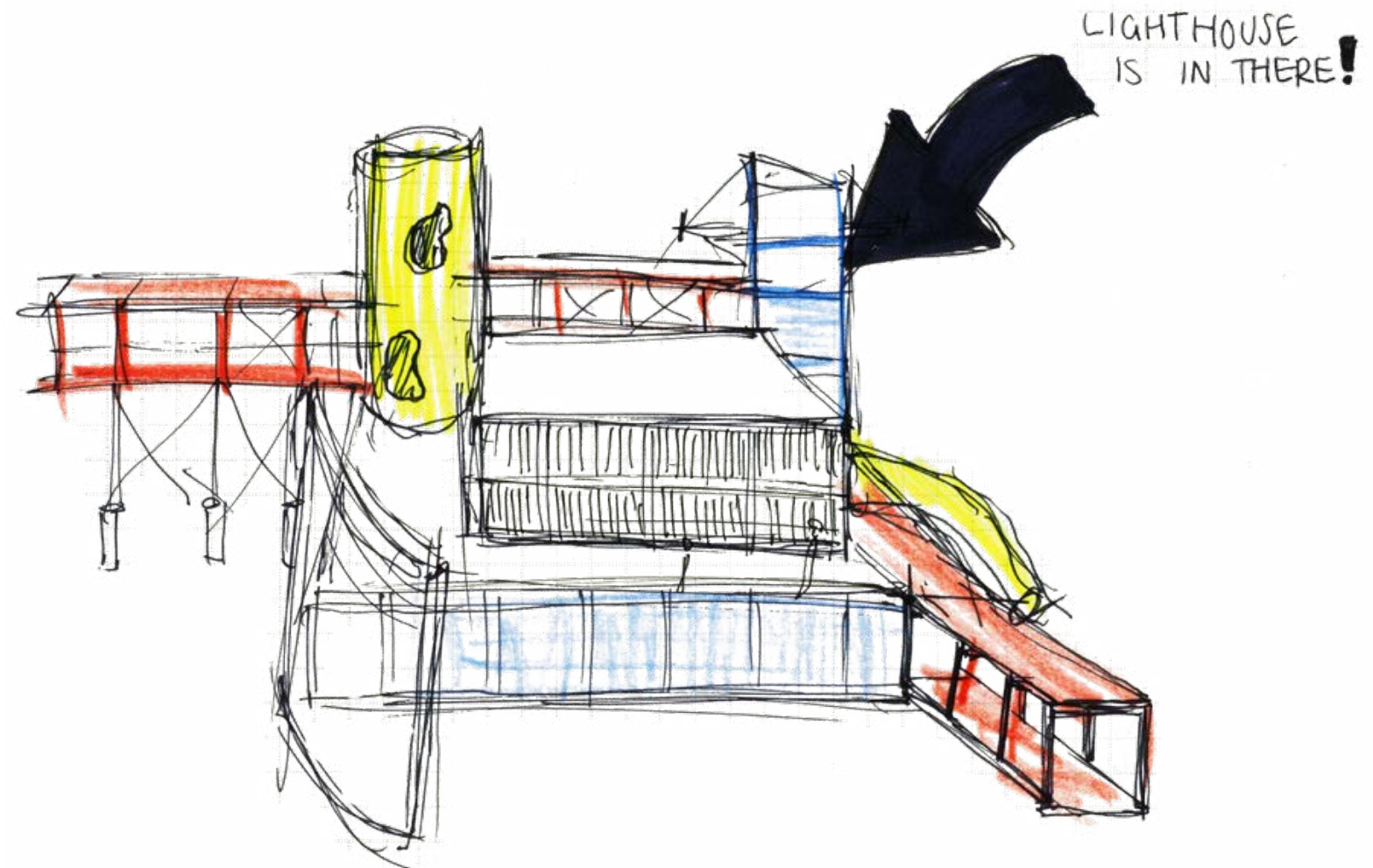

Figure 100 A more developed concept sketch, starting to introduce the shear walls seen in the final design along with the distinct bridges and tower, this composition shows the lighthouse fully hidden.

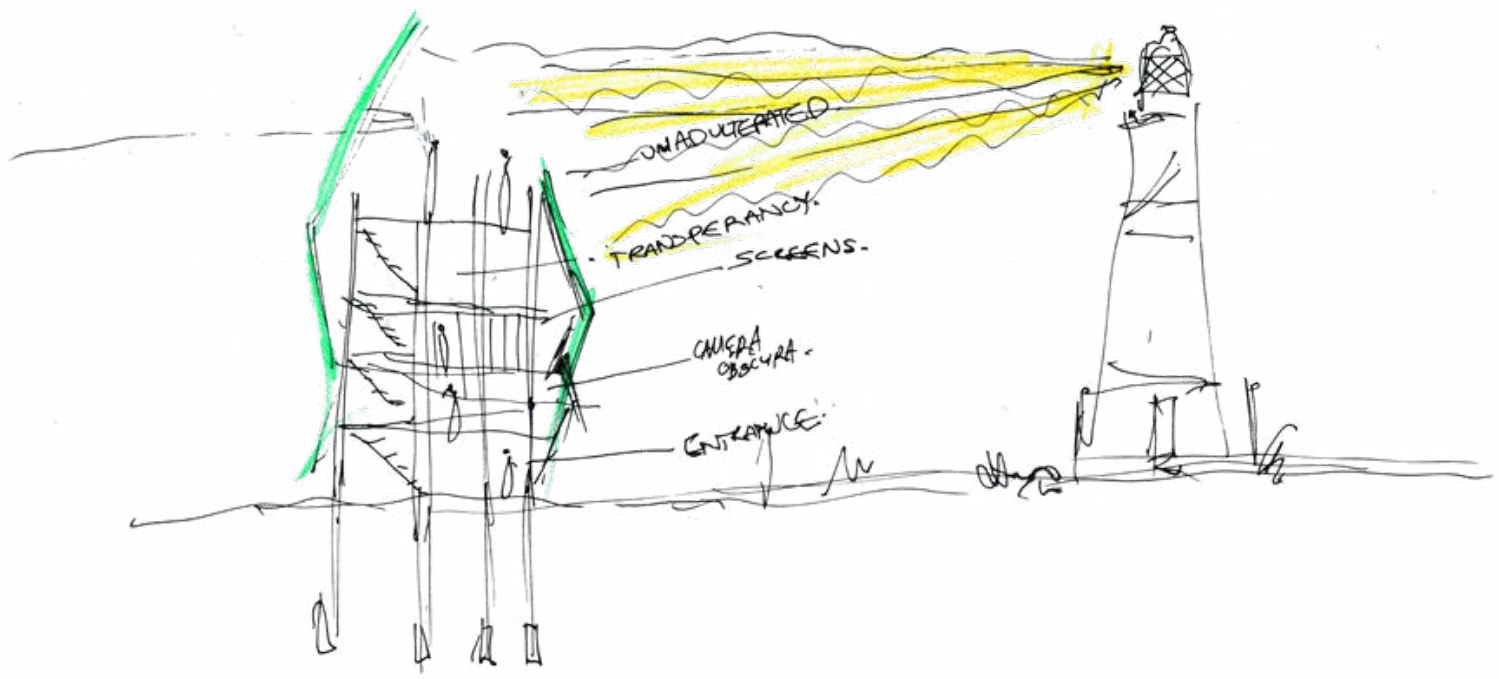




\section{Structure to enclose}

First a structural grid is used as a way of organising around the lighthouse and an option for enclosing it, the image pictured was a very early concept, looking at adding playful elements into the design.

\section{Circulation}

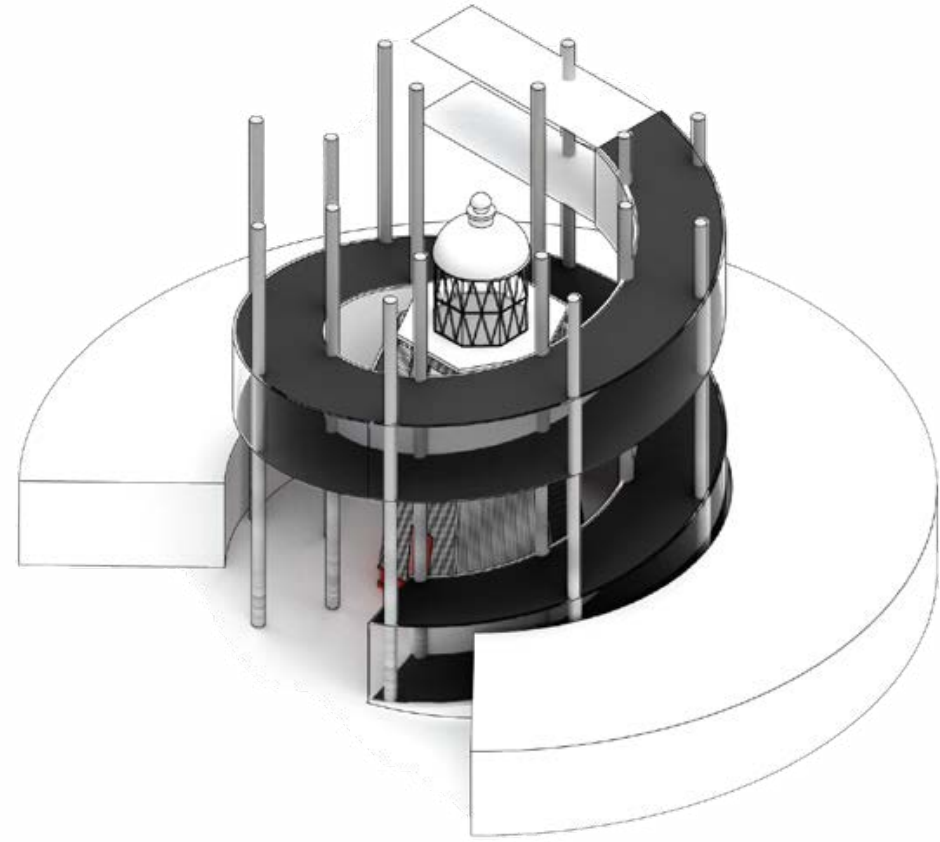

Circulation was vital to showcasing the light, a 3 story ramp is proposed to get to the top and be eyelevel with the lighthouse. The circulation is also implemented through bridges and the concentric structural grid and wall placement. 


\section{Circulation}

Circulation was vital to showcasing the light, a 3 story ramp is proposed to get to the top and be eyelevel with the lighthouse. The circulation is also implemented through bridges and the concentric structural grid and wall placement.
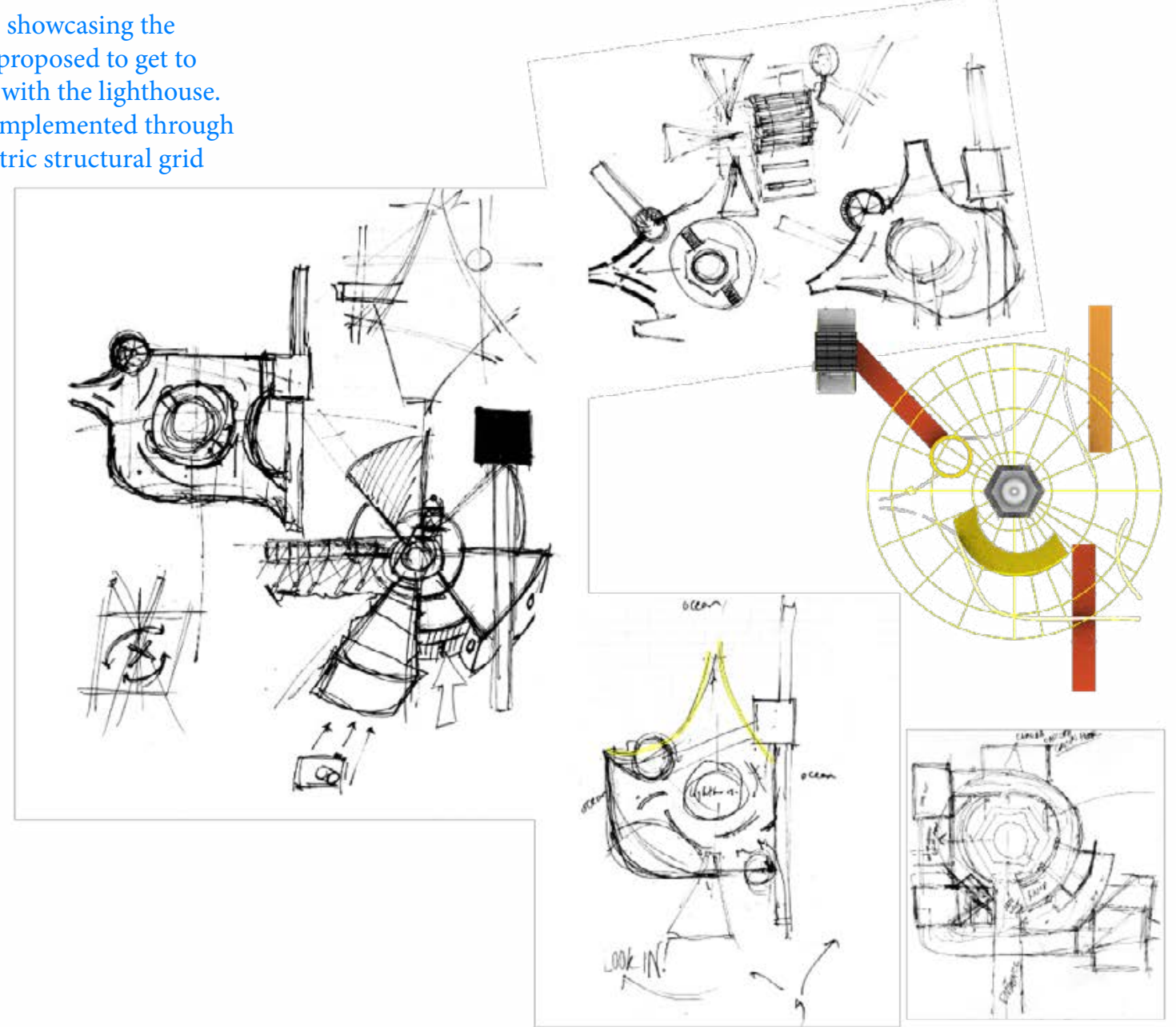

\section{Circulation}

Circulation was vital to showcasing the light, a 3 story ramp is proposed to get to the top and be eyelevel with the lighthouse. The circulation is also implemented through bridges and the concentric structural grid and wall placement.

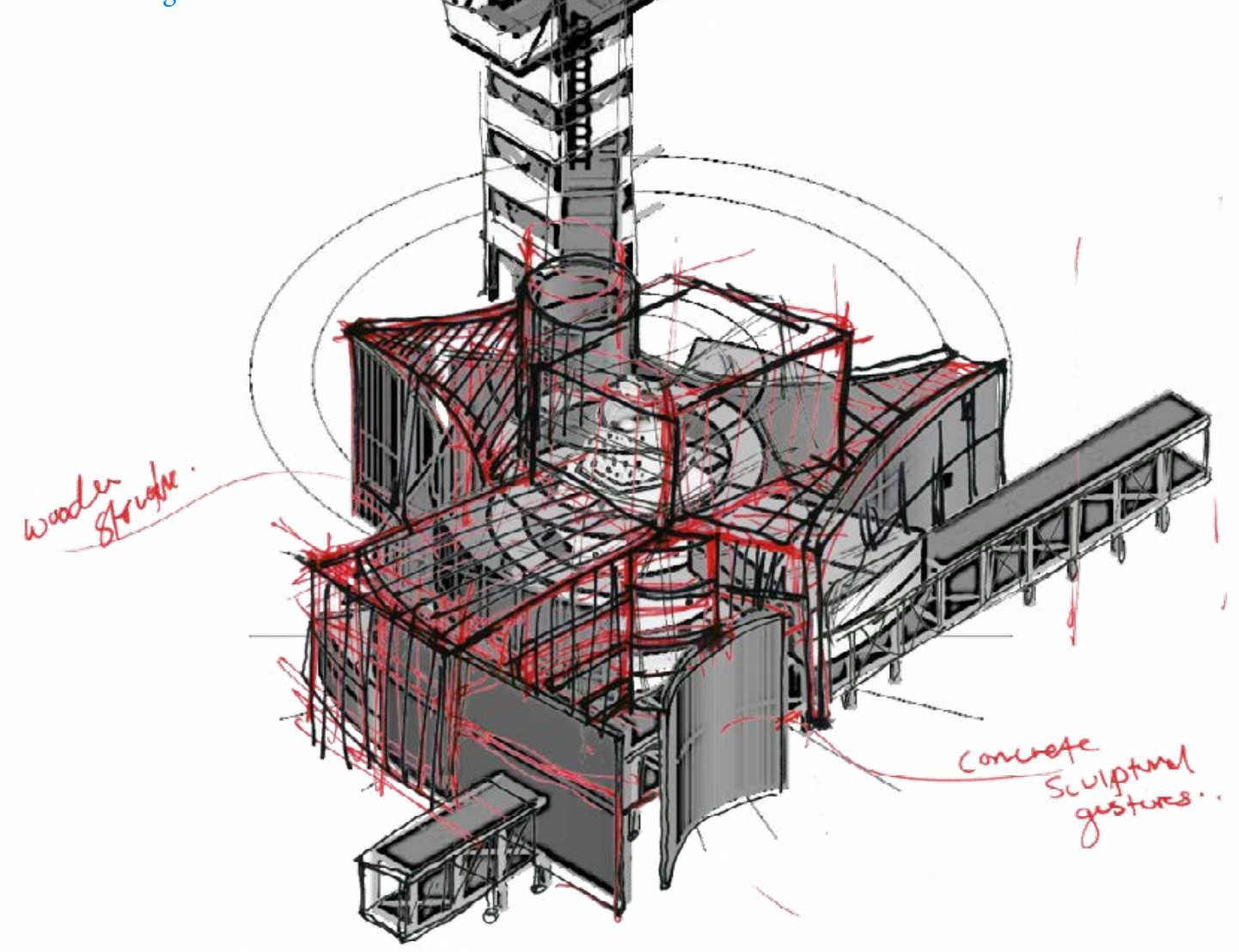




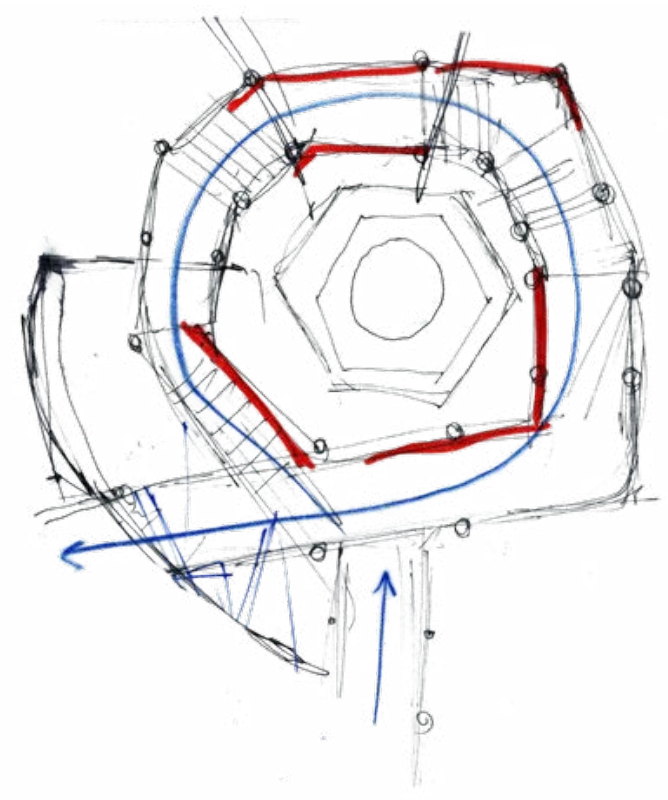

Ebit, omnihilibus is pos ea ex es resti rerum volore non rat eum aut $\mathrm{ab}$ is earis pedis quis magnimo lorionserspe sit modi doluptation cores dolo idist rehendebis viditae. Neque dolenis citasperibus eaquis et ipid ea susae velic totat expliquo qui beaquodit unto dolore cus.

Tet quodi quis ipsunde ndigendae necto et et eos eos sincid ellit la quo volo beruptatem vernatur aliquamet volupti oratium repudit quia quae si to qui simus.

Nam, officturio minum as nonsent re non resto eveles ra venditat.

Bus aborati buscid quas quunt quid que nos eat quiatur, ima quam id mo

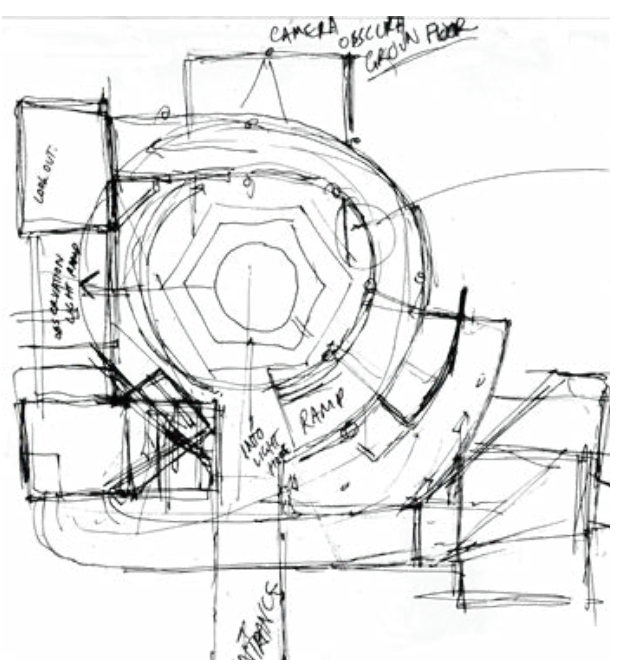



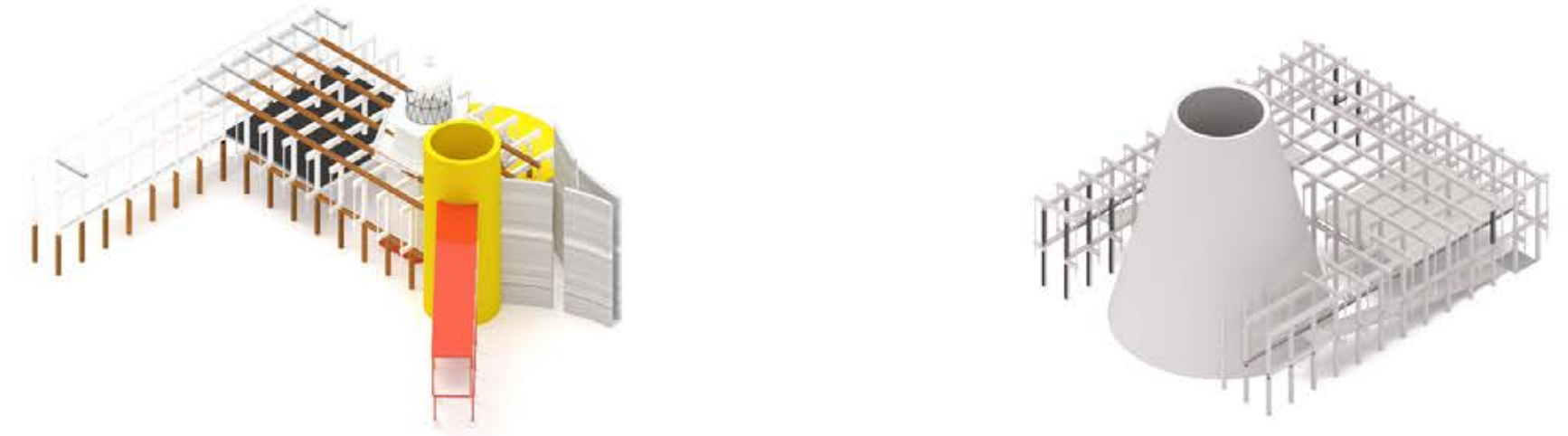

III.

IV.
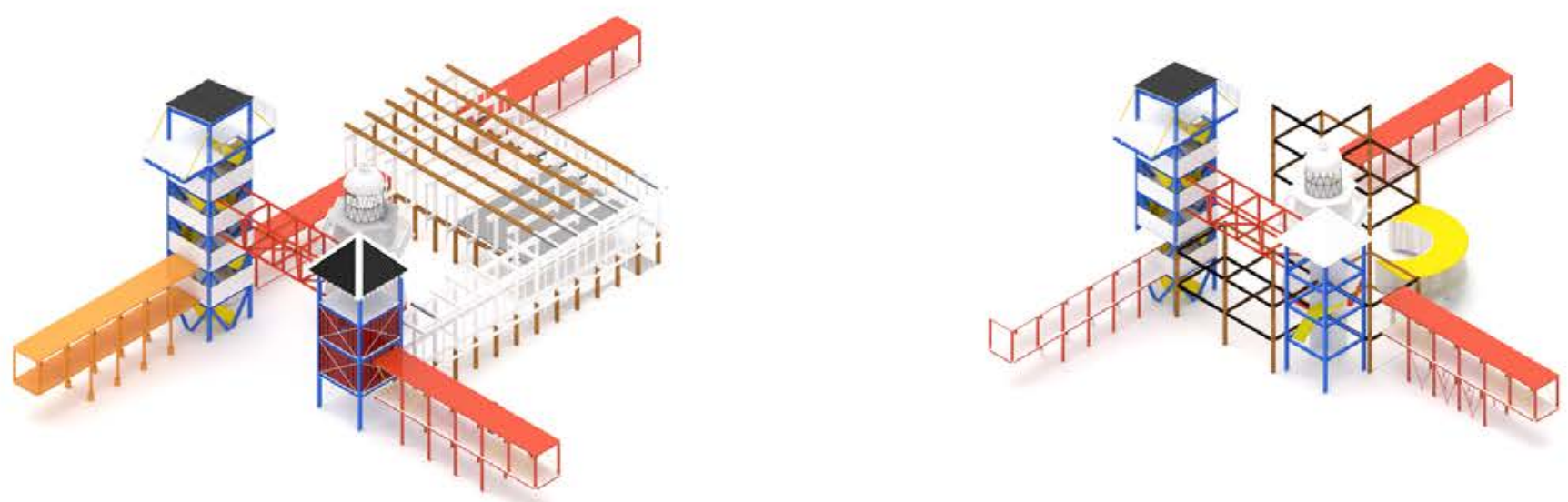

V.

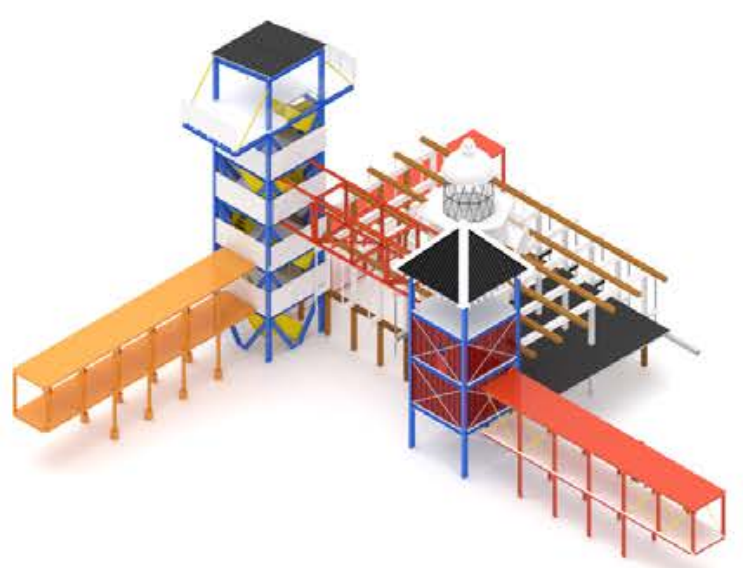

VI.

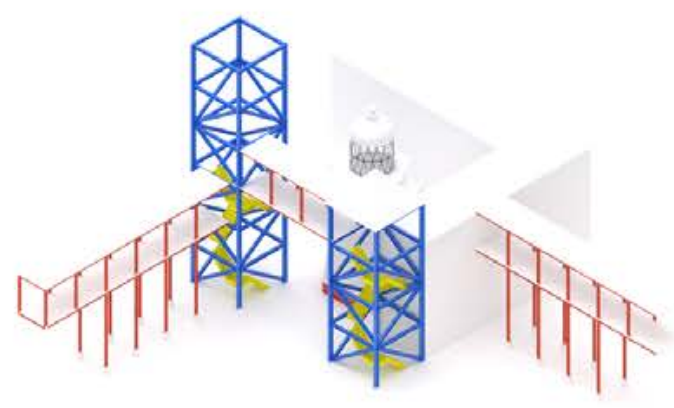



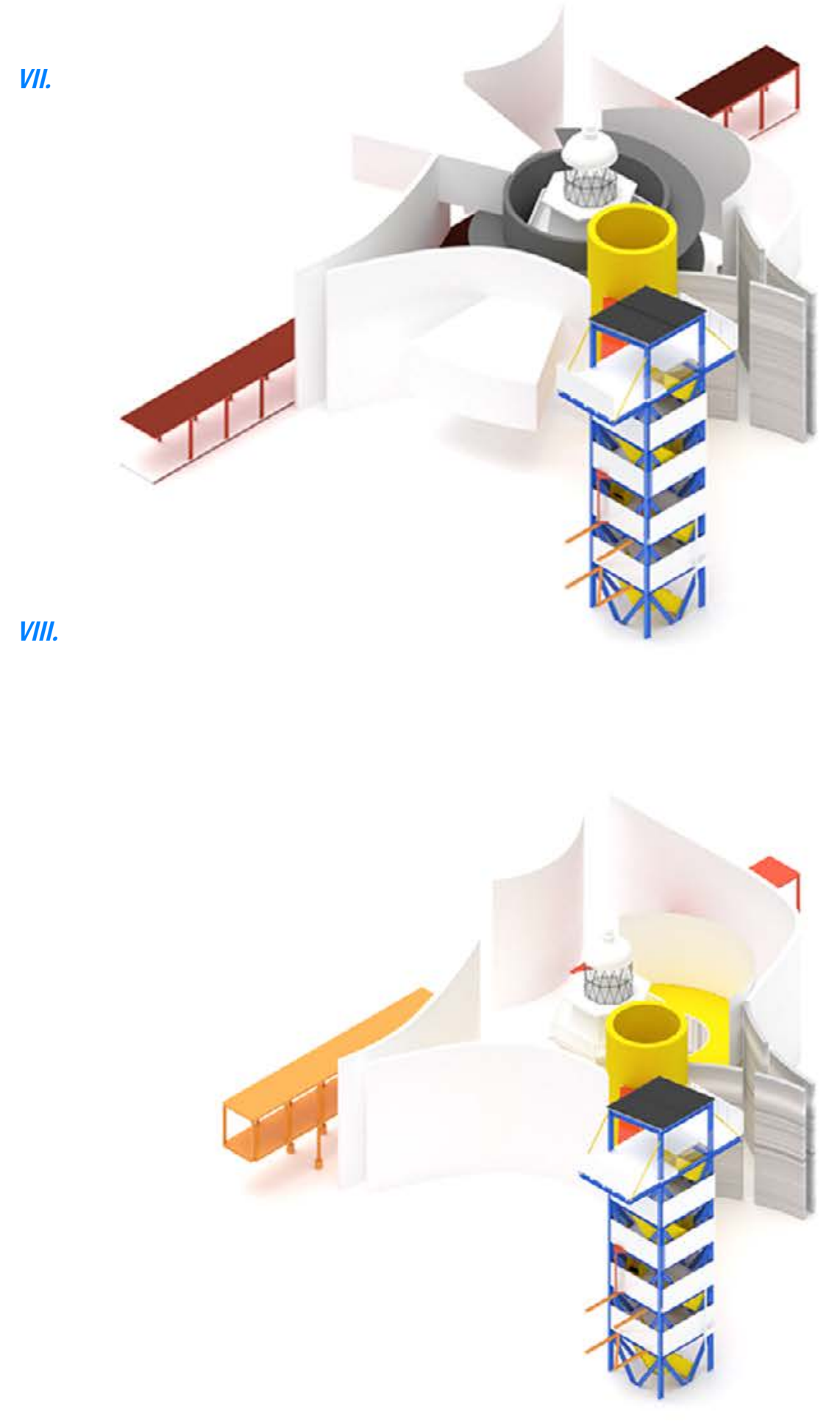


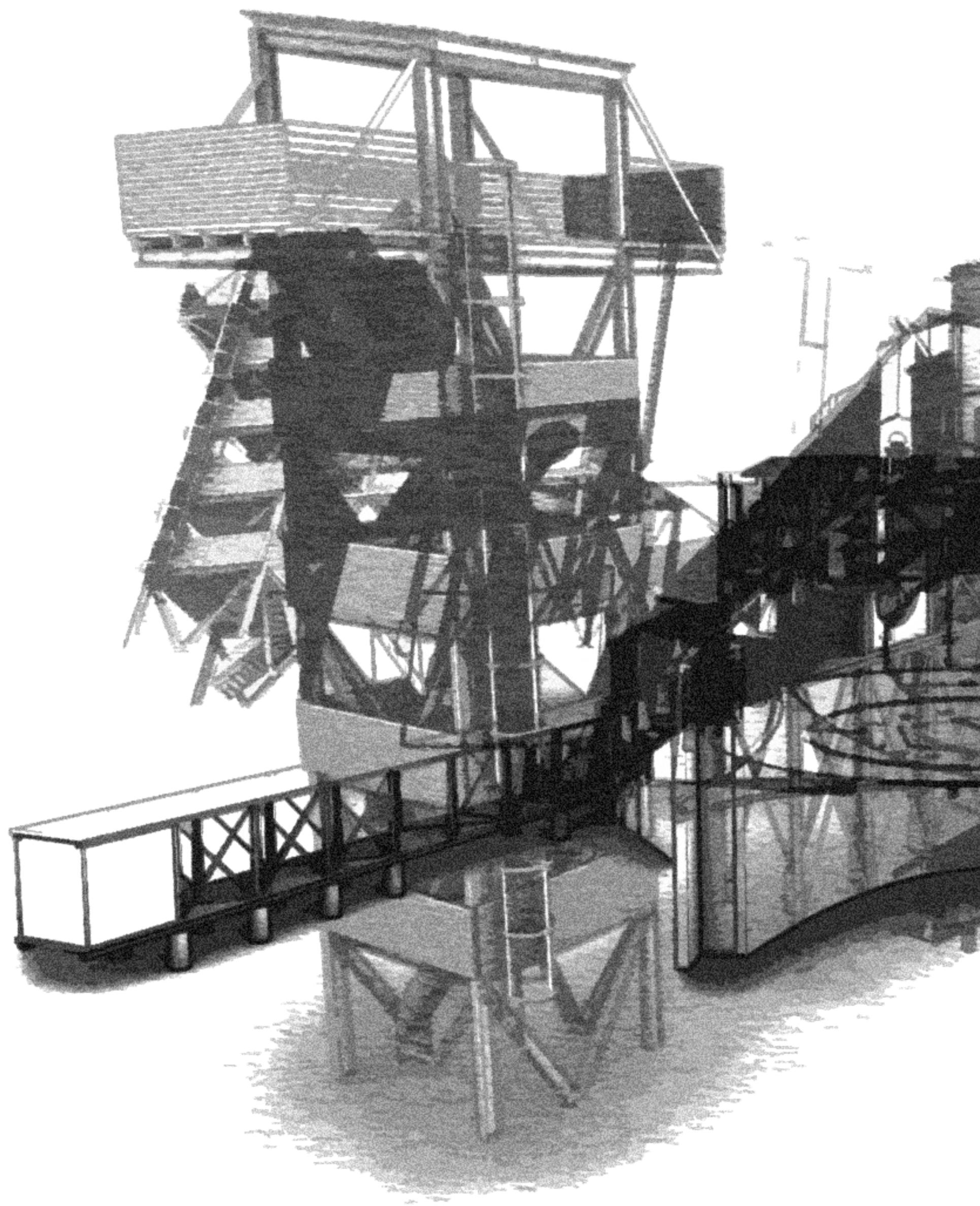




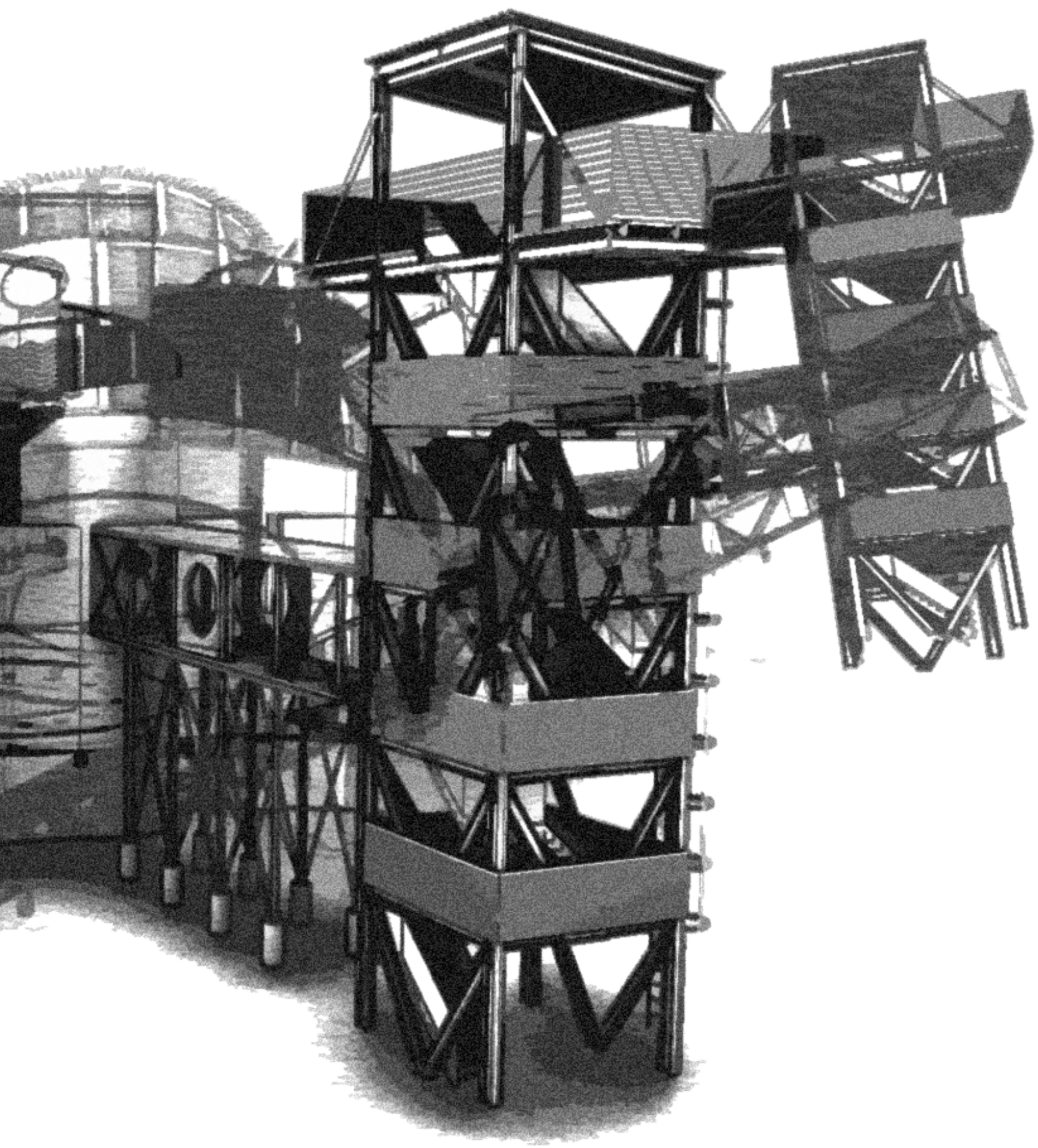




\subsection{THE STAGE COMPLETE}

The building is a camera, it frames, it captures, it preserves the visual but also evokes the intangible, if we break down the building as the camera housing then the window or opening is the lens. We look further than the camera, now this room is the photo, the façade breathes, you smell the salt air, you feel the wind and your arm hair stands erect from the breeze. The space will evoke deeply personal connections with memories you had, just as looking at any good photo does.

Now the building is the lamp shade, it houses the light, protects it and the architecture acts as a place to worship the light. You walk around the building engulfed in the lighthouses light, you walk up the ramp and eventually come face to face with the light, you understand what the lighthouse is now. It's on throughout the day and night, so the crux of the lighthouse is now exhibited permanently. There are still openings in the buildings fabric to still act as a lighthouse, but it has become something more.

In the daylight the building is colourful almost playful, it echoes the whimsy of the architectural object it encases but exaggerates it, it's 'too much', But it causes you to want to explore more. It oozes artifice but holds a seriousness, a tourist building 150 years old.

The architecture is introspective, looking in, to reveal and exhibit what it is, but is also a performer, a physical manifestation of the notions of itself, seen as t'oo much' as described in Sontag's sensibilities of camp. Its camp, but its intelligent, its bad art with a deep understanding of its purpose. It's a machine that currates how you consume the lighthouse in the modern world.

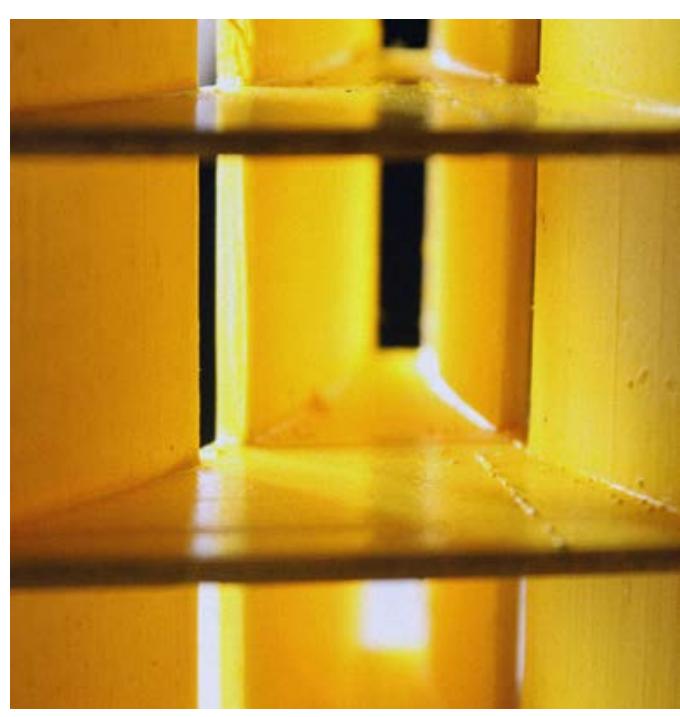


'To perceive Camp in objects and persons is to understand Being-as-Playing-a-Role. It is the farthest extension, in sensibility, of the metaphor of Iife as theater."

(Sontag, 1964, p. 4) 


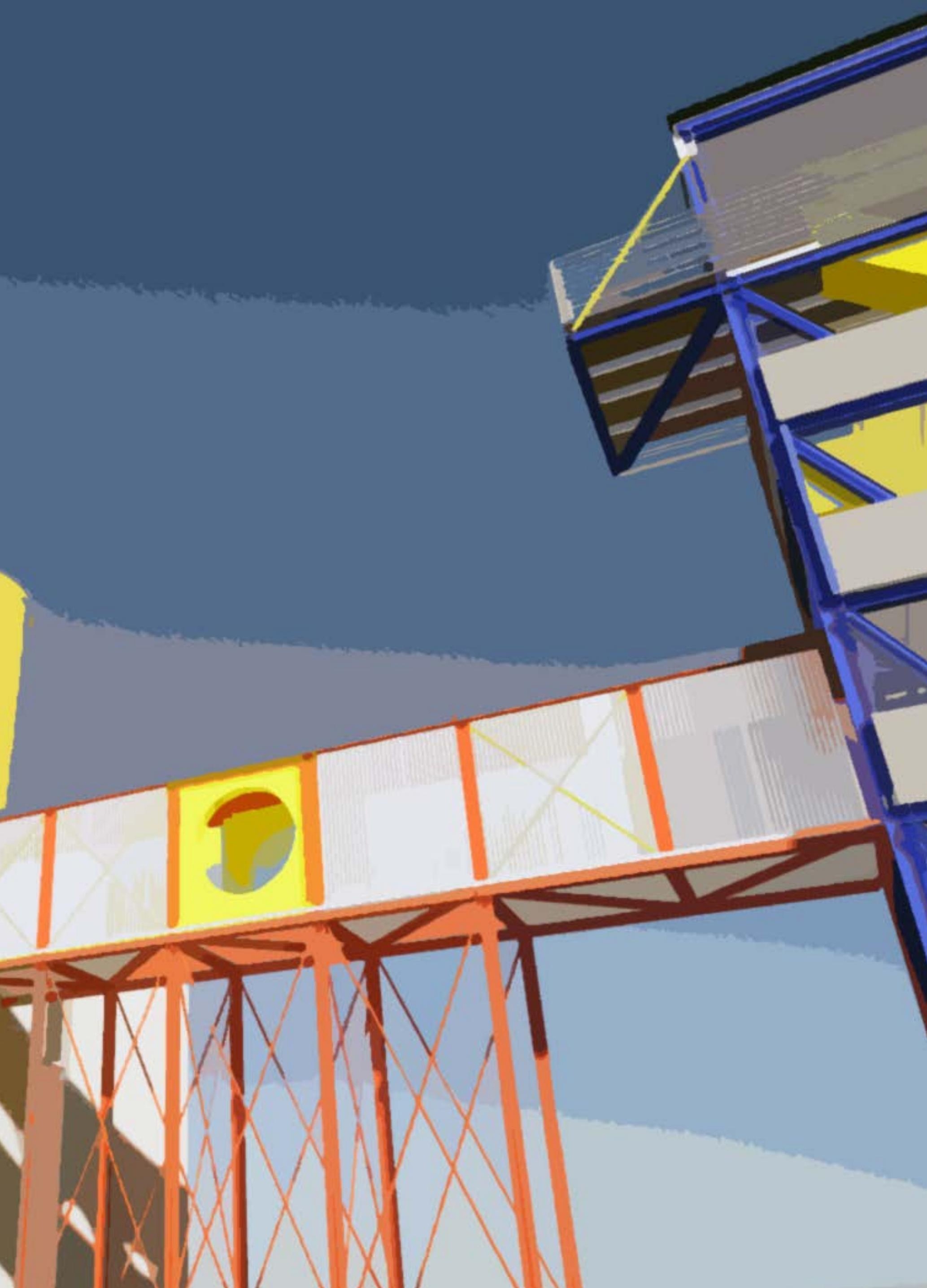




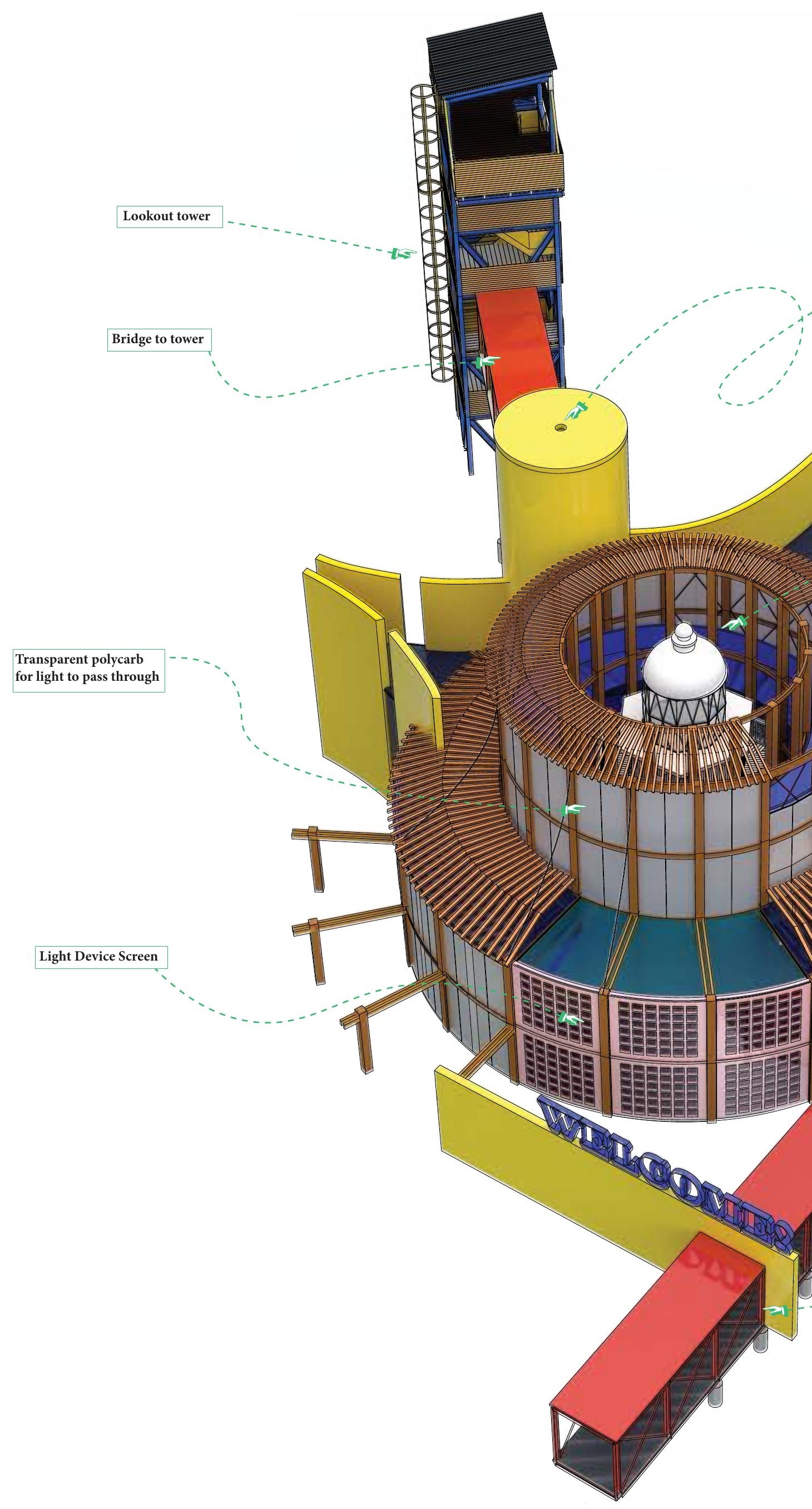



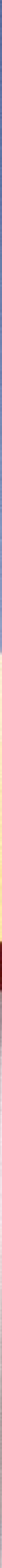
"camp is terribly hard to define but you'll find yourself wanting to use the word whenever you discuss aesthetics or philosophy or almost anything"

-(Gillespie, 2016, p. 1) 


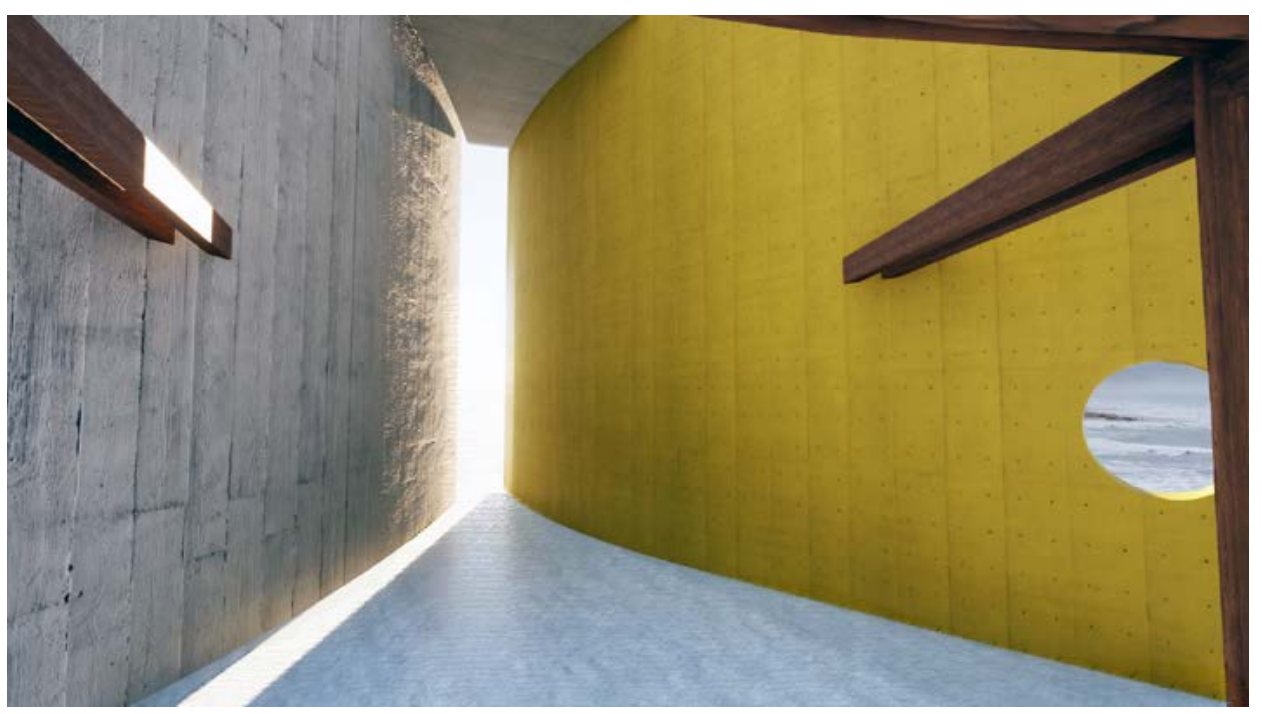

Three rendered views of the two freeform rooms, one double height the other two levels. Both rooms are pointed east and west, one out to the siteof the Tururua disaster the other, out to Foveaux Strait. The goal of the design, is to enclose the lighthouse but still allow it to remain operational for seafarers. In all three images, light conditions and views of the exterior are shown.
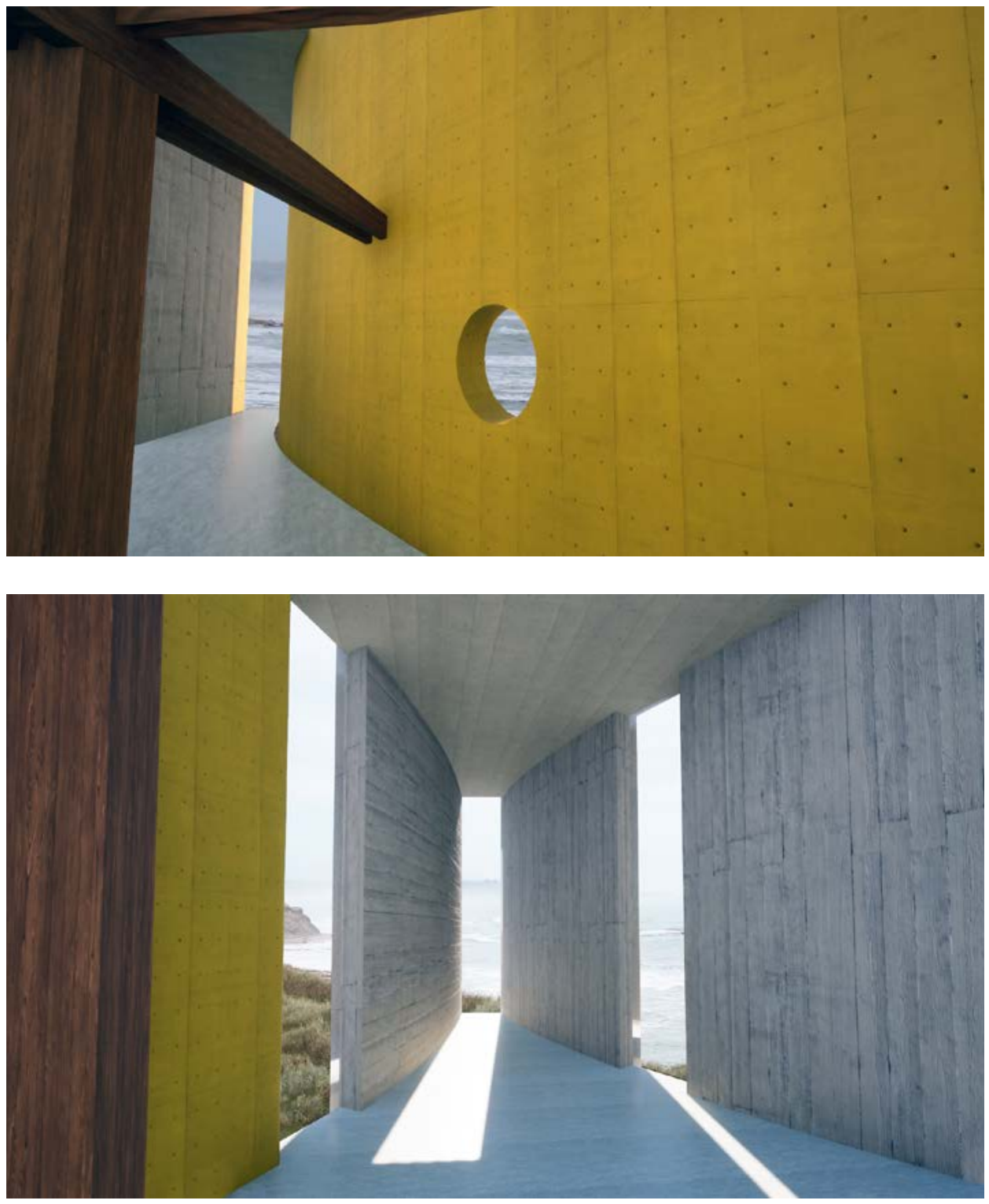
Rendered view between an exterior wall and an interior glass block wall, based upon the design phase two studies, allowing shadow play and light to filter from interior space outwards.
Rendered view in one of the freeform concrete rooms, the light channel from source out to the narrow opening at the end of room, based upon angle house by Diller + Scofidio. Seen in the image are the raw materials of concrete and the timber structure as well as the 'camp' statement walls.
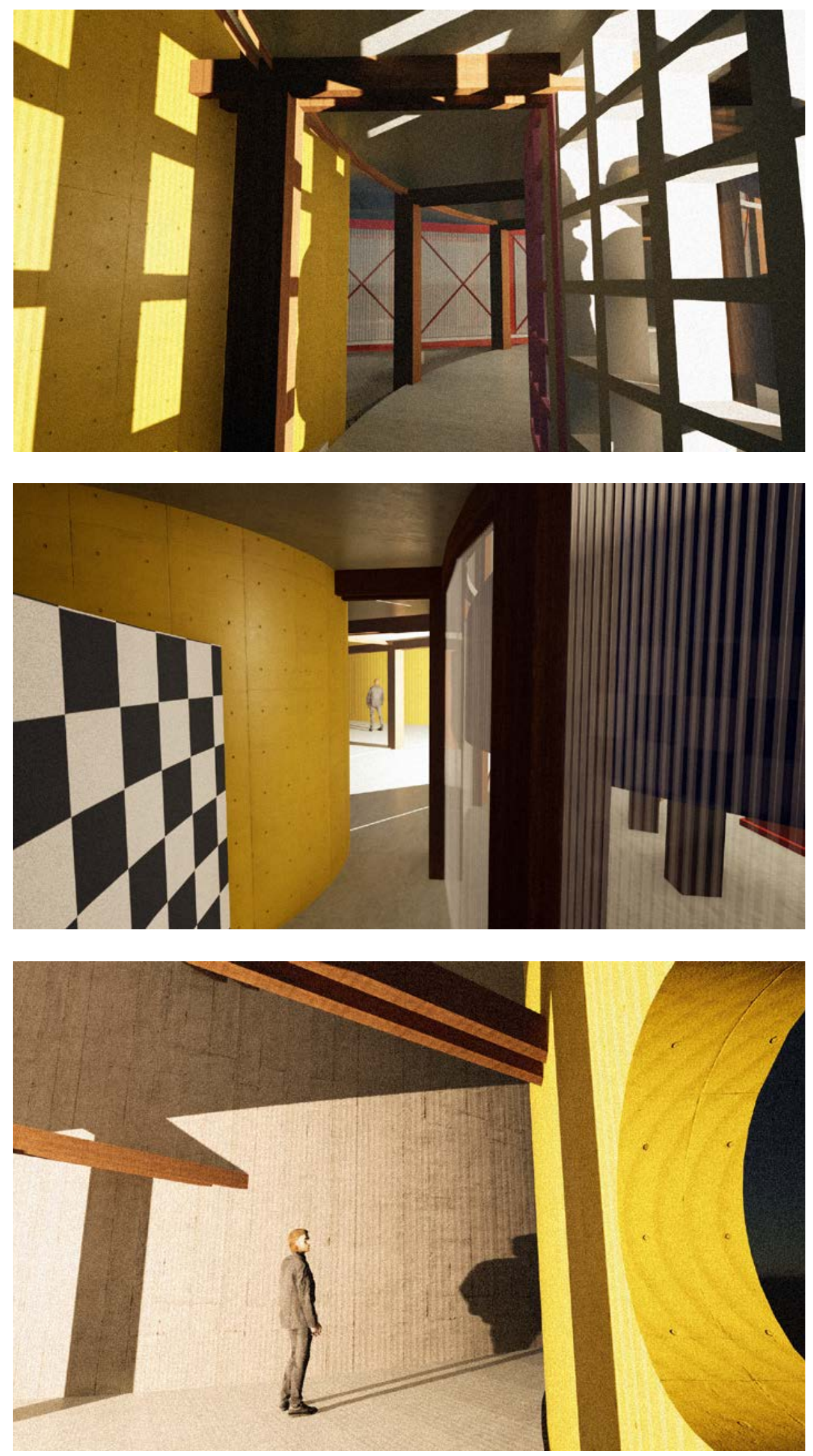
In the night, the lighthouse light shines. Layers of polycarb walls, of differing opacity filter light from the interior of the structure, past the circulation ramp and out the exterior layers. People externally are drawn into the building, curious of the experience within and those already in, are bething in the light of the lighthouse, while they scale up it using the ramp. 


\section{III}
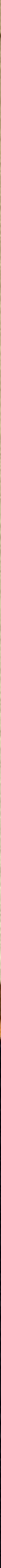


\section{○}

Rendered view of the interior of the stairwell looking from the top of the staircase up. a small aperture has been created to allow light to filter into the otherwise dark space. This acts as a threshold between the main building, which is typically flooded with light and shadow through day and night, this space signifies an entrance into the outside.

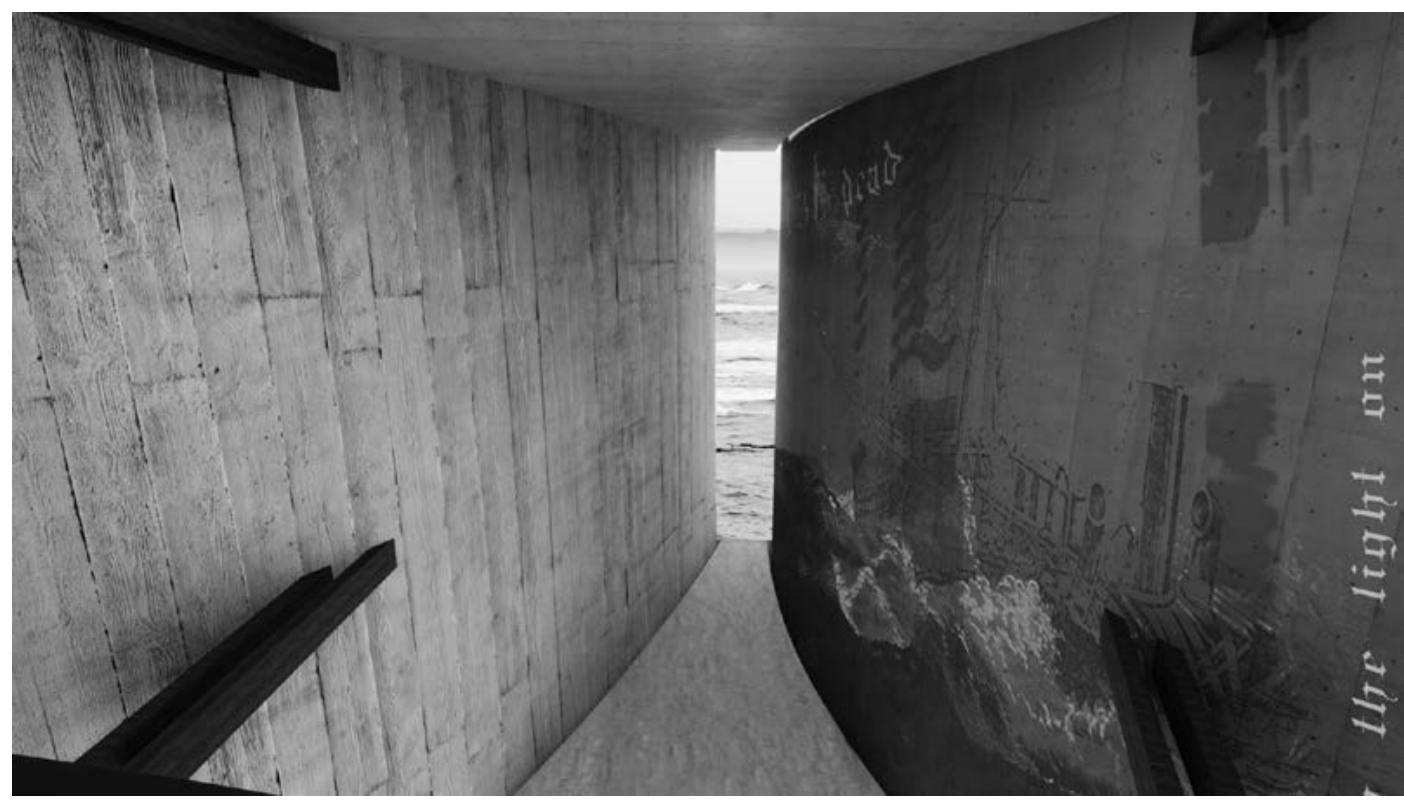

Rendered view of the curved room lookingout at the Tururua site, its proposed the double height wall has projections and other installations, to act as a memorial/museum to the disaster.

$\frac{E}{5}$

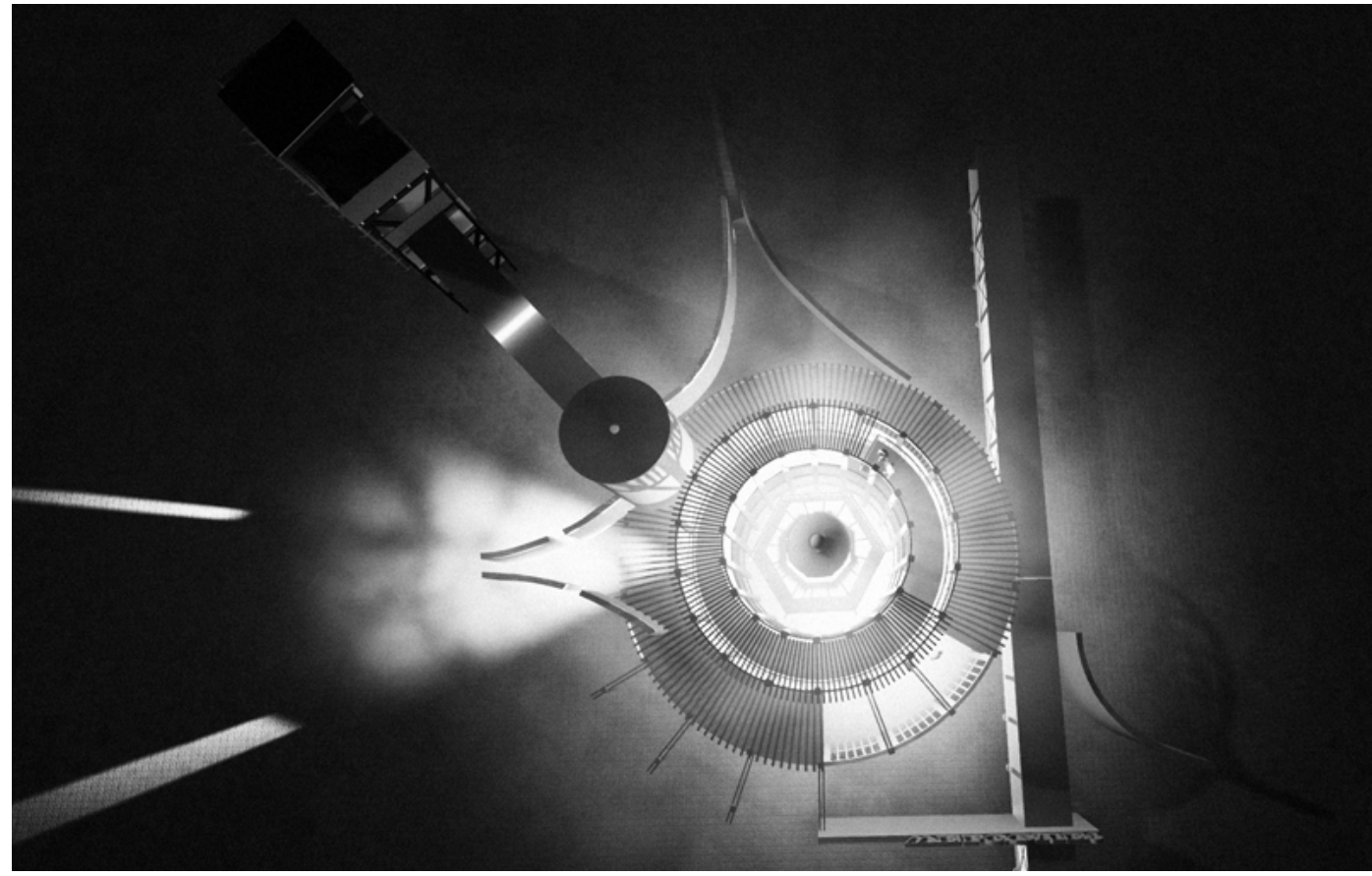

Rendered view of the whole building at night. 'The Stage Complete' is seen operating as it should, note the way the building is directing the light. 
View within the building on level two, looking in to the central ramp and lighthouse. Note the polycarb and light condition. Here the timber and concrete slab structure is clearly visible.

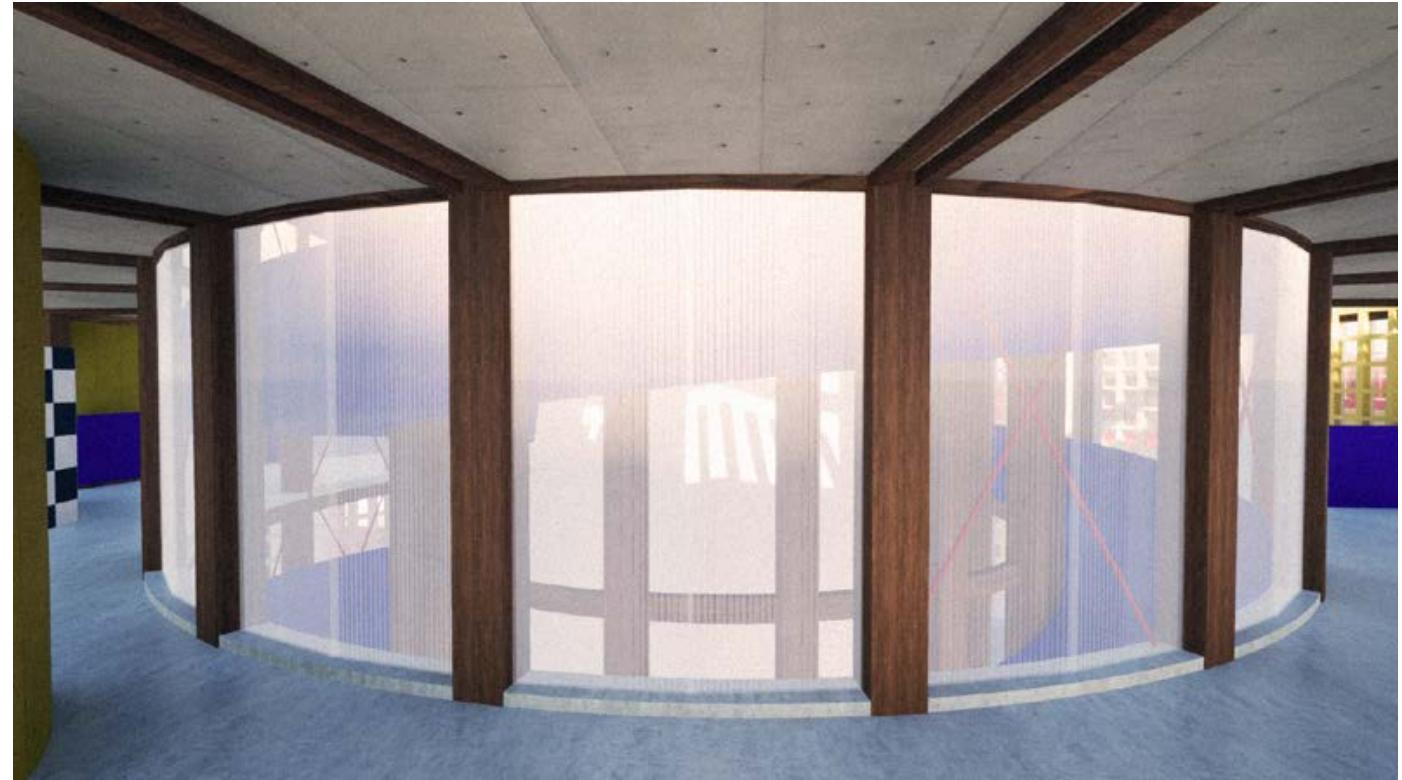

View from within the building looking out past the ramp to the ocean, on an overcast day, not only is the ramp great at exploring the ligthouse it is also excellent for viewing the ocean.
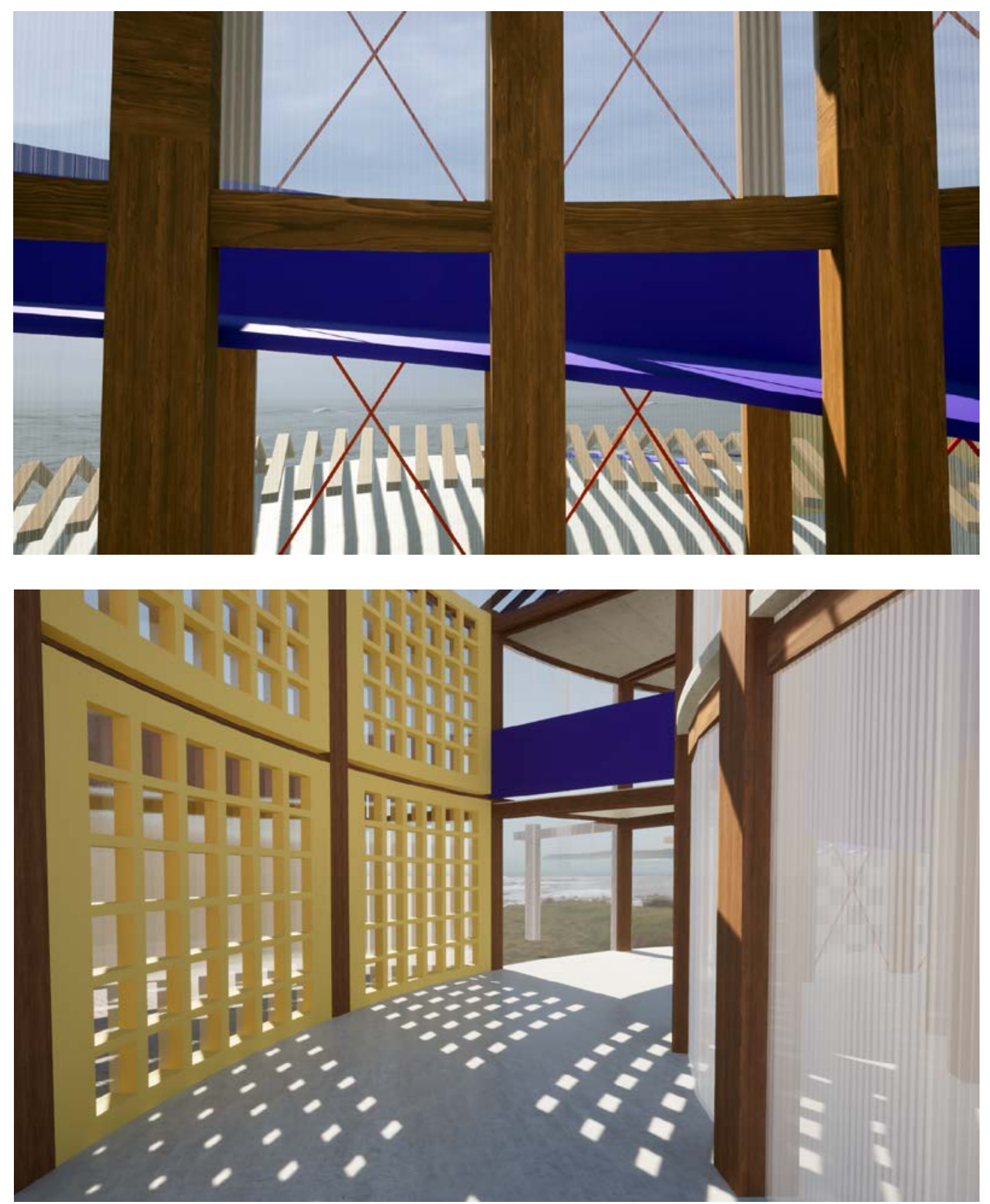
'The Stage Complete encloses the light, it in turn becomes the Lighthouse. In a way, I have designed a camp lamp shade. A device that does its original job but additionally allows the tourist to perform within and intimately connect with the light' 




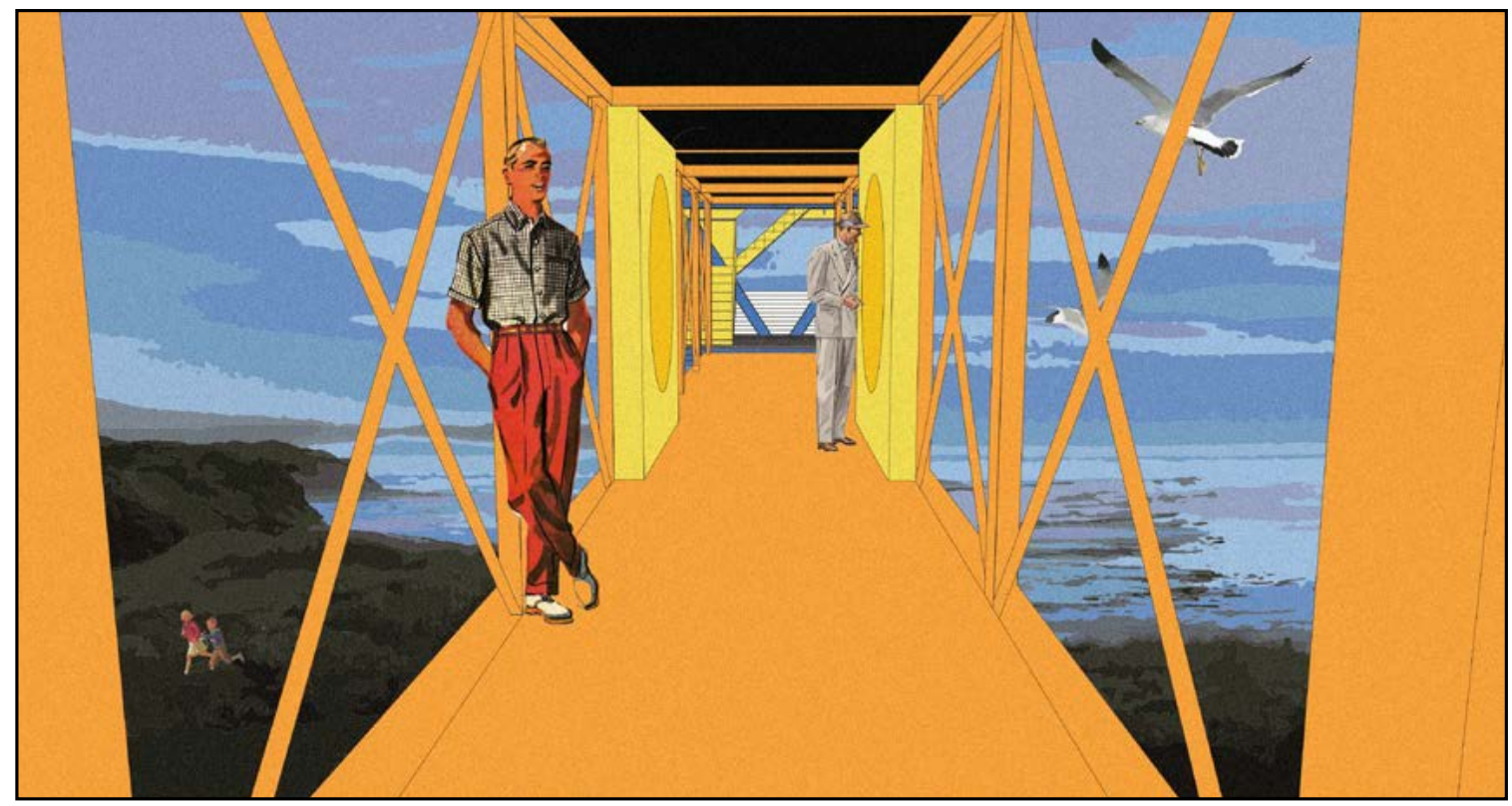

View looking towards the lookout tower, from bridge, note the circular aperture in the middle.

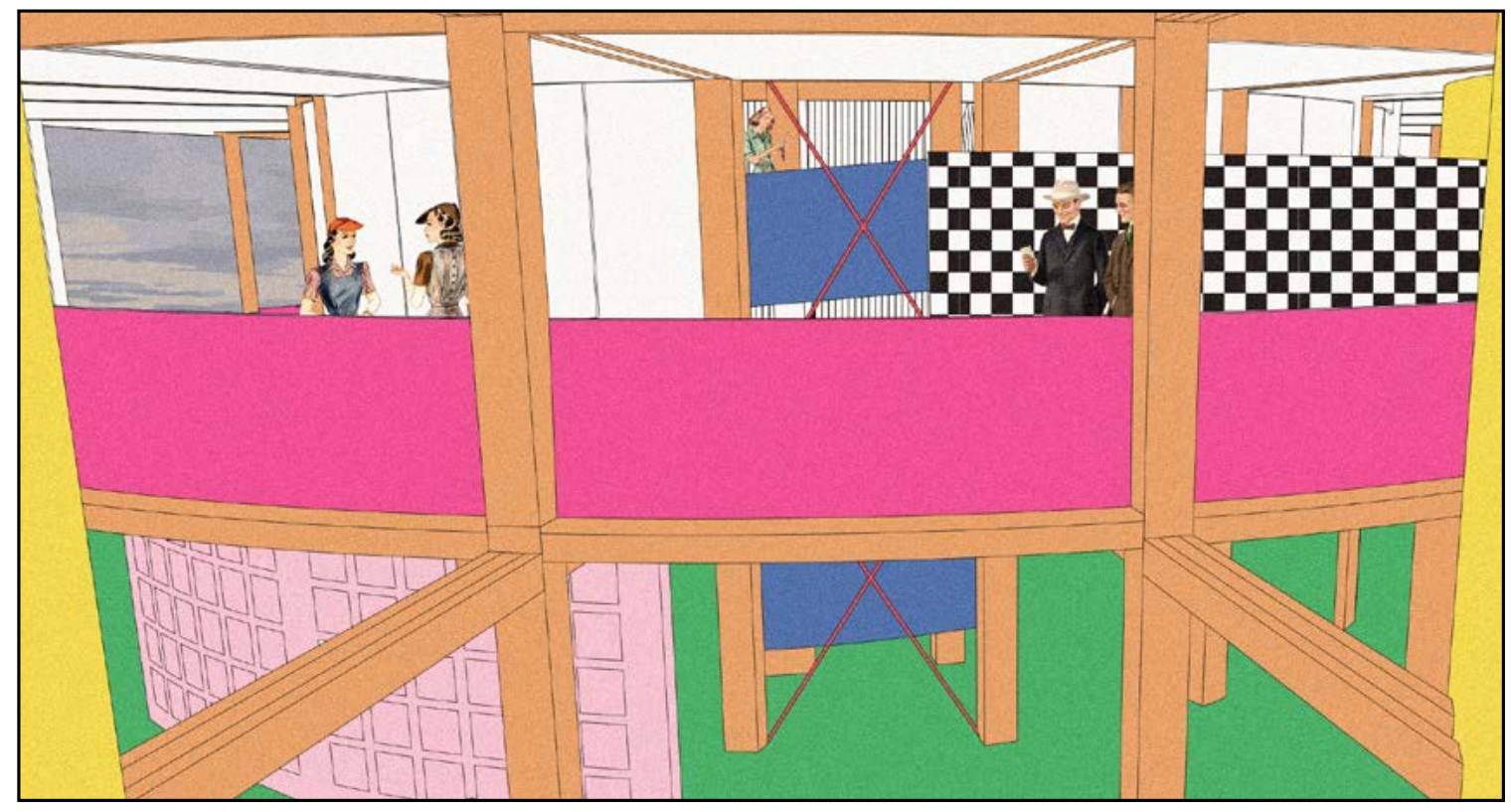

View looking at the interior of the building, here you can see the different levels and layers of the building.

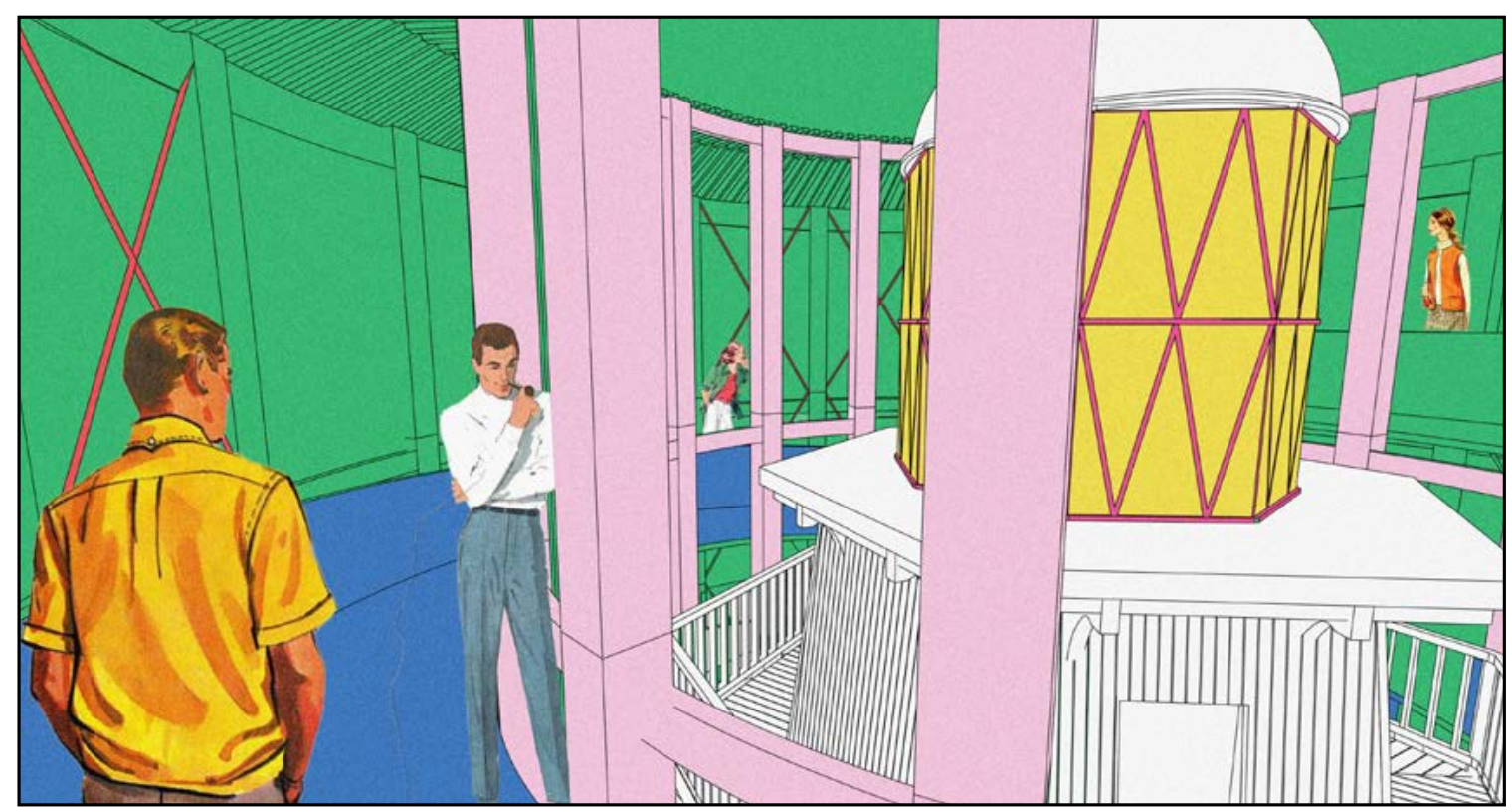

View looking at the top of the circulation ramp, looking at eye level to the light. 


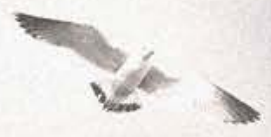
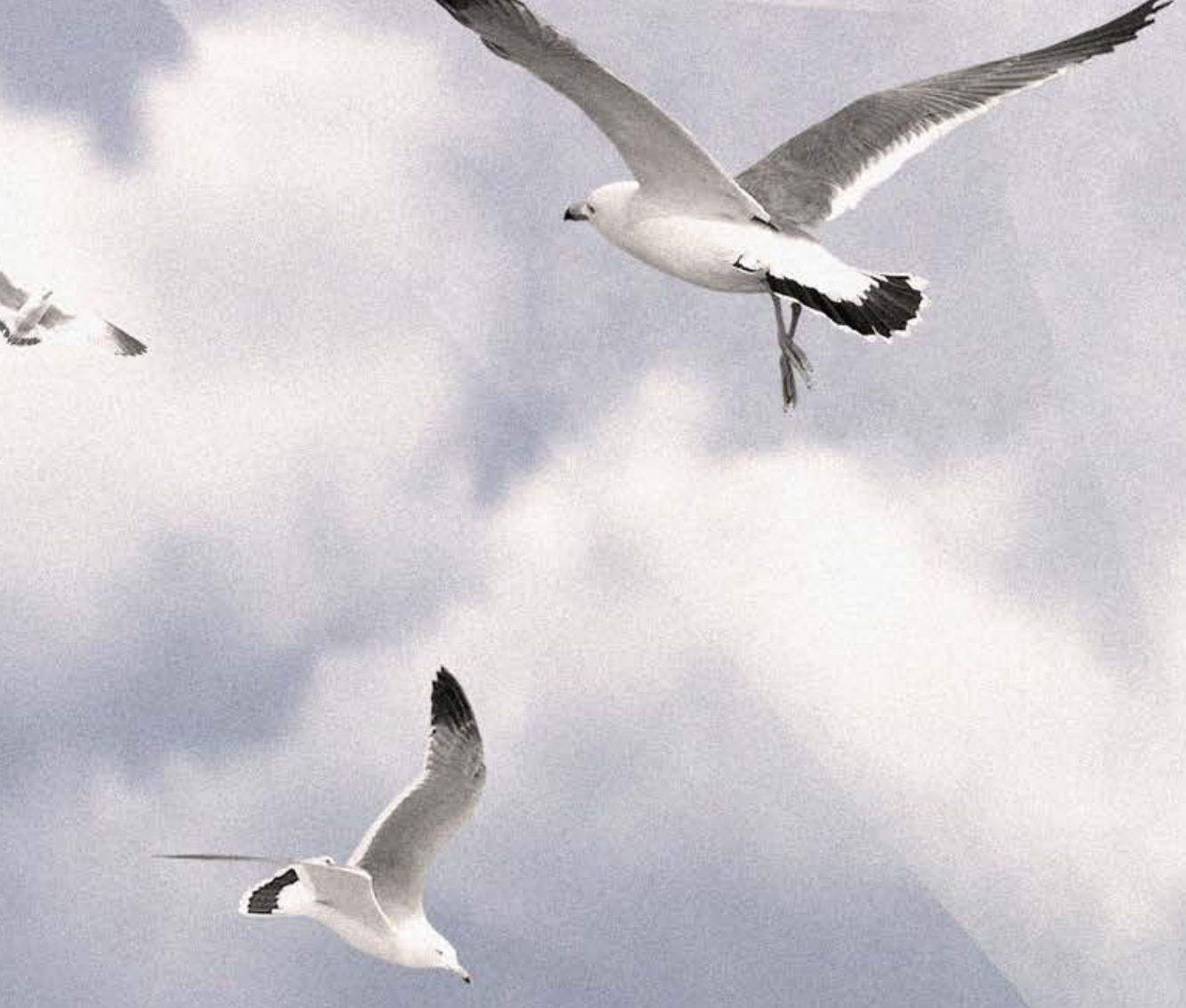

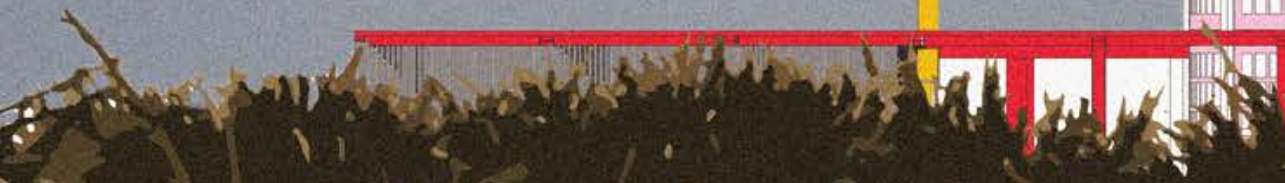
d.) 7515

ant $1=$ ?

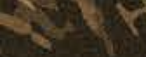


'It is hyper aware, It has created an architecture out of thin air. It literally is saying- look at that lighthouse in the deep south of New Zealand-let's examine it, then dismantle everything we know'
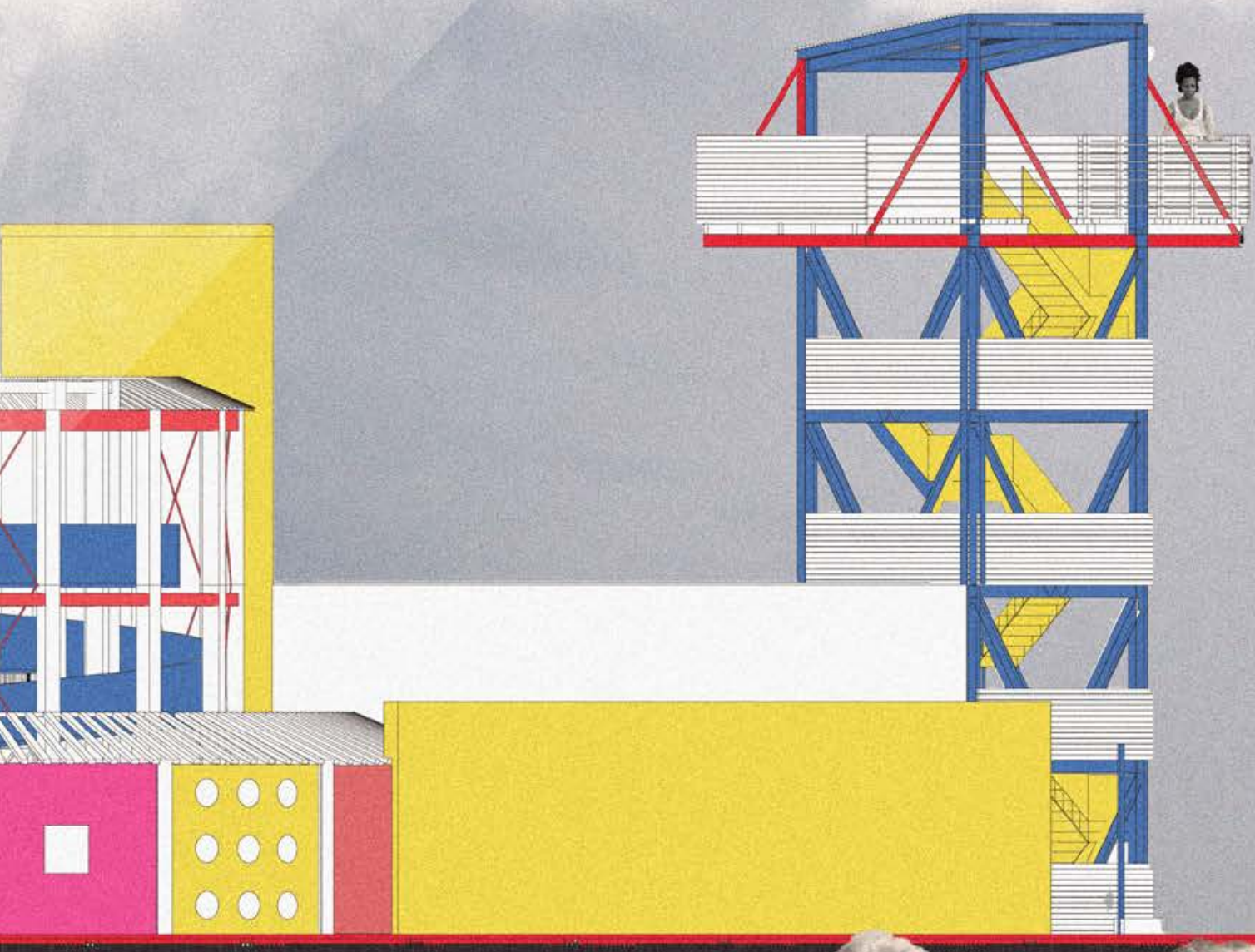

Mnom

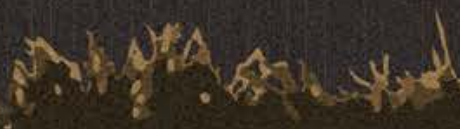




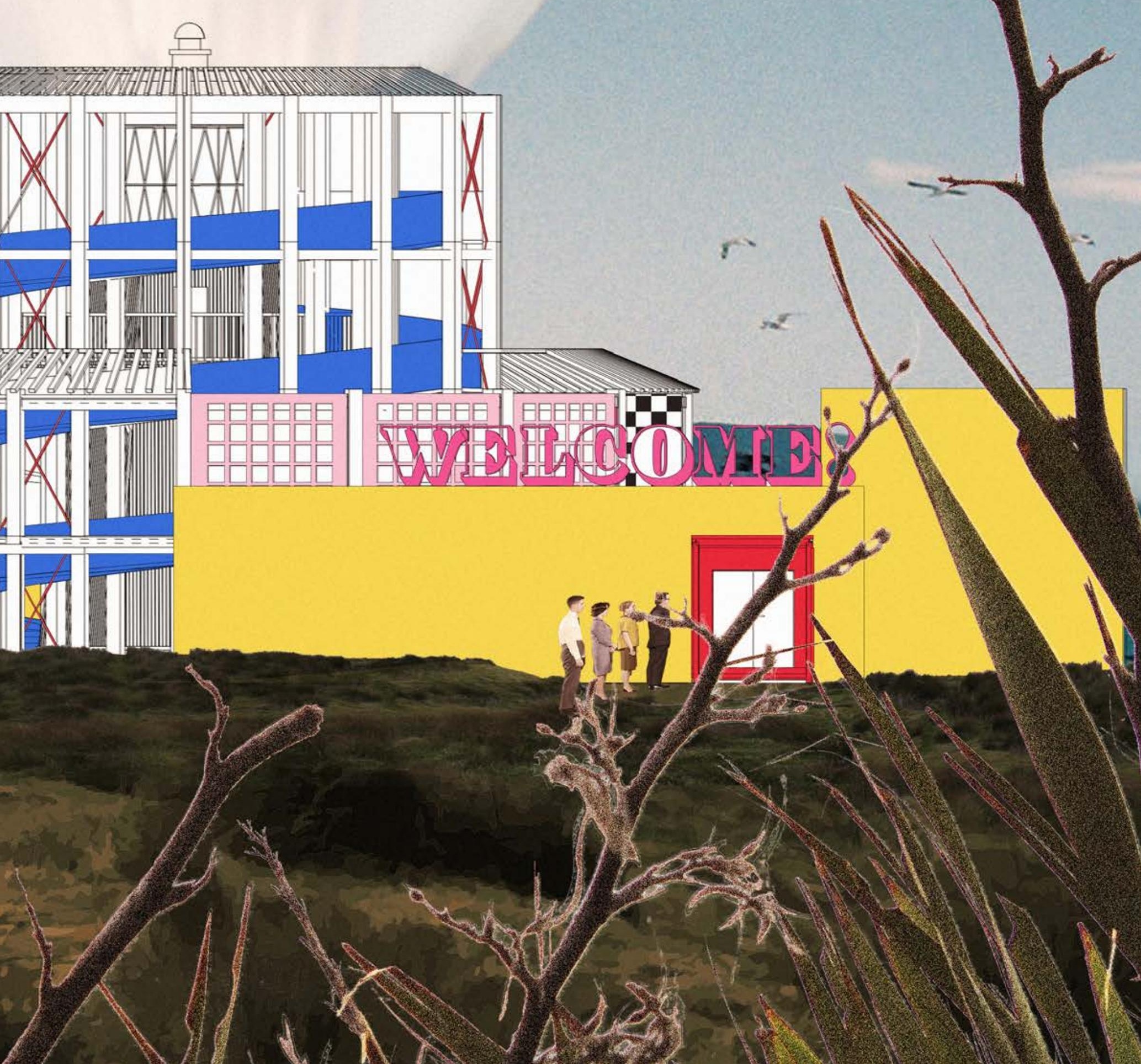




\section{LEVEL - GROUND}
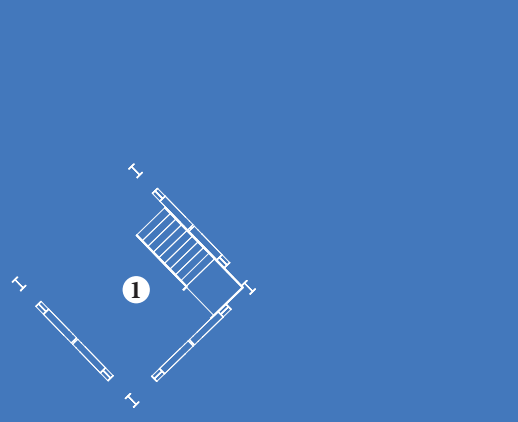

Q

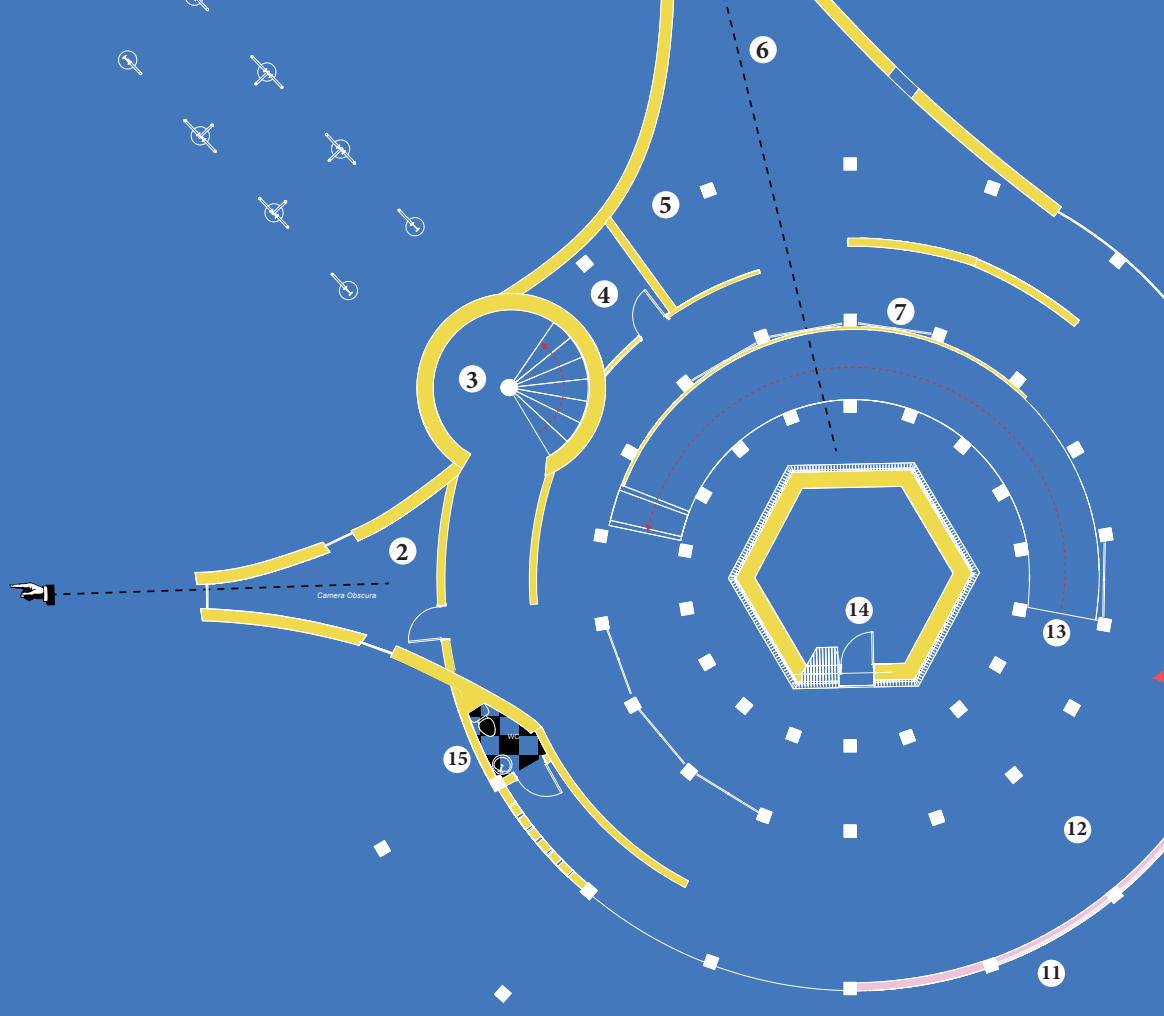

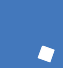

1. Lookout tower, to observe site and get above the light

2. Pre-cast Concrete room, proposed as a camera obscura

3. Spiral stair, upto the bridge to lookout tower

4. Store/Office for occupant
5. Proposed as an open classroom, for school trips and educational conservation purposes

6. Double height pre-cast concrete space

7. Cross Braced, Circular, Timber, post and beam structure

8. The Observation bridge, leads out to the Foveaux Strait
9. Entrance into Main Building

13. Ramp entrance

10. False Entrance, Wind Tunnel

14. The god damn Lighthouse

11. Shadow and light play wall.

15. Every REAL building needs a TOILET!!!!

12. Double Height, Atrium space a place for pause, where the many layers in the building are visible 


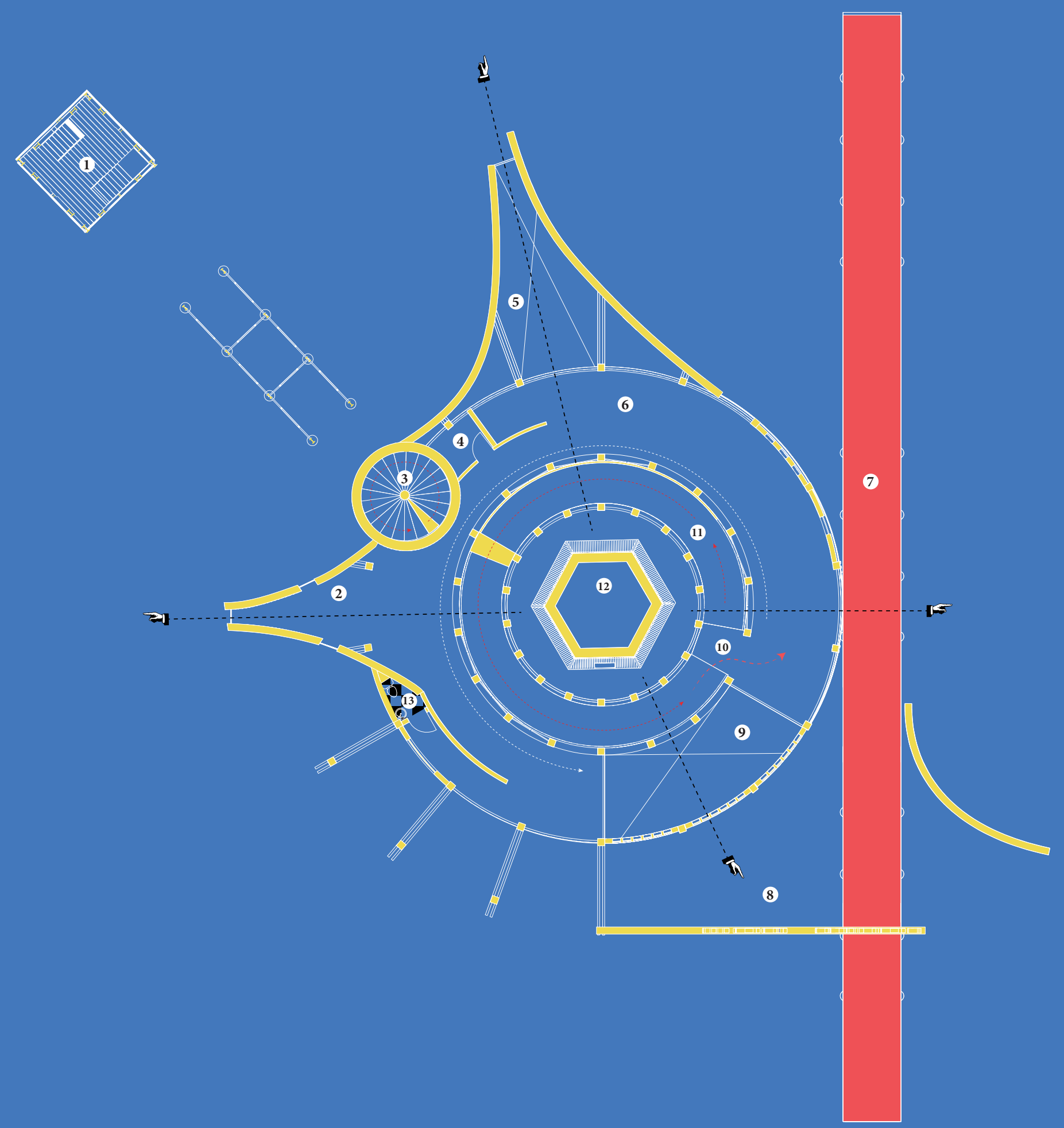

1. Lookout tower, to observe site and get above the light

2. Pre-cast Concrete room, one of the main outlets of the ligth houses light.

3. Spiral stair, upto the bridge to lookout tower

4. Store/Office for occupant
5. Double height space, proposed as space for projections, art installations, part of memorial.

6. Circulation space

7. Observation bridge

8. Courtyard space, wind tunnel
9. Double Height atrium space

13. Every REAL building needs a TOILET!!!!

10. Entry off ramp to level 2

11. Ramp up to lookout Human circulation

12. The god damn Lighthouse 


\section{LEVEL - TWO}

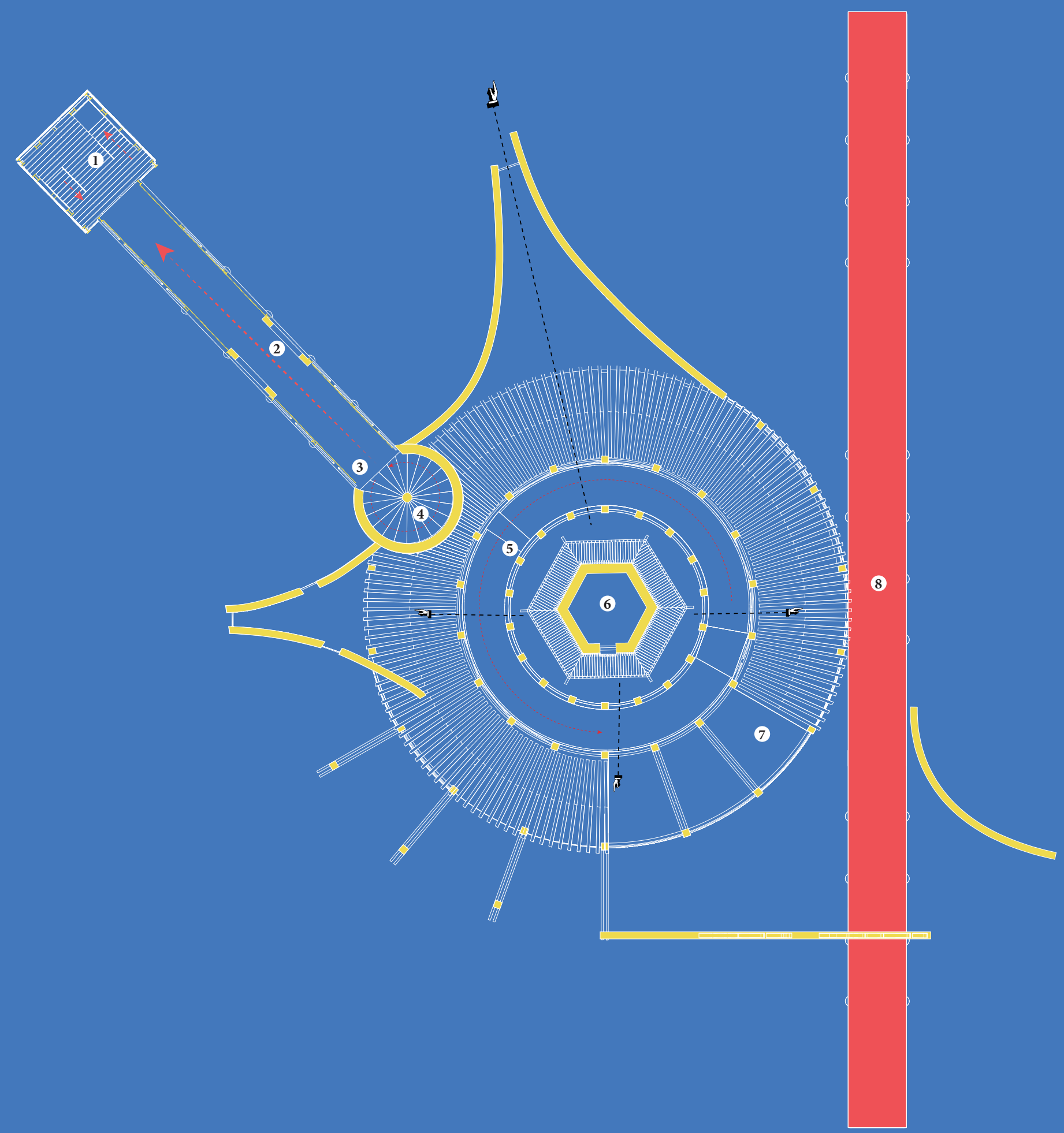

1. Lookout tower, to observe site and get above the light - The highest point

2. Circular window- out to sea.

3. Entrance to bridge to tower

4. Bridge spiral staircase
5. Circulation ramp

6. The god damn lighthouse

7. Atrium, skylight

8. Foveaux Strait observation bridge
- 5 Primary light path

Human circulation 


\section{LEVEL - FOUR}

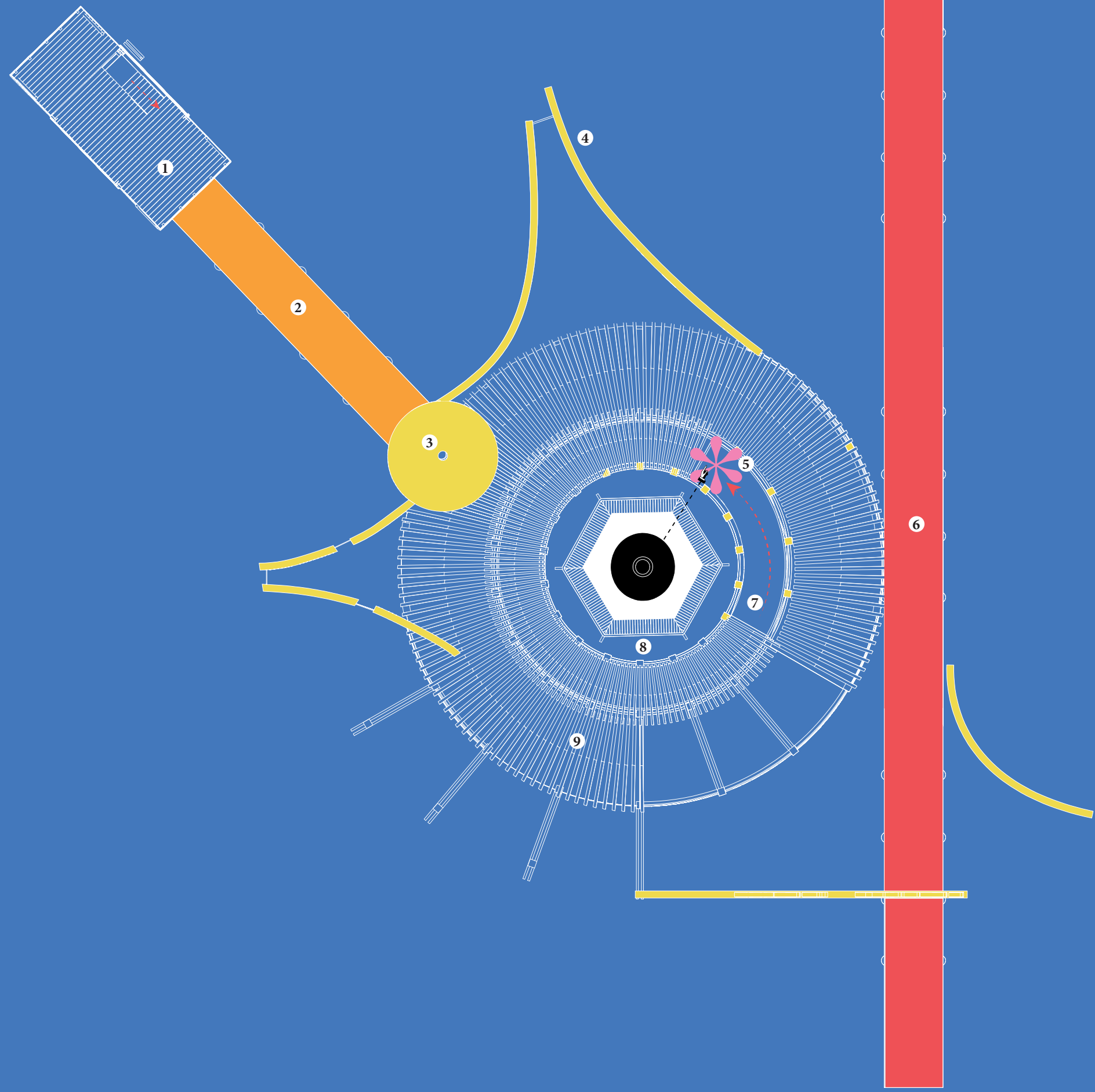

1. Lookout tower, to observe site and get above the light

2. Bridge to Tower

3. Spiral stairwell, note the light aperture, refer to perspective section.

4. Pre-cast walls, emitts directed beam of light when light is on
5. Final point on journey around lighthouse, eye to eye with the light

6. Observation bridge

7. Circulation ramp

8. The god damn lighthouse
9. Wooden, slatting, to create shadows in the day

Primary light path

Human circulation

* Final point of the Tourist performance, turn back around now 


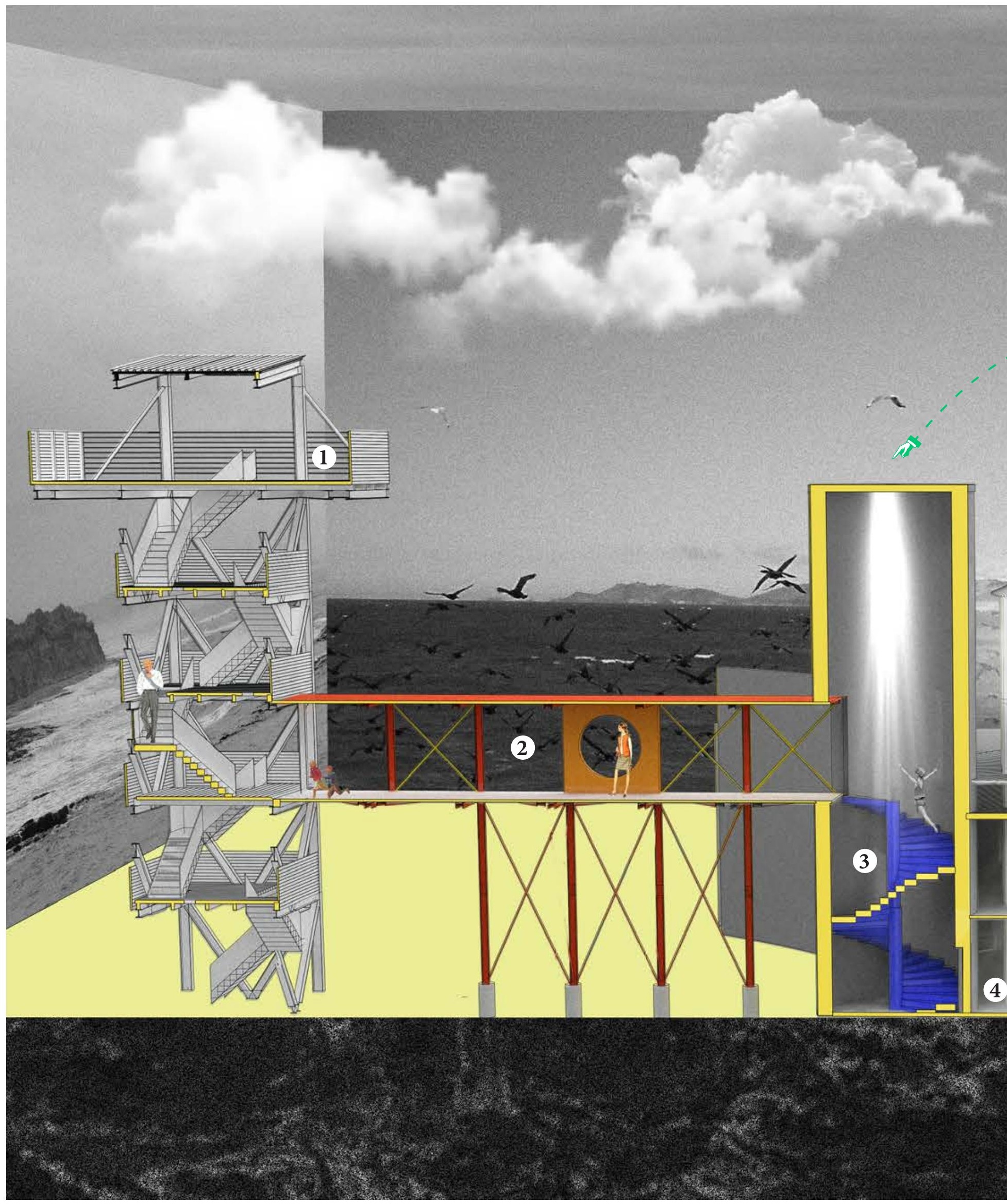

1. Lookout tower, to observe site and get above the light

2. Bridge, connecting main building with lookout tower

3. Stairwell or lightwell, connection to bridge from main building
4. Wrap-around hallway, connecting all spaces around lighthouse

5. Wrap-around ramp, circulation around the building and between the two levels.

6. The Lighthouse / The Lightsource
7. Top of ramp, lookout and eye to eye with the light

8. Entrance into main building

9. Double height atrium space 


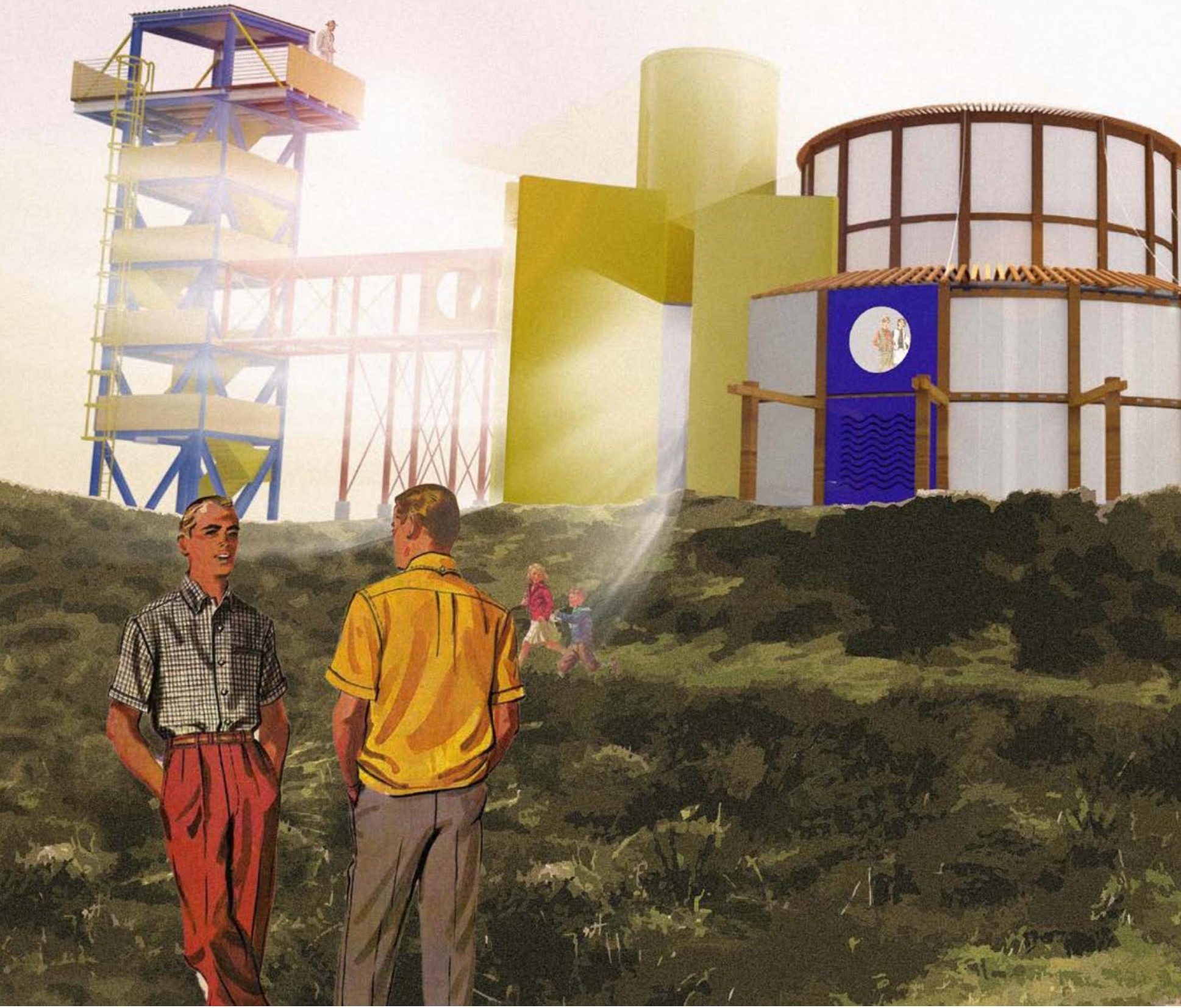

Image of 'The Stage Complete' operating in the light, with people lining up to perform and see the infamous Waipapa Lighthouse 


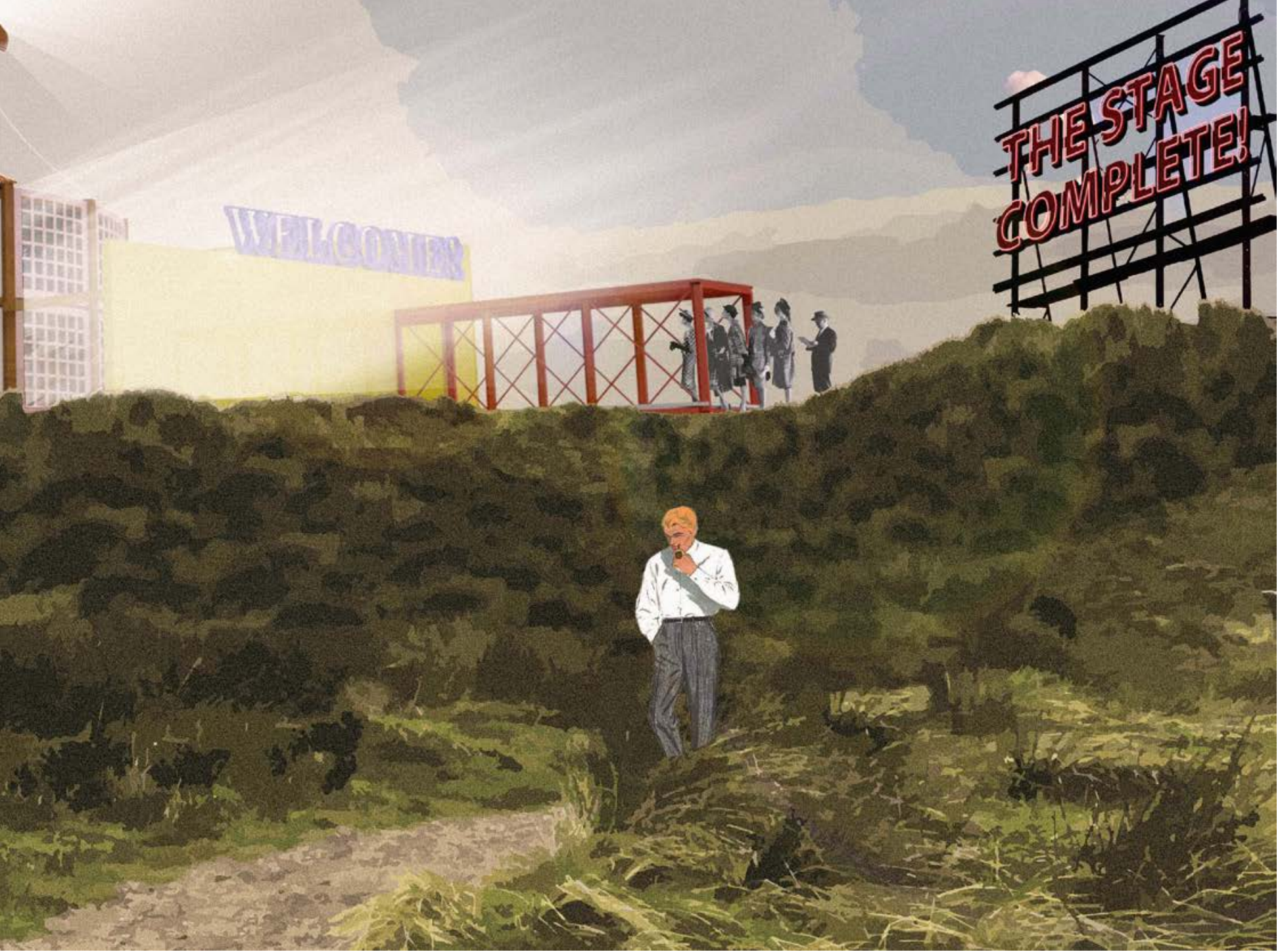



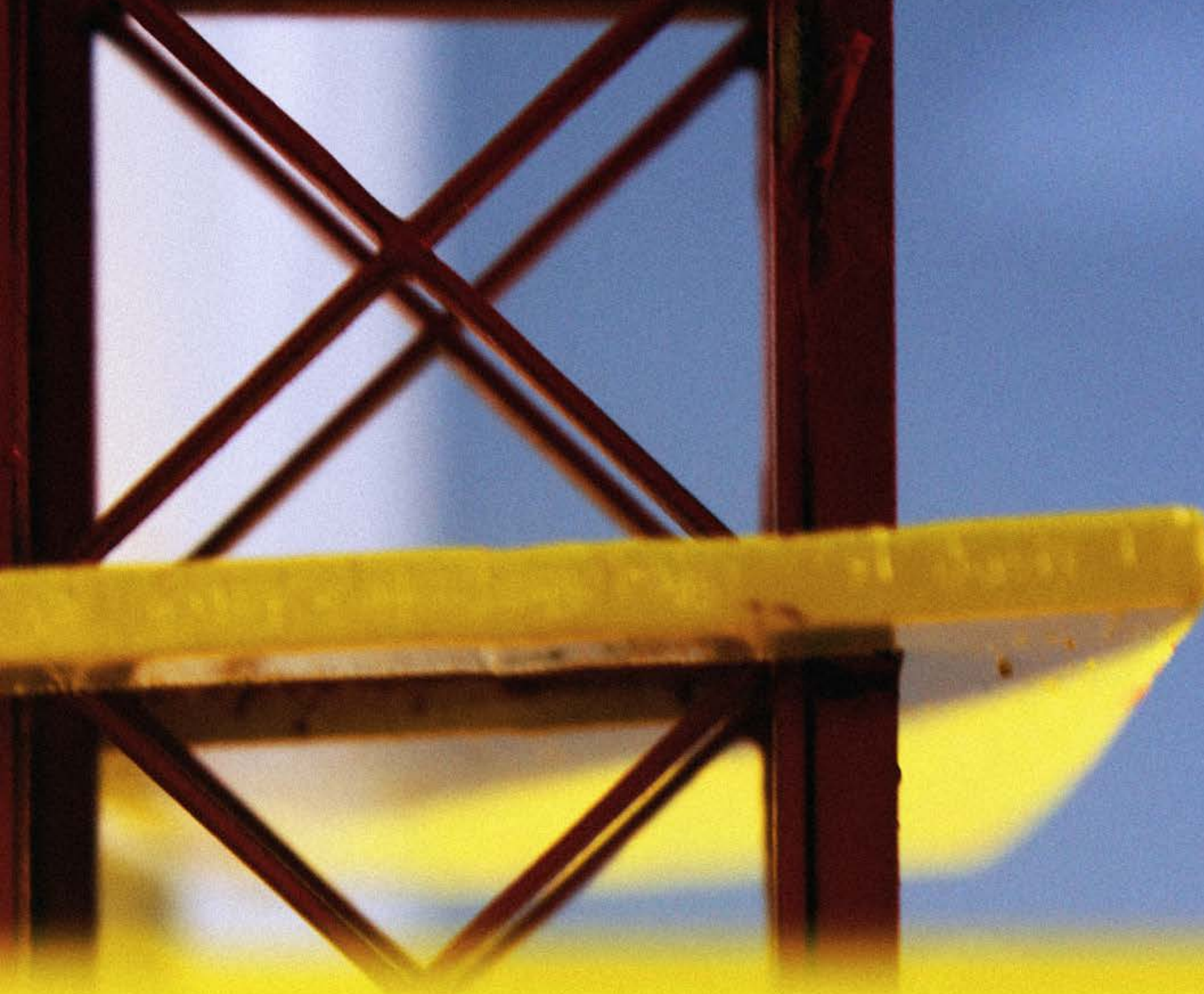


\subsection{STAGE COMPLETE - THE MODEL}

The Model was realised by using $3 \mathrm{~d}$ printing and laser cutting. The model is not a replica of the final digital model, it is seen as a separate and final design exploration, seen as a proof of concept, its goal was to create an architecture that would become a lampshade and direct light, enabling people, through the photography of the model to understand spatial conditions of the building. It is putting all the concepts explored throughout this body of work, from camp to the performance into one physical manifestation for people to understand the design at a 1:100 scale. A LED lightbulb was used as a replacement for the lighthouses light and elements of the original design such as spiral stairs, bridges, precast walls and the concentric plan was retained. The aesthetic treatment is camp and used to define individual elements. 


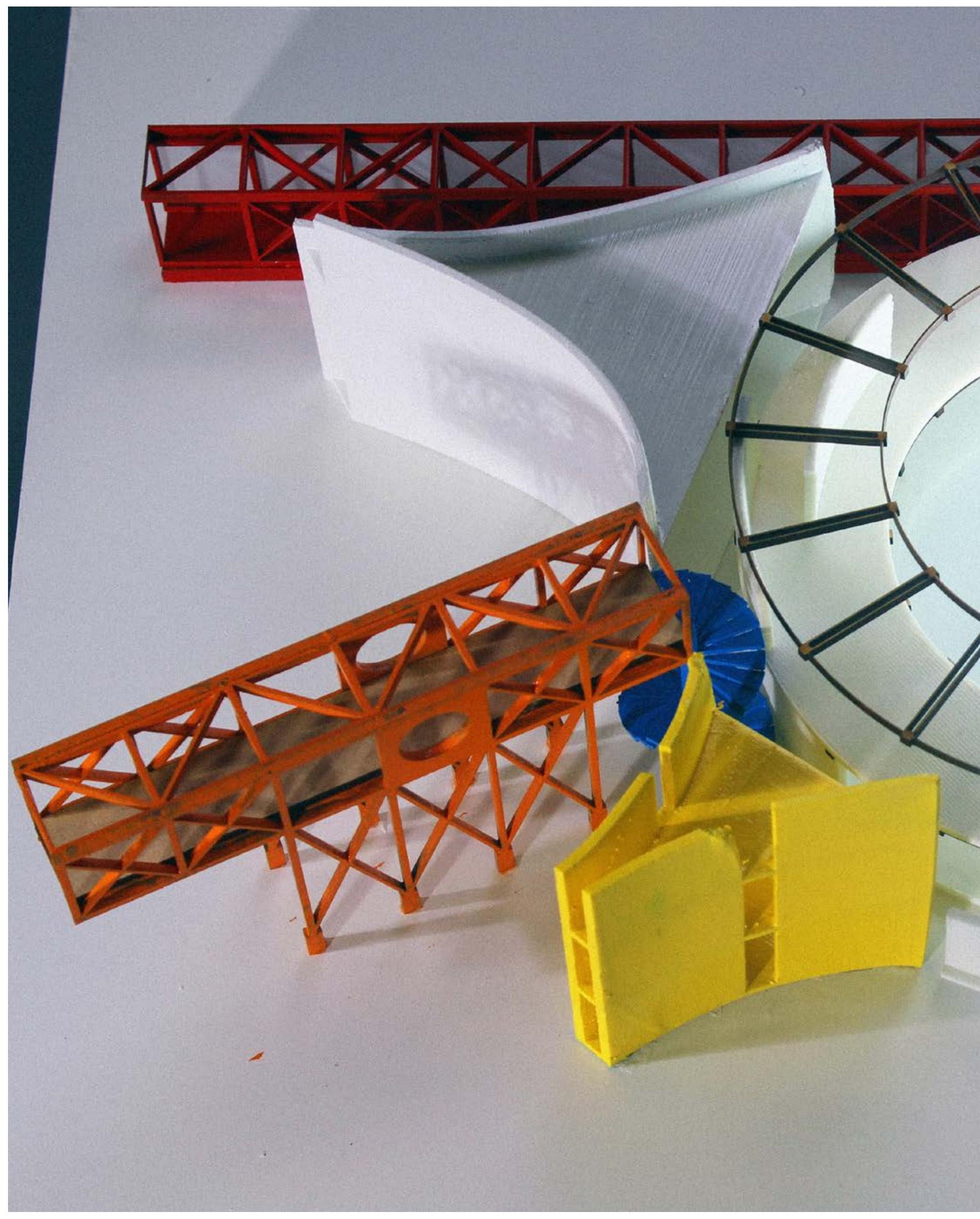

Photograph of the whole 'Stage Complete' model. 


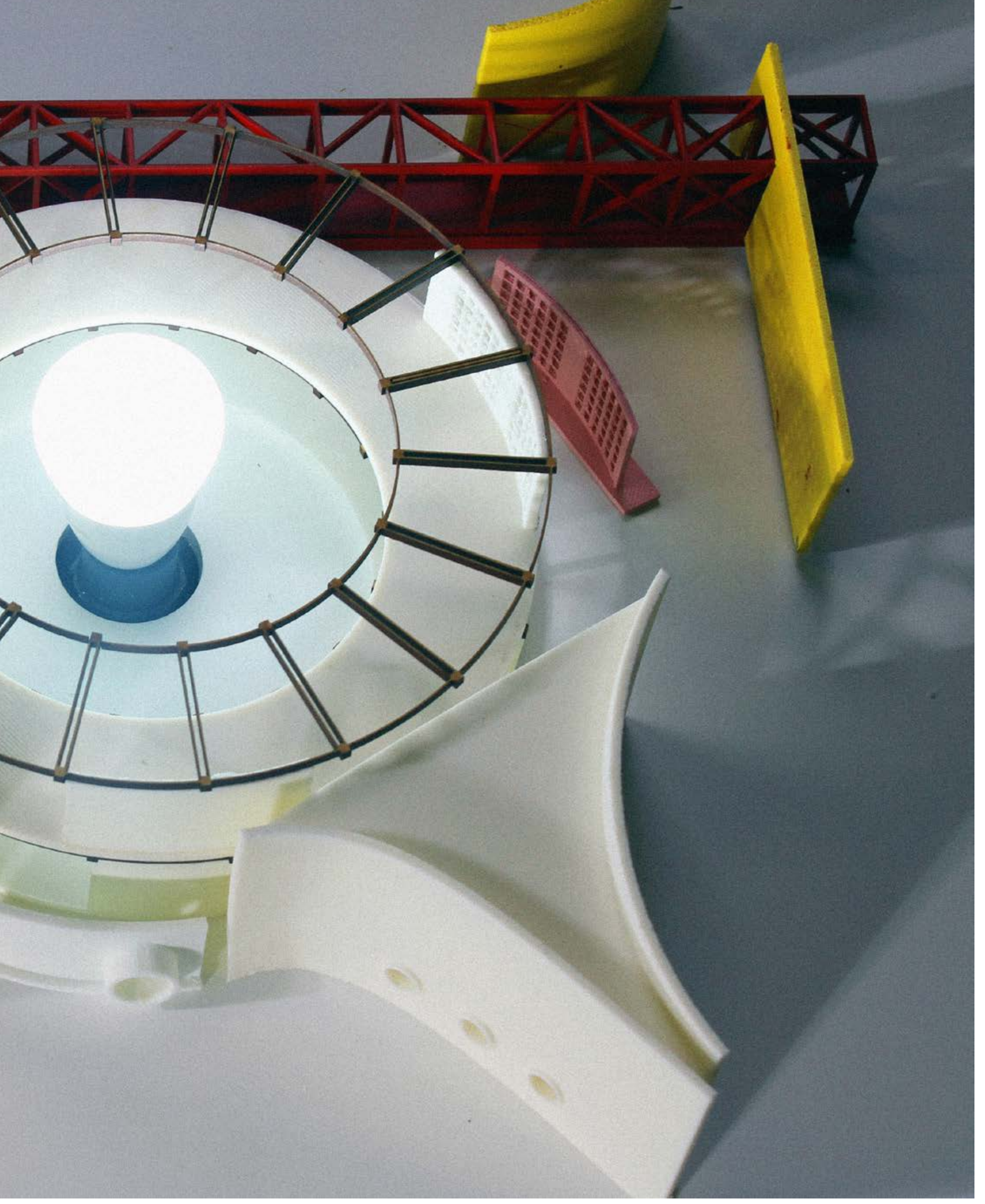


Various images of the model in action, the whimsical notion of the structural elements is visible, as well as a clear design language, to allow for circulation, interchanging of spaces and light and shadow play. 'The Stage Complete', a playground to explore the site, perform on and discover more about the lighthouse.

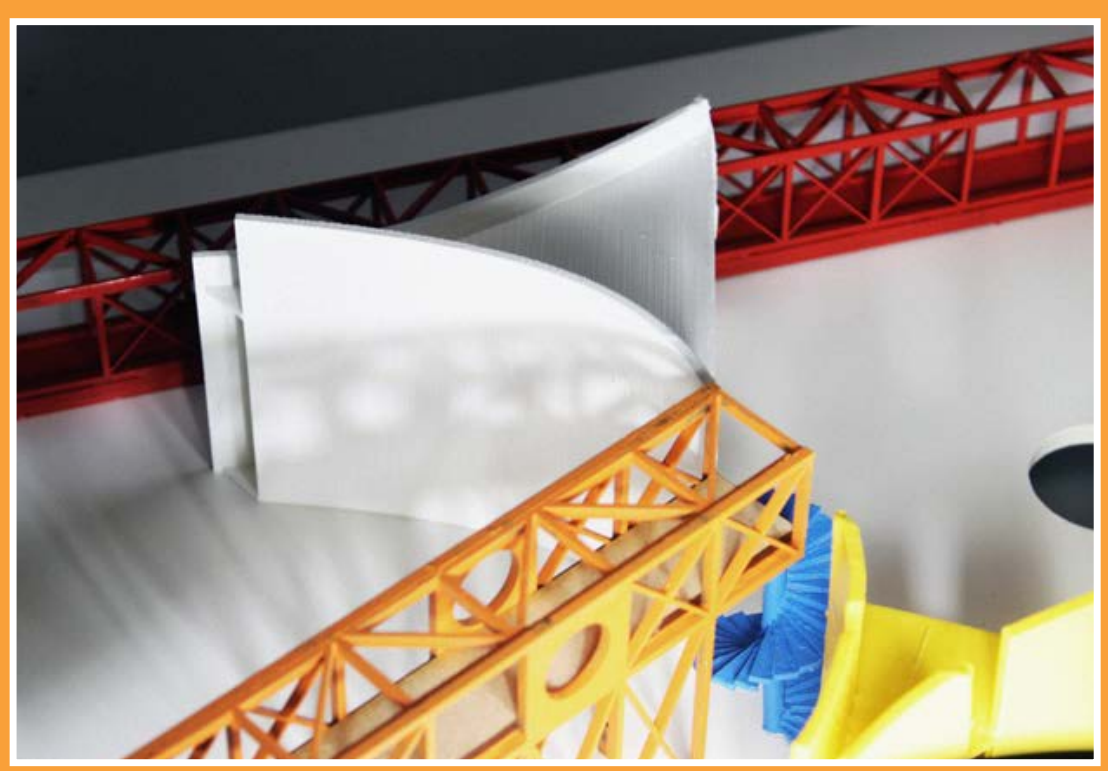

\section{象䄱}

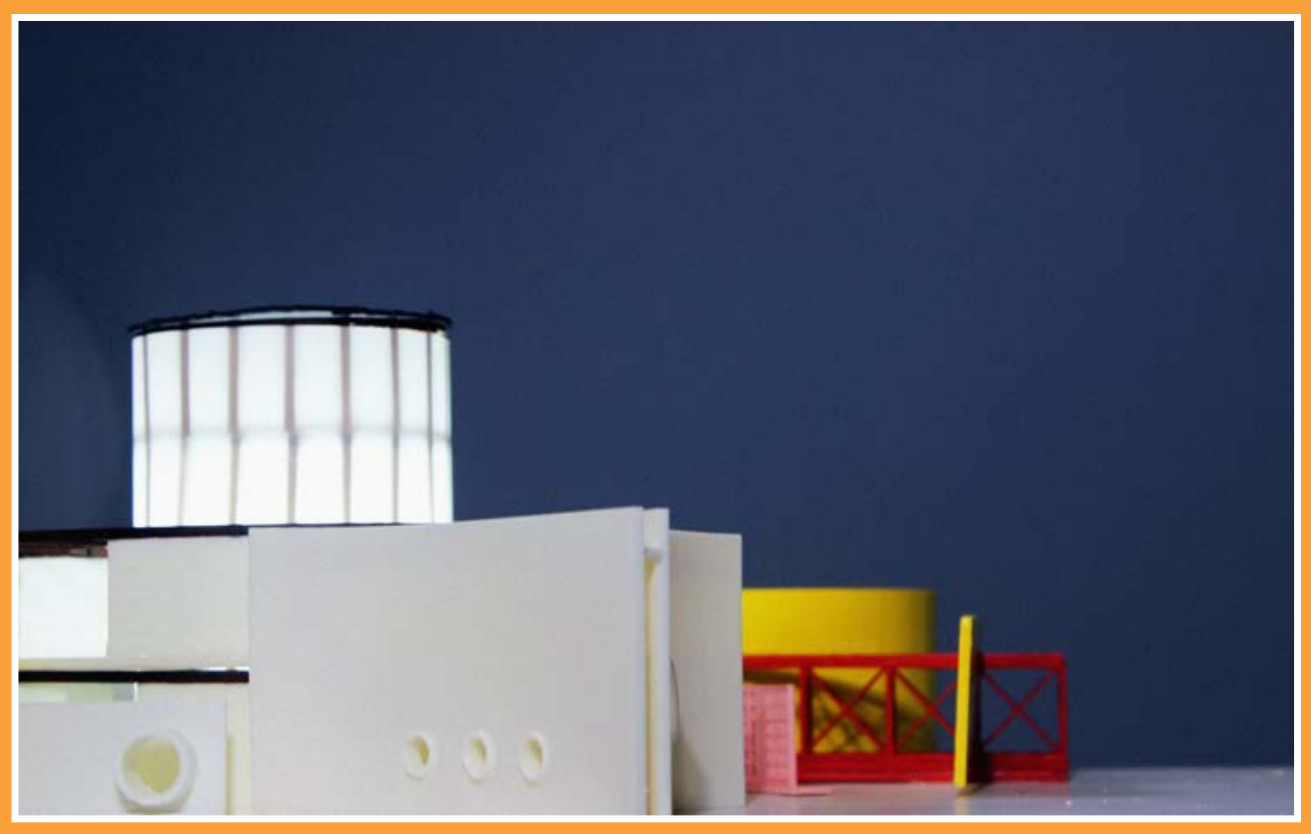



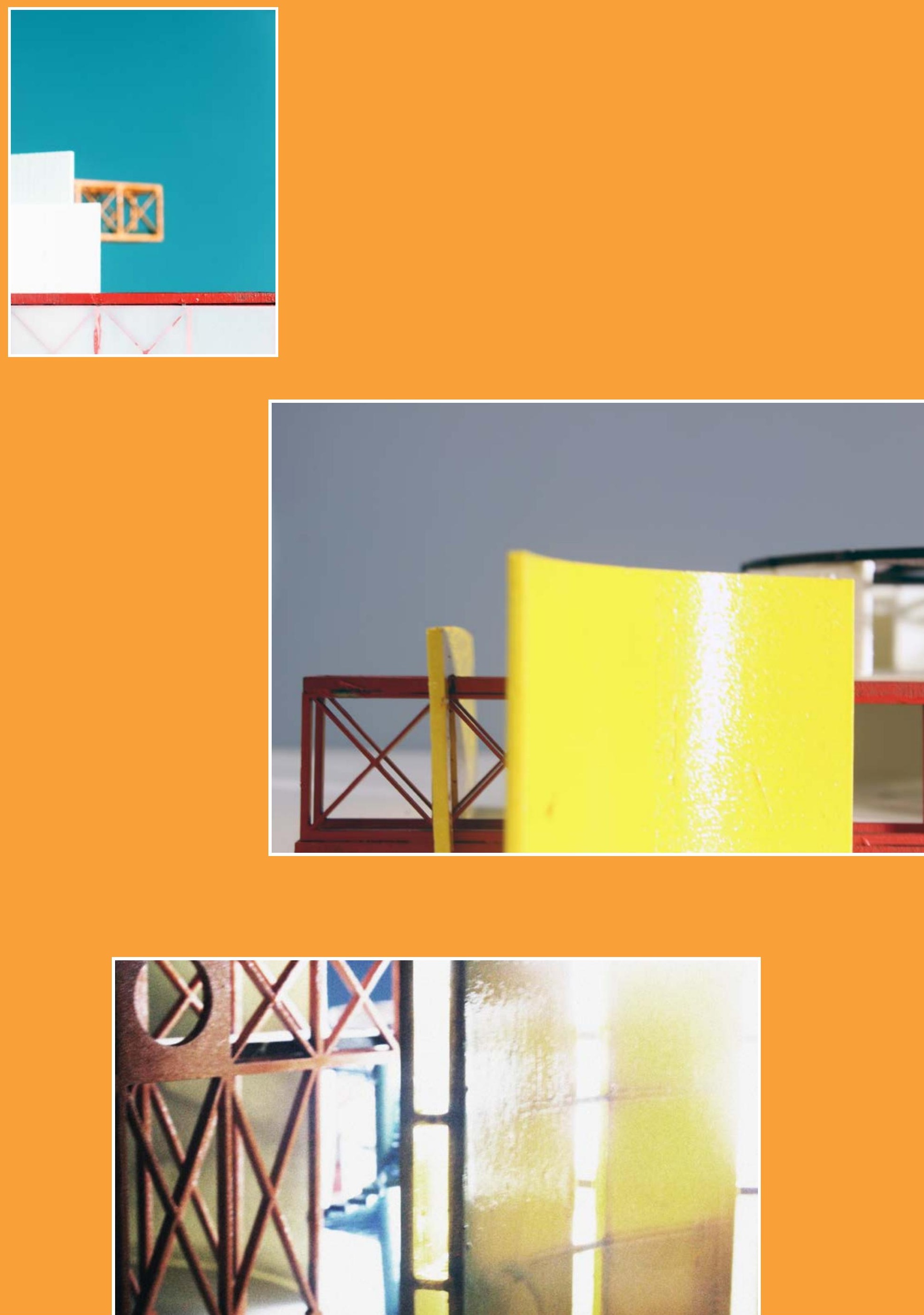

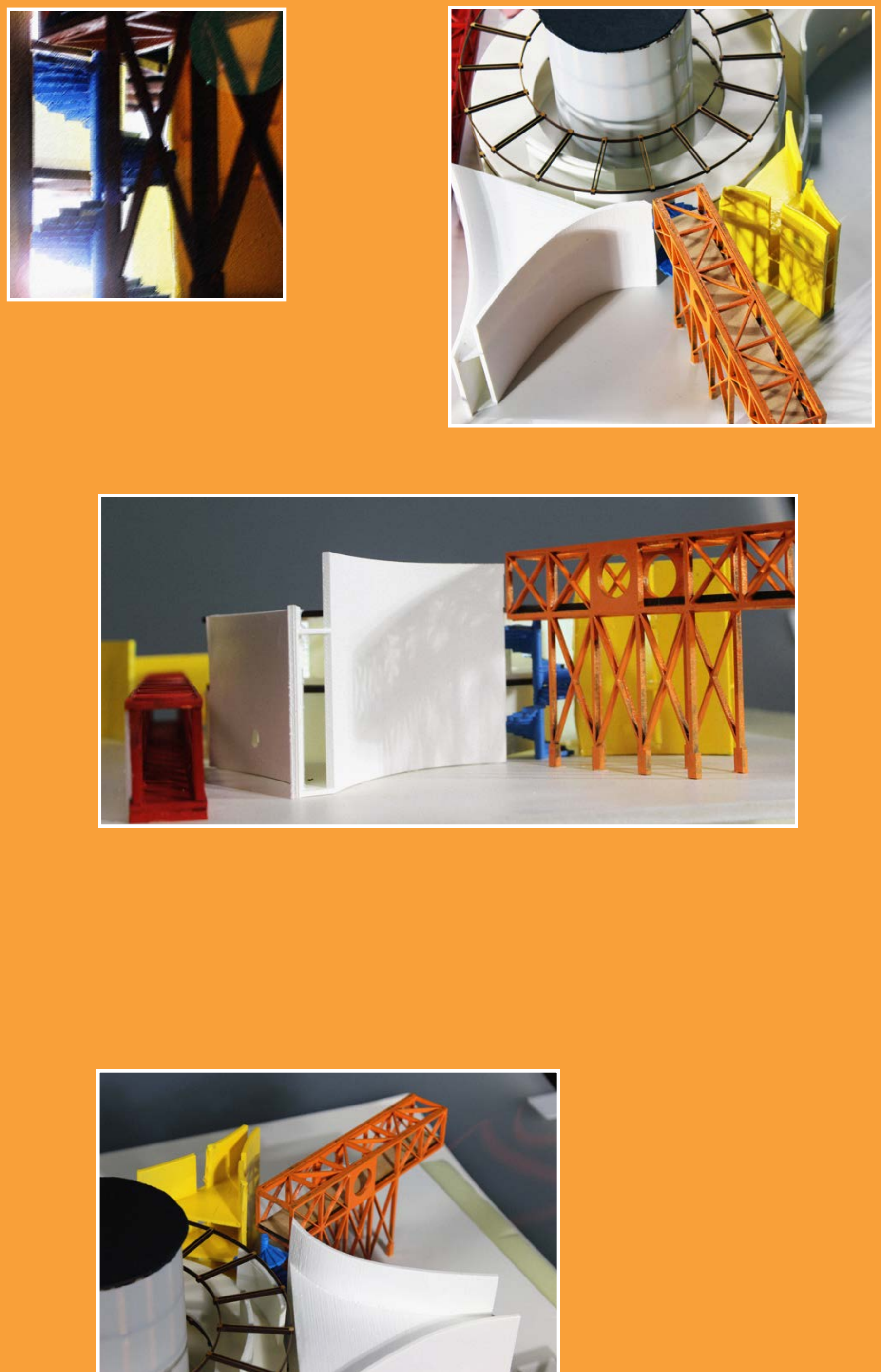

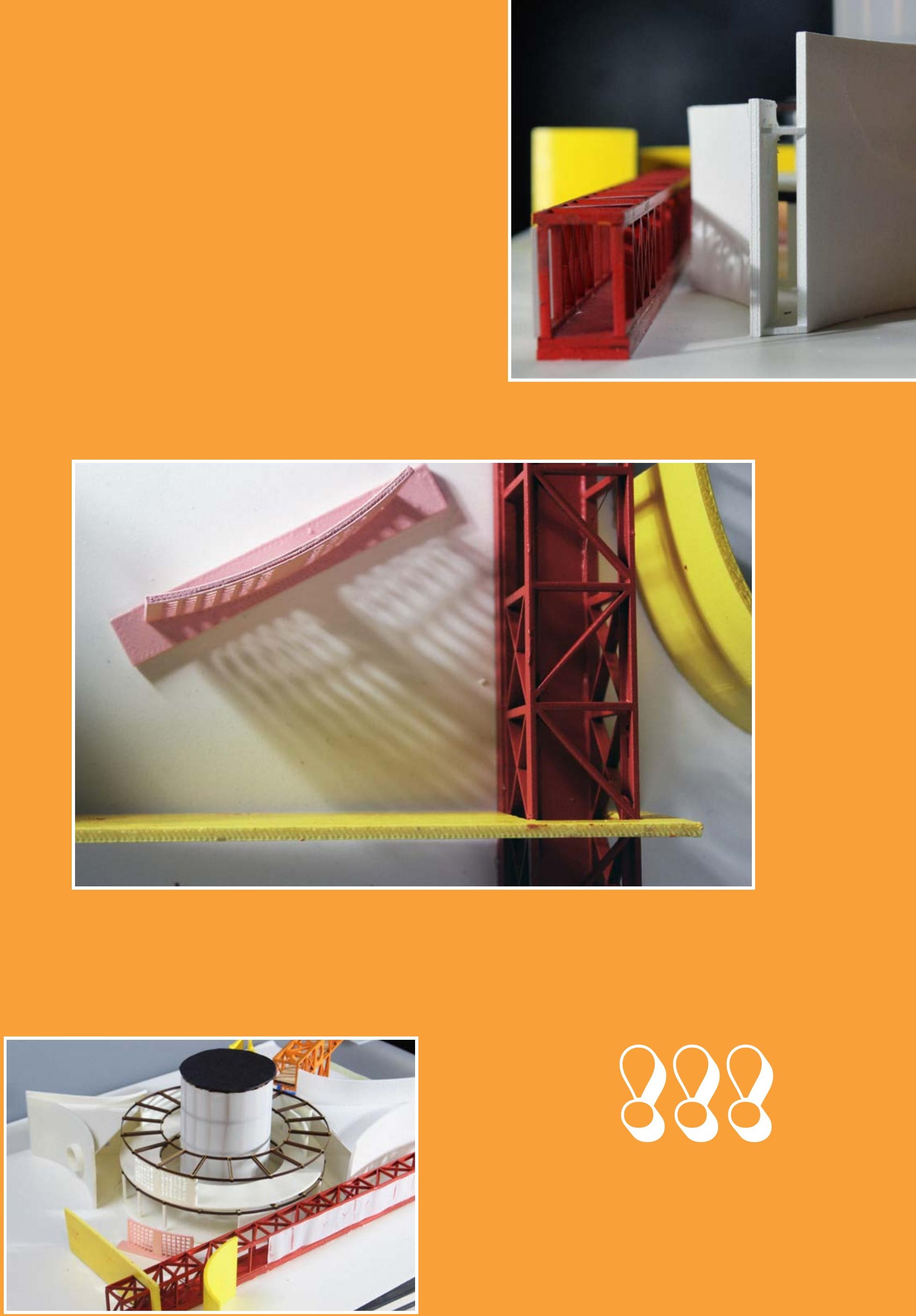



\section{IN THE DARK}

In the dark, once the lights are turned off is the true test, the same in design phase two, it is one thing to design and interpret under the camp sensibility but it is not camp if the authenticity of the project is flawed. The goal of the stage complete is to become a lamp shade of sorts to play with the crux of the lighthouse and manipulate the light to create experience, this was proven by photographing the model in darkness. 

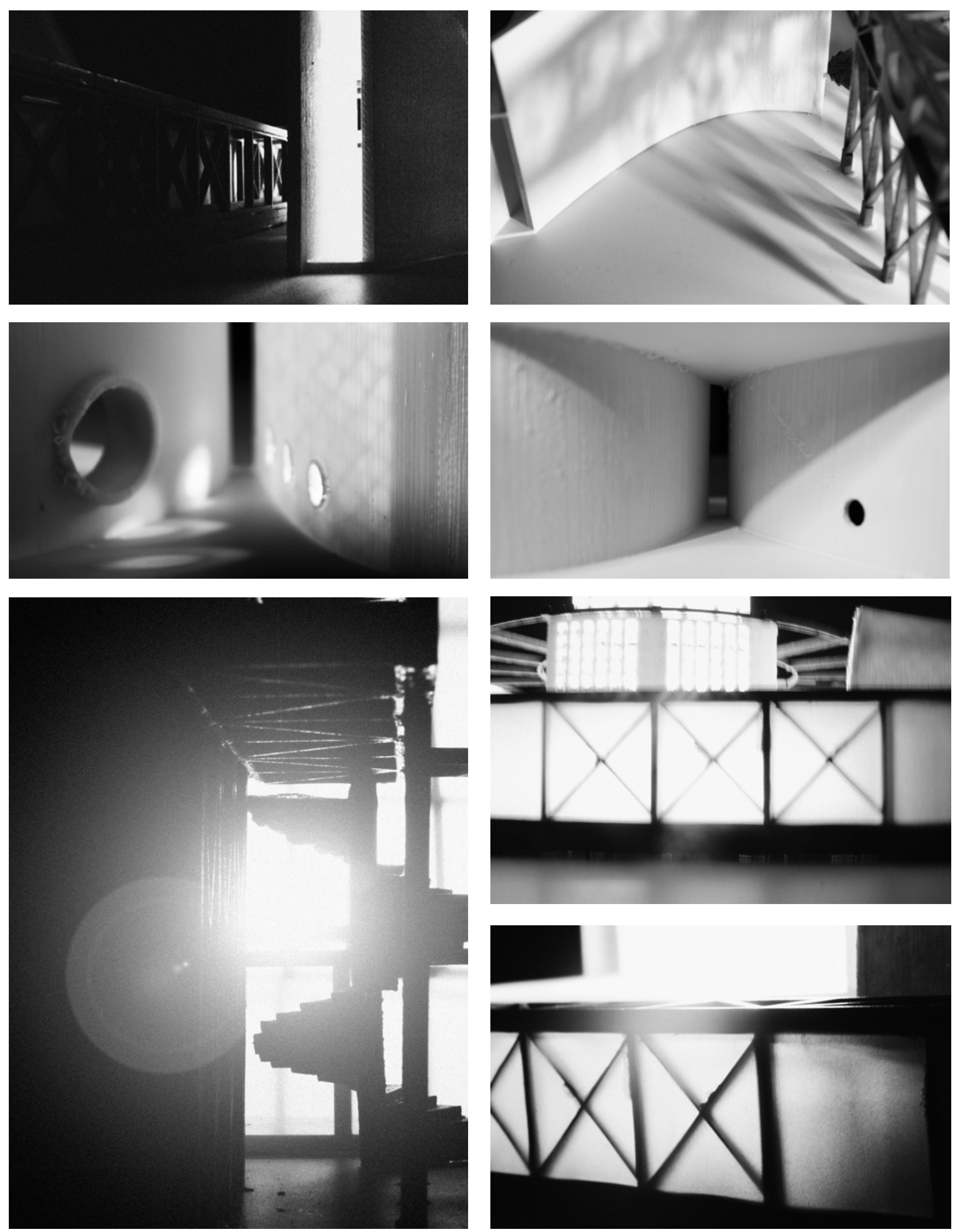

Various photographs of the whole 'Stage Complete' model. This time in darkness, photographs showcase the different light conditions of the model and how specefic apertures, materials and structural elements interact with the lightsource. 

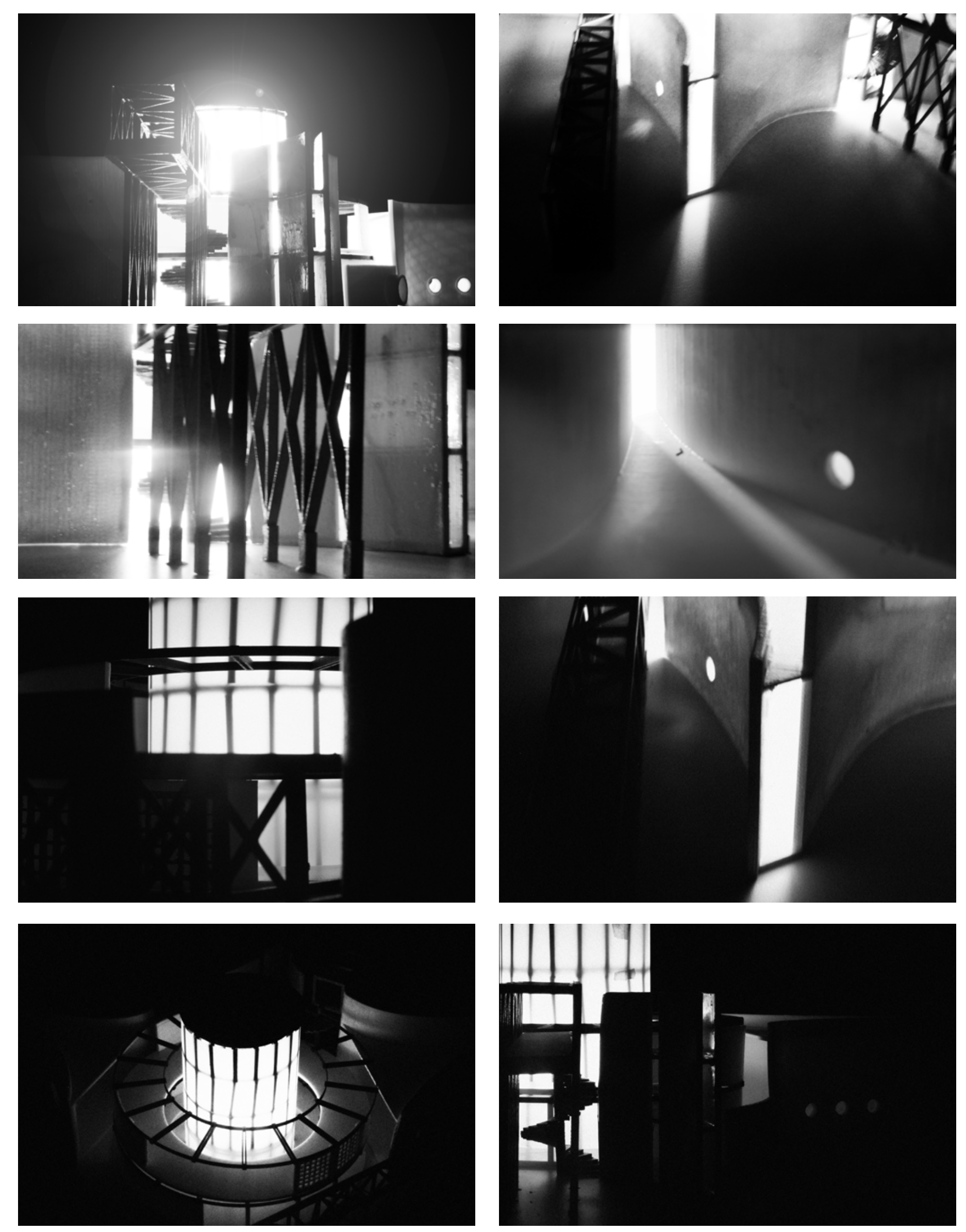



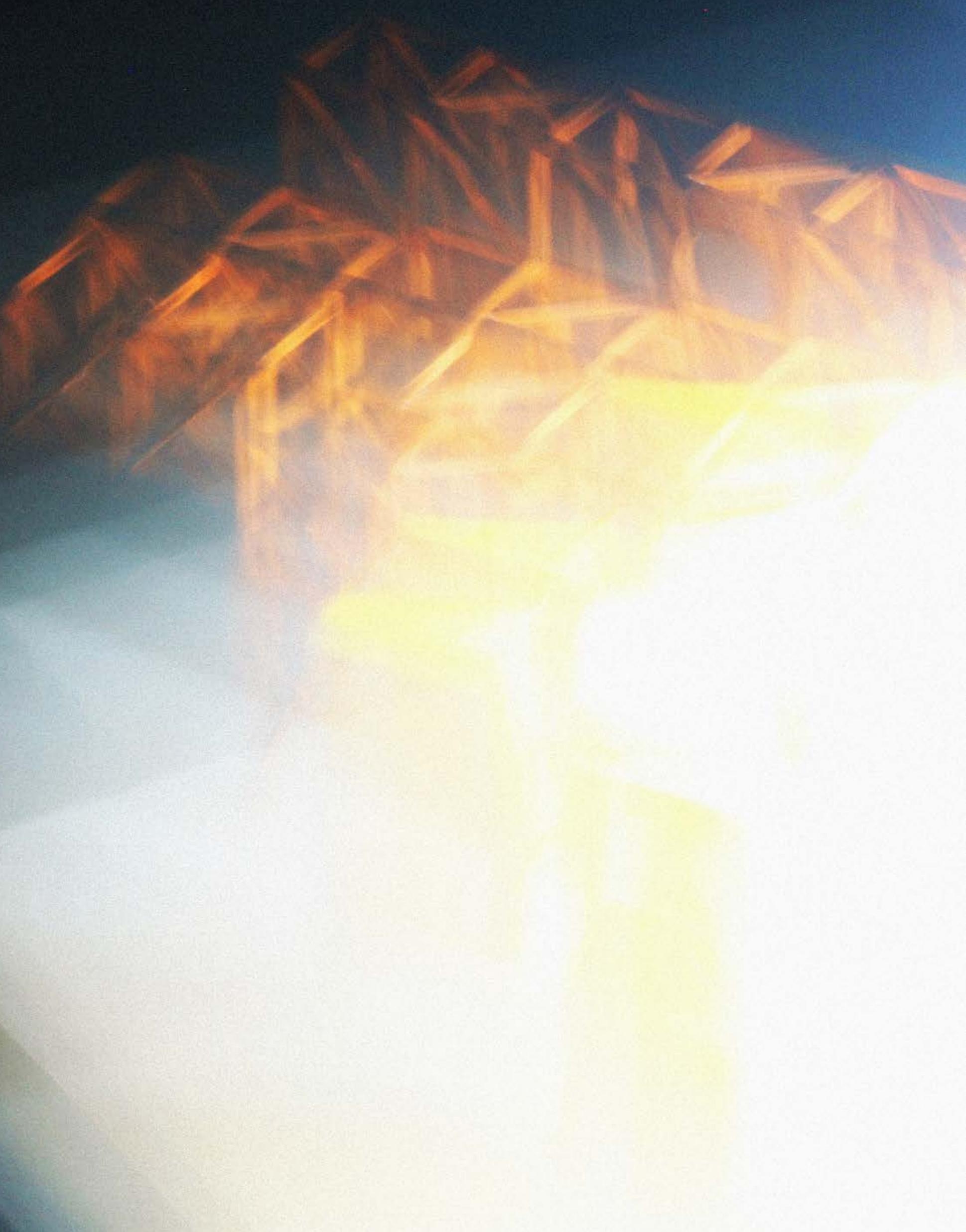





\subsection{REFLECTION}

Tested through three different design logics or phases, the proposition evolved and developed in scope and method at each distinct stage. Cold damn Disneyland attempted to use satirical methods and 'take the piss' out of mass tourism, I tried to create an architectural commentary, by using 'camp', I was making a point by going 'too far' and being 'too much', as if to say, look past the bullshit and take me seriously. What was realised was that in order for camp to work, I needed something to say, other than a commentary on placeless theme parks and gift shop consumption culture, there was no problem being solved through the intervention. The Second Logic sought to find depth in this thesis, using anti-camp, dropping the colour and artifice, looking directly at the core of the tourist object and how to go about it, physical modelling methods and photography helped shape a substance for this thesis and understand what can be used to help the tourist perform (Larsen \& Urry, 2011). The Third and final design logic, reinstated the camp lens with the added knowledge of having something to use/say, which was tourists are to engage with the light. A full building or stage was designed, and camp representation methods were used to sell the stage.

Following Sontag's notes on camp, to create a method of designing and way of viewing the project, I think it's important to state that I disagree with Sontag when she states that the best camp is unintentional, it no longer holds weight that where camp is performed intentionally, the product is somehow less. Camp sensibility is something that helped me design, or is more of a sensibility that I found to align with, and base this work in. I have always been interested in satirical representation methods, to me camp is the lie that tells the truth (Core, 1999). It just solidifies the idea that one can make a joke about something serious, it doesn't make it less serious, it just means it's easier to consume, in a range of representation images throughout this thesis, I was successful, in doing that.

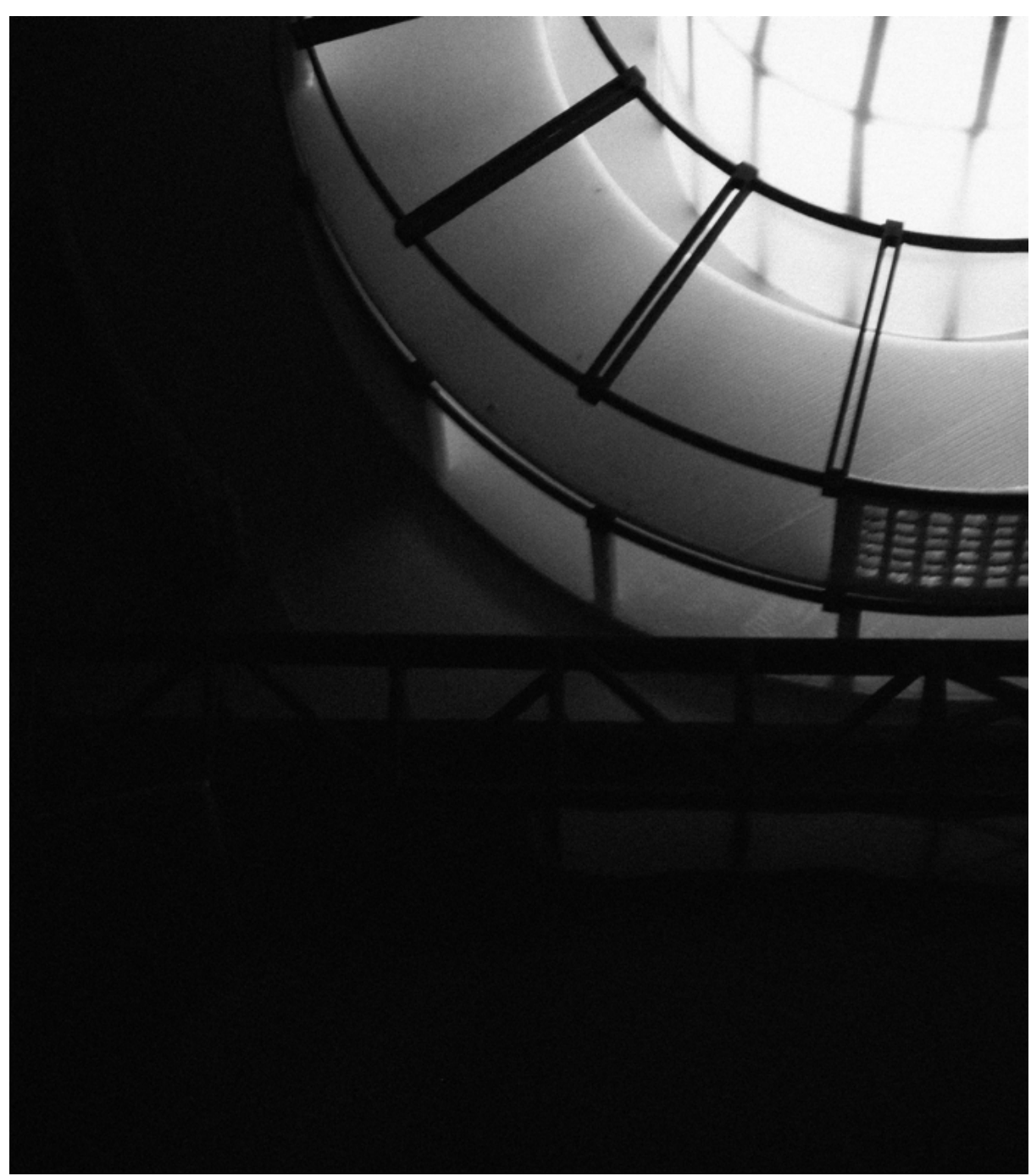

Testing the success of the investigation relies on addressing the design proposition. The proposition asks how can the architecture of tourism objects be relevant in a current world?'. While vague in its nature, Tourism object was chosen here as a replacement for 'lighthouse' as this thesis has been an experiment of 3 explorations, each one providing an option for a new way to interact and consume the lighthouse. In reality, this thesis is saying, that there's no reason the same can't be done to another tourist object. 

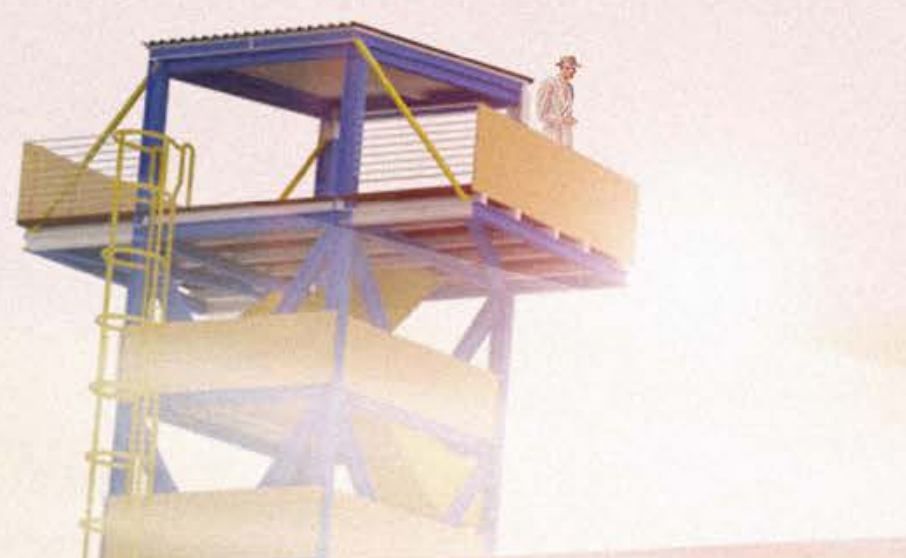


\subsection{CONCLUSION}

This thesis is about giving the lighthouse a new purpose in post-maritime New Zealand, it sought to evolve from just a tourist object, for a photograph but to engage the tourist much more. The thesis interrogated how tourists consume things, visually or otherwise, it interprets the theoretical understanding of how architecture can create stages for tourists to perform upon and is aware of the ways which tourists act in space, whether the gaze or performance (Edensor, 2001). It has criticised place, mass tourism and kitsch consumption through satirical and camp humour methods. The body of work rightly or wrongly used a sensibility in which one views the world, while this has been an exercise on how to dress a lighthouse in three million feathers so to speak. To camp the lighthouse is impossible. In my opinion, it is already camp, the structures are over the top, outrageous, extravagant, even audacious in the simplest of forms, with a meaning beyond what everyone perceives. This body of work started with a fascination of the photograph/and at playing the tourist, how an environment evokes something innate within oneself. It ended with myself creating a campy building that consumed the lighthouse as a proposed way to give these old tourism objects a new life. This Thesis laughs at itself throughout, but in turn takes itself very seriously. To conclude, I will leave you with the ultimate camp statement: "It's good, because it's awful." (Sontag, 1964, p. 13). I hope you had a laugh.
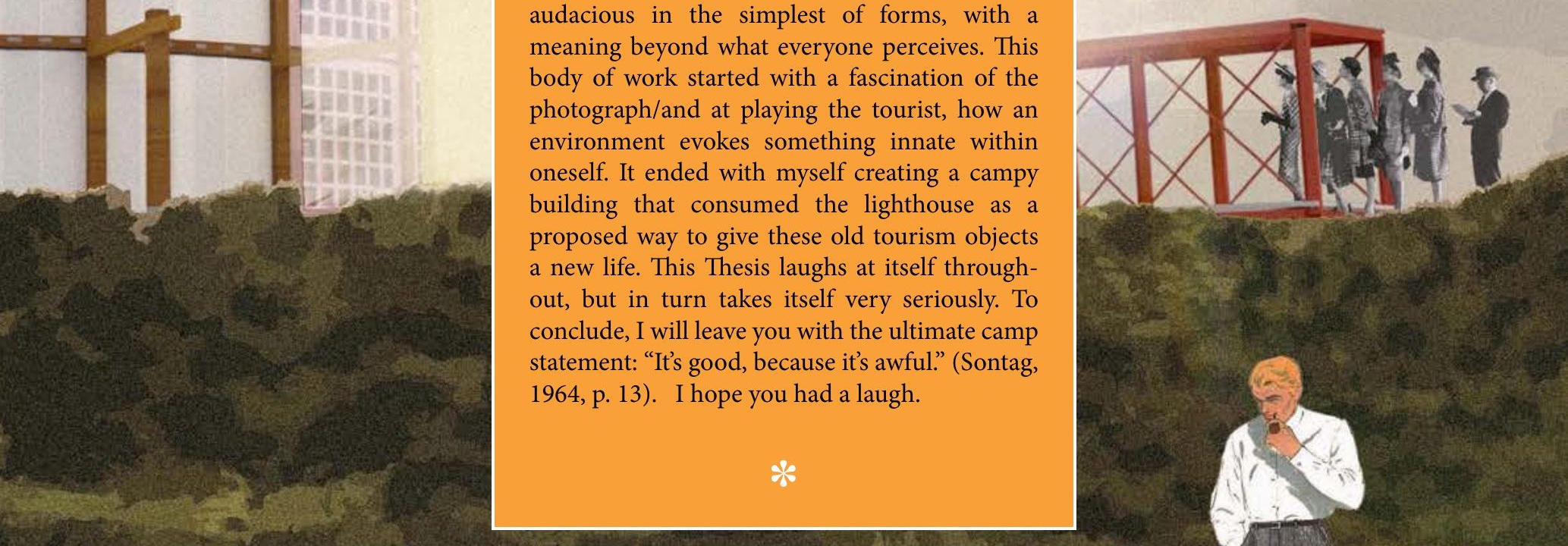

\section{\&}




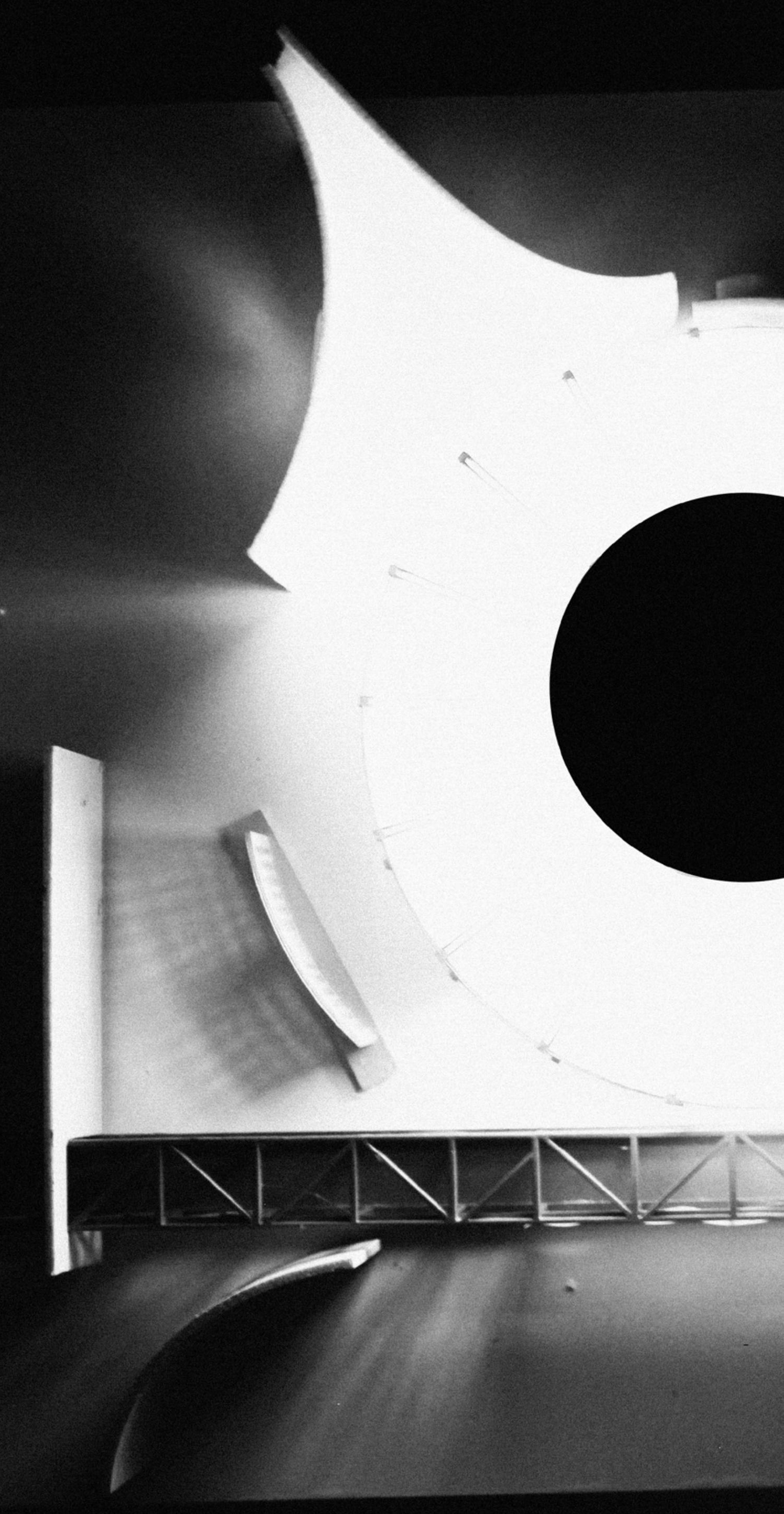




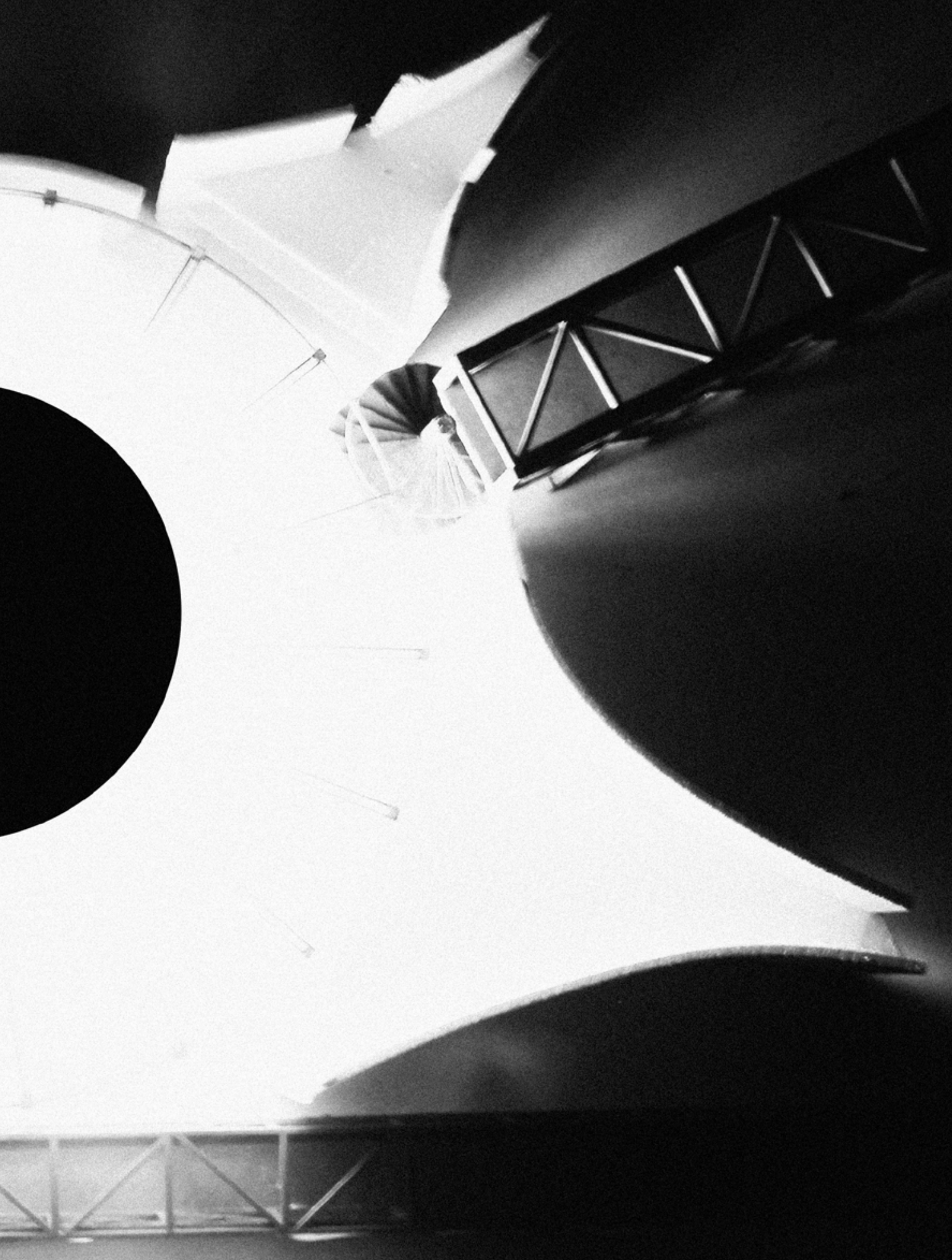




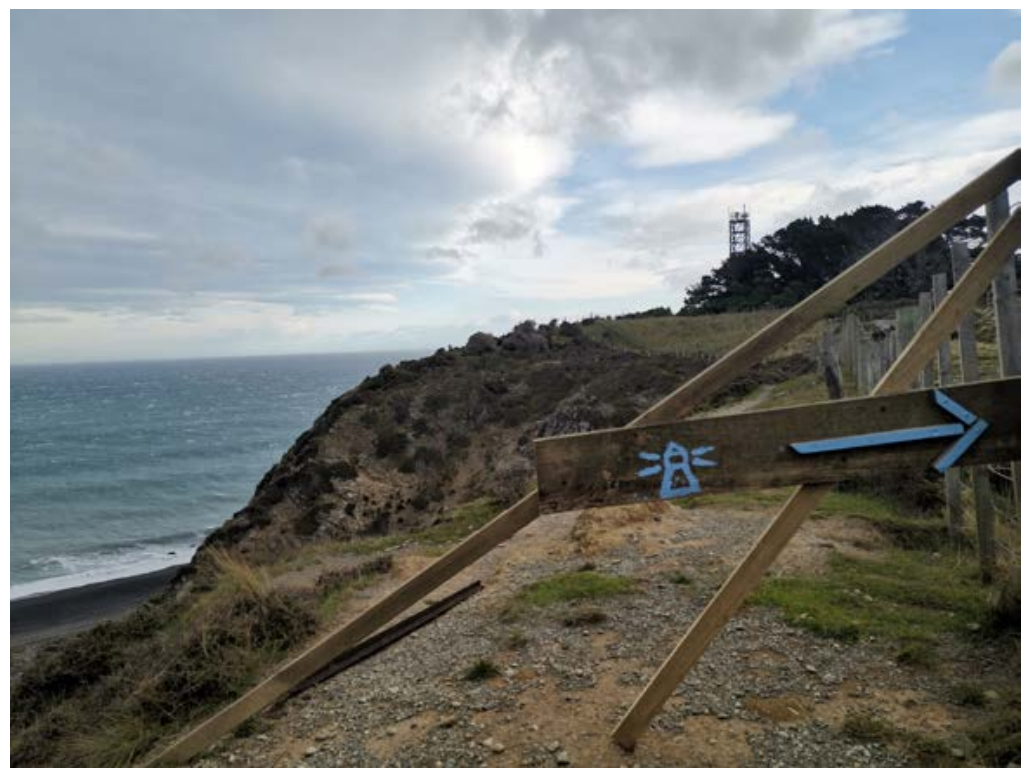

喥

'The God Damn Lighthouse is over there!' 


\section{BIBLIOGRAPHY}

Adam Nathaniel Furman and Sibling Architecture design Boudoir Babylon. (n.d.). Retrieved January 27, 2021, from https://www.dezeen.com/2020/12/20/boudoir-babylon-adam-nathaniel-furman-siblingarchitecture-ngv-triennial/

Anne Noble | Arts Foundation Laureate. (n.d.). Arts Foundation. Retrieved February 25, 2021, from https://www.thearts.co.nz/artists/anne-noble?token=296

Bain, Angela, New Zealand, and Department of Conservation. Lighthouses of Foveaux Strait: A History. Wellington [N.Z.: Dept. of Conservation, 2010.

Beaglehole, H. (2006). Lighting the coast: A history of New Zealand's coastal lighthouse system. Canterbury University Press.

Booth, M. (1999). Campe-toi!: On the origins and definitions of camp. In Cleto F. (Ed.), Camp: Queer Aesthetics and the Performing Subject: A Reader (pp. 66-79). Edinburgh: Edinburgh University Press. doi: $10.3366 /$ j.ctvxcrp56.9

Diller + Scofidio, Elizabeth Diller, Ricardo Scofidio. Slow House Project, North Haven, Long Island, New York, Perspective and plans of TV in Picture Window Apparatus, 1991 | MoMA. (n.d.). The Museum of Modern Art. Retrieved February 25, 2021, from https://www.moma.org/collection/works/440

Edensor, T. (2001). Performing tourism, staging tourism: (Re) producing tourist space and practice. Tourist Studies, 1(1), 59-81.

Churchman, G. B. (1989). New Zealand lighthouses. GP Books.

Cleto, F. (1999). Introduction: queering the camp. In Cleto F. (Ed.), Camp: Queer Aesthetics and the Performing Subject: A Reader (pp. 1-42). Edinburgh: Edinburgh University Press. doi:10.3366/j.ctvxcrp56.5

Core, P. (1999). From camp: the lie that tells the truth. In Cleto F. (Ed.), Camp: Queer Aesthetics and the Performing Subject: A Reader (pp. 80-86). Edinburgh: Edinburgh University Press. doi:10.3366/j. ctvxcrp56.10

Cotkin, G. (2016). Feast of excess: A cultural history of the new sensibility. Oxford University Press.

Crang, M. (1997). Picturing practices: Research through the tourist gaze. Progress in Human Geography, 21(3), 359-373. https://doi.org/10.1191/030913297669603510

Farrelly, E. M. (2008). Blubberland: The Dangers of Happiness. Cambridge, Mass: MIT Press

Gillespie, M. (2016). “The Triumph of the Epicene Style’: Nightwood and Camp.” Miranda, 12. https://doi. org/10.4000/miranda.8634

Holliday, Ruth, and Tracey Potts.(2012) Kitsch! Cultural Politics and Taste. Manchester: Manchester University Press.

Jencks, C. (1973). Recent American Architecture Camp- Non-Camp, Modern movements in architecture (pp 185-239). Penguin.

Kates, S. M. (1997). Sense Vs. Sensibility: An Exploration of the Lived Experience of Camp. ACR North American Advances, NA-24. https://www.acrwebsite.org/volumes/8027/volumes/v24/NA-24/full 
Kleinberg, S. (1992), "The New Masculinity of Gay Men, and Beyond", in Men's Lives, M. Kimmel and M. Messner, eds. Toronto: Maxwell MacMillan Canada

Larsen, J., \& Urry, J. (2011). Gazing and Performing. Environment and Planning D: Society and Space, 29(6), 1110-1125. https://doi.org/10.1068/d21410

Lucas, R. (2020). Anthropology for Architects: Social Relations and the Built Environment. Bloomsbury Visual Arts. https://doi.org/10.5040/9781474241533

Mathews, S. 2005, The Fun Palace: Cedric Price's experiment in architecture and technology, Technoetic Arts, vol. 3, no.2, retrieved 20 April 2018, pp. 73-91 <http://www.bcchang.com/transfer/articles/2/18346584.pdf>

Najafi, Mina, and Mustafa Kamal Bin Mohd Shariff. "The Concept of Place and Sense of Place in Architectural Studies," August 24, 2011. https://doi.org/10.5281/ZENODO.1082223.

Noble, A., Porter, G., \& Wedde, I. (2011). Anne Noble: Ice blink. Clouds

Perkins, H. C., \& Thorns, D. C. (2001). Gazing or Performing? Reflections on Urry's Tourist Gaze in the Context of Contemporary Experience in the Antipodes. International Sociology, 16(2), 185-204. https://doi. org/10.1177/0268580901016002004

Relph, E. C. Place and Placelessness. Research in Planning and Design 1. London: Pion, 1976.

Rosso, M. (Ed.). (2019). Laughing at Architecture: Architectural Histories of Humour, Satire and Wit. Bloomsbury Visual Arts. https://doi.org/10.5040/9781350022775

Rubin, L. D. (1974). Susan Sontag and the Camp Followers. The Sewanee Review, 82(3), 503-510. JSTOR.

Sara. (2012, March 24). Cedric Price \& the Fun Palace. Citymovement. https://citymovement.wordpress. com/2012/03/24/cedric-price/

Schuyt, M., Elffers, J., \& Collins, G. R. (1980). Fantastic architecture: Personal and eccentric visions. H. N. Abrams.

Sheehan, G., \& Gibbons, A. (Eds.). (1991). Leading lights: Lighthouses of New Zealand. Hazard Press. Slow House. (n.d.). Architect. Retrieved February 25, 2021, from https://www.architectmagazine.com/ project-gallery/slow-house

Sontag, S. (2001). Against interpretation, and other essays. Picador U.S.A.

Sontag, S. (1964). Notes on "camp." http://www.vlebooks.com/vleweb/product/ openreader? $\mathrm{id}=$ none\&isbn $=9780241339718$

Urry, John. Consuming Places. International Library of Sociology. London; New York: Routledge, 1995.

Urry, John. The Tourist Gaze. 2nd ed. Theory, Culture \& Society. London; Thousand Oaks, Calif: Sage Publications, 2002. 


\section{LIST OF FIGURES}

\section{Unattributed figures belong to the author.}

Figure 4 A photograph of maintenance work on Pencarrow Lighthouse, Wellington, 1980. (Alexander Turnbull Library ,Reference: EP/1980/0706/19A-F , Photographer:Ian Mackley )

Figure 5 Potrait of Susan Sontag photographed by Jill Krementz on November 18, 1974 (Sourced from: https://lithub.com/remembering-susan-sontags-final-days/)

Figure 8 Self potrait of Andy Warhol, 1986 (retrieved from: https://www.ngv.vic.gov.au/explore/ collection/work/4456/)

Figure 9 U.N., From Isek Kingelez’s exhibition 'Bodys', 1995 (Sourced from: https://www.moma.org/ collection/works/222868)

Figure 10 Poppy, Robert Mapplethorpe, 1988. (retrieved: https://time.com/4255881/the-perfect-timeto-rediscover-robert-mapplethorpe/)

Figure 11 Oscar Wilde, photographed in 1882 by Napoleon Sarony (retrieved: https://time. com/3890539/oscar-wilde-trial-history/)

Figure 12 The Rocky Horror Picture Show film poster ,1975 (retrieved: https://waldina. com/2019/09/25/the-ricky-horror-picture-show-1975/)

Figure 13 Potrait of Susan Sontag photographed by Jill Krementz on November 18, 1974 (Sourced from: https://lithub.com/remembering-susan-sontags-final-days/)

Figure 14 Anne and Charles Duncan Hall - Rice University designed by John Outram in 1996 (retrieved: http://baldheretic.com/2018/01/28/anne-and-charles-duncan-hall-rice-university)

Figure 15 The London Mastaba - a floating platform of wrapped oil barrels, moored on the Serpentine Lake, Hyde Park, 2016 by Christo (retrieved: https://www.urbismagazine.com/articles/summerof-architecture-and-art/

Figure 17 Potrait of Georgette Magritte, 1934; Belgium, Renee Magritte During the hey-day of the Art-Noveau scene- a commonly referenced era in relation to 'camp'. (sourced from: https://www.wikiart.org/en/rene-magritte/georgette-magritte-1934)

Figure 16 Potrait of Susan Sontag photographed by Jill Krementz on November 18, 1974 (Sourced from: https://lithub.com/remembering-susan-sontags-final-days/)

Figure 18 Sketch of a Kitsch building.

Figure 19 KITSCH collage of folly designs, each providing or facilitating a consumer stage for the tourist to perform.

Figure 20 'That way to the lighthouse!'

Figure 21 The Universal Tea Machine Developed concept sketch (sourced from: http://www.smoutallen. com/universal-tea-machine) 
Figure 22 The Universal Tea Machine Pavillion built (sourced from: http://www.smoutallen.com/ universal-tea-machine)

Figure 24 The Boudoir Babylon (sourced from: https://www.dezeen.com/2020/12/20/boudoir-babylonadam-nathaniel-furman-sibling-architecture-ngv-triennial/)

Figure 23 Potrait of Adam Nathaniel Furman, Photographed by Mark Cocksedge (Sourced from: http:// www.adamnathanielfurman.com/information.php?info_id=1)

Figure 25 'Kitsch City Baby' an Architecture made from kitsch objects

Figure 26 Dog Island Lighthouse watercolour, 2020

Figure 27 An aerial view of the Dog Island Lighthouse Settlement, while the island was still inhabitated

Figure 28 Building plan for Dog Island Lighthouse, (Maritime New Zealand, personal communication, July 3,2020 )

Figure 29 Bluff oysters on Dog Island, taking a popular concept and creating imagined architectures that would facilitate such an activity

Figure 30 Authors visual observations throughout the town of Bluff, the building treatment was rather 'fantastic', either channeling the whimsy nature of the lighthouse and maritime culture or completly mimicking it.

Figure 31 More site observations, of the condition of Bluff, Warfs, Stewart Island and Foveaux strait.

Figure 32 Bluff, New Zealand

Figure 34 Tiwai Point Aluminium Smelter's own jetty

Figure 33 Tiwai Point Aluminium Smelter from Bluff Hill

Figure 35 Potrait of Cedric Price. (Sourced from: https://www.architectural-review.com/essays/ reputations/cedric-price-1934-2003)

Figure 36 Self Potrait of Author during the covid pandemic, 2020, a homage to Cedric Price and Sontag's sensibilities on Camp.

Figure 37 The Consumer Palace in-situ on Dog Island.

Figure 38 Cedric Price’s Fun Palace,1964 (Sourced from: https://medium.com/@jackstocker96/cedricprices-fun-palace-1964-builds-on-situationism-to-create-spaces-that-encourage-situations$487 \mathrm{~d} 219 \mathrm{~d} 2 \mathrm{f} 3 \mathrm{f}$ )

Figure 39 Dog Island Consumer Palace

Figure 40 The Consumer Palace, with Dog Island Lighthouse within.

Figure 41 Dog Island Consumer Palace, Front Elevation

Figure 42 Dog Island Lighthouse Digital Collage using Adobe Dimension

Figure 43 Dog Island Lighthouse Collage using Adobe Dimension

Figure 44 Cups and saucers filled with children at the 'Mad Hatter's Tea Party' attraction in Fantasyland, Disneyland Amusement Park, California. (Loomis Dean/The Life Picture Collection via Getty 
images,n.d)

Figure 45 Disneyland's 'Jungle Cruise' featuring animatronic animals, California (Loomis Dean/The Life Picture Collection via Getty images,n.d)

Figure 46 An early digital collage, conceptualising what a 'Camp' architecture might look like, pulling post modern imagery and historic site photos to create a logic.

Figure 47 Authors photograph of Dog Island, and it's Lighthouse. Alongside an early collage of the proposed 'design', The Cold Damn Disneyland.

Figure 48 A preliminary site analysis drawing, conveying active site conditions and conceptually proposed attractions on the island.

Figure 49 A mock postcard for Cold Damn Disneyland, based off original postcards for Coney Island,USA.

Figure 50 Early design work, creating the ferry terminal and planning space.

Figure 51 The Ferry terminal

Figure 52 Passangers boarding the Ferry, on-route to Cold Damn Disneyland

Figure 53 An early render of a concept for the ferry terminal.

Figure 54 Site plan/advertising poster showing some of the designed folly-like attractions

Figure 55 Bob having the time of his life at Cold Damn Disneyland.

Figure 56 Karen, looking at Bluff in the distance from the comfort of the gondola.

Figure 57 A warmer than usual day at Cold Damn Disneyland, Lisa is having a Blast.

Figure 58 Amber escaped her parents to get a selfie from on top of the tuatara pavillion.

Figure 59 Rodge was asked to take a photo of this lovely family arriving at Cold Damn Disneyland, but got distracted! "Ahh, the serenity" he says.

Figure 60 Susie, Nigel and Timmy, on a lovely family outing.

Figure 61 Photos of the physical model of Cold Damn Disneyland, captured with spotlighting, as if it was on its own stage.

Figure 62 Photos of the physical model of Cold Damn Disneyland, captured with spotlighting, as if it was on its own stage.

Figure 63 Baring Point Lighthouse on an overcast day, 2020

Figure 64 Early Collage and extract from an Interview on lighthouses of New Zealand (Extracted from: Guardians of the Light | Television | NZ On Screen. (n.d.). Retrieved April 6, 2020, from https:// www.nzonscreen.com/title/guardians-of-the-light-2008

Figure 65 A shadow play by Chrisitan Boltanski, "Vanitas" within the crypt of Salzburg Cathedral, 2019

Figure 66 Authors photos as part of an earlier field trip, showing site conditions of Waipapa Point

Figure 67 Authors photos as part of an earlier field trip, showing site conditions of Waipapa Point

Figure 69 LINZ. (n.d). [Map of Waipapa Point]. Retrieved October 18, 2020 , from https://basemaps. linz.govt.nz/\#@-46.66077304,168.84872683,z17.829

Figure 68 Temple of Light. A preliminary sketch of an imagined building that projected its own light.

Figure 70 Building plan for Waipapa Point Lighthouse, (Maritime New Zealand, personal communication, July 3 , 2020)

Figure 71 Authors own photos of Waipapa Lighthouse on an overcast day 
